\author{
UNIVERSIDADE DE SÃO PAULO \\ FACULDADE DE CIÊNCIAS FARMACÊUTICAS \\ PROGRAMA DE PÓS-GRADUAÇÃO EM FARMACO E MEDICAMENTOS \\ ÁREA DE PRODUÇÃO E CONTROLE FARMACÊUTICOS
}

\title{
DESENVOLVIMENTO E VALIDAÇÃO DE MÉTODO INDICADOR DE ESTABILIDADE DE FORMULAÇÕES FARMACÊUTICAS DE USO TÓPICO CONTENDO PERÓXIDO DE BENZOÍLA
}

\section{FERNANDO LINO DIAS}
Dissertação apresentada para obtenção do Grau de MESTRE

Orientadora

Profa. Dra. Erika Rosa Maria Kedor-Hackmann

São Paulo

2014 


\author{
UNIVERSIDADE DE SÃO PAULO \\ FACULDADE DE CIÊNCIAS FARMACÊUTICAS \\ PROGRAMA DE PÓS-GRADUAÇÃO EM FARMACO E MEDICAMENTOS \\ ÁREA DE PRODUÇÃO E CONTROLE FARMACÊUTICOS
}

\title{
DESENVOLVIMENTO E VALIDAÇÃO DE MÉTODO INDICADOR DE ESTABILIDADE DE FORMULAÇÕES FARMACÊUTICAS DE USO TÓPICO CONTENDO PERÓXIDO DE BENZOÍLA
}

\section{FERNANDO LINO DIAS}
Dissertação apresentada para obtenção do Grau de MESTRE

Orientadora

Profa. Dra. Erika Rosa Maria Kedor-Hackmann

São Paulo

2014 
Ficha Catalográfica

Elaborada pela Divisão de Biblioteca e

Documentação do Conjunto das Químicas da USP

\begin{tabular}{|c|c|}
\hline \multirow[t]{4}{*}{ D54 ld } & $\begin{array}{l}\text { Dias, Fernando Lino } \\
\text { Desenvolvimento e validação de método indicador de } \\
\text { estabilidade de formulaçóes farmacêticas de uso tópico } \\
\text { contendo peróxido de benzoíla / Fernando Lino Dias. -- São } \\
\text { Paulo, } 2014 . \\
\quad 184 \mathrm{p} \text {. }\end{array}$ \\
\hline & $\begin{array}{l}\text { Dissertação (mestrado) - Faculdade de Ciências Farmacêticas } \\
\text { da Universidade de São Paulo. Departamento de Farmácia. } \\
\text { Orientador : Kedor-Hackmann, Erika Rosa Maria }\end{array}$ \\
\hline & $\begin{array}{l}\text { 1. Fármaco: Controle de qualidade 2. Estabilidade: } \\
\text { Medicamento: Análise farmacêutica 3. Antibiotico: } \\
\text { Farmacologia I. T. II. Kedor-Hackmann, Erika Rosa Maria, } \\
\text { orientador. }\end{array}$ \\
\hline & 615.19015 \\
\hline
\end{tabular}


Fernando Lino Dias

\title{
DESENVOLVIMENTO E VALIDAÇÃO DE MÉTODO INDICADOR DE ESTABILIDADE DE FORMULAÇÕES FARMACÊUTICAS DE USO TÓPICO CONTENDO PERÓXIDO DE BENZOÍLA
}

\author{
Comissão julgadora \\ da \\ Dissertação para obtenção do grau de \\ MESTRE
}
Profa. Titular Dra. Erika Rosa Maria Kedor-Hackmann
Orientadora/Presidente

$1^{\circ}$ Examinador

$2^{\circ}$ Examinador

São Paulo, de de 2014. 
A Deus,

Devemos tudo àquele que nos deu a oportunidade e sabedoria para trilharmos o caminho da nossa vocação, além de força e perseverança para que pudéssemos transformar um sonho, em alguns momentos tão distante e inatingível, em realidade. 
Agradeço, A Emília, minha eterna companheira, pelo amor, carinho, amizade e compreensão que sempre estiveram presentes na minha vida desde que nos conhecemos.

Aos meus amados pais, Ivanete e José, pelo amor incondicional e por dedicarem suas vidas à educação dos seus filhos.

Aos meus irmãos, Humberto e Henrique, por seu carinho e compreensão da minha ausência, além das inúmeras demonstrações de incentivo durante esta jornada.

A vocês, exemplos da minha vida, o meu mais que sincero e eterno agradecimento. 
A minha orientadora e amiga, Professora Dra. Erika Rosa Maria Kedor-Hackmann, por sua orientação, pelos ensinamentos profissionais e pessoais em todos esses anos de vida acadêmica, por acreditar em meu trabalho e me mostrar os verdadeiros caminhos da ciência.

A dois dos meus maiores exemplos profissionais, além de grandes amigos, o Mestre Bruno Augusto Leite Evangelista e o Dr. Hélio Salvio Neto, os quais muito contribuíram, cientificamente, em todas as etapas deste projeto.

A Professora Dra. Maria Aparecida Nicoletti, da Faculdade de Ciências Farmacêuticas (FCF) da Universidade de São Paulo, por acreditar em meu potencial e pelo grande incentivo que eu trilhasse o caminho da carreira acadêmica.

Ao Dr. Celso Blatt e a doutoranda Alana Figueiredo, da Agilent Technologies, pela grande colaboração no desenvolvimento do método qualitativo e quantitativo por LC-MS/MS.

A Professora Dra. María Segunda Aurora Prado, da Faculdade de Ciências Farmacêuticas (FCF) da Universidade de São Paulo, pela constante disponibilidade e por sempre contribuir como uma terceira opinião sobre a evolução e contribuição científica do trabalho.

Aos meus amigos Nelson Kenji Furuya, Sueli Higa, Ricardo Mikan, Saulo Statonato, Fernando Pereira de Lana Santos, Antonio Callejo, Wellington Pires Iglesias, Marcelo Lima, Maria Elisabete Lima de Souza, Enzo Yaguinuma, Renata Camargo lorio, José 
Suarez, Vanessa Fernandes, Mônica Cruz, Marco Liazi, Jarbas Mingorance, Henrique Pinheiro, Eduardo Emerich, Cláudio Bortalieiro, Talissa Kuratomi Taue, Arlane Maria de Sá, dos Laboratórios Stiefel, uma empresa GSK, pelo apoio, incentivo e companheirismo durante todo o tempo em que trabalhamos juntos.

Aos meus amigos, Sérgio Oliveira, Fabrício Motta, Alan Passero, Alexandre Carrara, Alexandre Reichenbach, Priscila Taromaru, Monique Santos, Márcia Takematsu, Tamara Carneiro, Ricardo Flores, Luciano Nogueira, Javier Barraza, Maria Carolina Semprini, Gislaine Zulli, Érika Silva, Maria Márcia Caldas, Fernanda Almeida, Micheli Araújo, Rosângela Moraes, da Johnson \& Johnson, pelas inúmeras discussões científicas, pela amizade e pelo exemplo de dedicação e profissionalismo sempre presente e nosso dia-adia.

Aos Laboratórios Stiefel, uma empresa GSK e a Johnson \& Johnson, por possibilitarem meu desenvolvimento profissional e pessoal, por fornecerem os recursos necessários para o desenvolvimento deste trabalho e pelo incentivo à pesquisa em nosso país.

À Faculdade de Ciências Farmacêuticas e ao Instituto de Química de São Paulo, pela oportunidade oferecida.

A todos aqueles que, de alguma maneira, participaram da execução deste trabalho, tornando assim possível sua realização. 


\section{SUMÁRIO DE TEMAS}

SUMÁRIO DE TEMAS...............................................................................................

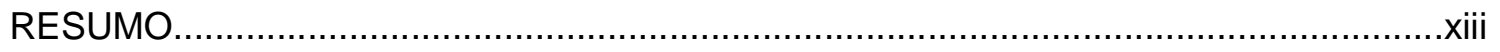

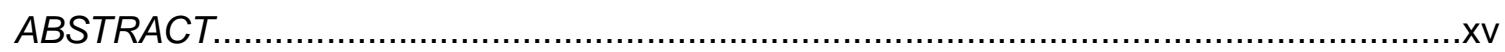

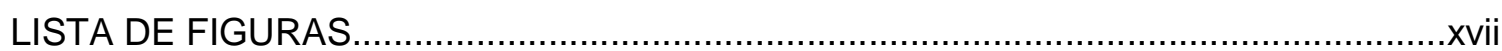

LISTA DE QUADROS.............................................................................................

LISTA DE TABELAS ..................................................................................

LISTA DE ABREVIATURAS E SIGLAS..............................................................xxx

CAPÍTULO I - INTRODUÇÃO E OBJETIVOS......................................................... 27

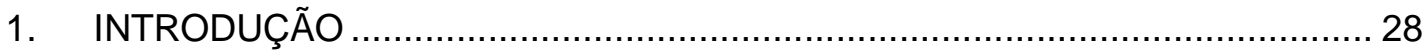

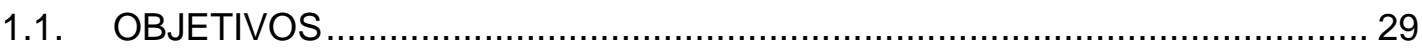

CAPÍTULO II - FISIOPATOLOGIA DA ACNE .......................................................... 30

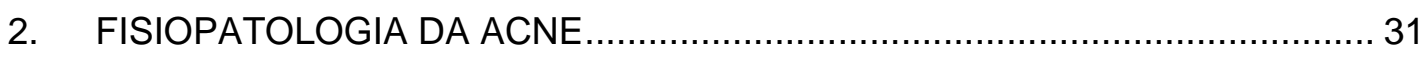

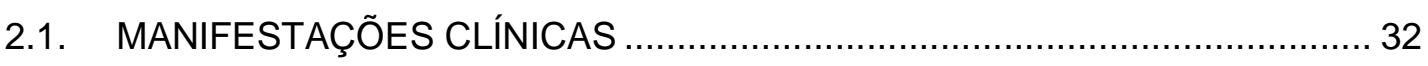

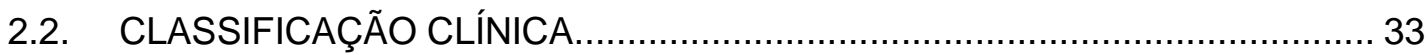

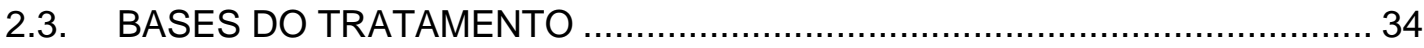

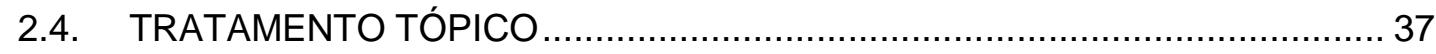

CAPÍTULO III - DESCRIÇÕES COMPENDIAIS DO PERÓXIDO DE BENZOÍLA ............ 38

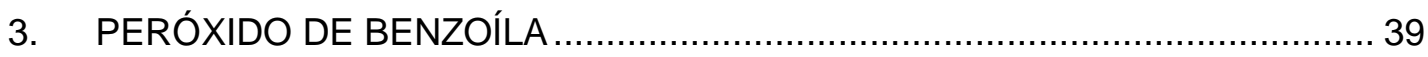

3.1. MECANISMO DE AÇÃO DO PERÓXIDO DE BENZOÍLA .............................. 39

3.2. SIINTESE DO PERÓXIDO DE BENZOÍLA ................................................... 40

3.3. DESCRIÇÃO FARMACOPEICA DO PERÓXIDO DE BENZOÍLA ................... 41

3.4. PRODUTOS DE DEGRADAÇÃO COMPENDIAIS DO PERÓXIDO DE

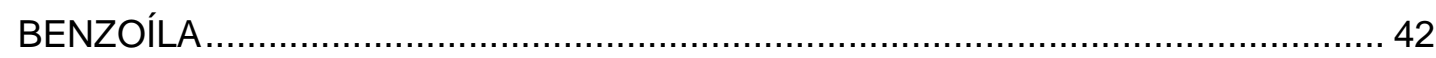

3.5. MONOGRAFIA USP DO PERÓXIDO DE BENZOÍLA HIDRATADO E

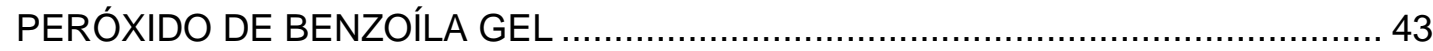

3.6. EVOLUÇÃO HISTÓRICA DA EVOLUÇÃO DO MÉTODO DE DOSEAMENTO DO PERÓXIDO DE BENZOÍLA SEGUNDO A FARMACOPÉIA AMERICANA (USP)43 
CAPÍTULO IV - TÉCNICAS ANALÍTICAS EMPREGADAS DURANTE O ESTUDO EXPLORATÓRIO DOS PRODUTOS DE DEGRADAÇÃO ............................................. 45

4. CROMATOGRAFIA LÍQUIDA DE ALTA EFICIÊNCIA (CLAE) ........................... 46

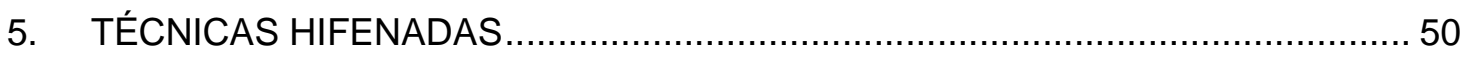

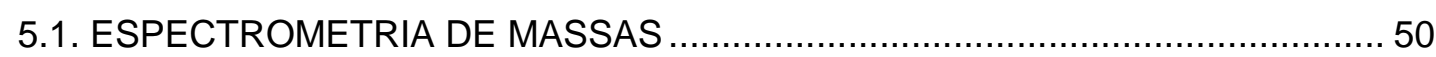

5.1.1. EVOLUÇÃO HISTÓRICA ......................................................... 50

5.1.2. ALGUMAS APLICAÇÕES DA TÉCNICA DE ESPECTROMETRIA DE MASSAS 50

5.1.3. DEFINIÇÃO E CONCEITO ...................................................... 51

5.1.4. ESQUEMA ILUSTRATIVO DO SISTEMA LC-MS/MS ...................... 53

5.1.5. ESCOLHA DA TÉCNICA DE IONIZAÇÃO E ANALISADOR DE MASSAS 53

5.2. TÉCNICAS DE IONIZAÇÃO 54

5.2.1. TÉCNICAS DE IONIZAÇÃO À PRESSÃO ATMOSFÉRICA .......................5 54

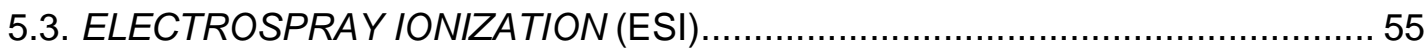

5.3.1. ELECTROSPRAY IONIZATION (ESI) ............................................ 55

5.4. ATMOSFERIC PRESSURE CHEMICAL IONIZATION (APCI) .......................... 56

5.5. ATMOSPHERIC PRESSURE PHOTO IONIZATION (APPI) …........................ 57

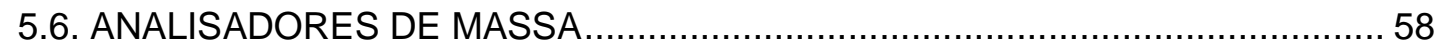

5.6.1. QUADRUPOLOS: SIMPLES (MS) ............................................... 58

5.6.2. QUADRUPOLOS: TRIPLO QUADRUPOLO (MS/MS OU $\left.\mathrm{MS}^{2}\right)$................. 58

5.7. MULTIPLE REACTION MONITORING / SELECTED REACTION MONITORING

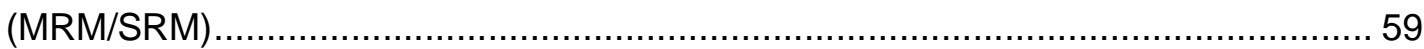

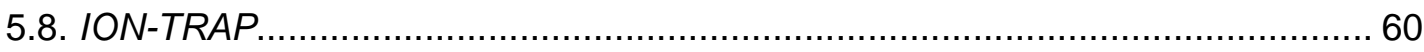

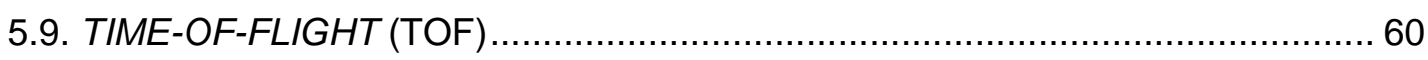

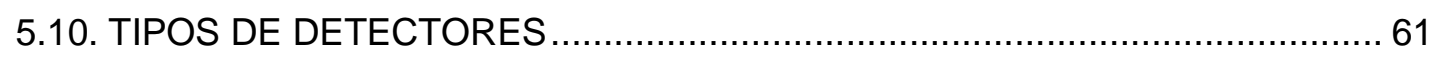

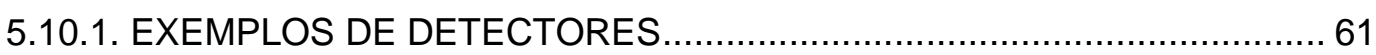

CAPÍTULO V - VALIDAÇÃO DE MÉTODOS ANALÍTICOS..........................................62

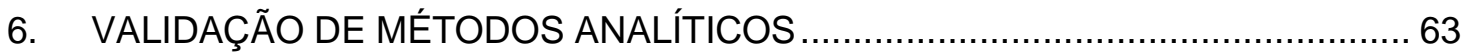

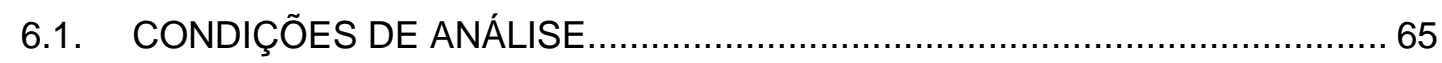

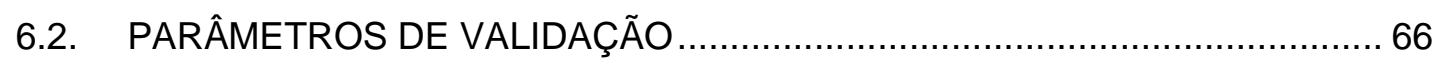

6.3. DEFINIÇÃO DOS PARÂMETROS DE VALIDAÇÃO .................................. 67 


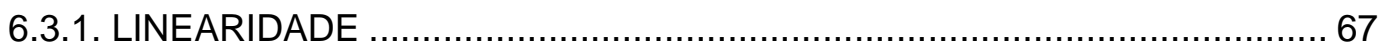

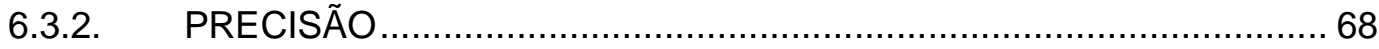

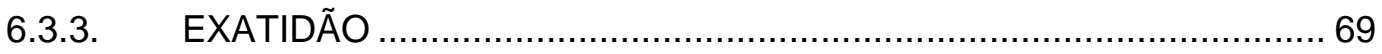

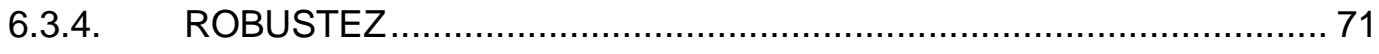

6.3.5. LIMITE DE DETECÇÃO ............................................................... 72

6.3.6. LIMITE DE QUANTIFICAÇÃO ................................................ 72

6.3.7. ESPECIFICIDADE E SELETIVIDADE ........................................ 73

CAPÍTULO VI - MÉTODOS INDICATIVOS DE ESTABILIDADE .................................. 75

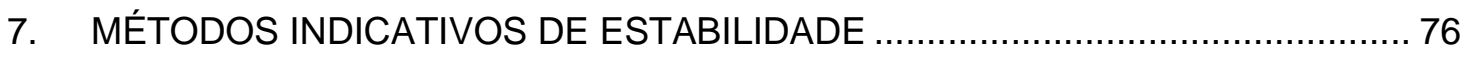

7.1. DEGRADAÇÃO FORÇADA …........................................................... 78

7.2. DELINEAMENTO DOS ESTUDOS DE DEGRADAÇÃO FORÇADA COM

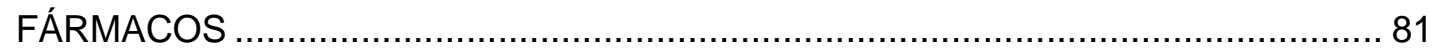

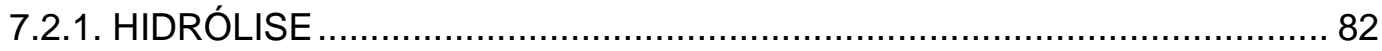

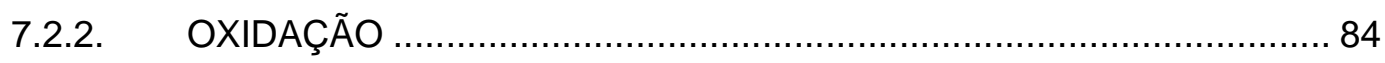

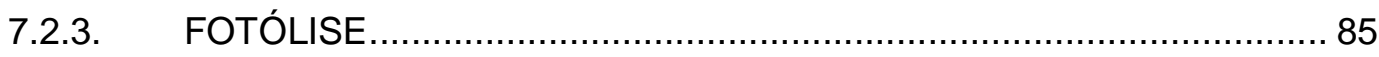

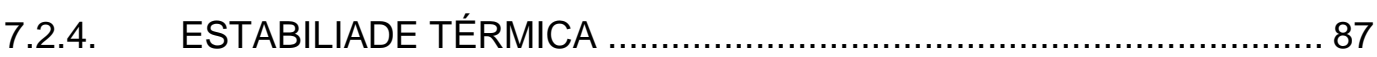

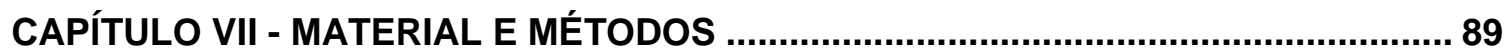

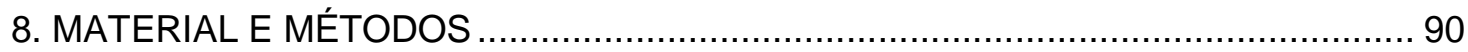

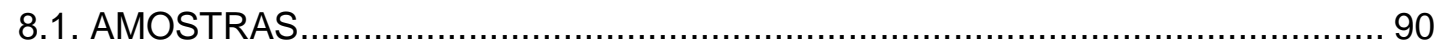

8.2. REAGENTES E PADRÕES ANALÍTICOS UTILIZADOS ................................ 90

8.3. EQUIPAMENTOS UTILIZADOS ............................................................. 91

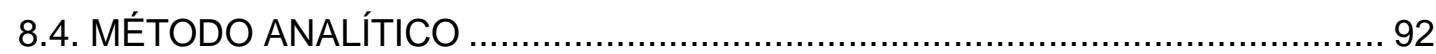

8.5. MÉTODO INDICATIVO DE ESTABILIDADE PARA O PERÓXIDO DE BENZOÍLA E SEUS PRODUTOS DE DEGRADAÇÃO COMPENDIAIS ..................................... 92 8.6. MÉTODO DE DOSEAMENTO DE PERÓXIDO DE BENZOÍLA E IDENTIFICAÇÃO DO PRODUTO DE DEGRADAÇÃO GERADO NA FOTÓLISE POR ESPECTROMETRIA DE MASSAS ............................................................... 98

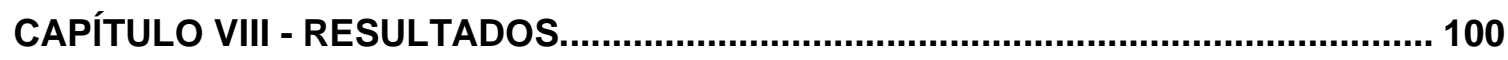

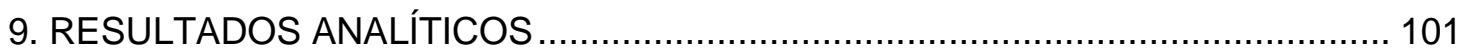

9.1. IDENTIFICAÇÃO DA MATÉRIA-PRIMA PERÓXIDO DE BENZOÍLA POR INFRAVERMELHO MÉDIO ......................................................................... 101 
9.2. VALIDAÇÃO DO MÉTODO INDICATIVO DE ESTABILIDADE POR CROMATOGRAFIA LÍQUIDA DE ALTA EFICIÊNCIA 102

9.2.1. LINEARIDADE 102

9.2.2. ESTRATÉGIA ADOTADA PARA REALIZAÇÃO DO ENSAIO DE

LINEARIDADE 102

9.2.4. RESULTADOS OBTIDOS NO ENSAIO DE LINEARIDADE .............. 103

9.2.4.1. ÁCIDO BENZÓICO .................................................................... 103

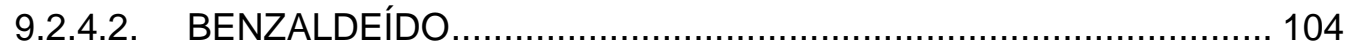

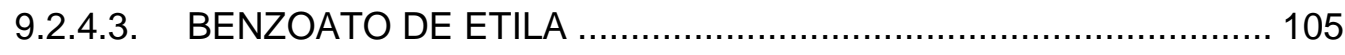

9.2.4.4. PERÓXIDO DE BENZOÍLA ........................................................ 106

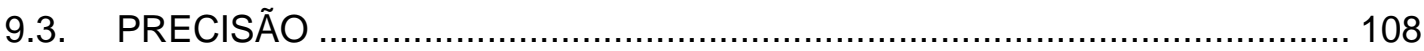

9.3.1. ESTRATÉGIA ADOTADA PARA REALIZAÇÃO DO ENSAIO DE PRECISÃO

9.3.2. CRITÉRIOS DE ACEITAÇÃO ......................................................... 109

9.3.3. RESULTADOS OBTIDOS NO ENSAIO DE PRECISÃO........................... 110

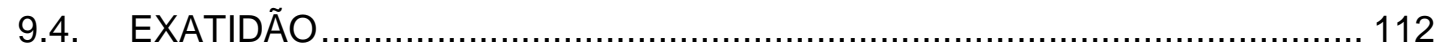

9.4.1. ESTRATÉGIA ADOTADA PARA REALIZAÇÃO DO ENSAIO DE EXATIDÃO

112

9.4.2. CRITÉRIOS DE ACEITAÇÃO ....................................................... 113

9.4.3. RESULTADOS OBTIDOS NO ENSAIO DE EXATIDÃO .................... 113

9.4.3.1. ÁCIDO BENZÓICO ............................................................... 113

9.4.3.2. BENZOATO DE ETILA …................................................... 114

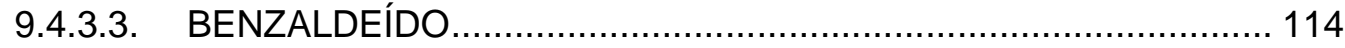

9.4.3.4. PERÓXIDO DE BENZOÍLA .................................................... 115

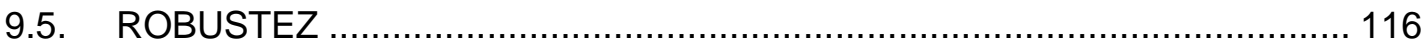

9.5.1. ESTRATÉGIA ADOTADA PARA REALIZAÇÃO DO ENSAIO DE

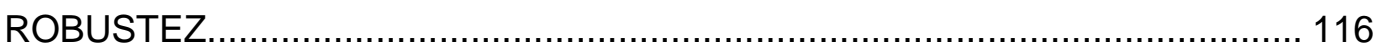

9.5.2. RESULTADOS OBTIDOS NO ENSAIO DE ROBUSTEZ ........................ 118

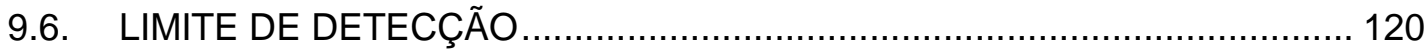

9.6.1. ESTRATÉGIA ADOTADA PARA REALIZAÇÃO DO ENSAIO DE LIMITE DE

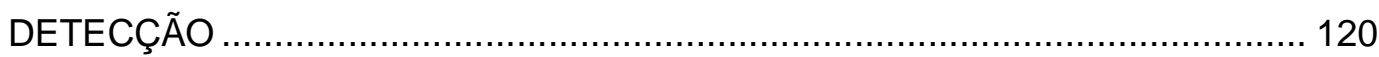

9.6.2. CRITÉRIOS DE ACEITAÇÃO …................................................ 120

9.6.3. RESULTADOS OBTIDOS NO ENSAIO DE LIMITE DE DETECÇÃO ....... 121 


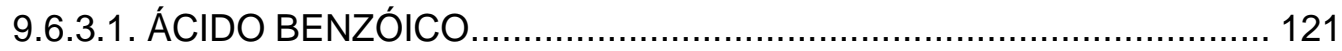

9.6.3.2. BENZOATO DE ETILA ............................................................. 122

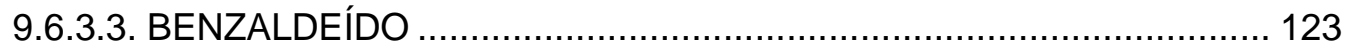

9.6.3.4. PERÓXIDO DE BENZOÍLA ....................................................... 124

9.7. LIMITE DE QUANTIFICAÇÃO …..................................................... 126

9.7.1. ESTRATÉGIA ADOTADA PARA REALIZAÇÃO DO ENSAIO DE LIMITE DE

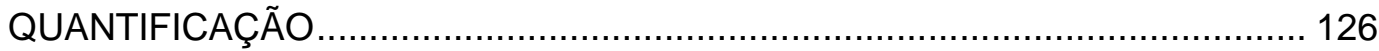

9.7.2. CRITÉRIOS DE ACEITAÇÃO ......................................................... 126

9.7.3. RESULTADOS OBTIDOS NO ENSAIO DE LIMITE DE

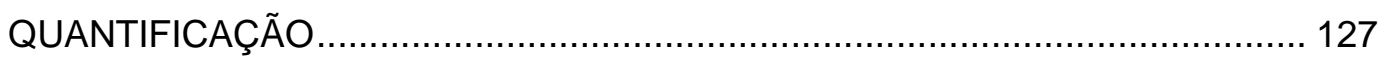

9.7.3.1. ÁCIDO BENZÓICO.................................................................. 127

9.7.3.2. BENZOATO DE ETILA .......................................................... 128

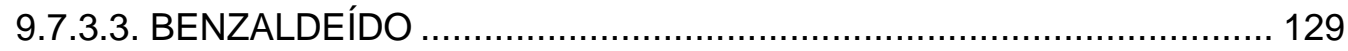

9.7.3.4. PERÓXIDO DE BENZOÍLA ......................................................... 130

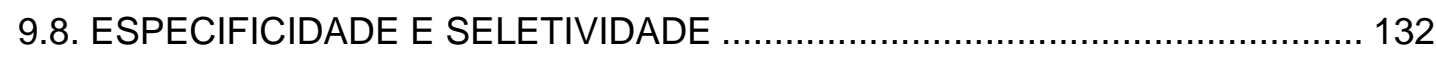

9.8.1. CRITÉRIOS DE ACEITAÇÃO ....................................................... 133

9.8.2. ESTRATÉGIA ADOTADA PARA REALIZAÇÃO DO ENSAIO DE

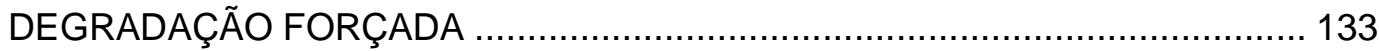

9.8.3. PREPARO DAS AMOSTRAS........................................................ 134

9.8.4. RESULTADOS OBTIDOS NO ENSAIO DE DEGRADAÇÃO FORÇADA . 137

9.8.4.1. HIDRÓLISE NEUTRA .............................................................. 137

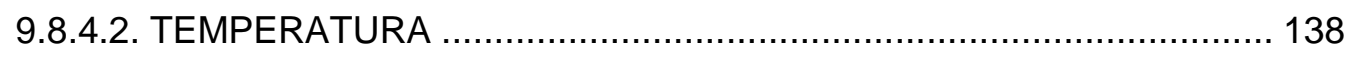

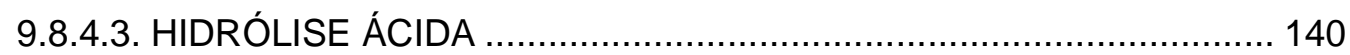

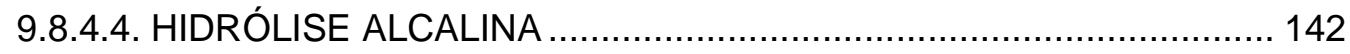

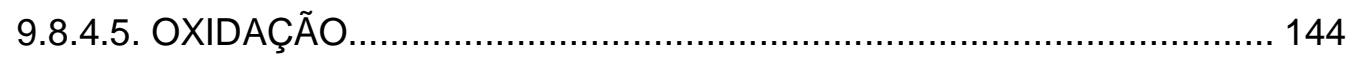

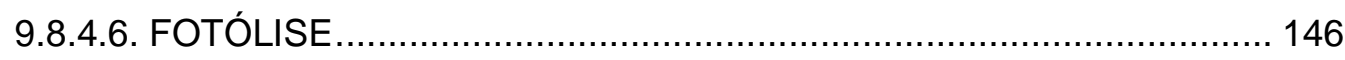

10. RESULTADOS DE LC-MS/MS OBTIDOS DURANTE A IDENTIFICAÇÃO DO PRODUTOS DE DEGRADAÇÃO FORMADO NA FOTÓLISE ................................. 151

10.1. FÁRMACO ISOLADO.................................................................. 151

10.2. FÁRMACO INSERIDO NA PREPARAÇÃO MEDICAMENTOSA ............... 155

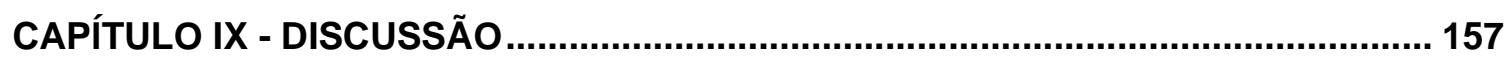

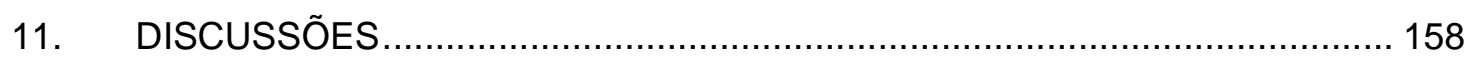


11.1. DESENVOLVIMENTO DO MÉTODO INDICATIVO DE ESTABILIDADE ........ 158 11.2. DESENVOLVIMENTO DO MÉTODO QUANTITATIVO DE PERÓXIDO DE BENZOÍLA POR ESPECTROMETRIA DE MASSAS. 159 11.3. IDENTIFICAÇÃO DO PRODUTO DE DEGRADAÇÃO GERADO NA FOTÓLISE 160

CAPÍTULO X - CONCLUSÕES 161

12. CONCLUSÕES 162

CAPÍTULO XII - ANEXOS 163

CAPÍTULO XIII - REFERÊNCIAS. 164

13. REFERÊNCIAS. 165 
Dias, F.L. Desenvolvimento e validação de método indicador de estabilidade de

formulações farmacêuticas de uso tópico contendo peróxido de benzoíla. Dissertação (mestrado). 2014

\section{RESUMO}

O peróxido de benzoíla, produto de interação do peróxido de sódio com cloreto de benzoíla, é um poderoso agente antibacteriano de amplo espectro com ação queratolítica, comedolítica, descamativa, antipruriginosa e desengordurante, além de também ser um potente agente oxidante, que reage com materiais orgânicos rompendo as membranas celulares de inúmeros agentes patogênicos. Em virtude de suas características, o peróxido de benzoíla é utilizado como produto de eleição como adjuvante no tratamento de sarnas (dermodicidoses), desqueratinizações, complexo seborréico, piodermites, foliculites superficiais, impetigo e piodermite de dobras.

Neste projeto é abordado o desenvolvimento e validação de um método indicador de estabilidade do fármaco peróxido de benzoíla, cujo objetivo é ser utilizado como ferramenta para a identificação e doseamento de maneira precisa e exata dos produtos de degradação desconhecidos formados, a partir de variados ambientes de acondicionamento estressantes, nos quais o medicamento possa ser eventualmente submetido durante o seu prazo de vida de prateleira.

O método analítico proposto foi validado conforme os requerimentos vigentes da ANVISA e se baseia na técnica de cromatografia líquida de alta eficiência (CLAE) para doseamento do princípio ativo e seus produtos de degradação, em uma única corrida analítica, o que permite determiná-los simultaneamente, e portanto é adequado para utilização durante o estudo de estabilidade acelerado e de longa duração, além de metodologia indicadora de estabilidade. 
Durante o estudo de degradação forçada foram geradas uma série de "picos" desconhecidos inerentes ao fármaco, especialmente nas condições de aquecimento, hidrólise em meios ácido e alcalino, e fotólise. Entretanto, durante o estudo foram investigados aqueles originados a partir desta última, uma vez a posologia da preparação medicamentosa estudada é via tópica, pois se trata da forma farmacêutica semi-sólida gel.

Para avaliação dos produtos de degradação gerados durante a fotólise foi utilizada a cromatografia líquida com detecção por espectrometria de massas, onde o fármaco foi ionizado na forma positiva (+) através da técnica Electrospray ionization $\left(\mathrm{ESI}^{+}\right)$, a qual permitiu a proposição da estrutura molecular da substância gerada, a partir da provável perda do grupamento alquil ou aldeído, justificando assim a razão massa carga 199,1 u.m.a. 
Dias, F.L. Development and validation of indicator stability method of

pharmaceutical formulations for topical use containing benzoyl peroxide.

Dissertação (mestrado). 2014

\section{ABSTRACT}

Benzoyl peroxide, the produced by interaction of sodium peroxide with Benzoyl chloride is a powerful antibacterial agent with keratolytic, comedolytic , scaly, antipruritic and degreasing action, as well as being a powerful oxidizing agent that reacts with organic materials disrupting the membrane cell of many pathogens agents. Due to its characteristics, benzoyl peroxide is used as the main choice in the treatment of scabies, seborrhea complex, pyoderma, superficial folliculitis, impetigo and pyoderma folds.

This project addresses the development and validation of an indicator stability method for benzoyl peroxide, which is intended to be used as a tool for the identification and accurate and preciously determination of unknown degradation products formed from various stressful environments, in which the API may eventually be submitted during the period of shelf life.

The proposed analytical method was validated according to the applicable/current requirements of ANVISA and it is based on the technique of high performance liquid chromatography (HPLC) assay for the active ingredient and its degradation products in a single analytical run, allowing dosing them simultaneously, and thus it is suitable for use during accelerated and long term stability studies and as stability indicating method.

During the forced degradation study many unknown "peaks" inherent to drug were generate, especially under heating, acid and alkaline hydrolysis, beyond photolysis conditions. However, throughout this study were investigated that obtained from the 
photolysis, since the sample preparation are applied topically because it is semi - solid dosage gel form.

To evaluate the degradation products generated during photolysis were used liquid chromatography with detection by mass spectrometry, where the drug was ionized in the positive (+) form by technical Electrospray ionization $\left(\mathrm{ESI}^{+}\right)$technique, which allowed the proposition of the molecular structure substance generated from the probable loss of the alkyl or aldehyde grouping , thus justifying the mass/charge ratio $199.1 \mathrm{amu}$. 


\section{LISTA DE FIGURAS}

FIGURA 1. Patogênese da acne - anatomia do folículo.

FIGURA 2. Pápulo-pústulas e lesões cicatriciais

FIGURA 3. Comedões abertos e fechados

FIGURA 4. Pápulas, nódulos e cistos eritematosos de acne inflamatória. 33

FIGURA 5. Reação de formação do peróxido de só'dio

FIGURA 6. Reação de formação do peróxido de benzoíla.

FIGURA 7. Estrutura molecular do peróxido de benzoíla

FIGURA 8. Estrutura molecular do ácido benzóico

FIGURA 9. Estrutura molecular do benzoato de etila. 42

FIGURA 10. Estrutura molecular do benzaldeído

FIGURA 11. Representação esquemática do equipamento de cromatografia líquida de alta eficiência (CLAE)

FIGURA 12. Esquema representativo do espectrômetro de massas. LC-MS/MS. .51

FIGURA 13. Esquema representativo do sistema de cromatografia líquida acoplada à espectrometria de massas. LC-MS/MS. .53

FIGURA 14. Gráfico ilustrativo para a escolha da técnica de ionização e analisador de massas...... .54 
FIGURA 15. Esquema ilustrativo da técnica de ionização Electrospray lonization (ESI)...55

FIGURA 16. Esquema ilustrativo da técnica de ionização Atmospheric Pressure Chemical Ionization (APCI).

FIGURA 17. Esquema ilustrativo da técnica de ionização Atmospheric Pressure Photo Ionization (APPI).

FIGURA 18. Analisador de massas - Quadrupolo simples.

FIGURA 19. Analisador de massas - Triplo Quadrupolo 59

FIGURA 20. Analisador de massas - Q1, Q2 e Q3. 59

FIGURA 21. Ilustração do analisador de Massas Ion-Trap... 60

FIGURA 22. Ilustração do analisador de Massas Time-of-flight (TOF)...... 60

FIGURA 23. Método convencional versus Método indicador de estabilidade.

FIGURA 24. Fluxograma do estudo de estresse: Hidrólise sob condições ácidas e básicas. 83

FIGURA 25. Fluxograma do estudo de estresse: Oxidação. .84

FIGURA 26. Fluxograma do estudo de estresse: Fotólise. 86

FIGURA 27. Cromatograma da solução de peróxido de benzoíla $0,42375 \mathrm{mg} \cdot \mathrm{mL}^{-1}$, ácido benzóico 0,10157 mg.mL ${ }^{-1}$, benzaldeído $0,0051 \mathrm{mg} \cdot \mathrm{mL}^{-1}$, benzoato de etila 0,00548 $\mathrm{mg} \cdot \mathrm{mL}^{-1}$ e metilparabeno $0,016 \mathrm{mg} \cdot \mathrm{mL}^{-1}$; Condições: coluna Luna C18 $100 \AA$ (5 $\mu \mathrm{m}, 250 \mathrm{x}$ 4,6mm), vazão: 1,5mL.min-1, fase móvel: ACN:HÁc (1000:1) e Água:HÁc (1000:1) gradiente; detecção: $235 \mathrm{~nm}$. .93 
FIGURA 28. Espectro de infravermelho do peróxido benzoíla, em célula ATR 101

FIGURA 29. Estratégia adotada para realização do ensaio de linearidade. 102

FIGURA 30. Ácido benzóico - Curva de calibração 104

FIGURA 31. Benzaldeído - Curva de calibração 105

FIGURA 32. Benzoato de etila - Curva de calibração 106

FIGURA 33. Peróxido de benzoíla - Curva de calibração. 107

FIGURA 34. Estratégia adotada para realização do ensaio de precisão. 108

FIGURA 35. Estratégia adotada para realização do ensaio de exatidão. 112

FIGURA 36. Estratégia adotada para realização do ensaio de robustez: (a) Fatores relacionados à técnica $\mathrm{CLAE}$. 116

FIGURA 37. Estratégia adotada para realização do ensaio de robustez: (b) Fatores relacionados à técnica CLAE e (c) Fatores relacionados ao preparo de amostra 117

FIGURA 38. Cromatograma da solução de ácido benzóico $0,001015695 \mathrm{mg} \cdot \mathrm{mL}^{-1}$;

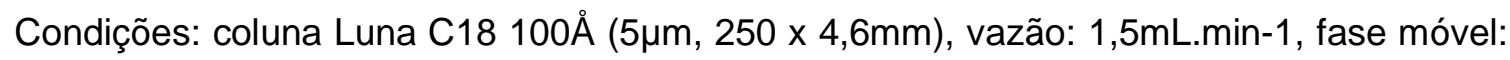
ACN:HÁc (1000:1) e Água:HÁc (1000:1) - gradiente; detecção: 235nm. 122

FIGURA 39. Cromatograma da solução de Benzoato de Etila $0,000822 \mathrm{mg} \cdot \mathrm{mL}^{-1}$;

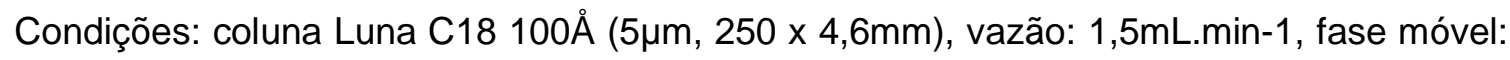
ACN:HÁc (1000:1) e Água:HÁc (1000:1) - gradiente; detecção: 235nm. 123 
FIGURA 40. Cromatograma da solução de Benzaldeído 0,001279872 mg.mL ${ }^{-1}$;

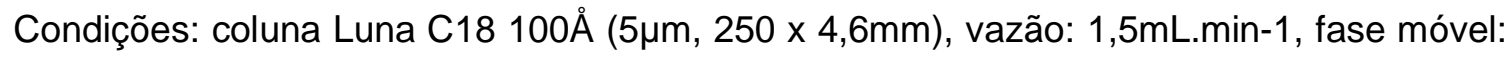
ACN:HÁc (1000:1) e Água:HÁc (1000:1) - gradiente; detecção: 235nm. 124

FIGURA 41. Cromatograma da solução de Peróxido de Benzoíla $0,000002559 \mathrm{mg} \mathrm{mL}^{-1}$;

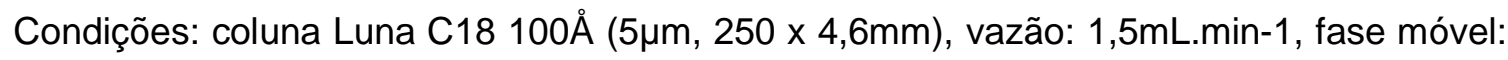
ACN:HÁc (1000:1) e Água:HÁc (1000:1) - gradiente; detecção: 235nm .125

FIGURA 42. Cromatograma da solução de ácido benzóico $0,002539238 \mathrm{mg}^{-1} \mathrm{~mL}^{-1}$;

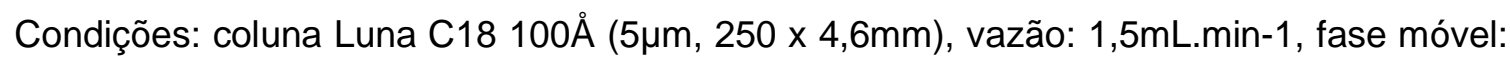
ACN:HÁc (1000:1) e Água:HÁc (1000:1) - gradiente; detecção: 235nm. 128

FIGURA 43. Cromatograma da solução de Benzoato de Etila $0,00274 \mathrm{mg} \cdot \mathrm{mL}^{-1}$;

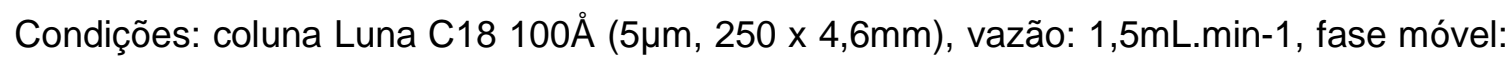
ACN:HÁc (1000:1) e Água:HÁc (1000:1) - gradiente; detecção: 235nm. 129

FIGURA 44. Cromatograma da solução de Benzaldeído 0,003839616mg. $\mathrm{mL}^{-1}$; Condições:

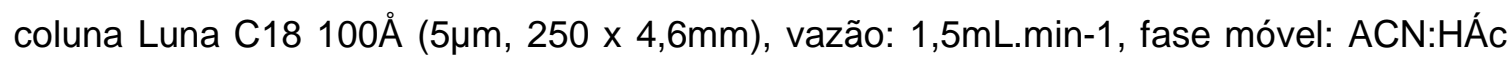
(1000:1) e Água:HÁc (1000:1) - gradiente; detecção: 235nm. 130

FIGURA 45. Cromatograma da solução de Peróxido de Benzoíla 0,000002559 mg.mL ${ }^{-1}$;

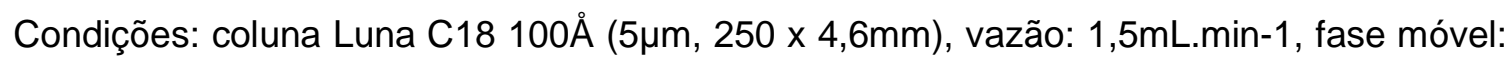
ACN:HÁc (1000:1) e Água:HÁc (1000:1) - gradiente; detecção: 235nm. .131

FIGURA 46. Descrição das condições de degradação forçada avaliadas. 133

FIGURA 47. Cromatograma da solução placebo: $11,964 \mathrm{mg} \cdot \mathrm{mL}^{-1}$ - Hidrólise neutra; Condições: coluna Luna C18 $100 \AA$ ( $5 \mu \mathrm{m}, 250$ x 4,6mm), vazão: 1,5mL. $\mathrm{min}^{-1}$, fase móvel: ACN:HÁc (1000:1) e Água:HÁc (1000:1) - gradiente; detecção: 235nm. 137

FIGURA 48. Cromatograma da solução peróxido de benzoíla gel $40 \mathrm{mg} / \mathrm{g}: 10,864 \mathrm{mg} \cdot \mathrm{mL}^{-1}$

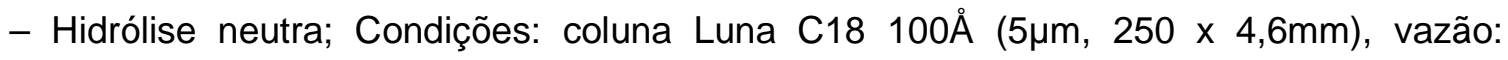


1,5mL.min ${ }^{-1}$, fase móvel: ACN:HÁc (1000:1) e Água:HÁc (1000:1) - gradiente; detecção: $235 \mathrm{~nm}$. 138

FIGURA 49. Cromatograma da solução do fármaco peróxido de benzoíla isolado: 0,6 mg.mL ${ }^{-1}$ - Hidrólise neutra; Condições: coluna Luna C18 $100 \AA$ ( $\left.5 \mu \mathrm{m}, 250 \times 4,6 \mathrm{~mm}\right)$, vazão: 1,5mL.minn ${ }^{-1}$, fase móvel: ACN:HÁc (1000:1) e Água:HÁc (1000:1) - gradiente; detecção: $235 \mathrm{~nm}$ 138

FIGURA 50. Cromatograma da solução placebo: $11,328 \mathrm{mg} \cdot \mathrm{mL}^{-1}$ - Calor; Condições: coluna Luna C18 $100 \AA ̊$ ( $5 \mu \mathrm{m}, 250$ x 4,6mm), vazão: 1,5mL.min ${ }^{-1}$, fase móvel: ACN:HÁc (1000:1) e Água:HÁc (1000:1) - gradiente; detecção: 235nm. 138

FIGURA 51. Cromatograma da solução do peróxido de benzoíla gel 40mg/g: 10,416 mg.mL ${ }^{-1}$ - Calor; Condições: coluna Luna C18 $100 \AA$ ( $\left.5 \mu \mathrm{m}, 250 \times 4,6 \mathrm{~mm}\right)$, vazão: 1,5mL. $\mathrm{min}^{-1}$, fase móvel: ACN:HÁc (1000:1) e Água:HÁc (1000:1) - gradiente; detecção: $235 \mathrm{~nm}$

FIGURA 52. Cromatograma da solução do fármaco peróxido de benzoíla isolado: 0,628 mg.mL ${ }^{-1}$ - Calor; Condições: coluna Luna C18 $100 \AA$ (5 $\mu \mathrm{m}, 250$ x 4,6mm), vazão: 1,5mL. $\mathrm{min}^{-1}$, fase móvel: ACN:HÁc (1000:1) e Água:HÁc (1000:1) - gradiente; detecção: $235 \mathrm{~nm}$.

FIGURA 53. Cromatograma da solução placebo: $12,92 \mathrm{mg} \cdot \mathrm{mL}^{-1}$ - Hidrólise ácida; Condições: coluna Luna C18 $100 \AA ̊$ ( $5 \mu \mathrm{m}, 250$ x 4,6mm), vazão: 1,5mL. $\mathrm{min}^{-1}$, fase móvel: ACN:HÁc (1000:1) e Água:HÁc (1000:1) - gradiente; detecção: 235nm. 140

FIGURA 54. Cromatograma da solução do peróxido de benzoíla gel 40mg/g: 10,772

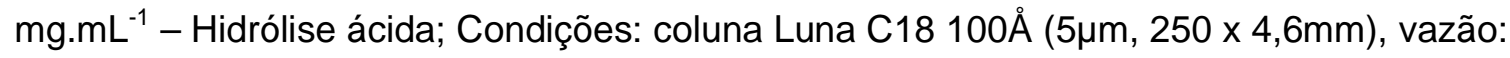
1,5mL. $\mathrm{min}^{-1}$, fase móvel: ACN:HÁc (1000:1) e Água:HÁc (1000:1) - gradiente; detecção: $235 \mathrm{~nm}$. 141

FIGURA 55. Cromatograma da solução do fármaco peróxido de benzoíla isolado: 0,57 mg. $\mathrm{mL}^{-1}$ - Hidrólise ácida; Condições: coluna Luna C18 $100 \AA$ ( $5 \mu \mathrm{m}, 250$ x 4,6mm), vazão: 
1,5mL. $\min ^{-1}$, fase móvel: ACN:HÁc (1000:1) e Água:HÁc (1000:1) - gradiente; detecção: $235 \mathrm{~nm}$.

FIGURA 56. Cromatograma da solução placebo: $10,326 \mathrm{mg} \cdot \mathrm{mL}^{-1}$ - Hidrólise alcalina; Condições: coluna Luna C18 $100 \AA ̊$ ( $5 \mu \mathrm{m}, 250$ x 4,6mm), vazão: 1,5mL.min ${ }^{-1}$, fase móvel: ACN:HÁc (1000:1) e Água:HÁc (1000:1) - gradiente; detecção: 235nm.

FIGURA 57. Cromatograma da solução do peróxido de benzoíla gel 40mg/g: 10,754

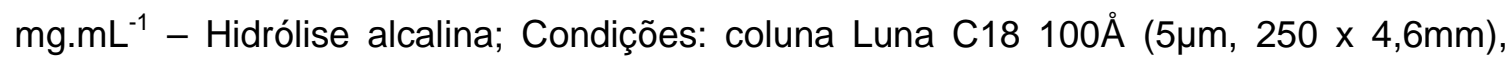
vazão: 1,5mL.min ${ }^{-1}$, fase móvel: ACN:HÁc (1000:1) e Água:HÁc (1000:1) - gradiente; detecção: $235 \mathrm{~nm}$

FIGURA 58. Cromatograma da solução do fármaco peróxido de benzoíla isolado: 0,544

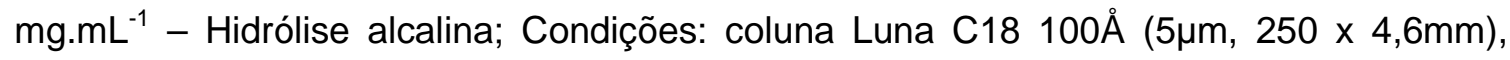
vazão: 1,5mL.min ${ }^{-1}$, fase móvel: ACN:HÁc (1000:1) e Água:HÁc (1000:1) - gradiente; detecção: $235 \mathrm{~nm}$.

FIGURA 59. Cromatograma da solução placebo: $10,158 \mathrm{mg} \cdot \mathrm{mL}^{-1}$ - Oxidação; Condições: coluna Luna C18 $100 \AA ̊$ ( $5 \mu \mathrm{m}, 250$ x 4,6mm), vazão: 1,5mL.min ${ }^{-1}$, fase móvel: ACN:HÁc (1000:1) e Água:HÁc (1000:1) - gradiente; detecção: 235nm.

FIGURA 60. Cromatograma da solução do peróxido de benzoíla gel 40mg/g: 10,50

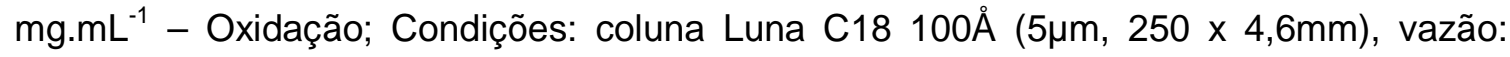
1,5mL. $\mathrm{min}^{-1}$, fase móvel: ACN:HÁc (1000:1) e Água:HÁc (1000:1) - gradiente; detecção: $235 \mathrm{~nm}$. 145

FIGURA 61. Cromatograma da solução do fármaco peróxido de benzoíla isolado: 0,576

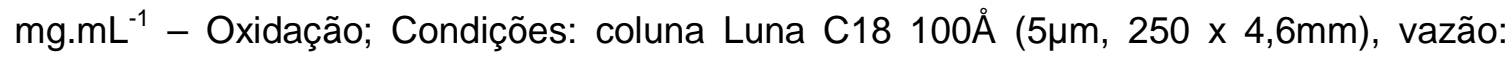
1,5mL. $\mathrm{min}^{-1}$, fase móvel: ACN:HÁc (1000:1) e Água:HÁc (1000:1) - gradiente; detecção: $235 \mathrm{~nm}$. .145 
FIGURA 62. Cromatograma da solução placebo: $12,812 \mathrm{mg} \cdot \mathrm{mL}^{-1}$ - Fotólise; Condições:

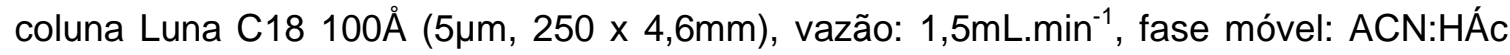
(1000:1) e Água:HÁc (1000:1) - gradiente; detecção: 235nm. 146

FIGURA 63. Cromatograma da solução do peróxido de benzoíla gel 40mg/g: 10,792 mg.mL ${ }^{-1}$ - Fotólise; Condições: coluna Luna C18 $100 \AA$ (5 $5 \mathrm{~m}, 250$ x 4,6mm), vazão: 1,5mL. in $^{-1}$, fase móvel: ACN:HÁc (1000:1) e Água:HÁc (1000:1) - gradiente; detecção: $235 \mathrm{~nm}$

FIGURA 64. Cromatograma da solução do fármaco peróxido de benzoíla isolado: 0,568

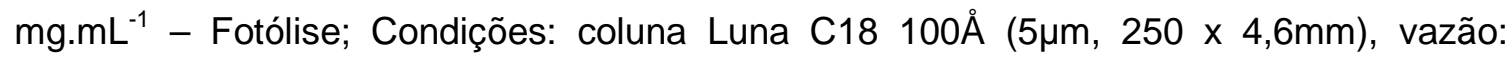
1,5mL. $\mathrm{min}^{-1}$, fase móvel: ACN:HÁc (1000:1) e Água:HÁc (1000:1) - gradiente; detecção: $235 \mathrm{~nm}$ 148

FIGURA 65. Cromatograma da solução branco - Acetonitrila grau HPLC; Condições: coluna Luna C18 $100 \AA ̊$ ( $5 \mu \mathrm{m}, 250$ x 4,6mm), vazão: 1,5mL.min ${ }^{-1}$, fase móvel: ACN:HÁc (1000:1) e Água:HÁc (1000:1) - gradiente; detecção: 235nm. 148

FIGURA 66. Cromatograma da solução do peróxido de benzoíla gel 40mg/g: 10,50

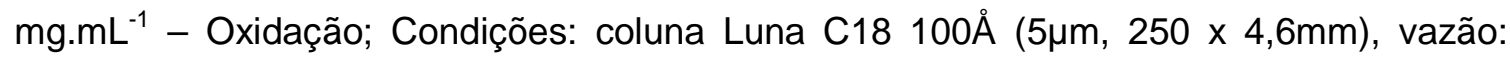
1,5mL. $\mathrm{min}^{-1}$, fase móvel: ACN:HÁc (1000:1) e Água:HÁc (1000:1) - gradiente; detecção: $235 \mathrm{~nm}$. 149

FIGURA 67. Cromatograma da solução do peróxido de benzoíla gel 40mg/g: 10,50

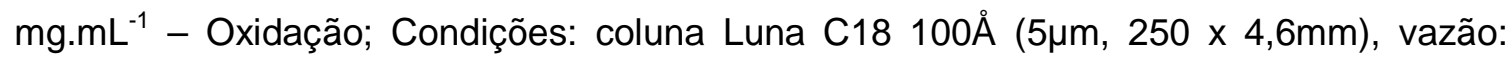
1,5mL. $\mathrm{min}^{-1}$, fase móvel: ACN:HÁc (1000:1) e Água:HÁc (1000:1) - gradiente; detecção: $235 \mathrm{~nm}$. 149

FIGURA 68. Cromatograma da solução do peróxido de benzoíla gel 40mg/g: 10,50

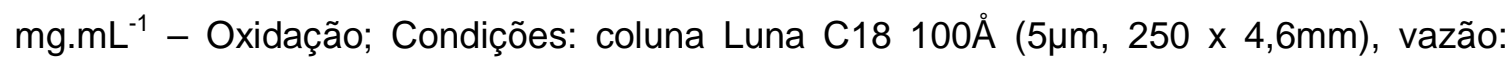
1,5mL. $\mathrm{min}^{-1}$, fase móvel: ACN:HÁc (1000:1) e Água:HÁc (1000:1) - gradiente; detecção: $235 \mathrm{~nm}$. 150 
FIGURA 69. Cromatograma da solução de peróxido de benzoíla (referência) 0,42375 $\mathrm{mg} \cdot \mathrm{mL}^{-1}$, ácido benzóico $0,10157 \mathrm{mg} \cdot \mathrm{mL}^{-1}$, benzaldeído $0,0051 \mathrm{mg} \cdot \mathrm{mL}^{-1}$, benzoato de etila $0,00548 \mathrm{mg} \cdot \mathrm{mL}^{-1}$ e metilparabeno $0,016 \mathrm{mg} \cdot \mathrm{mL}^{-1}$; Condições: coluna Luna C18 $100 \AA$ $(5 \mu \mathrm{m}, 250 \times$ 4,6mm), vazão: 1,5mL.min-1, fase móvel: ACN:HÁc (1000:1) e Água:HÁc (1000:1) - gradiente; detecção: $235 \mathrm{~nm}$. 150

FIGURA 70. Cromatograma exploratório no modo TIC do Peróxido de Benzoíla estressado por fotólise - volume de injeção $20 \mu \mathrm{L}$

FIGURA 71. Cromatograma exploratório no modo $\mathrm{ESI}^{+}$e DAD $(235 \mathrm{~nm})$ do Peróxido de Benzoíla estressado por fotólise - volume de injeção $20 \mu \mathrm{L}$

FIGURA 72. Espectro de massas do produto de degradação formado durante a fotólise 152

FIGURA 73. Espectro de massas da região sem a presença de grupos cromóforos. 152

FIGURA 74. Sobreposição dos Espectros de massas do produto de degradação formado durante a fotólise e da região sem a formação de cromóforos. 153

FIGURA 75. Espectro de massas do produto de degradação formado durante a fotólise, com detalhe no íon de m/z 199,1 153

FIGURA 76. Espectro de massas do produto de degradação formado durante a fotólise, com detalhe no íon de $\mathrm{m} / \mathrm{z} 239,1$ .154

FIGURA 77. Espectro de massas do produto de degradação formado durante a fotólise, com detalhe no íon de m/z 199,0 e 239,1 154

FIGURA 78. Cromatograma exploratório no modo TIC do Peróxido de Benzoíla estressado por fotólise - volume de injeção $20 \mu \mathrm{L}$. 155 
FIGURA 79. Cromatograma exploratório no modo TIC do Peróxido de Benzoíla estressado por fotólise - volume de injeção $20 \mu \mathrm{L}$ 155

FIGURA 80. Espectro de massas do peróxido de benzoíla estressado e incorporado ao medicamento. 156

FIGURA 81. Sobreposição de espectros de massas do produto de degradação formado e a região sem a presença de cromóforos. 156 


\section{LISTA DE QUADROS}

QUADR01. Patogênese da Acne. 40

QUADRO 2. Parâmetros necessários durante a validação de método. .67

QUADRO 3. Limites porcentuais do teor do analito que devem estar contidos no intervalo de linearidade para métodos analíticos. 68

QUADRO 4. Exemplos de fatores que devem ser considerados na determinação da robustez do método analítico. .71

QUADRO 5. Condições de estresse para a realização do estudo de degradação forçada. 80

QUADRO 6. Critérios de aceitação linearidade. 103

QUADRO 7. Critérios de aceitação para o ensaio de exatidão. 113 


\section{LISTA DE TABELAS}

TABELA 1. Condições cromatográficas .92

TABELA 2. Condições experimentais propostas para o método quantitativo por espectrometria de massas.

TABELA 3. Ácido Benzóico: Preparo das soluções padrões - Linearidade 103

TABELA 4. Ácido Benzóico: Valores de área obtidos - Linearidade. 103

TABELA 5. Benzaldeído: Preparo das soluções padrões - Linearidade 104

TABELA 6. Benzaldeído: Valores de área obtidos - Linearidade. 104

TABELA 7. Benzoato de Etila: Preparo das soluções padrões - Linearidade. 105

TABELA 8. Benzoato de etila: Valores de área obtidos - Linearidade. 105

TABELA 9. Peróxido de Benzoíla: Preparo das soluções padrões - Linearidade.. 106

TABELA 10. Peróxido de benzoíla: Valores de área obtidos - Linearidade. 106

TABELA 11. Peróxido de benzoíla gel 40mg/g e $80 \mathrm{mg} / \mathrm{g}$ - Precisão.

TABELA 12. Ácido benzóico: Preparo das soluções amostras - Exatidão 113

TABELA 13. Ácido benzóico: Valores de recuperação obtidos - Exatidão. 113

TABELA 14. Benzoato de etila: Preparo das soluções amostras - Exatidão. 114

TABELA 15. Benzoato de etila: Valores de recuperação obtidos - Exatidão. .114 
TABELA 16. Benzaldeído: Preparo de soluções amostras - Exatidão. 114

TABELA 17. Benzaldeído: Valores de recuperação obtidos - Exatidão. 115

TABELA 18.Peróxido de benzoíla: Preparo das soluções amostras - Exatidão 115

TABELA 19. Peróxido de benzoíla: Valores de recuperação obtidos - Exatidão. 115

TABELA 20. Peróxido de benzoíla gel 40mg/g: Avaliação da variação do comprimento de onda - Robustez. 118

TABELA 21. Peróxido de benzoíla gel $80 \mathrm{mg} / \mathrm{g}$ : Avaliação da variação do comprimento de onda - Robustez.

TABELA 22. Peróxido de benzoíla gel $40 \mathrm{mg} / \mathrm{g}$ : Avaliação da variação do volume de injeção - Robustez.

TABELA 23. Peróxido de benzoíla gel $80 \mathrm{mg} / \mathrm{g}$ : Avaliação da variação do volume de injeção - Robustez. 119

TABELA 24. Ácido benzóico: Preparo da solução 1\% (p/v) - Limite de detecção 121

TABELA 25. Ácido Benzóico: Valores de área obtidos - Limite de detecção 121

TABELA 26. Benzoato de etila: Preparo da solução 15\% (p/v) - Limite de detecção....122

TABELA 27. Benzoato de etila: Valores de área obtidos - Limite de detecção. 122

TABELA 28. Benzaldeído: Preparo da solução 25\% (p/v) - Limite de detecção 123

TABELA 29. Benzaldeído: Valores de área obtidos - Limite de detecção. 123 
TABELA 30. Peróxido de benzoíla: Preparo da solução $0,05 \%(p / v)$ - Limite de detecção. 123

TABELA 31. Peróxido de benzoíla: Valores de área obtidos - Limite de detecção........124

TABELA 32. Ácido benzóico: Preparação da solução $2,5 \%$ (p/v) - Limite de quantificação...XXX

TABELA 33. Ácido benzóico: Valores de área obtidos - Limite de quantificação. 127

TABELA 34. Benzoato de etila: Preparação da solução $50 \%$ (p/v) - Limite de quantificação 128

TABELA 35. Benzoato de etila: Valores de área obtidos - Limite de quantificação...128

TABELA 36. Benzaldeído: Preparação da solução $75 \%$ (p/v) - Limite de quantificação 129

TABELA 37. Benzaldeído: Valores de área obtidos - Limite de quantificação. 129

TABELA 38. Peróxido de benzoíla: Preparação da solução $0,1 \%(p / v)$ - Limite de quantificação 130

TABELA 39. Peróxido de benzoíla: Valores de área obtidos - Limite de quantificação.130

TABELA 40. Tomadas de ensaio: Peróxido de benzoíla gel 40mg/g, placebo e fármaco isolado - Degradação forçada. 134 


\section{LISTA DE ABREVIATURAS E SÍMBOLOS}

Água: HÁc Solução de água purificada e ácido acético glacial

ANVISA Agência Nacional de Vigilância Sanitária

API Active pharmaceutical ingredient

ATR Attenuaed Total Reflectance

CLAE Cromatografia líquida de alta eficiência

cm Centímetro

Desv. Pad. Desvio padrão

DPR Desvio padrão relativo

g Grama

g/mol Grama por mol

${ }^{\circ} \mathrm{C} \quad$ Grau Celsius

HÁc Ácido acético glacial

$\mathrm{H}_{2} \mathrm{O} \quad$ Água

$\mathrm{H}_{2} \mathrm{O}_{2} \quad$ Peróxido de hidrogênio

HPLC High-Performance Liquid Chromatography

$\mathrm{ICH}$ International Conference on Harmonization

I Um

II Dois

III Três

IV Quatro

LC-MS/MS Cromatografia líquida acoplada a um analisador de massas quadrupolo

$\mathrm{L} / \min \quad$ Litros por minuto

mAU Absortion unit 


\begin{tabular}{|c|c|c|}
\hline $\mathrm{mg}$ & Miligrama & xxxi \\
\hline $\mathrm{mg} / \mathrm{g}$ & Miligrama por grama & \\
\hline $\mathrm{mg} / \mathrm{mL}$ & Miligrama por mililitro & \\
\hline $\min$ & Minuto(s) & \\
\hline $\mathrm{mL}$ & Mililitro & \\
\hline mseg & Milissegundo & \\
\hline$\mu \mathrm{g} / \mathrm{mL}$ & Micrograma por mililitro & \\
\hline$\mu \mathrm{L}$ & Microlitro & \\
\hline NA & Não se aplica & \\
\hline $\mathrm{NaCl}$ & Cloreto de sódio & \\
\hline $\mathrm{NaOH}$ & Hidróxido de sódio & \\
\hline $\mathrm{Na}_{2} \mathrm{O}_{2}$ & Peróxido de sódio & \\
\hline ND & Não detectado & \\
\hline NF & National Formulary & \\
\hline $\mathrm{O}_{2}$ & Oxigênio & \\
\hline pip & Pipetar & \\
\hline $\mathrm{p} / \mathrm{p}$ & Relação peso sobre peso & \\
\hline $\mathrm{p} / \mathrm{v}$ & Relação peso sobre volume & \\
\hline$\%$ & Porcentagem & \\
\hline P.acnes & Propionibacterum acnes & \\
\hline q.s.p. & Quantidade suficiente para & \\
\hline (B) & Marca registrada & \\
\hline SE & Solução estoque & \\
\hline TIC & Total ion chromatogram & \\
\hline $\mathrm{tR}$ & Tempo de retenção & \\
\hline
\end{tabular}


DESENVOLVIMENTO E VALIDAÇÃO DE MÉTODO INDICADOR DE ESTABILIDADE DE FORMULAÇÕES FARMACÛTICAS DE USO TÓPICO CONTENDO PERÓXIDO DE BENZOÍLA

tRs Tempos de retenção

USP United States Pharmacopeia

xxxii

UPLC $\quad$ Ultra Performance Liquid Chromatography 


\section{CAPÍTULO I - INTRODUCC̃̃O E OBJETIVOS}

Neste capítulo, é descrita a contextualização da utilização do fármaco peróxido de benzoíla no tratamento da acne vulgaris bem como as justificativas que levaram à sua escolha como fármaco de estudo. 


\section{INTRODUÇÃO}

A acne vulgar é uma enfermidade inflamatória da unidade pilossebácea da pele, caracterizada inicialmente pela presença de um cômedo, comedão ou "cravo". Essa estrutura ocorre pela obstrução do orifício de saída da unidade pilossebácea, com acúmulo de secreções, restos celulares e algumas vezes um ácaro: o demodex foliculorum.

A acne ocorre mais frequentemente em jovens e adolescentes, sendo possível caracterizá-la como fisiológica em muitos casos pela frequência com que ocorre nessa faixa etária (PLEWIG, KLIGMAN, 2000). Estes dois dados: inflamação comedoniana e faixa etária jovem - envolvem as principais características clínicas da acne. Estima-se que $80 \%$ da população sofre algum tipo de acne durante a vida (PLEWIG, KLIGMAN, 2000). A acne é, frequentemente, uma manifestação temporária da puberdade, correlacionando-se mais com a idade puberal do que com a idade cronológica. Entretanto pode acompanhar o indivíduo até os 30 anos de idade, especialmente no sexo feminino. O comprometimento severo é mais comum no sexo masculino (RIVITTI, SAMPAIO, 2000).

Vários são os fatores que influenciam a gravidade do quadro e o seu surgimento. Porém a elevação da carga hormonal com as modificações características da pele são os principais responsáveis. É possível que a acne possua componente genético na conformação do folículo, facilitando sua obstrução (STRAUSS et al., 1997). A severidade das lesões é variada, desde cômedos isolados até nódulos dolorosos e cicatrizes deformantes, o que justifica a procura dos pacientes e a preocupação do médico. 


\subsection{OBJETIVOS}

- Desenvolver e validar metodologia analítica indicadora de estabilidade;

- Caracterizar os produtos de degradação formados durante o estudo de degradação forçada, com a utilização de técnicas cromatográficas e hifenada; 


\section{CAPÍTULO II - FISIOPATOLOGIA DA ACNE}

Neste capítulo são discutidos os mecanismos de manifestação fisiológica da acne além de seu tratamento através de medicamentos. 


\section{FISIOPATOLOGIA DA ACNE}

Quatro são os principais pilares da patogênese da acne: (a) a comedogênese (formação do cômedo), (b) a produção de sebo, (c) a colonização bacteriana pelo Propionibacterium acnes (P.acnes) e (d) o processo inflamatório. Os dois primeiros são diretamente favorecidos pela mudança dos padrões estruturais da glândula por estímulo hormonal, que geralmente ocorre na adolescência e em distúrbios hiperandrogênicos. Algumas glândulas pilossebáceas sofrem uma modificação fundamental para o processo de formação da acne. Há uma hipertrofia de toda a glândula decorrente da ação androgênica sobre sua estrutura, não necessariamente levando à formação da acne, mas criando condições para a formação do cômedo. Uma hiperproliferação no infundíbulo da glândula (porção epidérmica) forma uma "rolha" e oclui o óstio ductal, impedindo a drenagem do sebo normalmente produzido pela glândula e favorecendo a comedogênese.

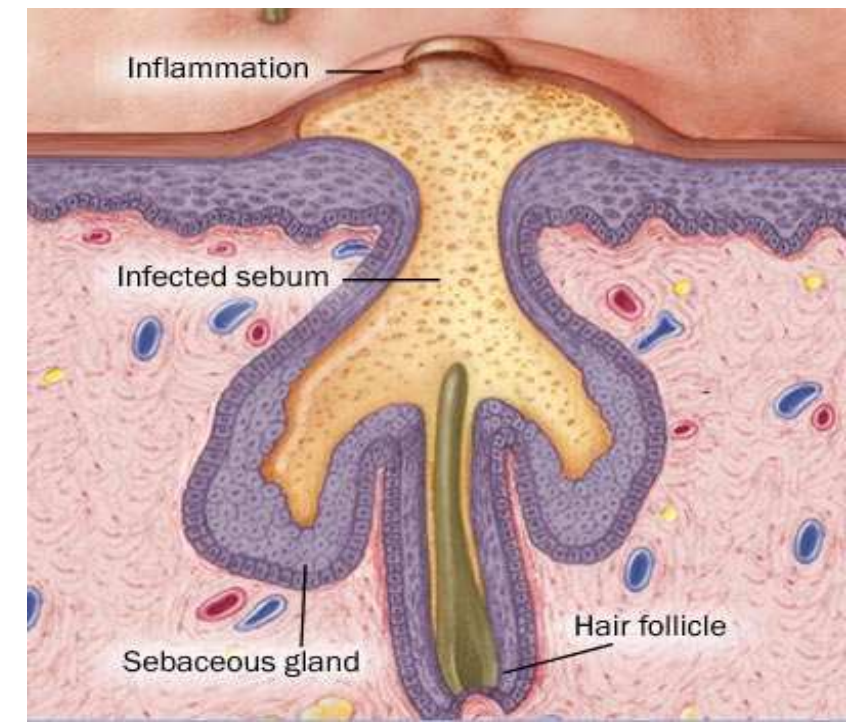

FIGURA 1. Patogênese da acne - anatomia do folículo (BRENNER, et al, 2006) 
Além da barreira mecânica produzida pelo cômedo, existe também uma hiperestimulação androgênica para a produção da secreção sebácea. A produção de sebo retida pelo cômedo oclusivo propicia a colonização bacteriana principalmente pelo $P$. acnes e a instalação do processo inflamatório e infeccioso em toda a glândula. Os pacientes com acne têm glândulas sebáceas maiores e produzem mais sebo que os indivíduos sem acne, que praticamente não tem P.acnes na flora cutânea (FREEDBERG, 1999).

\subsection{MANIFESTAÇÕES CLÍNICAS}

O diagnóstico da acne é clínico e se estabelece por uma mescla de lesões localizadas principalmente na face, no dorso e no tórax. As lesões devem ser caracterizadas pela presença do cômedo, que pode ser fechado, com aspecto esbranquiçado, geralmente medindo de 1 a $2 \mathrm{~mm}$; ou aberto, de cor enegrecida devido à oxidação das gorduras e aumento da deposição de melanina por atividade dos melanócitos.

Pápulas eritematosas e sólidas com $1 \mathrm{~cm}$ de diâmetro podem ocorrer ao redor dos cômedos, o que indica atividade inflamatória da doença, podendo evoluir com a formação de pústulas circunscritas de até $1 \mathrm{~cm}$ de diâmetro . Cistos, nódulos e abscessos correspondem a uma fase avançada da acne, tendo tamanhos variados. Esses frequentemente drenam secreção purulenta e deixam cicatrizes, que podem ser uma consequência natural de lesões inflamatórias, ou o resultado da manipulação das lesões pela destruição das células germinativas localizadas na região mediana do folículo. 


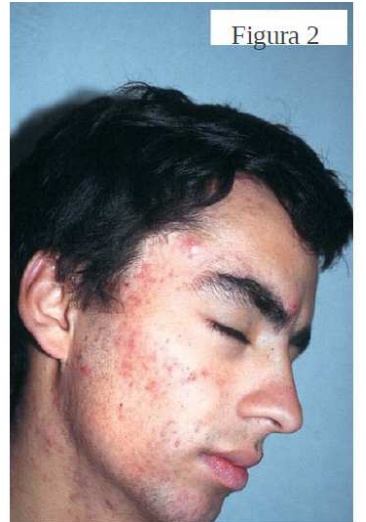

FIGURA 2. Pápulo-pústulas e lesões cicatriciais (HERANE, 2005)

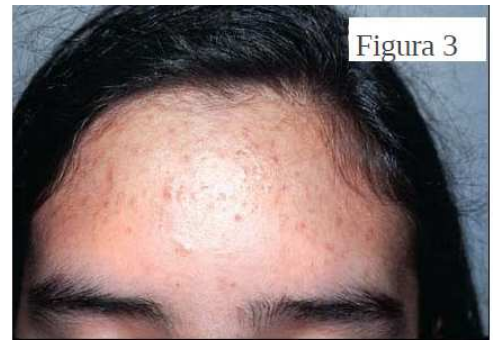

FIGURA 3. Comedões abertos e fechados (HERANE, 2005)

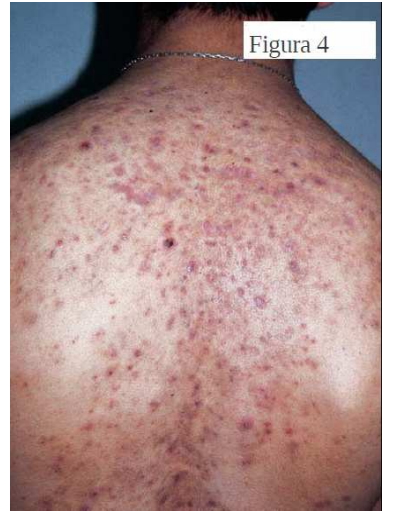

FIGURA 4. Pápulas, nódulos e cistos eritematosos de acne inflamatória (HERANE, 2005)

Além do período da adolescência, a acne pode ocorrer também em outras fases da vida. A ação dos andrógenos maternos nas primeiras 6 semanas de vida é responsável pela acne neonatal (FREEDBERG, et al., 1999). A acne infantil é mais comum em meninos e se inicia entre terceiro e o sexto mês de vida, pelas secreções precoces de andrógenos gonadais. A acne do adulto é mais frequente em mulheres (acne da mulher madura), sendo uma continuação da acne da adolescência ou tendo início na idade adulta. $\mathrm{Na}$ acne da mulher madura o quadro se exacerba com o ciclo menstrual e pode estar associado a outros sinais de hiperandrogenismo, como seborréia, acne, hirsutismo e alopecia. Outras variantes incluem a acne escoriada, fundamentalmente de origem neurótica ou psicótica; a acne estival ou do verão, que ocorre após a exposição solar, e a acne cosmética, decorrente do uso de produtos tópicos oclusivos (SÁ, 2002).

\subsection{CLASSIFICAÇÃO CLÍNICA}

A acne vulgar pode ser dividida em inflamatória e não inflamatória, conforme as lesões predominantes, podendo ser graduada de I a $\mathrm{V}$, conforme a gravidade do quadro 
(FREEDBERG, 1999). A acne grau I, não inflamatória ou comedoniana, apresenta predomínio de cômedos. A acne inflamatória é responsável pelos graus II, III, IV e V. Na acne grau II há o predomínio de lesões pápulo-pustulosas além dos cômedos. Na acne grau III nódulos e cistos podem ser observados. A acne grau IV ou conglobata é uma forma severa da doença com múltiplos nódulos inflamatórios, formação de abscessos e fístulas. Uma forma rara e grave, de instalação abrupta, acompanhada de manifestações sistêmicas (febre, leucocitose e atralgia), é a acne fulminante ou grau V.

Um aspecto a ser considerado na dimensão da severidade da acne é o grau de sofrimento psicossocial do paciente (PLEWIG, KLIGMAN, 2000). O período da adolescência é conturbado pelas diversas modificações corporais e psicológicas. Muitas vezes o aparecimento da acne favorece quadros de depressão e fobia social.

Geralmente, o diagnóstico de acne vulgar não é difícil, o quadro clínico é bastante típico, com lesões e sintomas locais característicos e ausência de manifestações sistêmicas. Os principais diagnósticos diferenciais envolvem: foliculites, rosácea, dermatite perioral, erupções acneiformes e tumores benignos como: hiperplasia sebácea, siringoma e esclerose tuberosa.

\subsection{BASES DO TRATAMENTO}

O tratamento da acne pode ser tópico, sistêmico e até cirúrgico, quando predominam as cicatrizes, os cômedos e cistos. A escolha depende do grau de acometimento da pele, da tolerância e, no nosso meio, do poder aquisitivo dos pacientes. Muitas vezes as três modalidades podem ser usadas simultaneamente para o controle mais rápido das lesões. Nas meninas, o plano de gestação deve ser considerado. 
Alguns cuidados do dia-a-dia podem auxiliar o tratamento da acne. A lavagem das área afetadas várias vezes ao dia tem pouco efeito, executando-se a melhoria do aspecto da face oleosa. Qualquer sabonete de boa qualidade pode ser utilizado. Sabonetes antibacterianos não são particularmente benéficos, os abrasivos podem esfoliar a pele, mas também podem irritá-la e diminuir a aderência ao tratamento. As compressas de água quente ajudam a amolecer os cômedos, tornando a sua remoção mais fácil (SÁ, 2002). O uso de produtos pouco oleosos com base alcoólica ou em gel são indicados, enquanto cremes, loções e cosméticos oleosos devem ser evitados. Apesar de muitos pacientes referirem piora das lesões com a ingestão de determinados alimentos, atualmente não há estudos que comprovem tal relação (RASMUSSEN, 1982). 


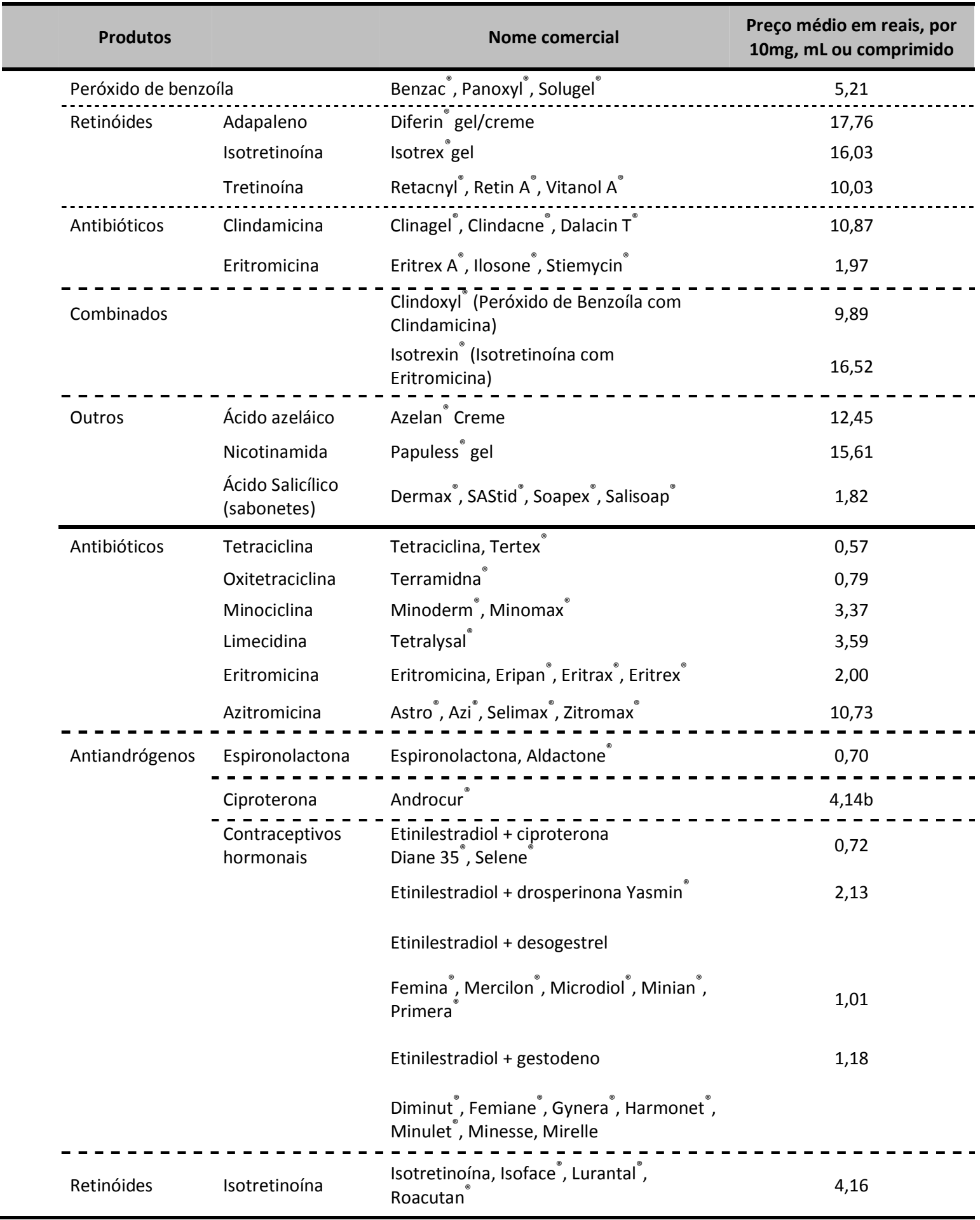

Fonte: Revista ABCFARMA, órgão oficial da Associação Brasileira de Comércio Farmacêutico. Ano 1, número 1, junho de 2004. Baseado no preço máximo por $10 \mathrm{~g}$ ou $10 \mathrm{~mL}$ dos produtos nos estados com ICMS de $17 \%$ (Rio de Janeiro tem alíquota de $19 \% \mathrm{~s}$ São Paulo, Minas Gerais e Paraná tem alíquota de 18\%) 


\subsection{TRATAMENTO TÓPICO}

O tratamento tópico tem papel importante em todos os pacientes com acne e pode ser usado isoladamente nas formas leves e moderadas. Os produtos prescritos mais frequentemente são os antibióticos em associação a outros agentes como peróxido de benzoíla, ácido retinóico, ácido salicílico, nicotinamida e ácido azeláico (LEYDEN, 2003). 


\section{CAPÍTULO III - DESCRICÕES COMPENDIAIS DO PERÓXIDO DE BENZOÍLA}

Neste capítulo é discutida a revisão da literatura inerente ao peróxido de benzoíla e seus produtos de degradação, tanto na forma de fármaco isolado quanto na forma farmacêutica gel, além do levantamento histórico dos métodos de teste publicados para dosá-lo. 


\section{PERÓXIDO DE BENZOÍLA}

O peróxido de benzoíla tem atividade antibacteriana e ceratolítica e é considerado fármaco de primeira linha no tratamento para a acne leve a moderada. A combinação do peróxido de benzoíla com antibióticos tópicos (eritromicina ou clindamicina) ou retinóides tópicos é mais efetiva que a monoterapia (EADY, et al., 1996; BERSON, SHALITA, 1995). O peróxido de benzoíla possui efeito antinflamatório e comedolítico menor que os retinoídes tópicos.

Os microorganismos da flora residente não desenvolvem resistência ao peróxido de benzoíla (THIBOUT, 2002).

Uma redução de $90 \%$ dos microorganismos e de $40 \%$ dos ácidos graxos livres é observada após poucos dias de uso de peróxido de benzoíla.

O peróxido de benzoíla deve ser aplicado, uma vez ao dia, em toda a pele da face e não só nas lesões visíveis. As concentrações disponíveis variam desde 1\% até $10 \%$ e podem ser usadas na gestação (PLEWIG, KILGMAN, 2000; SYKES, WEBSTER, 1994).

A supressão do P.acnes é similar com as concentrações de $2,5 \%, 5,0 \%$ ou $10,0 \%$, o que determina a opção pelas baixas concentrações que são menos irritantes (THIBOUT, 2002).

Os efeitos comuns são pele seca, eritema e descamação. Os pacientes devem ser advertidos que o peróxido de benzoíla pode manchar roupas e tecidos.

\subsection{MECANISMO DE AÇÃO DO PERÓXIDO DE BENZOÍLA}

As moléculas de oxigênio dos radicais livres presentes no peróxido de benzoíla são altamente reativas com compostos orgânicos, podendo reagir com a parede da célula 
bacteriana, destruindo o microorganismo. Ao diminuir o número de $P$.acnes, há a redução dos ácidos graxos livres dentro dos folículos, não afetando a produção do sebo, nem sua composição. Não há evidência de toxicidade sistêmica causada pelo peróxido de benzoíla em humanos, já que o peróxido de benzoíla absorvido pela pele é metabolizado pelo aminoácido cisteína para ácido benzóico e radical livre de $\mathrm{O}_{2}$ e é excretado como benzoato na urina (ZURITA, 2011).

\section{Patogênese da Acne}

Desqueratinização folicular $\rightarrow$ Formação do Comedo

Secreção de androgênio $\rightarrow$ Produção de Sebo $\rightarrow$ Proliferação do Propionibacterium acnes

Hipersensibilização pelo Propionibacterim acnes $\rightarrow$ Aumento da inflamação

QUADRO1. Patogênese da Acne (WEBSTER, 2001).

\subsection{SÍNTESE DO PERÓXIDO DE BENZOÍLA}

A reação de síntese do peróxido de benzoíla pode ser dividida em duas etapas:

a) Reação de formação do peróxido de sódio:

\begin{tabular}{|c|c|c|c|c|c|}
\hline $2 \mathrm{NaOH}$ & $\mathrm{H}_{2} \mathrm{O}_{2}$ & $\rightarrow$ & $\mathrm{Na}_{2} \mathrm{O}_{2}$ & + & $2 \mathrm{H}_{2} \mathrm{O}$ \\
\hline $\begin{array}{l}\text { Hidróxido } \\
\text { de sódio }\end{array}$ & $\begin{array}{c}\text { Peróxido } \\
\text { de hidrogênio }\end{array}$ & & $\begin{array}{l}\text { Peróxido } \\
\text { de sódio }\end{array}$ & & Água \\
\hline 1M: 40 & *MM: 34 & & *MM: 78 & & IM: 18 \\
\hline
\end{tabular}

FIGURA 5. Reação de formação do peróxido de sódio 
b) Reação de formação do peróxido de benzoíla:

2<smiles>O=C(Cl)c1ccccc1</smiles>

Cloreto de benzoíla

*MM: 140,6
$+\mathrm{Na}_{2} \mathrm{O}_{2}$

Peróxido de sódio

*MM: 78<smiles>O=C(OOC(=O)c1ccccc1)c1ccccc1</smiles>

Peróxido de benzoíla

*MM: 242,2
$2 \mathrm{NaCl}$

Cloreto de sódio

*MM: 58,5

* Massa molecular (unidades de massa atômica - u.m.a)

FIGURA 6. Reação de formação do peróxido de benzoíla

\subsection{DESCRIÇÃO FARMACOPEICA DO PERÓXIDO DE BENZOÍLA}

Descrição USP36 - NF31: "Pó granular branco, com odor característico. Solúvel em acetona, clorofórmio e éter. Parcialmente solúvel em água e álcool”.

O peróxido de benzoíla hidratado contém não menos que $65 \%$ e não mais que $82 \%$ de peróxido de benzoíla. Este contém aproximadamente $26 \%$ de água com a finalidade de reduzir sua inflamabilidade e sensibilidade ao choque (USP, 2013). O peróxido de benzoíla é utilizado na indústria farmacêutica, como princípio ativo de preparações destinadas ao tratamento tópico da acne vulgaris, em formas farmacêuticas semi-sólidas, tais como gel, creme e loção (USP, 2013).

\section{Peróxido de Benzoíla}<smiles>O=C(OOC(=O)c1ccccc1)c1ccccc1</smiles>

INCI name: Benzoyl Peroxide, Hydrous

Fórmula/massa molecular: $\mathrm{C}_{14} \mathrm{H}_{10} \mathrm{O}_{4}=242,2 \mathrm{~g} / \mathrm{mol}$

CAS number: 94-36-0

FIGURA 7. Estrutura molecular do peróxido de benzoíla (USP, 2013) 


\subsection{PRODUTOS DE DEGRADAÇÃO COMPENDIAIS DO PERÓXIDO DE BENZOÍLA}

\section{Ácido Benzóico}

INCI name: Benzoic acid

Fórmula/massa molecular: $\mathrm{C}_{6} \mathrm{H}_{5}(\mathrm{O}) \mathrm{OH}=122,12 \mathrm{~g} / \mathrm{mol}$ CAS number: $65-85-0$

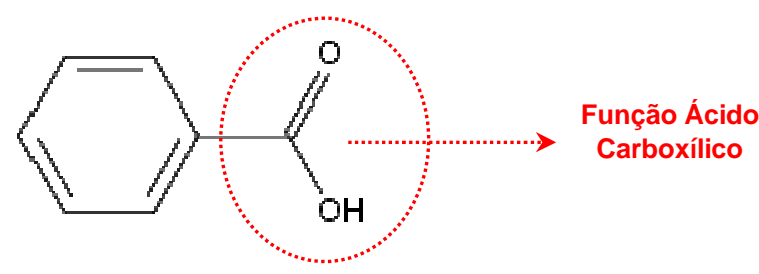

FIGURA 8. Estrutura molecular do ácido benzóico (USP, 2012)

\section{Benzoato de Etila}

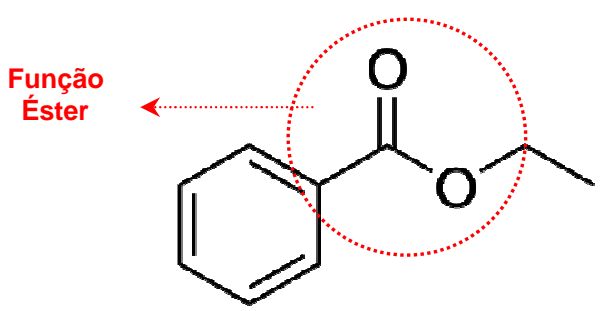

INCI name: Ethyl Benzoate

Fórmula/massa molecular: $\mathrm{C}_{9} \mathrm{H}_{10} \mathrm{O}_{2}=150,17 \mathrm{~g} / \mathrm{mol}$

CAS number: 93-89-0

FIGURA 9. Estrutura molecular do benzoato de etila (USP, 2012)

\section{Benzaldeído}

INCI name: Benzaldehyde

Fórmula/massa molecular: $\mathrm{C}_{6} \mathrm{H}_{5} \mathrm{CHO}=106,13 / \mathrm{mol}$

CAS number: $100-52-7$

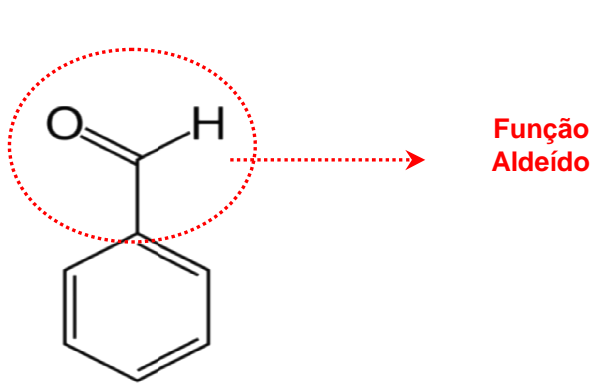

FIGURA 10. Estrutura molecular do benzaldeído (USP, 2013) 


\subsection{MONOGRAFIA USP DO PERÓXIDO DE BENZOÍLA HIDRATADO E PERÓXIDO DE BENZOÍLA GEL}

Os métodos farmacopêicos para o doseamento de peróxido de benzoíla e suas substâncias relacionadas ácido benzóico, benzoato de etila e benzaldeído, na forma farmacêutica semi-sólida gel, são ensaios individuais, entretanto ambos são realizados a partir da técnica de cromatografia líquida de alta eficiência (CLAE).

Vide as monografias da USP36-NF31 (2013) do peróxido de benzoíla hidratado e peróxido de benzoíla na forma farmacêutica gel, no "CAPÍTULO XII - ANEXOS".

\subsection{EVOLUÇÃO HISTÓRICA DA EVOLUÇÃO DO MÉTODO DE DOSEAMENTO DO PERÓXIDO DE BENZOÍLA SEGUNDO A FARMACOPÉIA AMERICANA (USP)}

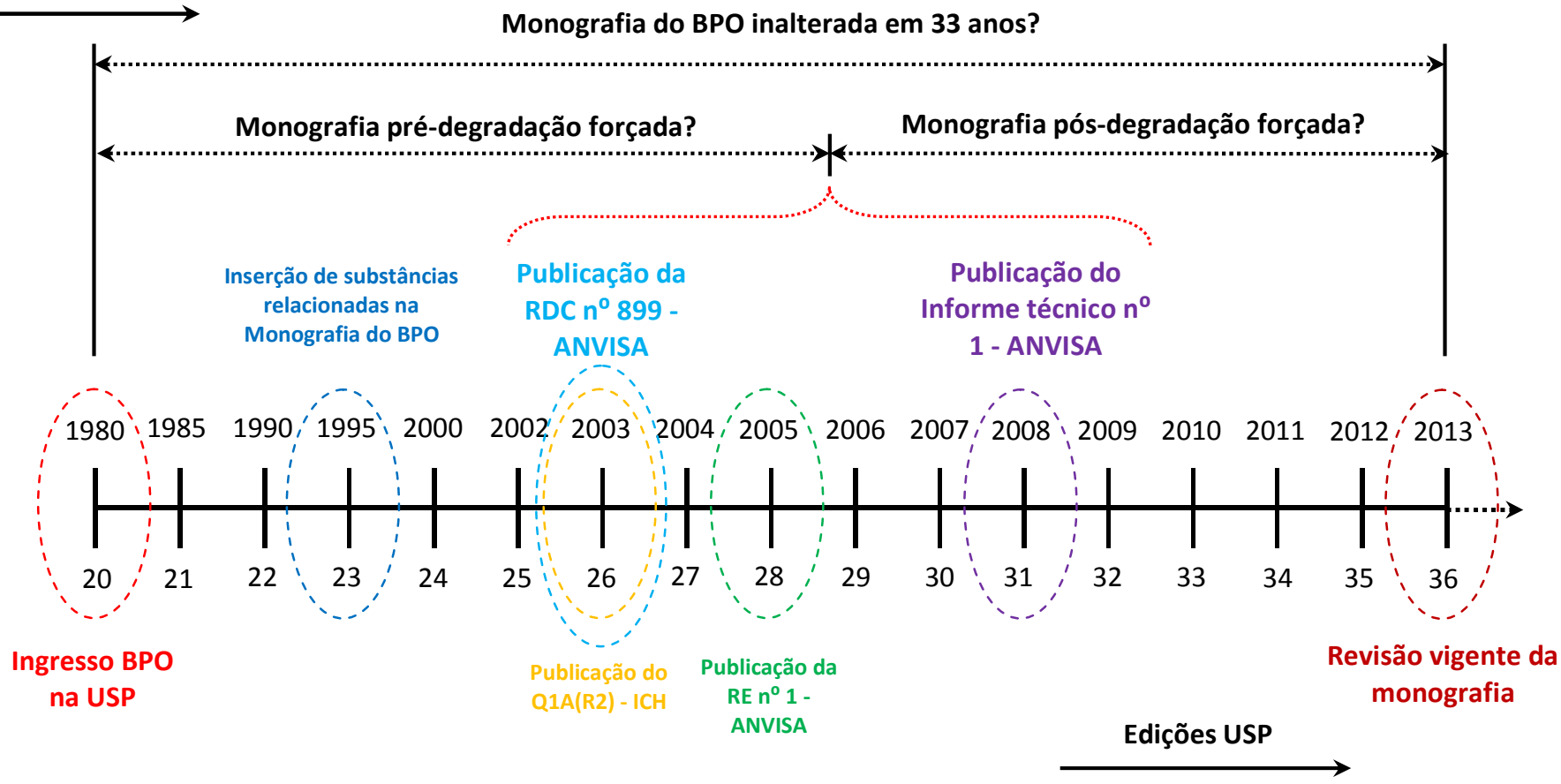


Conforme descrito ilustrado no esquema anterior, não há registros nas literaturas compendiais vigentes de métodos de teste que dosem o peróxido de benzoíla e seus produtos de degradação, em medicamentos, diferentes daqueles já preconizados pela farmacopéia americana (USP). A mesma abordagem encontramos para literaturas não compendiais atuais. Além disso vale ressaltar que, a monografia do peróxido de benzoíla gel se mantém inalterada desde a revisão 24 , ou seja, o documento se mantém inalterado desde 2000. 


\section{CAPÍTULO IV - TÉCNICAS ANALÍTICAS EMPREGADAS DURANTE O ESTUDO EXPLORATÓRIO DOS PRODUTOS DE DEGRADACÃO}

Neste capítulo são discutidas as técnicas analíticas cromatografia líquida de alta eficiência e cromatografia líquida acoplada à espectrometria de massa, utilizadas durante o desenvolvimento e validação do método indicativo de estabilidade além da investigação dos produtos de degradação formados a partir do peróxido de benzoíla. 


\section{CROMATOGRAFIA LÍQUIDA DE ALTA EFICIÊNCIA (CLAE)}

Dentre os métodos instrumentais utilizados na separação, identificação e quantificação de componentes químicos, a cromatografia alcançou a confiança e espaço de destaque no setor farmacêutico (GIL, 2007).

A cromatografia é um método físico-químico de separação, no qual os analitos são separados através da passagem em duas fases: uma fase fixa de grande área superficial denominada fase estacionária, e outra constituída por um fluído que a percorre, denominada fase móvel. Com o passar dos anos foi sendo aprimorada e se subdividiu em diversas técnicas com o mesmo princípio, desde a cromatografia de camada delgada, a gasosa, por troca iônica, até uma das mais recentes a cromatografia líquida de ultra performance (UPLC).

A cromatografia gasosa, uma das mais antigas possui uma limitação: a maioria dos fármacos não são suficientemente voláteis ou se decompõe em altas temperaturas. Por esse motivo, a CLAE ganhou importância no campo do controle de qualidade de medicamentos (COLLINS et al., 2006).

O equipamento de CLAE é basicamente constituído de 5 componentes. O reservatório de solventes (a) é o local onde se encontram os solventes da fase móvel que é impulsionada até a coluna cromatográfica por um sistema de bomba composto de uma ou mais bombas de alta pressão (b). A coluna cromatográfica (c) é o local onde ocorre a separação de amostra que é introduzida através do injetor (d) que se localiza entre a bomba e a coluna. A composição do eluente que passa pela coluna gera sinais elétricos através do detector (e) e esses sinais são compilados em um processador de dados, um computador, que os transforma em um conjunto de picos conhecido como cromatograma (COLLINS et al., 2006; GIL, 2007). 
(a)

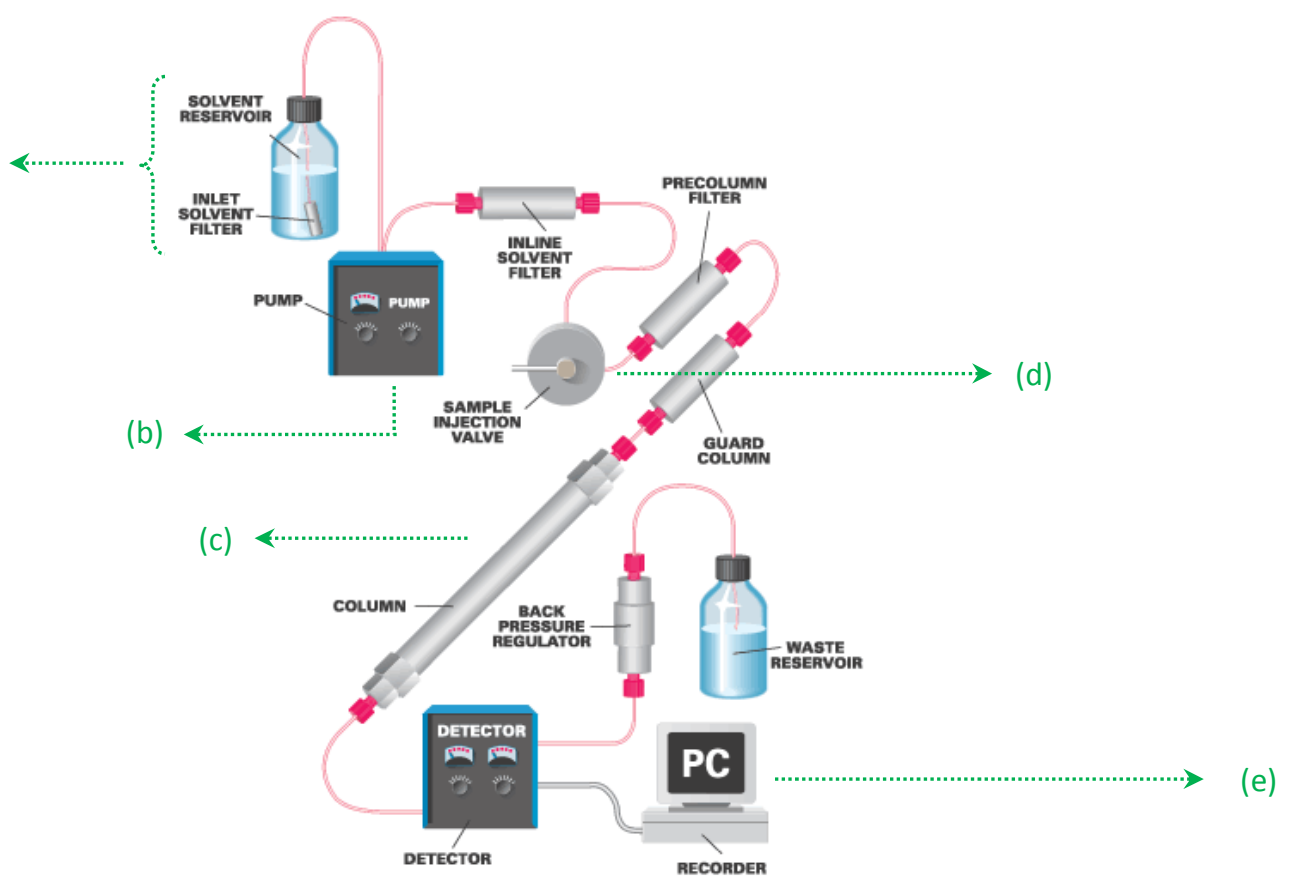

FIGURA 11. Representação esquemática do equipamento de cromatografia líquida de alta eficiência (CLAE) (COLLINS et al.. 2006: GIL. 2007)

Para realizar a separação de analitos utilizam-se colunas cromatográficas de aço inoxidável ou de plástico com comprimento de 5 a $30 \mathrm{~cm}$ e diâmetro interno de 1 a $5 \mathrm{~mm}$. Estas colunas são empacotadas com fase estacionária ou suportes que podem ser constituídos por diversos materiais.

Os suportes mais utilizados em CLAE são formados por partículas porosas de sílica de formato esférico, elevado grau de pureza e área superficial permeável aos solventes. Estas características tornam a coluna apropriada para a separação de moléculas de baixa ou alta massa molar, permitindo ainda a formação de leitos estáveis às altas pressões e aumentando o tempo de vida útil de uma coluna que possui custo elevado (COLLINS et al., 2006; SNYDER et al., 1997). 
Considerando que a fase móvel de um método por CLAE é a responsável por conduzir a amostra até a fase estacionária, a escolha dos solventes, concentração adequada e pH que a compõe são fatores essenciais para obtenção de picos bem definidos e com eficiência.

As principais características de uma fase móvel são: não decompor ou dissolver as fase estacionária, não decompor, mas dissolver a amostra, apresentar baixa viscosidade e ponto de ebulição, ser compatível com o detector. Cada solvente que pode compor uma fase móvel possui uma força peso que também influência nas análises, assim, quanto mais fraco o solvente maior a retenção de um analito na fase estacionária.

Há dois principais modos de separação em CLAE: fase normal e fase reversa. A fase normal é composta por uma fase estacionária mais polar (com grupos amina, nitrila, ciano ou diol) do que a fase móvel. Outro diferencial é a composição da fase móvel, que é constituído por solventes orgânicos, sem adição de água, tornando-se de custo mais elevado, exceto quando utilizada para a separação de compostos iônicos. As colunas são mais estáveis quando se utilizam solventes não aquosos. A maioria dos compostos orgânicos é solúvel e a pressão necessária, menor (SNYDER et al., 1997).

A mais utilizada é a fase reversa, que consiste na utilização de uma fase estacionária de menor polaridade (octil, octadecil, silano, fenil, etc.) e uma fase móvel de maior polaridade, enquanto a fase normal, as polaridades são invertidas. Esta fase apresenta várias vantagens, tais como: uso de fase móveis menos tóxicas e de menor custo, como metanol e água, fases estacionárias estáveis de muitos tipos diferentes, rápido equilíbrio da coluna após a mudança da fase móvel, facilidade de empregar eluição por gradiente, maior rapidez em análises e boa reprodutibilidade dos tempos de retenção. Além disso, são muito aplicadas à separação de solutos de diferentes polaridades, massas molares e funcionalidades químicas (COLLINS et al., 2006). 
As principais vantagens da CLAE são: alta eficiência através de picos estreitos e bem definidos, alta resolução, análises rápidas, baixos limites de detecção, versatilidade, mecanização, excelente reprodutibilidade, repetibilidade e obtenção de resultados qualitativos e quantitativos confiáveis. Esta técnica ainda pode ser melhorada com a capacidade de ser incorporada a outros sistemas de detecção de fluorescência e espectrometria de massas. A CLAE possui algumas limitações, tais como o custo da instrumentação e da operação, alto consumo de solventes e necessidade de profissionais capacitados (COLLINS et al., 2006; HARRIS, 2005).

Já as principais desvantagens observadas em ensaios realizados por CLAE são: altamente dependente de ótima resolução cromatográfica (ajuste fino da composição da fase móvel, pH), análise usualmente longas (10 minutos ou mais), reduzida sensibilidade e seletividade (limite de quantificação de aproximadamente $2 \mu \mathrm{g} / \mathrm{mL}$ ), os ensaios fornecem pouca ou nenhuma informação estrutural (JOURNAL OF PHARMACEUTICAL AND BIOMEDICAL ANALYSIS, 1996).

Apesar das vantagens e desvantagens, a CLAE vem sendo amplamente utilizada na área farmacêutica para análises quantitativas e principalmente quantitativas, o que pode ser confirmado pelo número de trabalhos publicados e confiança na técnica por parte das indústrias e laboratórios farmacêuticos (HARRIS, 2005). 


\section{TÉCNICAS HIFENADAS}

"O termo técnicas hifenadas se refere ao acoplamento entre duas ou mais técnicas analíticas com o objetivo de obter uma ferramenta analítica mais eficiente e rápida que as técnicas tradicionais" (REHDER, 2006).

\subsection{ESPECTROMETRIA DE MASSAS}

\subsubsection{EVOLUÇÃO HISTÓRICA}

Técnica analítica amplamente utilizada na indústria farmacêutica em estudos diversos (ex. investigação de produtos de degradação de fármacos)

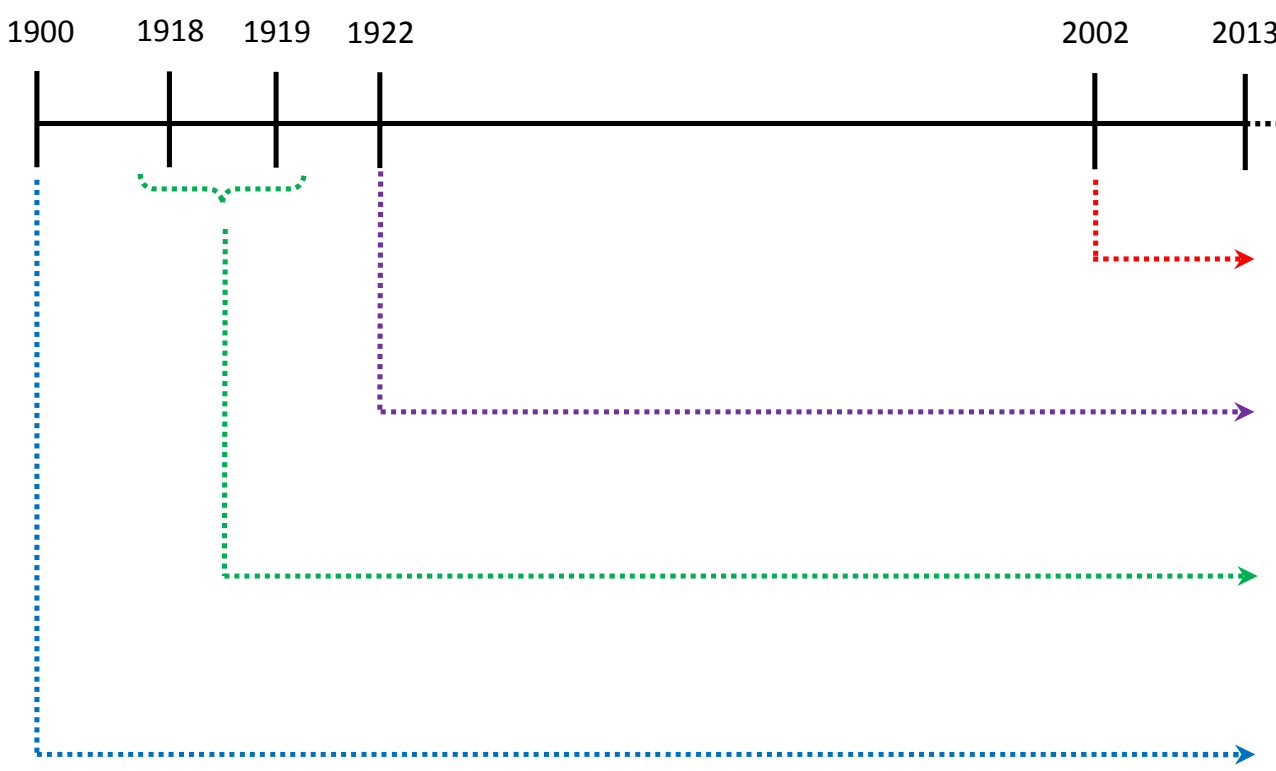

Os cientistas W.Wien e J.J. Thompson introduziram o conceito de espectrometria de massas (EMassas)

\subsubsection{ALGUMAS APLICAÇÕES DA TÉCNICA DE ESPECTROMETRIA DE MASSAS}

- Caracterização estrutural de novos fármacos e biomoléculas: Quebras específicas do composto revelam informações sobre sua estrutura molecular; 
- Determinação de traços (impurezas, resíduos de limpeza, análise ambiental, etc.) na ordem de $\mathrm{ppb}(\mathrm{ng} / \mathrm{mL})$ e ppt $(\mathrm{pg} / \mathrm{mL})$;

- Determinação de fármacos em amostras biológicas (plasma, sangue, urina, entre outras), devido a sua (a) elevada confiabilidade de resultados o que a leva a ser utilizada em (b) estudos de bioequivalência, permeação cutânea, antidoping, drogas de abuso, estudos toxicológicos, etc.;

\subsubsection{DEFINIÇÃO E CONCEITO}

Definição: é uma técnica analítica utilizada para medir a razão massa/carga (m/z) de íons e de seus fragmentos. Desta forma, o analito avaliado por EMassas deve estar na forma ionizada.

Espectrometria de Massas é uma técnica utilizada para fornecer características estruturais de moléculas:

\begin{tabular}{|c|c|c|c|}
\hline $\begin{array}{l}\text { lonização a } \\
\text { pressão atmosférica }\end{array}$ & Possibilitou & $\begin{array}{l}\text { Acoplamento do EMassas às } \\
\text { técnicas cromatográficas }\end{array}$ & $\begin{array}{c}\text { Ex. LC-MS/MS para } \\
\text { guantificacão de comnostos }\end{array}$ \\
\hline
\end{tabular}

Espectrômetro de massas: pode ser subdividido em 3 partes:

(a) Fonte de ionização

(b) Analisador de massas

(c) Detector

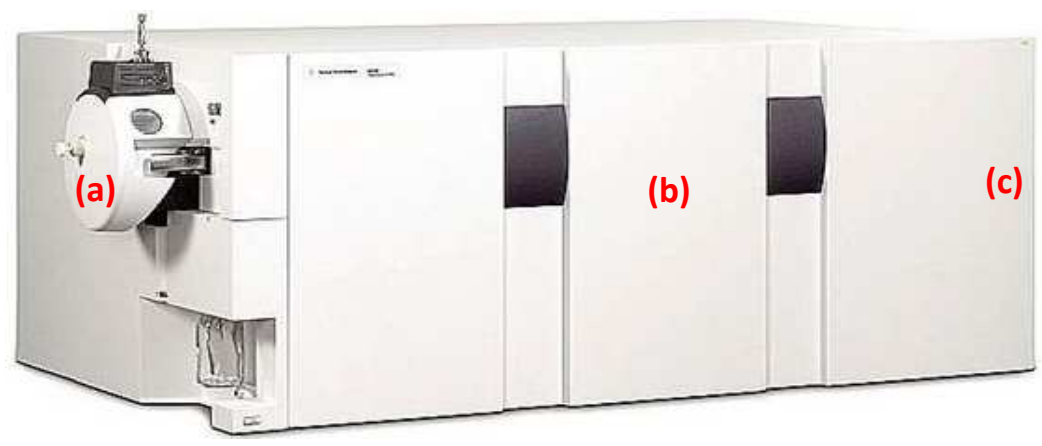

FIGURA 12. Esquema representativo do espectrômetro de massas. LC-MS/MS. Modelo 6460 System, fabricante Agilent Technologies 


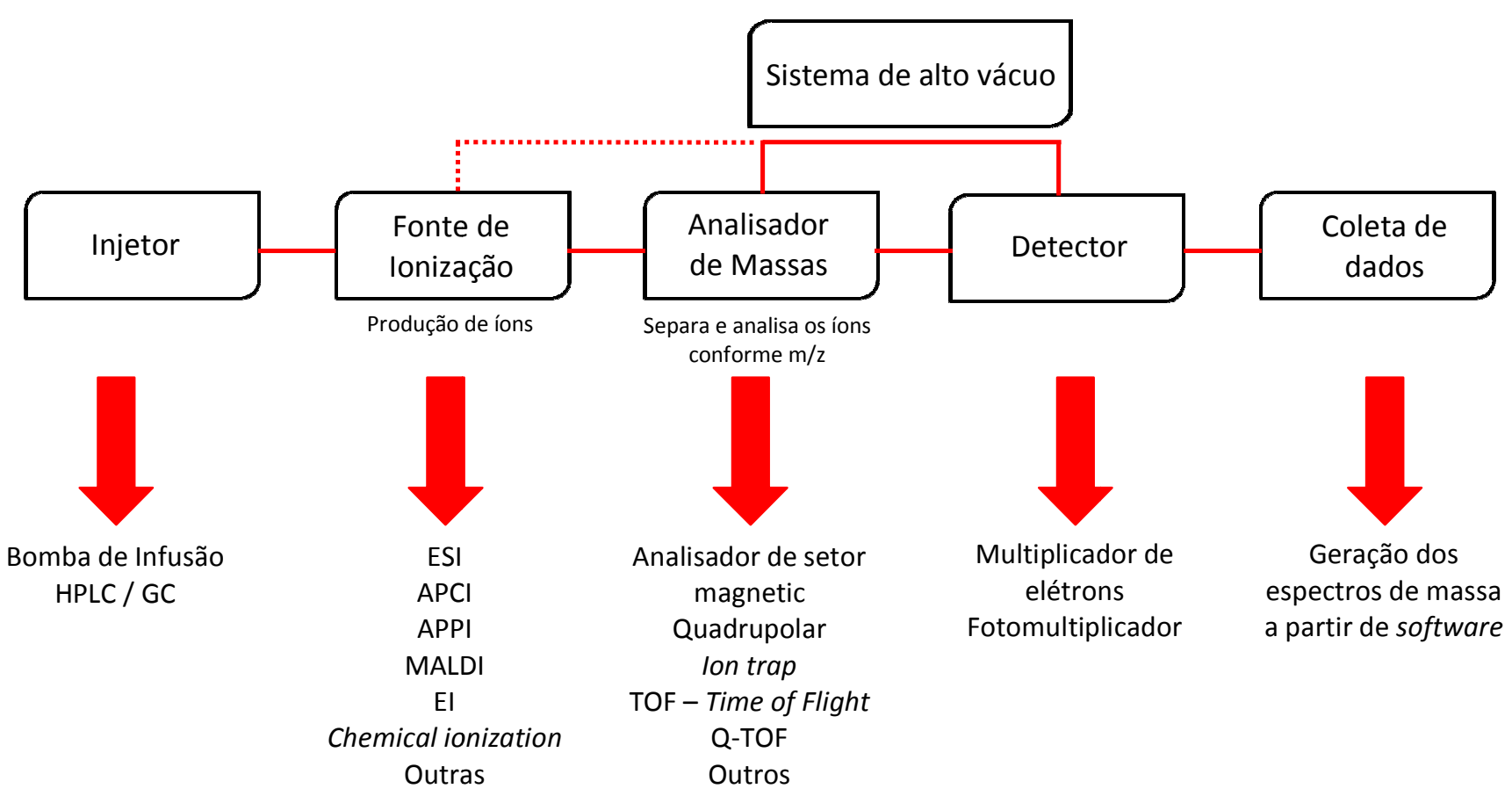




\subsubsection{ESQUEMA ILUSTRATIVO DO SISTEMA LC-MS/MS}

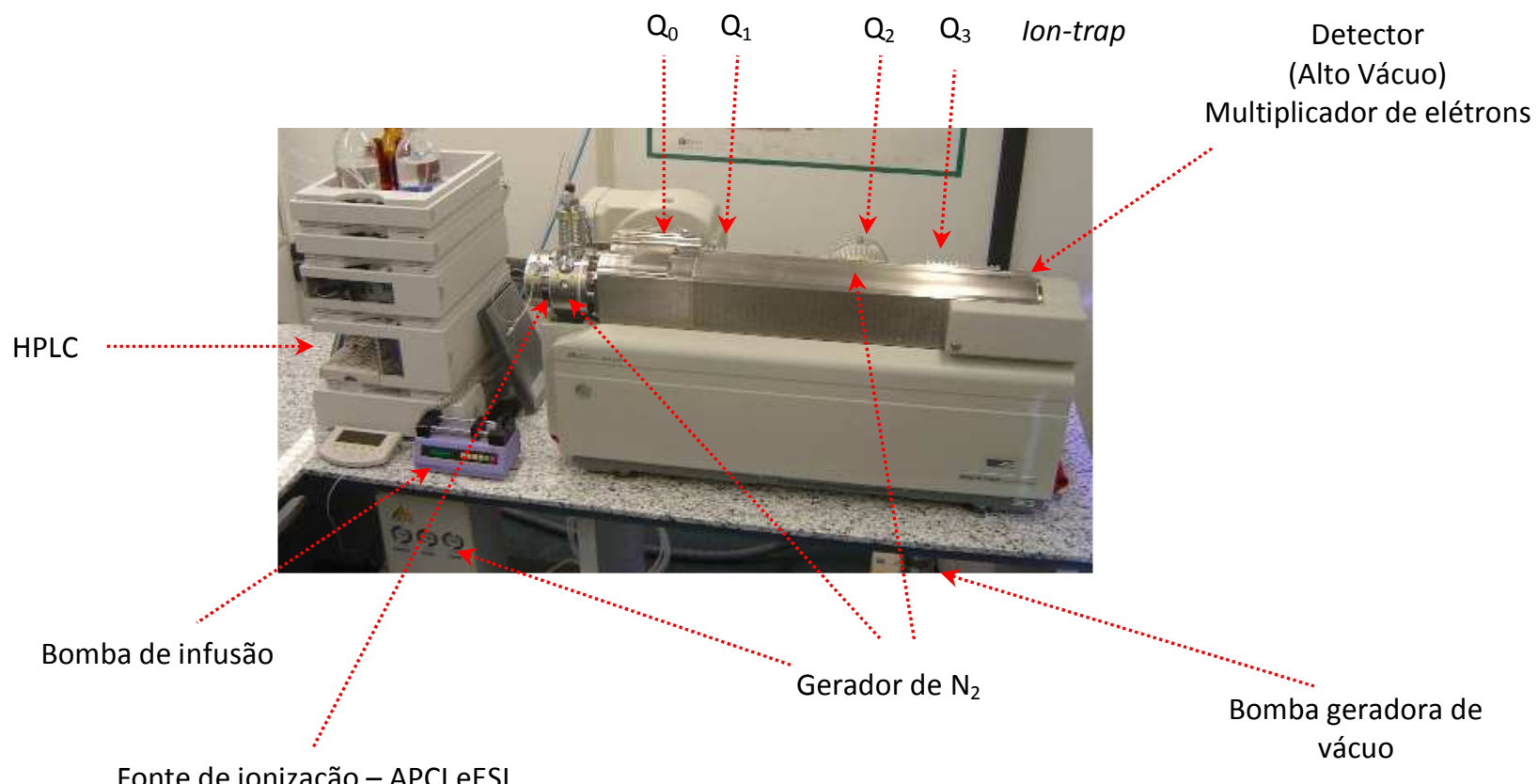

(Pressão atmosférica)

FIGURA 13. Esquema representativo do sistema de cromatografia líquida acoplada à espectrometria de massas. LC-MS/MS. CLAE: Modelo 1100, fabricante Agilent Technologies - MS: Modelo: API 4000 Q-Trap, fabricante: Applied Biosvstem

\subsubsection{ESCOLHA DA TÉCNICA DE IONIZAÇÃO E ANALISADOR DE MASSAS}

Para a escolha da técnica de ionização mais adequada em função do objetivo do estudo, devem ser levadas em consideração as seguintes variáveis:

1ㅁ VARIÁVEL: Verificar qual é o tipo da molécula a ser estudada?

Avaliar sua polaridade, tamanho, termoestabilidade, e volatilidade da molécula.

2a VARIÁVEL: Qual é o objetivo do estudo?

(a) Caracterização estrutural de macromoléculas: logo há a necessidade de

Sistema de alta resolução de massas $\longrightarrow$ TOF; 
(b) Caracterização estrutural de moléculas: há o estudo de quebras na estrutura molecular, ou seja, $\mathrm{MS}^{\mathrm{n}} \longrightarrow$ Ion-trap;

(c) Ensaios quantitativos: exige a presença de resolução unitária entre massas, logo o analisador de massas mais indicado $\longrightarrow$ Quadrupolos;

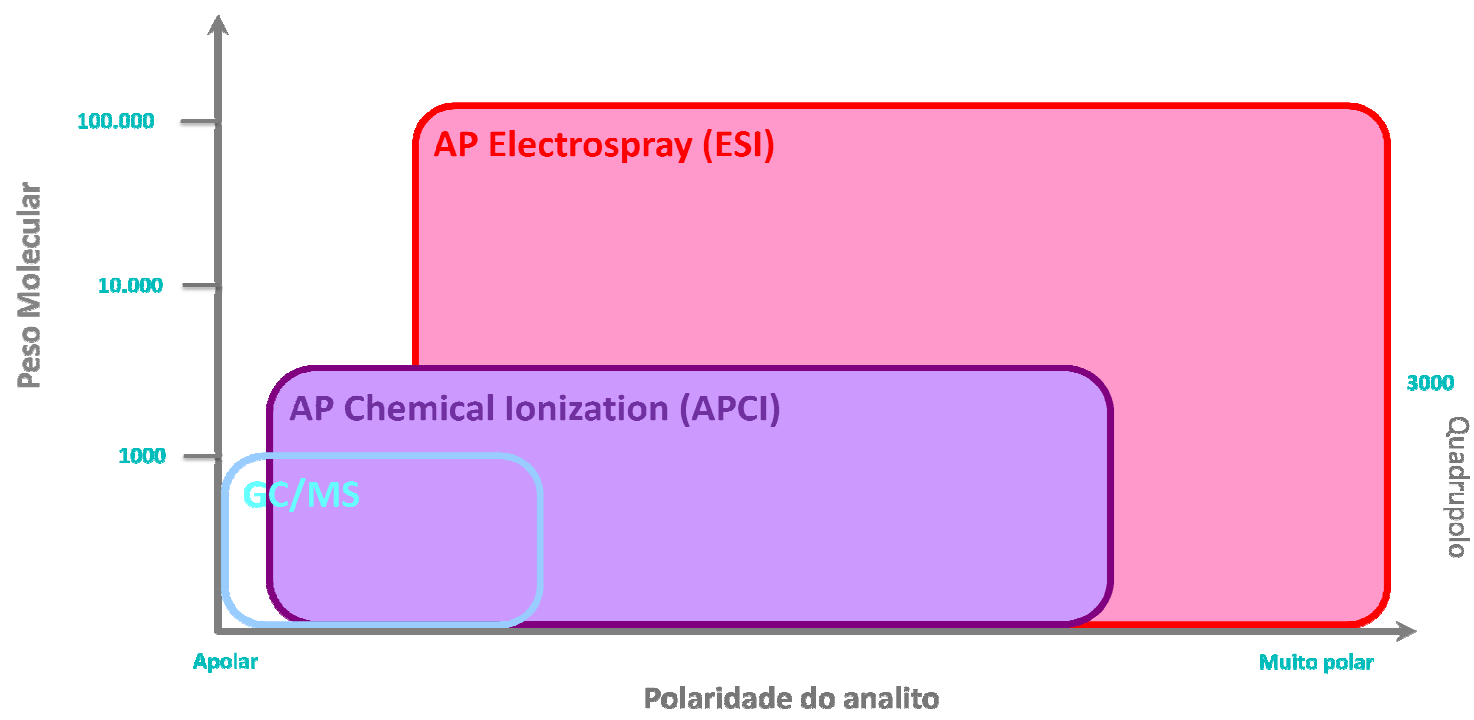

FIGURA 14. Gráfico ilustrativo para a escolha da técnica de ionização e analisador de massas.

\subsection{TÉCNICAS DE IONIZAÇÃO}

\subsubsection{TÉCNICAS DE IONIZAÇÃO À PRESSÃO ATMOSFÉRICA}

- Electrospray Ionization (ESI);

- Atmosferic Pressure lonization (API);

- Atmosferic Pressure Photo lonization (APPI); 


\subsection{ELECTROSPRAY IONIZATION (ESI)}

\section{Características gerais:}

○ lonização ocorre à pressão atmosférica;

- $90 \%$ dos fármacos podem ser analisados por ESI;

○ lonização ocorre em solução;

○ Ionização ocorre pode ocorrer no modo positivo (+) ou no modo negativo (-);

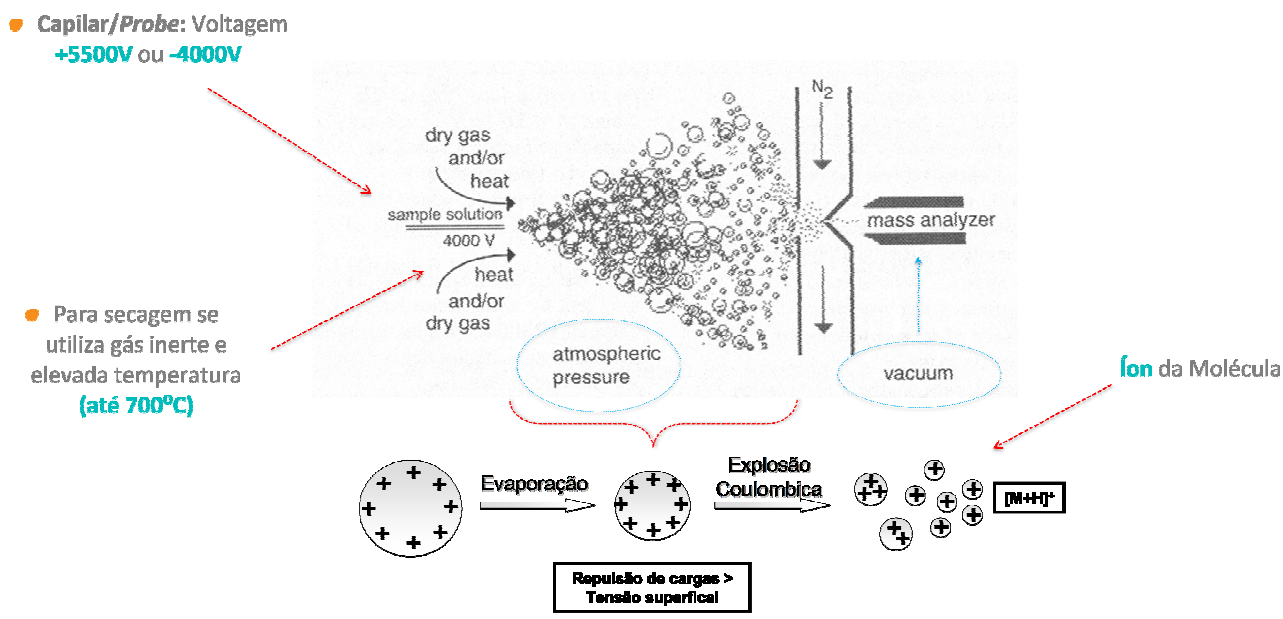

FIGURA 15. Esquema ilustrativo da técnica de ionização Electrospray lonization (ESI).

\subsubsection{ELECTROSPRAY IONIZATION (ESI)}

\section{Condições de Ionização}

- Há a necessidade de uso de aditivos na fase móvel (ex. ácido fórmico, ácido acético, hidróxido de amônio, acetato de amônio, etc.) que obrigatoriamente devem ser voláteis. Estes aditivos auxiliam na ionização dos compostos.

- Pouca fragmentação é provocada na obtenção do íon gasoso. 
- lonizacão no modo positivo: molécula recebe próton ou forma aduto com cátions.

- lonização no modo negativo: ocorre despronotação da molécula ou há a formação de aduto com cátions.

Espectro de Massas (m/z)
Qual é o íon precursor de interesse?
Protonada?

Formação de aduto? Ionização radicalar? Distribuição isotópica?

\subsection{ATMOSFERIC PRESSURE CHEMICAL IONIZATION (APCI)}

\section{Características gerais:}

○ Ionização à pressão atmosférica;

- Pouca fragmentação é provocada na obtenção do íon gasoso;

- Ionização já ocorre na fase gasosa: analitos devem ser voláteis e termoestáveis;

- Técnica recomendada para compostos de menor massa;

- Ionização no modo positivo: analito recebe próton do solvente protonado;

- Ionização no modo negativo: analito doa próton para o solvente desprotonado;

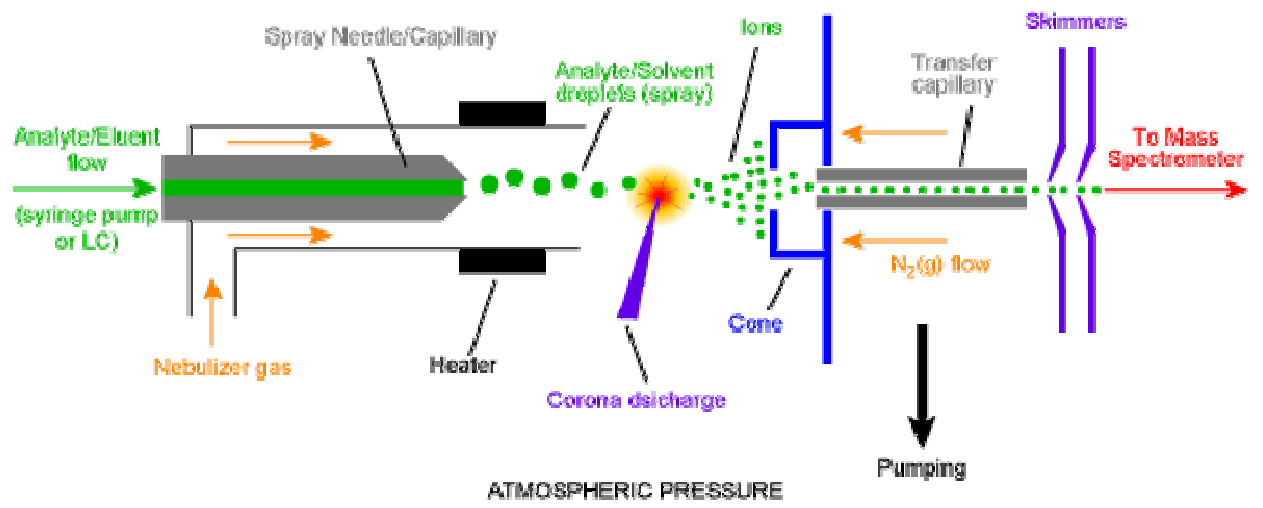




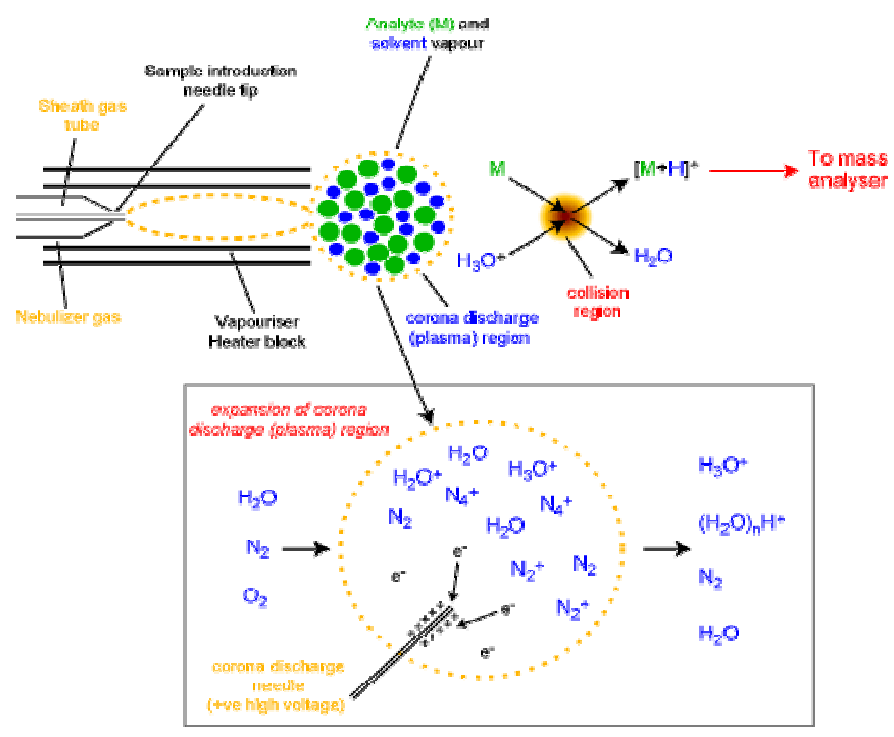

FIGURA 16. Esquema ilustrativo da técnica de ionização Atmospheric Pressure Chemical lonization (APCI).

\subsection{ATMOSPHERIC PRESSURE PHOTO IONIZATION(APPI)}

\section{Características gerais:}

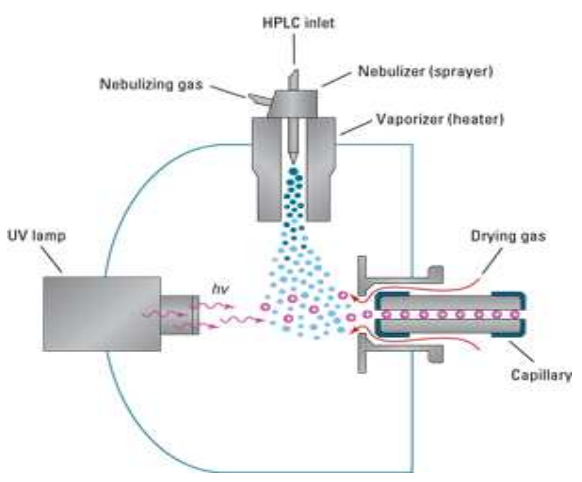

- APCI modificada;

- Utilização de lâmpada para ionização de moléculas em fase gasosa;

- Análise de compostos que não sofrem ionização por ESI ou APCl;

FIGURA 17. Esquema ilustrativo da técnica de ionização Atmospheric Pressure Photo Ionization (APPI). 


\subsection{ANALISADORES DE MASSA}

\subsubsection{QUADRUPOLOS: SIMPLES (MS)}

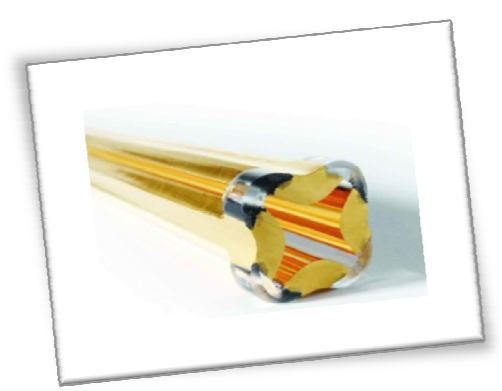

- Os íons gasosos saem da fonte e são focalizados no interior entre os quadrupolos $\left(Q_{0}\right)$;

- Quadrupolos: 4 barras metálicas paralelas que operam variando potencial e frequência;

- Trajetória dos íons ocorre no espaço entre os quadrupolos e depende da $\mathrm{m} / \mathrm{z}$;

- Somente o $\mathrm{m} / \mathrm{z}$ selecionada atravessa este campo;

\section{QUADRUPOLO SIMPLES}
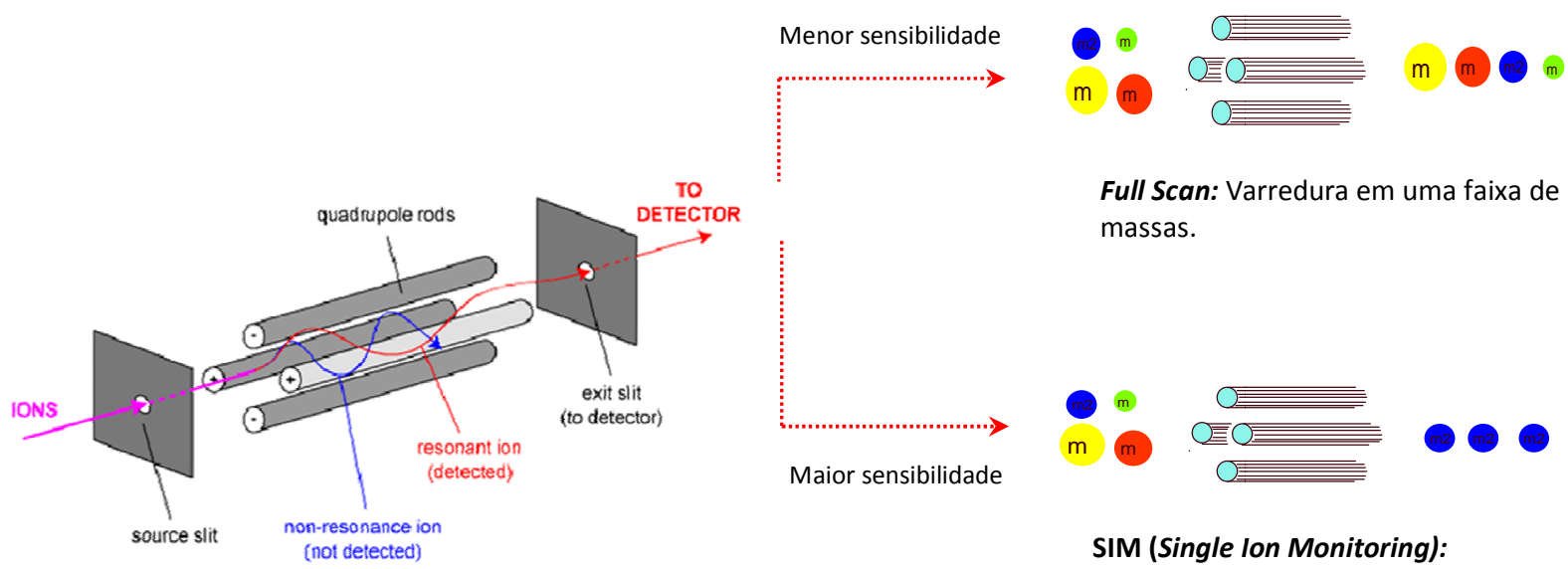
massas.
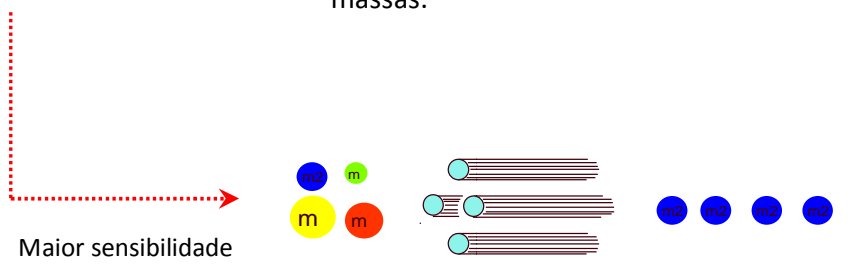

SIM (Single lon Monitoring):

Varredura da(s) massa(s) de interesse.

FIGURA 18. Analisador de massas - Quadrupolo simples.

\subsubsection{QUADRUPOLOS: TRIPLO QUADRUPOLO (MS/MS OU $\mathrm{MS}^{2}$ )}

○ $\mathbf{Q}_{0}$ : Focaliza o(s) íon(s) para iniciar a trajetória no interior dos quádruplos;

$\circ Q_{1}\left(1^{\circ}\right.$ Analisador de Massas): seleciona o(s) íon(s) precursor(es) a serem fragmentado(s);

○ $\mathbf{Q}_{2}$ (Câmara de colisão): fragmenta o(s) precursor(es) selecionado(s) em $Q_{1}$; 
$\circ \mathbf{Q}_{3}\left(2^{\circ}\right.$ Analisador de Massas): analisa os íons produtos formados em $Q_{2}$, no modo Scan (íons produtos na faixa $\mathrm{m} / \mathrm{z}$ selecionada) ou no modo SIM (escolha do fragmento $\mathrm{m} / \mathrm{z}$ a ser monitorado);

\section{Triplo Quadrupolo (MS/MS ou MS²)}
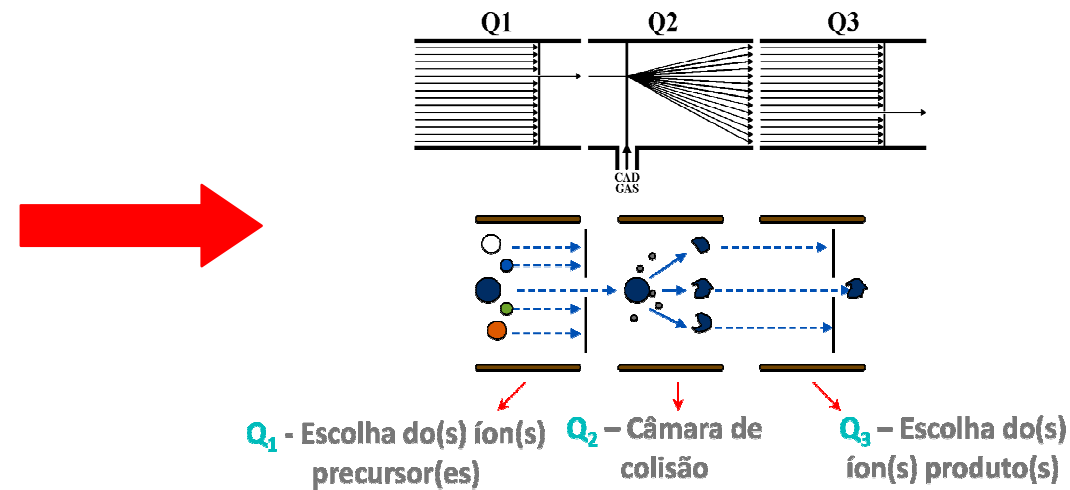

FIGURA 19. Analisador de massas - Triplo Quadrupolo.

\subsection{MULTIPLE REACTION MONITORING / SELECTED REACTION MONITORING (MRM/SRM)}

Escolha da(s) transição (ções) específica(s) entre o íon precursor e o íon produto formado na câmara de colisão.

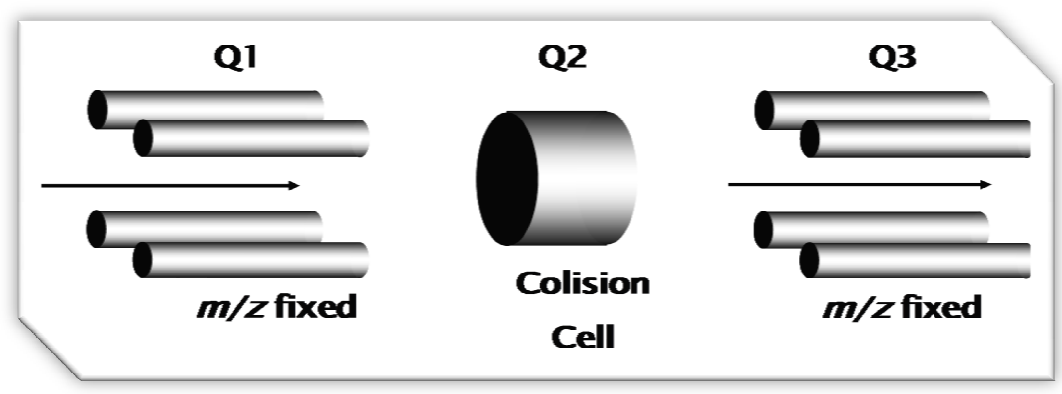

FIGURA 20. Analisador de massas - Q1, Q2 e Q3.

\section{Características gerais:}

- A transição selecionada pode ser monitorada e originar ensaios quantitativos com exatidão e precisão adequada; 
- Pode monitorar até 5 transições de um único precursor;

\subsection{ION-TRAP}

$\circ$ dos 3 eletrodos hiperbólicos;

- Inúmeras voltagens são aplicadas pelo eletrodo na armadilha contendo os íons, podendo gerar inúmeras fragmentações;

- Uma gradual mudança de potencial faz com que os íons sejam ejetados em uma razão crescente de $\mathrm{m} / \mathrm{z}$ para o detector;

- Principal aplicacão: elucidação estrutural de moléculas;

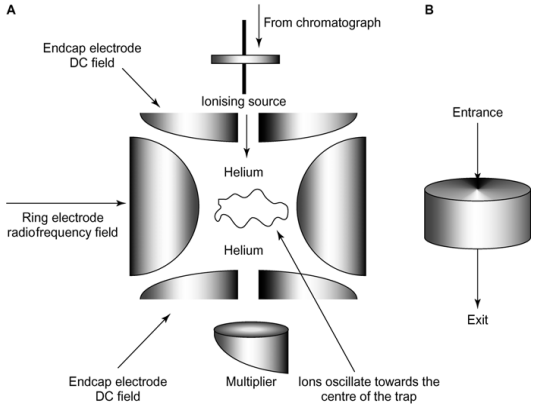

FIGURA 21. llustração do analisador de Massas Ion-Trak

\subsection{TIME-OF-FLIGHT (TOF)}

- Analisador de massas de alta resolução e exatidão;

- Íon é acelerado em alta velocidade por um campo elétrico. Cada valor de $\mathrm{m} / \mathrm{z}$ tem o seu tempo de voo característico (da fonte de íons até o detector);

- Ílons menores alcançam o detector mais rapidamente;

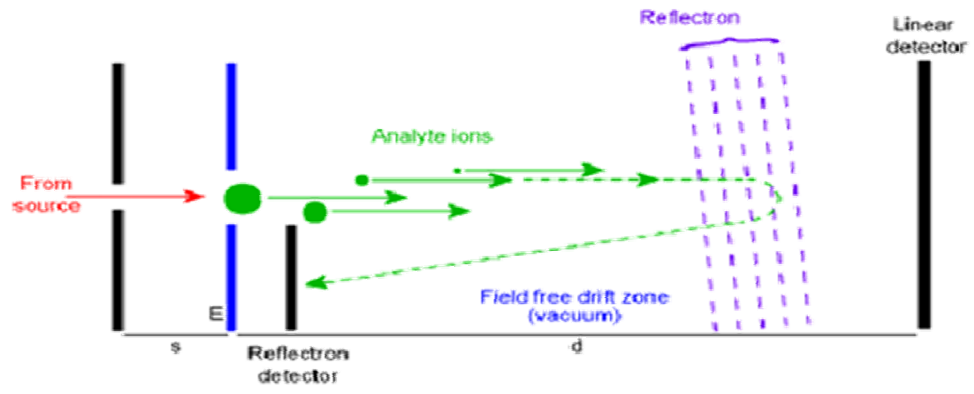

FIGURA 22. Ilustração do analisador de Massas Time-of-flight (TOF). 


\subsection{TIPOS DE DETECTORES}

- Última etapa do detector de massas;

- Mede a carga ou corrente elétrica produzida quando o íon passa ou se choca contra a superfície;

Número de íons que deixam o analisador de massas por um instante é muito pequeno

Amplificação da resposta para se obter um bom sinal

\subsubsection{EXEMPLOS DE DETECTORES}

- Multiplicadora de elétrons: tanto os íons positivos quanto os negativos são convertidos em elétrons, os quais são amplificados por efeito cascata e geram uma corrente elétrica. Amplamente utilizada em Quadrupolos e Ion-trap;

- Fotomultiplicadora: Conversão dos íons em elétrons por um dinodo. Os elétrons se chocam contra um material que passa a emitir fótons, e uma fotomultiplicadora amplifica os sinais;

- Placas de microcanais: Os íons se chocam contra uma placa de área extensa, gerando corrente elétrica. Mais utilizado em analisadores de massa do tipo TOF;

- Copos de Faraday; 


\section{CAPÍTULO V - VALIDACC̃̃O DE MÉTODOS ANALÍTICOS}

Neste capítulo são abordados os conceitos de validação de métodos analíticos a partir de recomendações de compêndios e órgão reguladores nacionais e internacionais. 


\section{VALIDAÇÃO DE MÉTODOS ANALÍTICOS}

A ANVISA, através da RE n`899, de 29 de maio de 2003, define o objetivo da validação como "demonstrar que o método é apropriado para a finalidade pretendida, ou seja, a determinação qualitativa, semi-quantitativa e/ou quantitativa de fármacos e outras substâncias em produtos farmacêuticos" (BRASIL, 2003).

A palavra validação originou-se do latim validus que significa forte e sugere que algo deve ser provado que é verdadeiro e útil, sendo assim aceito como padrão. Desta maneira, deste termo se refere à capacidade de medir o "real" ou a capacidade que um instrumento tem de evitar o erro (ARAÚJO, 2009).

Para métodos analíticos, a discussão a respeito da validação começou nos anos 40, quando estudos pela American Chemical Society e Merck \& Co. apontaram o uso da análise matemática e estatística como pré-requisito para um desenvolvimento analítico eficaz (ARAÚJO, 2009).

No início dos anos 70, trabalhos científicos apontaram a necessidade de que todo o procedimento possuísse um conjunto de características mínimas e padronizadas necessárias para a obtenção de métodos analíticos confiáveis. Hoje, esses parâmetros são estabelecidos por diversos laboratórios de referência e agências reguladoras que fornecem guias e orientações para validação de métodos analíticos e temas relacionados.

Os principais guias utilizados durante a validação de métodos analíticos e processos, principalmente para a área farmacêutica, são oferecidos por associações de química analítica e agências reguladoras: Association of Official Analytical Chemists (AOAC), American Society for Testing and Material (ASTM), Codex Committee on Methods of Analysis and Sampling (CCMAS), European Committee for Normalization (CEN), Cooperation on International Traceability in Analytical Chemistry (CITAC), 
European Cooperation for Accreditation (EA), Food and Agricultural Organization (FAO), United States and Drug Administration (FDA), International Laboratory Accreditation Cooperation (ILAC), Organização Mundial da Saúde (OMS), International Organization for Standardization (ISO), International Union of Pure and Applied Chemistry (IUPAC), United States Pharmacopeia (USP) e no Brasil, pela Agência Nacional de Vigilância Sanitária (ANVISA) e Instituto Nacional de Metrologia, Normalização e Qualidade Industrial (ARAUJO, 2009).

As definições de validação estão constantemente em evolução e atualização por parte de agências reguladoras vigentes (RIBANI, 2004):

"A validação deve garantir, através de estudos experimentais, que o método atenda às exigências das publicações analíticas, assegurando a confiabilidade dos resultados" (ANVISA, 2003).

"Validação é o processo de definir uma exigência analítica e confirmar que o método sob investigação tem capacidade de desempenho consistente com que a aplicação requer" (Eurachem Working Group).

"Confirmação por testes e apresentação de evidências objetivas de que determinados requisitos são preenchidos para um dado uso intencional" (ISSO/IEC 17025).

A validação de métodos assegura sua credibilidade durante o uso rotineiro, sendo algumas vezes mencionado como o "processo que fornece uma evidência documentada de que o método realiza aquilo para o qual é indicado para fazer" (USP).

"Avaliação sistemática de um procedimento analítico para demonstrar que está sob as condições nas quais deve ser aplicado"(OMS).

Dentre diversas definições, o International Conference on Harmonization (ICH, 2005) foi o resultado de uma conferência realizada por representantes de indústrias e 
agências reguladoras dos EUA, Europa e Japão, na tentativa de harmonizar todas as definições, parâmetros, requerimentos para metodologias analíticas com aplicações farmacêuticas. Com essa base, cada país tem sua legislação e procedimentos. Mesmo assim, todos apresentam o mesmo objetivo: demonstrar que as análises executadas fornecem resultados que permitam uma avaliação dos parâmetros especificados de qualidade do produto, assegurando a implantação do método e verificando a confiabilidade dos resultados analíticos em função do procedimento utilizado (RIBANI et al., 2004; SHABIR, 2003).

\subsection{CONDIÇÕES DE ANÁLISE}

A validação de um método proposto é baseada em condições de preparo, tratamento de amostras e instrumentação bem definidas e documentadas, com o objetivo de extração de informações qualitativas e/ou quantitativas com um nível de incerteza aceitável (ARAUJO, 2009).

A definição das condições de análise, geralmente, são baseadas em testes preliminares e algumas considerações como propriedades químicas, concentração do analitos e amostras, velocidade, custo de análise, etc. (ARAÚJO, 2009).

De modo geral, uma análise pode ser visualizada como um sistema de três elementos, ou seja, entrada, conversão e saída. Em geral, a entrada e saída são designadas pelas letras $x$ e y e representam a concentração e a resposta experimental, respectivamente (ARAÚJO, 2009). 


\subsection{PARÂMETROS DE VALIDAÇÃO}

A literatura possui amplo número de guias para avaliação de desempenho de métodos analíticos, apresentando diferentes terminologias e formas de expressar resultados. Apesar destas variações, todas levam a um mesmo propósito (TAVENIERS et al., 2004).

Cada método analítico possui suas variações e determinantes, principalmente devido às diferentes necessidades de cada caso. Por esses motivos, no General Chapter <1225>, a USP dividiu em quatro categorias os parâmetros, necessários para os diferentes propósitos da validação, onde:

- Categoria I: Procedimento para quantificação de fármacos, excipientes ou ingredientes ativos (incluindo conservantes) em produtos farmacêuticos;

- Categoria II: Procedimento para determinação de impurezas, incluindo os ensaios quantitativos e testes limites;

- Categoria III: Procedimentos analíticos para determinação de desempenho de ensaio como, dissolução, desintegração, etc.;

- Categoria IV: Testes de identificação; 
QUADRO 2. Parâmetros necessários durante a validação de método (BRASIL, 2003)

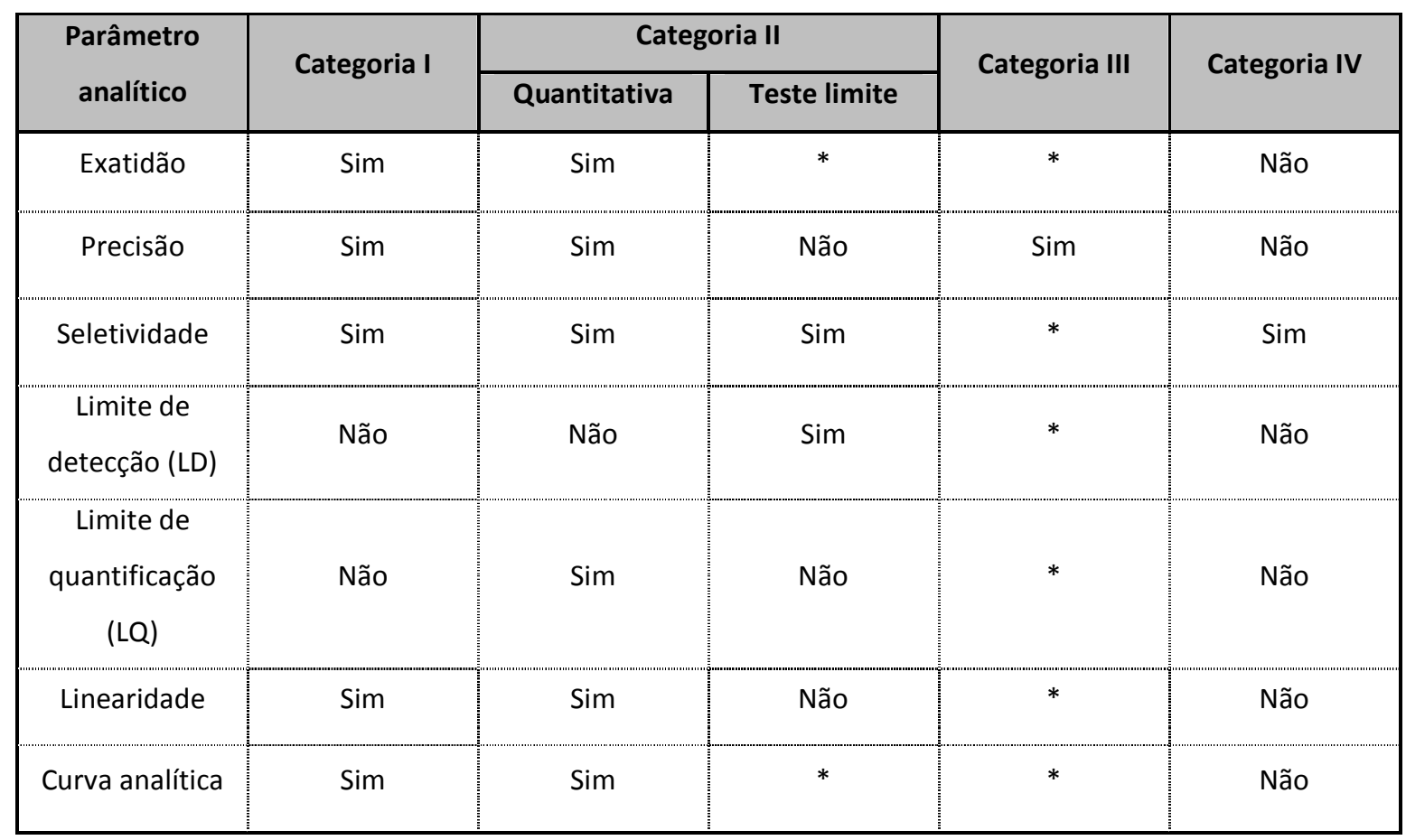

*Ensaio que pode ser requerido, dependendo da natureza do teste de especificidade/seletividade.

\subsection{DEFINIÇÃO DOS PARÂMETROS DE VALIDAÇÃO}

\subsubsection{LINEARIDADE}

É a capacidade de uma metodologia analítica de demonstrar que os resultados obtidos são diretamente proporcionais à concentração do analito na amostra, dentro de um intervalo especificado (BRASIL, 2003).

Segundo a $R E n^{\circ} 899$, de 29 de maio de 2003, recomenda-se que o ensaio de linearidade seja determinado pela avaliação de, no mínimo, 5 concentrações diferentes, conforme a quadro a seguir: 


\begin{tabular}{|c|c|}
\hline Ensaio & \multicolumn{1}{|c|}{ Alcance } \\
\hline $\begin{array}{c}\text { Determinação quantitativa do analito em matérias-primas ou em } \\
\text { formas farmacêuticas }\end{array}$ & De $80 \%$ a $120 \%$ da concentração teórica do teste \\
\hline Determinação de impurezas & $\begin{array}{l}\text { Do nível da impureza esperado até } 120 \% \text { do limite máximo } \\
\text { especificado. Quando apresentarem importância toxicológica ou } \\
\text { efeitos farmacológicos inesperados, os limites de quantificação e } \\
\text { deteção devem ser adequados às quantidades de impurezas a } \\
\text { serem controladas }\end{array}$ \\
\hline
\end{tabular}

QUADRO 3. Limites porcentuais do teor do analito que devem estar contidos no intervalo de linearidade para métodos analíticos (BRASIL, 2003).

\subsubsection{PRECISÃO}

A precisão de um método analítico indica a dispersão de resultados entre os ensaios independentes, repetidos de uma mesma amostra ou padrões, sob condições definidas. Esse parâmetro é expresso através do desvio padrão relativo (DPR) ou coeficiente de variação (CV), em porcentagem (\%) (ICH, 2005).

A precisão é a avaliação da proximidade dos resultados obtidos em uma série de medidas de uma amostragem múltipla de uma amostra (BRASIL, 2003).

Para a determinação de precisão os guias de validação recomendam três ensaios distintos: repetibilidade, precisão intermediária e reprodutibilidade:

- Repetibilidade (precisão intra-corrida): concordância entre os resultados dentro de um curto período de tempo com o mesmo analista e mesma instrumentação;

○ Precisão intermediária (precisão inter-corridas): concordância entre os resultados do mesmo laboratório, mas obtidos em dias diferentes (recomenda-se o 
mínimo de 2 dias de diferença), com analistas diferentes e/ou equipamentos diferentes;

○ Reprodutibilidade (precisão inter-laboratorial): concordância entre os resultados obtidos em diferentes laboratórios, como em estudos colaborativos. Estes dados não precisam ser apresentados para a concessão do registro;

\subsubsection{EXATIDÃO}

Exatidão é à medida que representa o grau de concordância entre a determinação de um analito (valor real ou encontrado) e seu padrão (valor verdadeiro) (TAVENIERS et al., 2004).

A forma de sua medida varia de acordo com o ensaio realizado. Os mais utilizados são: materiais de referência, comparação de métodos adição de padrão e testes de recuperação (RIBANI et al., 2004).

A exatidão de um método analítico é a proximidade dos resultados obtidos pelo método em um estudo em relação ao valor verdadeiro (BRASIL, 2003).

A exatidão pode ser avaliada das seguintes maneiras:

\section{A) FÁRMACO ISOLADO}

- Aplicação de metodologia analítica proposta na análise de uma substância de pureza conhecida (padrão de referência); 
- Comparação dos resultados obtidos pela metodologia proposta, com aqueles resultantes de uma metodologia bem caracterizada, cuja exatidão já tenha sido estabelecida;

\section{B) FORMA FARMACÊUTICA}

- Na análise de uma amostra, na qual quantidade conhecida de fármaco foi adicionada a uma mistura dos componentes do medicamento (placebo contaminado);

- Nos casos em que amostras de todos os componentes do medicamento estão indisponíveis, se aceita para avaliação da exatidão, a análise pelo método de adição do padrão, no qual se adiciona quantidades conhecidas do analito (padrão de referência) ao medicamento;

\section{C) IMPUREZAS}

- Análise pelo método de adição do padrão, no qual se adiciona quantidades conhecidas de impurezas e/ou produtos de degradação ao medicamento ou ao fármaco isolado;

- No caso de indisponibilidade de amostras de certas impurezas e/ou produtos de degradação, se aceita a comparação dos resultados obtidos com um segundo método bem caracterizado (metodologia farmacopêica ou outro procedimento analítico validado); 
A exatidão é determinada a partir do seguinte cálculo:

$$
\frac{C M E}{C T} \times 100 \%=\text { Exatidão }
$$

Onde:

CME - Concentração Média Experimental;

CT - Concentração teórica;

\subsubsection{ROBUSTEZ}

A robustez de um método analítico, é a medida de sua capacidade em resistir a pequenas e deliberadas variações dos parâmetros analíticos, o que o confere confiança durante seu uso em rotinas (BRASIL, 2003).

Durante a validação de métodos analíticos, pela técnica de cromatografia líquida de alta eficiência (CLAE), exemplos dos fatores a serem avaliados estão descritos no quadro a seguir:

\begin{tabular}{|c|c|}
\hline Fatores & Exemplos de fatores a serem avaliados \\
\hline Preparo de amostras & $\begin{array}{l}\text { - Estabilidade das soluções analíticas } \\
\text { - Tempo de extração }\end{array}$ \\
\hline $\begin{array}{l}\text { Cromatografia líquida de alta eficiência } \\
\qquad \text { (CLAE) }\end{array}$ & $\begin{array}{l}\text { - Variação de pH da fase móvel } \\
\text { - Variação na composição da fase móvel } \\
\text { - Diferentes lotes ou fabricantes de colunas } \\
\text { - Temperatura } \\
\text { - Fluxo de fase móvel }\end{array}$ \\
\hline
\end{tabular}

QUADRO 4. Exemplos de fatores que devem ser considerados na determinação da robustez do método analítico (BRASIL, 2003) 


\subsubsection{LIMITE DE DETECÇÃO}

O limite de detecção (LD) é a menor quantidade do analito presente em uma amostra que pode ser detectado, porém não necessariamente quantificado, sob as condições experimentais estabelecidas.

O limite de detecção é estabelecido por meio da análise de soluções de concentrações conhecidas e decrescentes do analito, até o menor nível detectado (BRASIL, 2003).

\subsubsection{LIMITE DE QUANTIFICAÇÃO}

O limite de quantificação (LQ) é a menor concentração de um analito que pode ser determinada quantitativamente com precisão e exatidão, sob as condições experimentais definidas. Geralmente, esse teste é utilizado para determinação de impurezas ou produtos de degradação em uma matriz (USP, 2010; TAVARES et al., 2004).

O limite de quantificação é um parâmetro determinado, principalmente, para ensaios quantitativos de impurezas, produtos de degradação em fármacos e produtos de degradação em formas farmacêuticas e é expresso como concentração do analito na amostra (BRASIL, 2003). 


\subsubsection{ESPECIFICIDADE E SELETIVIDADE}

De acordo com o guia de validação do ICH (2008), seletividade é o teste realizado com o placebo para a avaliação da presença do analito, impurezas, produtos de degradação, etc. presentes na matriz da amostra, que possam interferir no resultado final do analito em questão, garantindo que a resposta seja, exclusivamente, a do composto de interesse.

Há diversos procedimentos para a determinação da seletividade. Uma das formas é comparando-se a matriz isenta de substâncias de interesse (placebo), com a matriz adicionada de padrão de interesse, sendo neste caso não deve apresentar interferentes eluindo no mesmo tempo de retenção que o analito, bem como se deve apresentar separada dos demais compostos presentes na amostra. Outra maneira de identificar e determinar os compostos é submeter à amostra a condições de estresse utilizando variação de temperatura e meios ácidos e alcalino, avaliando-se os produtos de degradação que possam interferir no resultado final (RIBANI et al., 2004).

Para análise quantitativa (teor) e análise de impurezas, a especificidade pode ser determinada pela comparação dos resultados obtidos de amostra (fármaco ou medicamento) contaminadas com quantidades apropriadas de impurezas ou excipientes e amostras não contaminadas, para demonstrar que o resultado do teste não é afetado por esses materiais. Quando a impureza ou o padrão do produto de degradação não estiverem disponíveis, pode-se comparar os resultados do teste das amostras contendo impurezas ou produtos de degradação com os resultados de um segundo procedimento bem caracterizado (por exemplo metodologia farmacopêica ou outro procedimento validado). Estas comparações devem incluir amostras armazenadas sob condições de 
DESENVOLVIMENTO E VALIDAÇÃO DE MÉTODO INDICADOR DE ESTABILIDADE DE FORMULAÇÕES FARMACÛTICAS DE USO TÓPICO CONTENDO PERÓXIDO DE BENZOÍLA

estresse tais como: luz, calor, umidade, hidrólise ácida, hidrólise básica, e oxidação (BRASIL, 2003). 


\section{CAPÍTULO VI - MÉTODOS INDICATIVOS DE ESTABILIDADE}

Neste capítulo são abordados os conceitos de métodos indicativos de estabilidade, definição de estratégia e critérios de aceitação para realização do ensaio de degradação forçada. 


\section{MÉTODOS INDICATIVOS DE ESTABILIDADE}

A estabilidade é definida como o tempo durante o qual a especialidade farmacêutica ou mesmo a matéria-prima considerada isoladamente, mantém dentro dos limites especificados e durante todo o período de estocagem e uso, as mesmas condições e características que possuía quando da época da sua fabricação. Pode também ser definida como o período de tempo compreendido entre o momento no qual o produto está sendo fabricado àquela que sua potência está reduzida a não mais do que $10 \%$, desde que os produtos de alteração estejam seguramente identificados e previamente reconhecidos seus efeitos (TABORIANSKI,2003; VEHABOVIC et al., 2003; STULZER, SILVA, 2006).

A estabilidade dos produtos farmacêuticos depende de fatores ambientais como temperatura, umidade, luz, e outros fatores relacionados ao próprio produto como propriedades físicas e químicas, de substâncias ativas e excipientes farmacêuticos, forma farmacêutica e sua composição, processo de fabricação, tipo e propriedades dos materiais de embalagem (BRASIL, 2005).

Os estudos de estabilidade são preconizados com a finalidade de garantir a integridade química, física, microbiológica, terapêutica e toxicológica do fármaco e da forma farmacêutica dentro dos limites especificados, sob influência dos fatores ambientais em função do tempo. (MATHEWS, 1999; LUCAS et al., ANSEL et al., 2007).

O estudo de estabilidade descrito pela RE $n^{\circ} 1,29$ de julho de 2005, possui como principal aplicabilidade à determinação do prazo de validade do produto farmacêutico. Porém, também determina a quantificação de produtos de degradação e o método analítico correspondente, que resultou na publicação de um Informe técnico n¹/2008, com o objetivo de esclarecer procedimentos nos casos em que impureza ou o padrão do 
produto de degradação não estão disponíveis. Estes procedimentos envolvem a realização de testes de estresse sob condições variadas (BRASIL, 2008).

A realização do teste de estresse, assim como o desenvolvimento do método analítico para identificação e quantificação de produtos de degradação (método indicador de estabilidade) é de extrema importância para as indústrias farmacêuticas, pois no momento do registro, pós-registro e renovação, o estudo de estresse, acompanhado de sua análise crítica deve ser contemplada.
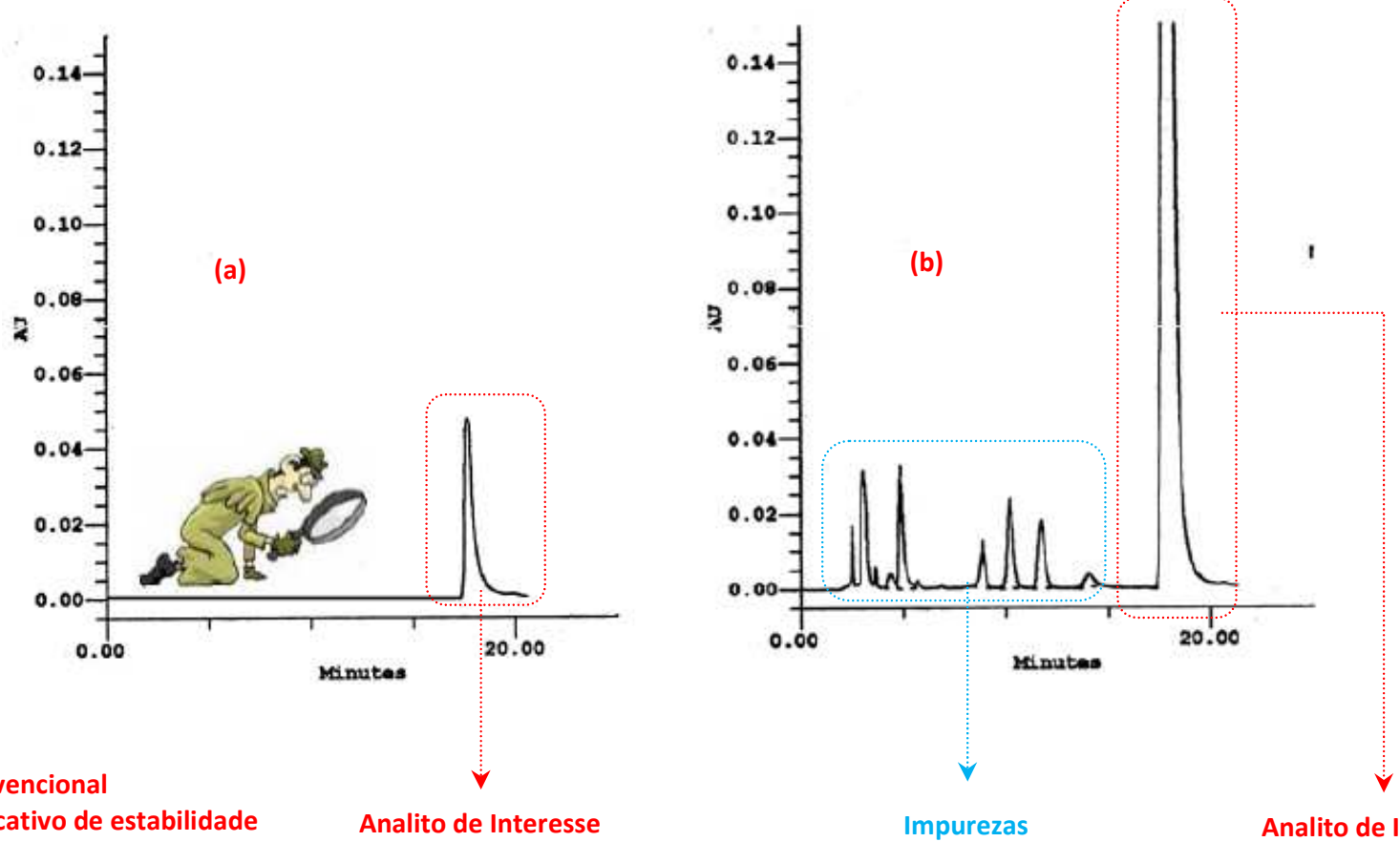

(b) Método indicativo de estabilidade

Analito de Interesse

Impurezas

Analito de Interesse

FIGURA 23. Método convencional versus Método indicador de estabilidade

O uso de métodos indicadores de estabilidade seletivos aos princípios ativos e seus produtos de degradação, são altamente recomendados pela ANVISA para acompanhamento de resultados provenientes de estudos de estabilidade de medicamentos (BRASIL, 2003; BRASIL, 2005). No entanto, poucas monografias 
existentes em farmacopéias incluem metodologias para análise de produtos de degradação, e poucos fabricantes conhecem e desenvolvem metodologias validadas para a detecção e quantificação desses produtos. Para o desenvolvimento e validação de metodologias indicativas de estabilidade, preconiza-se a realização de testes de estresse e identificação dos produtos de degradação formados (BAKSHI, SINGH, 2002; BOUDREAU et al., 2004; CARVALHO et al., 2005).

\subsection{DEGRADAÇÃO FORÇADA}

A degradação forçada ou teste de estresse é definido como um teste de estabilidade para fármacos e medicamentos sob condições extremas. Este teste mostrase como uma tendência dentro do planejamento para o desenvolvimento de uma forma farmacêutica, pois a investigação da estabilidade intrínseca do fármaco fornece abordagens de formulação e indica tipos de adjuvantes, aditivos de proteção específicos e de acondicionamento, que provavelmente melhorarão a integridade do fármaco e do produto. Demonstrando-se assim, que o conhecimento do comportamento químico pode ser usado para garantir a estabilidade da forma farmacêutica desejada (REYNOLDS et al., 2002; AULTON, 2005).

Um dos principais objetivos a serem atingidos através deste teste é demonstrar a especificidade ao desenvolver um método indicativo de estabilidade, sobretudo quando poucas informações estão disponíveis sobre os possíveis produtos de degradação e dos produtos formados, que poderiam ser produtos formados, que poderiam ser produzidos durante o período de armazenamento (REYNOLDS et al., 2002). 
A natureza do teste de estresse utilizado para o fármaco depende de suas características intrínsecas e da forma farmacêutica a ser desenvolvida. Para o medicamento, o planejamento de estudo deve ser baseado nas propriedades do fármaco e dos excipientes utilizados na formulação, assim como nas condições de armazenamento. Neste caso, são utilizadas condições mais severas do que as condições do estudo de estabilidade acelerado, como estratégia para a fase de desenvolvimento da forma farmacêutica (KLICK et al., 2005). No entanto, tais exames podem ser necessários, se for demonstrado que os produtos de degradação não são formados sob condições de estudo de estabilidade acelerado ou de longa duração (ICH, 2003).

Embora o conceito de estudo de degradação forçada não seja novo para indústria farmacêutica, o procedimento para a sua realização não foi claramente definido pelo guia de estabilidade do International Conference on Harmonization (ICH), assim como por outros órgãos regulatórios. Devido à falta dessas informações detalhadas, a realização do teste sofre variações extremas nos procedimentos utilizados pelas companhias farmacêuticas para a obtenção dos resultados, sendo observada a condução dos estudos sem respaldo científico, levando a resultados muitas vezes duvidosos, principalmente quando são aplicadas as condições extremas em um curto intervalo de tempo (ICH, 2003; ASLANTE et al., 2003; KLICK et al., 2005).

No Brasil, a ANVISA, através do Informe Técnico $n^{\circ} 1$, esclarece procedimentos a serem seguidos, uma vez que a identificação e quantificação dos produtos de degradação já eram exigidas no item 2.2.6 da RE n560/2002 e no item 2.8 da $R E$ n³98/2004, assim como as recomendações para a sua realização no Anexo II da mesma. Já no item 2.9 do anexo da RE $n^{\circ} 1$, de 29 de julho de 2005 - Guia para realização dos Estudos de Estabilidade, já era preconizada a realização do ensaio de identificação e quantificação de 
produtos de degradação e métodos analíticos correspondente no estudo de estabilidade, para todos os produtos a serem registrados (BRASIL, 2005).

O item 2.1.2 da RE n`899 de 29 de maio de 2003 - Guia de Validação de Métodos Analíticos preconiza que "quando a impureza ou o padrão do produto de degradação não estiverem disponíveis, pode-se comparar os resultados do teste das amostras contendo impurezas ou produtos de degradação com os resultados de um segundo procedimento analítico bem caracterizado"(por exemplo, metodologia farmacopêica ou outro procedimento validado) (BRASIL, 2003).

Este procedimento inclui a realização de testes sob condições de estresse especificadas pela ANVISA, que resultaram na apresentação da análise dos produtos de degradação nos estudos de estabilidade acelerada e de longa duração com a forma farmacêutica final.

QUADRO 5. Condições de estresse para a realização do estudo de degradação forçada

\begin{tabular}{|c|c|}
\hline Meio de Estresse & Condições de Estresse \\
\hline Aquecimento & $60^{\circ} \mathrm{C}$ \\
\hline Umidade & Mínimo $75 \%$ de umidade relativa (UR) \\
\hline Solução Ácida & Ou $0,1 \mathrm{M}$ \\
\hline Solução Alcalina & $\mathrm{NaOH} 0,1 \mathrm{M}$ \\
\hline Solução Oxidativa & $\mathrm{H}_{2} \mathrm{O}_{2} 3 \%$ \\
\hline Fotolítica & UV-B fluorescente \\
\hline 'Ílons metálicos (opcional) & $0,05 \mathrm{M} \mathrm{Fe}^{+2} \mathrm{ou} \mathrm{Cu}^{+2}$ \\
\hline
\end{tabular}

Fonte: Informe Técnico n¹/2008 - ANVISA (BRASIL, 2008)

O objetivo dos testes realizados através deste procedimento, não é degradar totalmente o composto, mas promover uma degradação de pequena extensão (10-30\%), evitando-se a formação de compostos secundários. Sendo observada ausência total de 
degradação do composto após 10 dias, o fármaco deve ser considerado estável. Se este for inferior a 10\%, devem-se aumentar as condições de estresse. Contudo, a legislação vigente permite a utilização de publicações de literatura científica, que possam vir a corroborar com os dados experimentais enviados, mas não com a finalidade de substituir os dados referentes aos ensaios exigidos (REYNOLDS et al., 2002; BRASIL, 2008).

Um importante fator referente à identificação dos produtos de degradação está relacionada à segurança dos medicamentos, pois pode ocorrer a formação de produtos tóxicos e/ou perda parcial ou total da atividade terapêutica do fármaco, sendo necessários o isolamento e a caracterização das suas propriedades físicas e químicas, assegurando a segurança biológica a partir da determinação dos níveis de segurança aceitáveis e de seus limites de quantificação, com relação à posologia diária (MORIWAKI et al., 2001).

\subsection{DELINEAMENTO DOS ESTUDOS DE DEGRADAÇÃO FORÇADA COM FÁRMACOS}

Os estudos de degradação forçada inclui os efeitos causados pela variação de temperatura, umidade, oxidação, fotólise e suscetibilidade à hidrólise por extensa variação dos valores de $\mathrm{pH}$, que são condições típicas de degradação de fármacos. Vários estudos vêm sendo realizados para obtenção de produtos de degradação de muitos fármacos utilizados na terapêutica, utilizando diferentes métodos de obtenção e identificação (KAPOOR et al., 2006; KUMAR et al., 2008; BEDSE et al., 2009).

Contudo não existe um padrão para realização desses estudos. Na ausência destes procedimentos, dificuldades são enfrentadas pelos profissionais, ao decidir sobre as condições de estresse a serem utilizadas para um novo fármaco. Alguns estudos, 
como o realizado por SINGH e BAKSHI (2000), propõem um sistema de classificação dos fármacos, tomando como base o comportamento da estabilidade de fármacos diante de variações nas condições submetidas (AULTON, 2005).

\subsubsection{HIDRÓLISE}

A água é considerada como um dos principais catalisadores em reações de degradação. Muitos fármacos são considerados como instáveis nesse meio e necessitam de intervenções durante a formulação e armazenamento, para que a eficácia e sua estabilidade e da forma farmacêutica final não sejam comprometidas. Para a avaliação da instabilidade sob a condição de hidrólise, também deve ser levado em consideração o pH do meio, pois os íons de hidrogênio e hidroxila podem acelerar ou retardar o processo de degradação (ANSEL et al., 2007).

Para realizar o estudo de estresse em condição de hidrólise ácida, utiliza-se principalmente ácido clorídrico e para a hidrólise básica hidróxido de sódio, sendo que, muitas variações são observadas no tempo e na temperatura de exposição de fármacos para essa condição. Existem poucos relatos na literatura sobre a hidrólise realizada em $\mathrm{pH}$ neutro, onde geralmente se utiliza água como agente de hidrólise. Nessa condição, a taxa de decomposição é lenta, o que é compreensível, porque as reações em pH neutro são não catalíticas e por isso podem ser necessários períodos muito longos e condições de temperaturas extremas, para conseguir quantidades suficientes de produtos de degradação (SINGH, BAKSHI, 2000).

As condições de estresse iniciais são realizadas, assumindo que o fármaco seja instável, portanto, sujeito a receber condições mais amenas. Dependendo dos resultados 
obtidos, aumenta-se ou diminui-se a concentração das condições da reação utilizada (SINGH, BAKSHI, 2000).

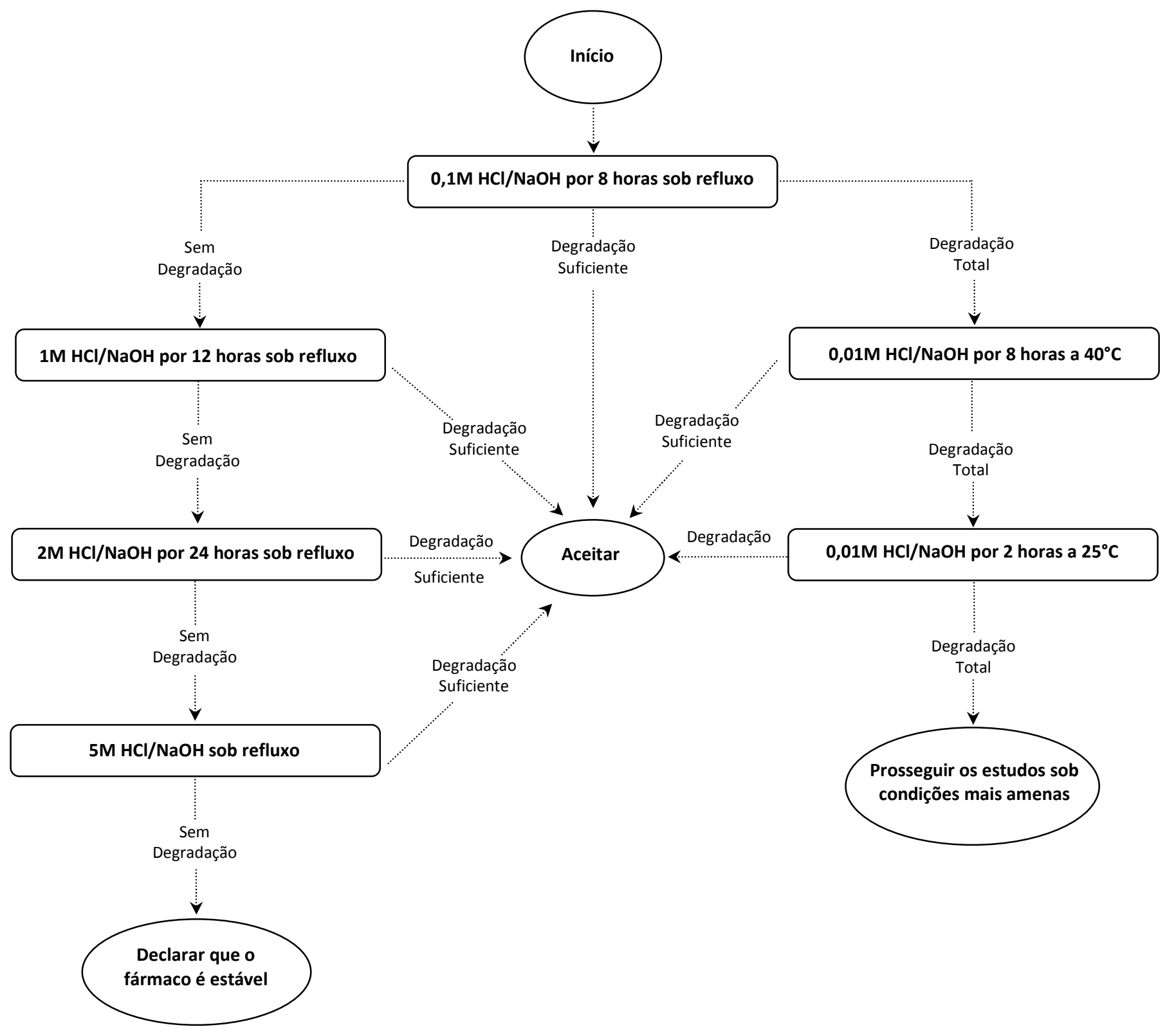

FIGURA 24. Fluxograma do estudo de estresse: Hidrólise sob condições ácidas e básicas (Fonte: Adaptado de: SINGH, BAKSHI, 2000) 


\subsubsection{OXIDAÇÃO}

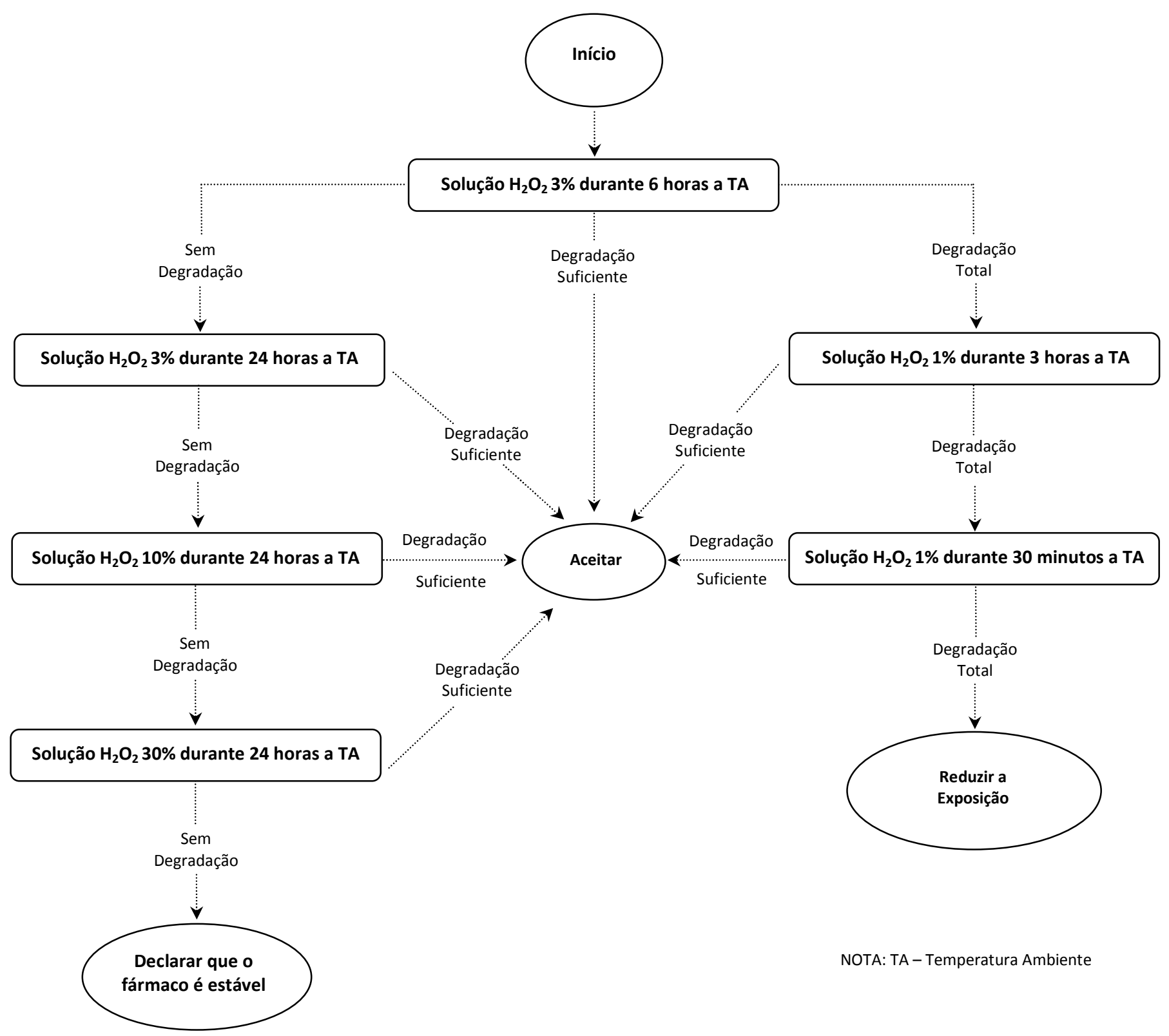

FIGURA 25. Fluxograma do estudo de estresse: Oxidação (Fonte: Adaptado de: SINGH, BAKSHI, 2000)

A degradação oxidativa é uma das principais causa de instabilidade de fármacos, dentre os mais conhecidos e estudados têm-se os esteróides, antibióticos, vitaminas, óleos e gorduras. A oxidação envolve a remoção de um átomo eletropositivo ou radical. 
Muitas oxidações são reações em cadeia, que procedem lentamente sob a influência do oxigênio molecular. Tal processo de reação é referido como uma auto-oxidação (FLORENCE, ATTWOOD, 2003).

O peróxido de hidrogênio é utilizado para criar as condições de estresse empregadas para o estudo de oxidação. Essa parece ser muito mais popular para o propósito que qualquer outro agente oxidante. A concentração do peróxido utilizada varia entre $1 \%$ a $30 \%$.

A estabilização de fármacos frente a condições oxidativas envolve a observação de um número de precauções durante a manufatura e a estocagem. O oxigênio em recipientes farmacêuticos deve ser substituído por nitrogênio ou dióxido de carbono; assim como o contato com os íons de metais pesados, que catalisam a oxidação, devem ser evitados e a estocagem deve ser a temperaturas reduzidas (FLORENCE, ATTWOOD, 2003).

\subsubsection{FOTÓLISE}

A reação de fotólise é iniciada após a absorção de radiação eletromagnética. A maioria dos princípios ativos empregados na preparação de medicamentos apresenta máximos de absorção na região do ultravioleta do espectro eletromagnético. A radiação ultravioleta é muito energética e pode propiciar a clivagem de muitas ligações químicas, ocorrendo à degradação da molécula. Desta forma, é importante conhecer a foto estabilidade dos fármacos utilizados como medicamentos e os produtos formados devido à fotólise, além de avaliar a toxicidade destes últimos (MORIWAKI et al., 2001). 
O estudo de fotoestabilidade é atualmente uma importante ferramenta para a indicação de estabilidade de fármacos e formas farmacêuticas dentro da indústria.

Existe muita variação da maneira na qual o estresse de fotoestabilidade é realizado. Os fármacos podem sofrer exposição a comprimentos de onda curtas ou longas dentro da faixa de UV, ou luz fluorescente de iluminação que varia na faixa de 400-1580 foot candles, sob temperatura ambiente. O período de exposição varia de algumas horas a vários meses, dependendo da intensidade da fonte luminosa. Para saber se um fármaco é sensível à fotólise ou não, depende da variação do comportamento de decomposição observado. Os estudos de fotoestabilidade são feitos em fármacos na forma sólida ou em solução (SINGH, BAKSHI, 2000).

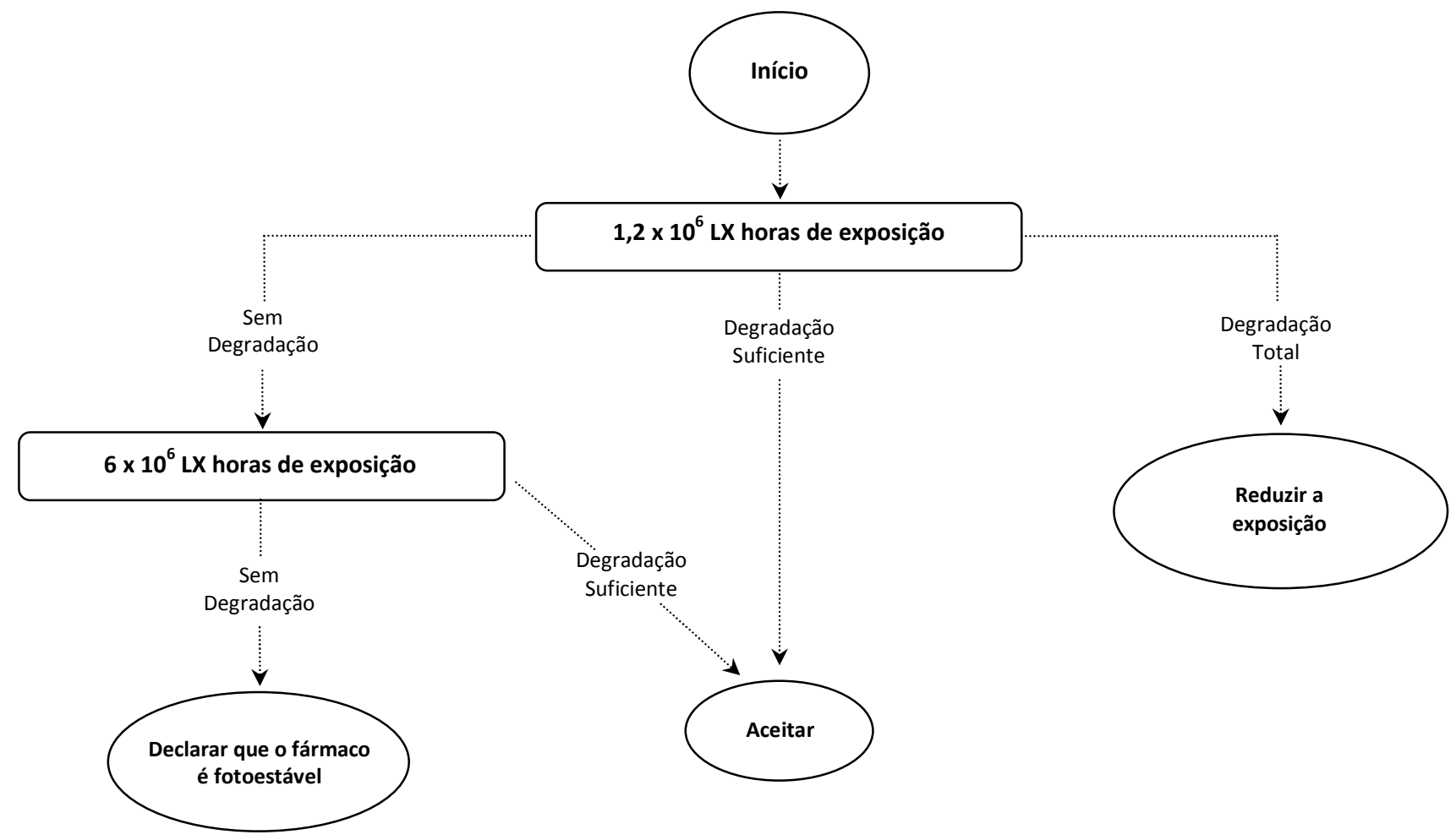

FIGURA 26. Fluxograma do estudo de estresse: Fotólise (Fonte: Adaptado de: SINGH, BAKSHI, 2000) 
Produtos farmacêuticos podem ser adequadamente protegidos da decomposição induzida pela luz com o uso de recipientes de vidro colorido e estocagem no escuro. Vidros de cor âmbar filtram luzes de comprimento de onda menores do que 470nm e oferecem considerável proteção aos compostos sensíveis à luz ultravioleta. O revestimento de comprimidos com um filme polimérico contendo absorventes de radiação ultravioleta tem sido sugerido como um método adicional para proteção contra a luz (ICH, 1996; FLORENCE, ATTWOOD, 2003).

\subsubsection{ESTABILIADE TÉRMICA}

Um dos principais fatores que devem ser avaliados no desenvolvimento de formulações é o estudo da estabilidade. Estes estudos são realizados rotineiramente pela indústria farmacêutica, porém, requerem longos períodos de armazenamento das amostras, sob condições controladas de temperatura e umidade (RODANTE et al., 2002). Embora não substituam os estudos convencionais, as técnicas termoanalíticas mostramse extremamente úteis em estudos de estabilidade, possibilitando a escolha das formulações mais estáveis com extrema rapidez, fator desejável especialmente para a indústria farmacêutica (BAZZO, SILVA, 2005).

A análise térmica possibilita uma ampla faixa de aplicação para medidas de propriedades físicas como: estudo de reações químicas, avaliação de estabilidade térmica, determinação da composição de materiais e desenvolvimento de metodologia analítica (FARIA et al., 2002).

Essas análises têm sido utilizadas na área farmacêutica como ferramenta útil para avaliar rapidamente uma possível interação entre os componentes ativos e os excipientes 
em estudos de compatibilidade na pré-formulação, além de avaliar a existência de polimorfismo, compostos de inclusão e dispersões sólidas, determinação de pureza química, estudos de reações no estado sólido, análise de formas farmacêuticas sólidas e controle de qualidade (ALENCAR et al., 2006; SILVA et al., 2009; TOMASSETTI et al., 2005; MAMEDE et al., 2006). 


\section{CAPÍTULO VII - MATERIAL E MÉTODOS}

Neste capítulo são descritos os métodos analíticos utilizados durante a execução da parte experimental do projeto bem como a descrição das amostras utilizadas para sua realização. 


\section{MATERIAL E MÉTODOS}

\subsection{AMOSTRAS}

Foram avaliadas amostras comerciais de Peróxido de Benzoíla Gel nas apresentações 40 e $80 \mathrm{mg} / \mathrm{g}$, conforme a preparação a seguir:

\section{Peróxido de Benzoíla Gel 40mg/g}

Peróxido de benzoíla $40,0 m g$

Excipiente q.s.p. $1,0 g$

\section{Peróxido de Benzoíla Gel $80 \mathrm{mg} / \mathrm{g}$}

Peróxido de benzoíla $.80,0 m g$

Excipiente q.s.p $1,0 g$

Excipientes: água purificada, álcool cetílico, álcool estearílico/ceteareth 20, perfume herbal fresh, simeticona e metildimetil issorbida.

\subsection{REAGENTES E PADRÕES ANALÍTICOS UTILIZADOS}

- Água purificada;

- Acetonitrila grau HPLC JTBaker ${ }^{\circledR}$ Lote\#K37C51 Val.: 09.Set.21

○ Ácido acético glacial grau P.A. JTBaker ${ }^{\circledR}$ Lote\#J20C60 Val.: 19.Mai.15

○ Solução reagente de iodeto de potássio $50 \%$; 
- Solução indicadora de amido iodetado;

- Solução volumétrica de tiossulfato de sódio 0,1N Fator de correção: 0,9992;

- Padrão matéria-prima de peróxido de benzoíla Lote\#1036918 Pureza: 71,90\% Val.: Dezembro. $2013 \quad$ Fabricante: Arkema ${ }^{\circledR}$;

○ Padrão reagente de ácido benzóico Lote\#20113216 Pureza: 99,97\% Val.: 31.Outubro.2014 Fabricante: Merck ${ }^{\circledR}$;

- Padrão reagente de benzaldeído Lote\#00196HJ Pureza: 99,99\% Val.: 30.Abril.2014 Fabricante: Sigma-Aldrich ${ }^{\circledR}$;

- Padrão reagente de benzoato de etila Lote\#1323083 Pureza: 100,0\% Val.: Junho.2013 Fabricante: Fluka;

○ Padrão reagente de metilparabeno Lote\# 20103089 Pureza: 100,0\% Val.: 30.Dezembro.2014 Fabricante: Merck ${ }^{\circledR}$;

\subsection{EQUIPAMENTOS}

- Cromatógrafo líquido

Fabricante: Agilent ${ }^{\circledR}$ Technologies

Modelo: 1100;

- Balança Analítica Fabricante: Sartorius ${ }^{\circledR} \quad$ Modelo: LA 2305;

- Espectrômetro de infravermelho médio, com célula ATR Fabricante: Perkin Elmer $^{\circledR} \quad$ Modelo: FT-I Spectrometer 100;

- Câmara de fotoestabilidade Suntest CPS+ Fabricante: Atlas $^{\circledR} \quad$ Número de série: 1107010.

- Espectrômetro de massas Fabricante: Agilent ${ }^{\circledR}$ Technologies Modelo: 6460 System; 


\subsection{MÉTODOS ANALÍTICOS}

\subsection{MÉTODO INDICATIVO DE ESTABILIDADE PARA O PERÓXIDO DE BENZOÍLA E SEUS PRODUTOS DE DEGRADAÇÃO COMPENDIAIS}

Durante a realização das atividades de pesquisa foi proposto o método analítico para o doseamento de peróxido de benzoíla e seus produtos de degradação, pela técnica analítica de cromatografia líquida de alta eficiência (CLAE), a partir da método de substâncias relacionadas preconizada na monografia do peróxido de benzoíla na USP36NF31, conforme descrito a seguir:

\begin{tabular}{|c|c|c|c|}
\hline Cromatógrafo & \multicolumn{3}{|l|}{ Cromatógrafo Líquido } \\
\hline Detector & \multicolumn{3}{|l|}{ Diode array (DAD) } \\
\hline Comprimento de onda & \multicolumn{3}{|c|}{ 235nm, BW: 4 e Referência: Desativado } \\
\hline Coluna cromatográfica & \multicolumn{3}{|c|}{ Phenomenex Luna C18 $100 \AA-250 \mathrm{~mm} \times 4,6 \mathrm{~mm} \times 5 \mu \mathrm{m}$} \\
\hline Fluxo de fase móvel & \multicolumn{3}{|c|}{$1,5 \mathrm{~mL} / \mathrm{minuto}$} \\
\hline \multirow[t]{5}{*}{ Fase Móvel } & \multicolumn{3}{|l|}{ Gradiente: } \\
\hline & Tempo (minutos) & Solução A (\%) & Solução B (\%) \\
\hline & 00,0 & 10,0 & 90,0 \\
\hline & 20,0 & 60,0 & 40,0 \\
\hline & 30,0 & 60,0 & 40,0 \\
\hline Volume de injeção & \multicolumn{3}{|l|}{$15 \mu \mathrm{L}$} \\
\hline Temperatura da coluna & \multicolumn{3}{|l|}{$25^{\circ} \mathrm{C}$} \\
\hline Tempo de retenção & \multicolumn{2}{|c|}{ Tempo de retenção (minutos) } & etenção relativo \\
\hline Ácido Benzóico & \multicolumn{2}{|c|}{11,7} & 0,42 \\
\hline Metilparabeno & \multicolumn{2}{|l|}{12,2} & 0,44 \\
\hline Benzaldeído & \multicolumn{2}{|l|}{13,8} & 0,49 \\
\hline Benzoato de Etila & \multicolumn{2}{|l|}{21,2} & 0,78 \\
\hline Peróxido de Benzoíla & \multicolumn{2}{|l|}{27,9} & 1,00 \\
\hline Tempo de corrida & \multicolumn{3}{|l|}{30 minutos } \\
\hline Tempo pós corrida & \multicolumn{3}{|l|}{05 minutos } \\
\hline
\end{tabular}

TABELA 1. Condições cromatográficas (USP, 2012)

Entretanto a metodologia original propõe somente o doseamento dos produtos de degradação ácido benzóico, benzoato de etila e benzaldeído, a partir da relação em área com o pico inerente ao peróxido de benzoíla. Porém durante o desenvolvimento das atividades experimentais, foi proposto o doseamento do peróxido de benzoíla e seus 
produtos de degradação, a partir da mesma corrida analítica, e portanto em função da modificação do propósito do método original, foi necessário sua validação, conforme requisição da $R E$ n`899, de 29 de maio de 2003 - Guia de Validação de Métodos Analíticos, da ANVISA.

Para o desenvolvimento da metodologia proposta foi utilizado um cromatógrafo líquido de alta eficiência (CLAE), modelo 1100 e 1200, fabricante Hewlett Packard ${ }^{\circledR}$ e fornecedor Agilent Technologies ${ }^{\circledR}$.

\section{PREPARO DA FASE MÓVEL}

- Solução A: Acetonitrila grau HPLC:Ácido Acético Glacial [1000:1]

- Solução B: Água Purificada: Ácido Acético Glacial [1000:1]

\section{CROMATOGRAMA CARACTERÍSTICO}

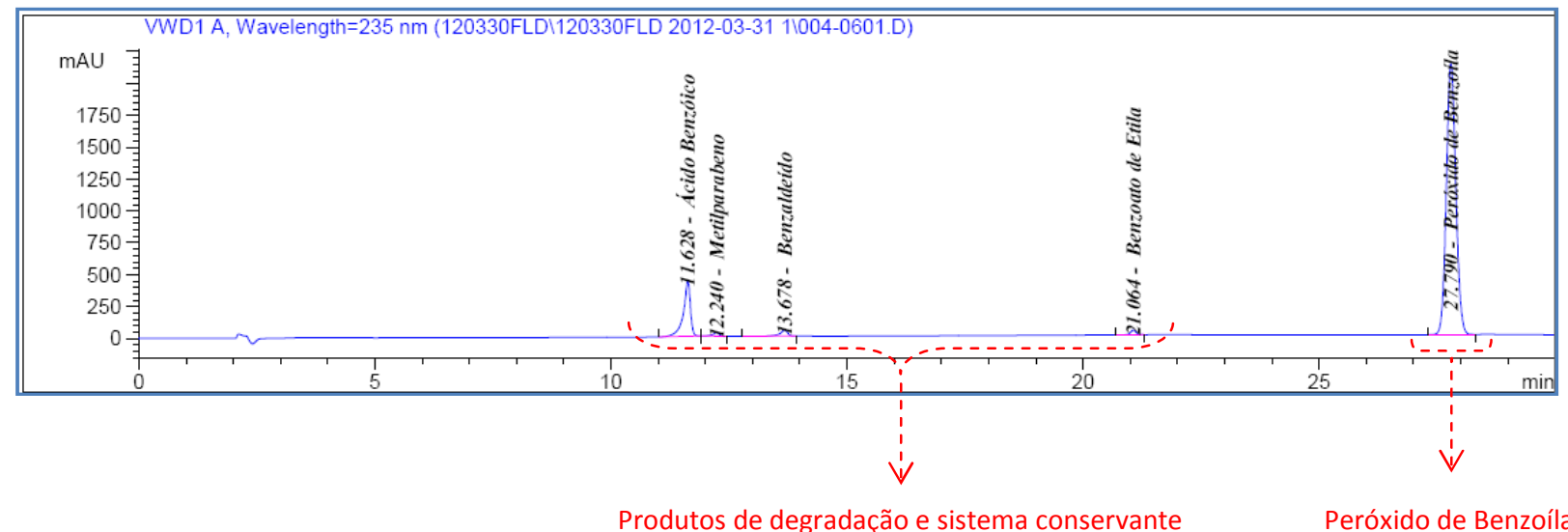

FIGURA 27. Cromatograma da solução de peróxido de benzoíla $0,42375 \mathrm{mg}^{\mathrm{mL}} \mathrm{L}^{-1}$, ácido benzóico $0,10157 \mathrm{mg} \cdot \mathrm{mL}^{-1}$, benzaldeído $0,0051 \mathrm{mg} \cdot \mathrm{mL}^{-1}$, benzoato de etila $0,00548 \mathrm{mg} \cdot \mathrm{mL}^{-1}$ e metilparabeno $0,016 \mathrm{mg} \cdot \mathrm{mL}^{-1}$; Condições: coluna Luna C18 $100 \AA$ (5 $5 \mathrm{~m}$, 250 x 4,6mm), vazão: 1,5mL.min-1, fase móvel: ACN:HÁc (1000:1) e Água:HÁc (1000:1) - gradiente; detecção: 235nm. 


\section{PREPARAÇÃO DA SOLUÇÃO PADRÃO DE ÁCIDO BENZOÍCO}

Pesar 50mg $\pm 1 \mathrm{mg}$ de ácido benzóico padrão em um balão volumétrico âmbar de 50mL. Em seguida adicionar $25 \mathrm{~mL}$ de acetonitrila grau HPLC, e submeter a banho ultrassom durante 5 minutos. Quando finalizado completar o volume com acetonitrila grau HPLC e homogeneizar (SOLUÇÃO A).

\section{PREPARAÇÃO DA SOLUÇÃO PADRÃO DE METILPARABENO}

Pesar $16 \mathrm{mg} \pm 1 \mathrm{mg}$ de metilparabeno padrão em balão volumétrico âmbar de 100 $\mathrm{mL}$. Em seguida adicionar $50 \mathrm{~mL}$ de acetonitrila grau HPLC, e submeter a banho ultrassom durante 5 minutos. Quando finalizado completar o volume com acetonitrila grau HPLC e homogeneizar (SOLUÇÃO B).

\section{PREPARAÇÃO DA SOLUÇÃO PADRÃO DE BENZALDEÍDO E BENZOATO DE ETILA}

Pesar 10mg $\pm 1 \mathrm{mg}$ de benzaldeído e benzoato de etila padrão em balão volumétrico âmbar de $100 \mathrm{~mL}$. Em seguida adicionar $50 \mathrm{~mL}$ de acetonitrila grau HPLC, e submeter a banho ultrassom durante 5 minutos. Quando finalizado completar o volume com acetonitrila grau HPLC e homogeneizar (SOLUÇÃO C). 


\section{PREPARAÇÃO DA SOLUÇÃO PADRÃO DE TRABALHO}

Pesar 28mg $\pm 1 \mathrm{mg}$ do padrão de peróxido de benzoíla padrão em balão volumétrico âmbar de $50 \mathrm{~mL}$. Em seguida adicionar $25 \mathrm{~mL}$ de acetonitrila grau HPLC, e submeter a banho ultrassom durante 5 minutos. Quando finalizado transferir volumetricamente $5 \mathrm{~mL}$ da SOLUÇÃO A, $5 \mathrm{~mL}$ da SOLUÇÃO B e $2 \mathrm{~mL}$ da SOLUÇÃO C, e completar o volume com acetonitrila grau HPLC e homogeneizar. Transferir esta solução diretamente para um vial âmbar.

\section{PREPARAÇÃO DAS SOLUÇÕES AMOSTRAS}

Pesar $525 \mathrm{mg} \pm 25 \mathrm{mg}$ ou $262,5 \mathrm{mg} \pm 25 \mathrm{mg}$ das amostras de peróxido de benzoíla gel 40 e 80 mg/g respectivamente para um balão volumétrico âmbar de $50 \mathrm{~mL}$. Imediatamente adicionar $10 \mathrm{~mL}$ de água purificada e agitar em vortéx ${ }^{\circledR}$ durante 30 segundos. Em seguida adicionar cerca de $30 \mathrm{~mL}$ de acetonitrila grau HPLC e manter a solução amostra em repouso durante 20 minutos e/ou até que re-estabeleça a temperatura ambiente. Logo após completar o volume com acetonitrila grau HPLC e homogeneizar. Filtrar em membrana filtrante PTFE de poro de $0,45 \mu \mathrm{m}$ de diâmetro.

\section{CÁLCULOS}

\section{a) ÁCIDO BENZÓICO}

$$
\frac{A A m \times \text { TeStd } \times 5 \times \text { PStd } \times 50}{A S t d \times 50 \times 50 \times \text { TeAm }} \times 100 \%=\%(p / p) \text { de ácido benzóico }
$$


Onde:

$\boldsymbol{A A m}$ - Área do pico de ácido benzóico na solução amostra;

$\boldsymbol{A S t d}$ - Área do pico de ácido benzóico na solução padrão;

TeStd - Tomada de ensaio do padrão de ácido benzóico (mg);

TeAm - Tomada de ensaio da amostra $(\mathrm{mg})$;

PStd - Fator de pureza do padrão de ácido benzóico;

\section{b) BENZALDEÍDO}

$$
\frac{A A m \times \text { TeStd } \times 2 \times \text { PStd } \times 50}{A S t d \times 100 \times 50 \times \text { TeAm }} \times 100 \%=\%(p / p) \text { de benzaldeído }
$$

Onde:

$\boldsymbol{A A m}$ - Área do pico de benzaldeído na solução amostra;

AStd - Área do pico de benzaldeído na solução padrão;

TeStd - Tomada de ensaio do padrão de benzaldeído (mg);

TeAm - Tomada de ensaio da amostra (mg);

PStd - Fator de pureza do padrão de benzaldeído;

\section{c) BENZOATO DE ETILA}

$$
\frac{A A m \times \text { TeStd } \times 2 \times \text { PStd } \times 50}{A S t d \times 100 \times 50 \times \text { TeAm }} \times 100 \%=\%(p / p) \text { de benzoato de etila }
$$

Onde:

$\boldsymbol{A A m}$ - Área do pico de benzoato de etila na solução amostra;

$\boldsymbol{A S t d}$ - Área do pico de benzoato de etila na solução padrão; 
TeStd - Tomada de ensaio do padrão de benzoato de etila (mg);

TeAm - Tomada de ensaio da amostra $(\mathrm{mg})$;

PStd - Fator de pureza do padrão de benzoato de etila;

d) PERÓXIDO DE BENZOÍLA

$$
\frac{A A m \times \text { TeStd } \times \text { PStd } \times 50}{A S t d \times 50 \times \text { TeAm }} \times 100 \%=\%(p / p) \text { de peróxido de benzoíla }
$$

Onde:

$\boldsymbol{A A m}$ - Área do pico de peróxido de benzoíla na solução amostra;

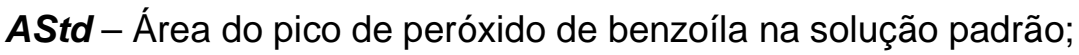

TeStd - Tomada de ensaio do padrão de peróxido de benzoíla (mg);

TeAm - Tomada de ensaio da amostra $(\mathrm{mg})$;

PStd - Fator de Pureza do padrão de peróxido de benzoíla;

\section{e) IMPUREZAS DESCONHECIDAS}

$$
\frac{\text { AImpureza }}{\text { ATotal }} \times 100 \%=\%(p / p) \text { da impureza desconhecida }
$$

Onde:

Almpureza - Área do pico da impureza desconhecida na solução amostra;

ATotal - Somatório da área de todos os picos na solução amostra, incluindo o pico da impureza desconhecida; 


\subsection{MÉTODO DE DOSEAMENTO DE PERÓXIDO DE BENZOÍLA E IDENTIFICAÇÃO DO PRODUTO DE DEGRADAÇÃO GERADO NA FOTÓlISE POR ESPECTROMETRIA DE MASSAS}

O método de teste foi desenvolvido nas dependências do laboratório da Agilent ${ }^{\circledR}$ Technologies, entidade na qual possui parceria técnica com a Faculdade de Ciências Farmacêuticas (FCF), da Universidade de São Paulo.

O método quantitativo foi proposto a partir das transições 260,1>105 e 260,1>78,1, as quais correspondem ao peróxido de benzoíla hidratado, ionizado no modo $\mathrm{ESI}^{+} \mathrm{e}$ fragmentado em seus "'íons filhos" mais abundantes, m/z 105 e m/z 78,1, respectivamente.

As condições cromatográficas propostas estão descritas a seguir:

\begin{tabular}{|c|c|c|}
\hline \multirow{4}{*}{ Condições cromatográficas } & Temperatura da coluna & $40^{\circ} \mathrm{C}$ \\
\hline & Fase móvel & Isocrático [Fase Móvel A / Fase Móvel B (2:8)] \\
\hline & Volume de injeção $(\mu \mathrm{L})$ & 0,20 \\
\hline & Tempo de corrida (min) & 4 \\
\hline \multirow{7}{*}{ Parâmetros do EMassas } & "'Deteç̧ão & Espectrometria de massas \\
\hline & Scan type & MRM \\
\hline & Polaridade & Positiva (+3000 volts) \\
\hline & Q1 (u.m.a) & 260,1 \\
\hline & Q3 (u.m.a) & 105 e 78,1 \\
\hline & Dwell time (mseg) & 200 \\
\hline & CE (volts) & 2 (105 u.m.a) e 6 (78,1 u.m.a) \\
\hline \multirow{4}{*}{ Parâmetros da fonte de ionização } & Técnica de ionização & Electrospray ionization (ESI) \\
\hline & Temperatura gás de secagem $\left({ }^{\circ} \mathrm{C}\right)$ & 250 \\
\hline & Fluxo do gás (L/min) & 10 \\
\hline & Nebulizador (psi) & 50 \\
\hline
\end{tabular}

TABELA 2. Condições experimentais propostas para o método quantitativo por espectrometria de massas 
Para proposição da estrutura molecular do produto de degradação formado o método base utilizado foi o acima descrito, entretanto, as conclusões deste estudo estão descritas no “CAPÍTULO IX - DISCUSSÕES".

\section{*Fase móvel:}

- Fase móvel A: Água purificada aditivada com ácido fórmico 0,1\%;

- Fase Móvel B: Metanol grau HPLC; 


\section{CAPÍTULO VIII - RESULTADOS}

Neste capítulo são descritos os resultados analíticos obtidos durante a validação do método indicativo de estabilidade por cromatografia líquida de alta eficiência, do desenvolvimento do método de doseamento do peróxido de benzoíla por espectrometria de massas além de identificação do produto de degradação gerado durante a fotólise. 


\section{RESULTADOS}

\subsection{IDENTIFICAÇÃO DA MATÉRIA-PRIMA PERÓXIDO DE BENZOÍLA POR}

\section{INFRAVERMELHO MÉDIO}

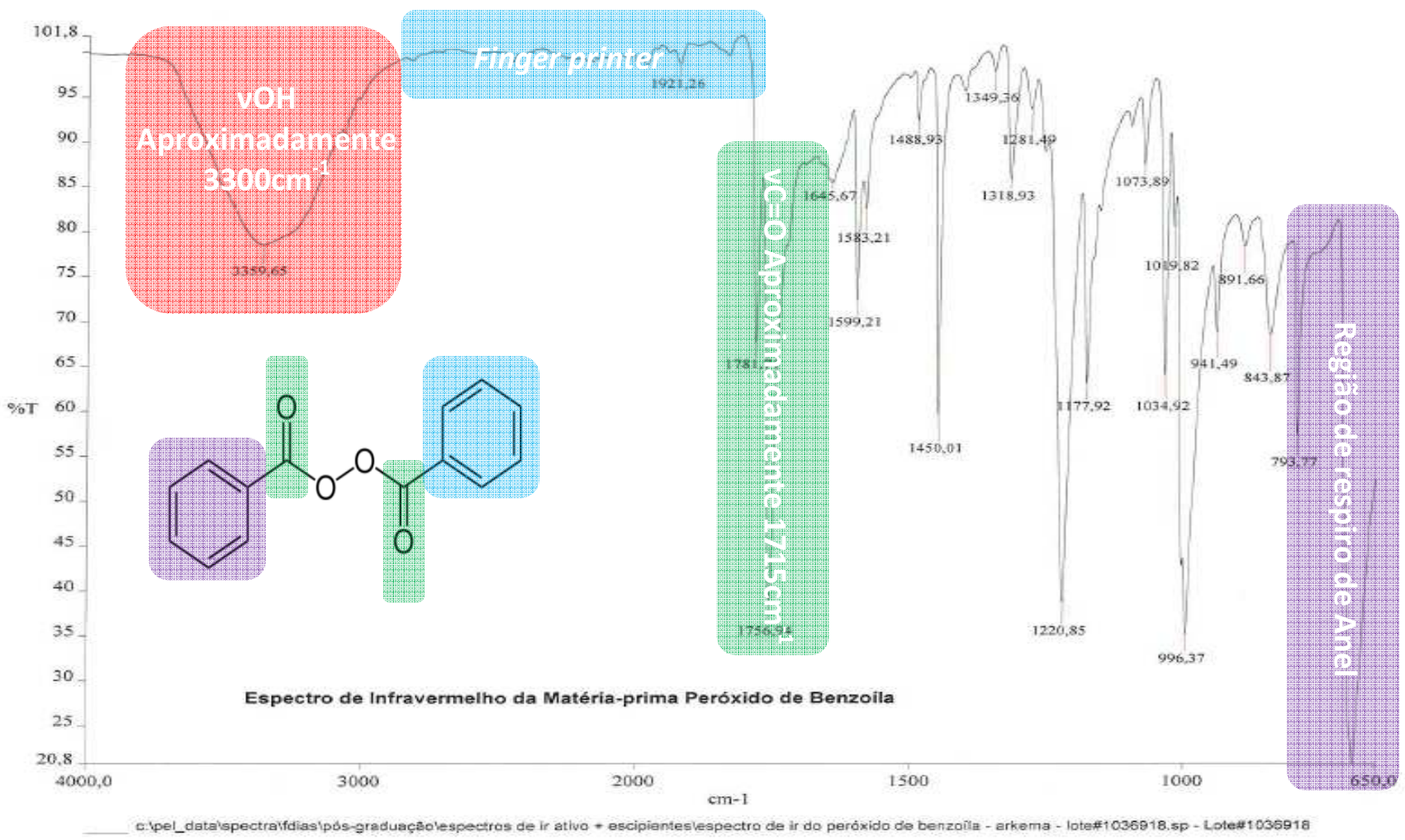

FIGURA 28. Espectro de infravermelho do peróxido benzoíla, em célula ATR. 


\subsection{VALIDAÇÃO DO MÉTODO INDICATIVO DE ESTABILIDADE POR CROMATOGRAFIA LÍQUIDA DE ALTA EFICIÊNCIA}

\subsubsection{LINEARIDADE}

Para avaliação da linearidade da metodologia proposta, foram preparadas amostras em diferentes níveis de concentração utilizando 3 replicatas de cada nível para composição da curva de calibração.

\subsubsection{ESTRATÉGIA ADOTADA PARA REALIZAÇÃO DO ENSAIO DE LINEARIDADE}

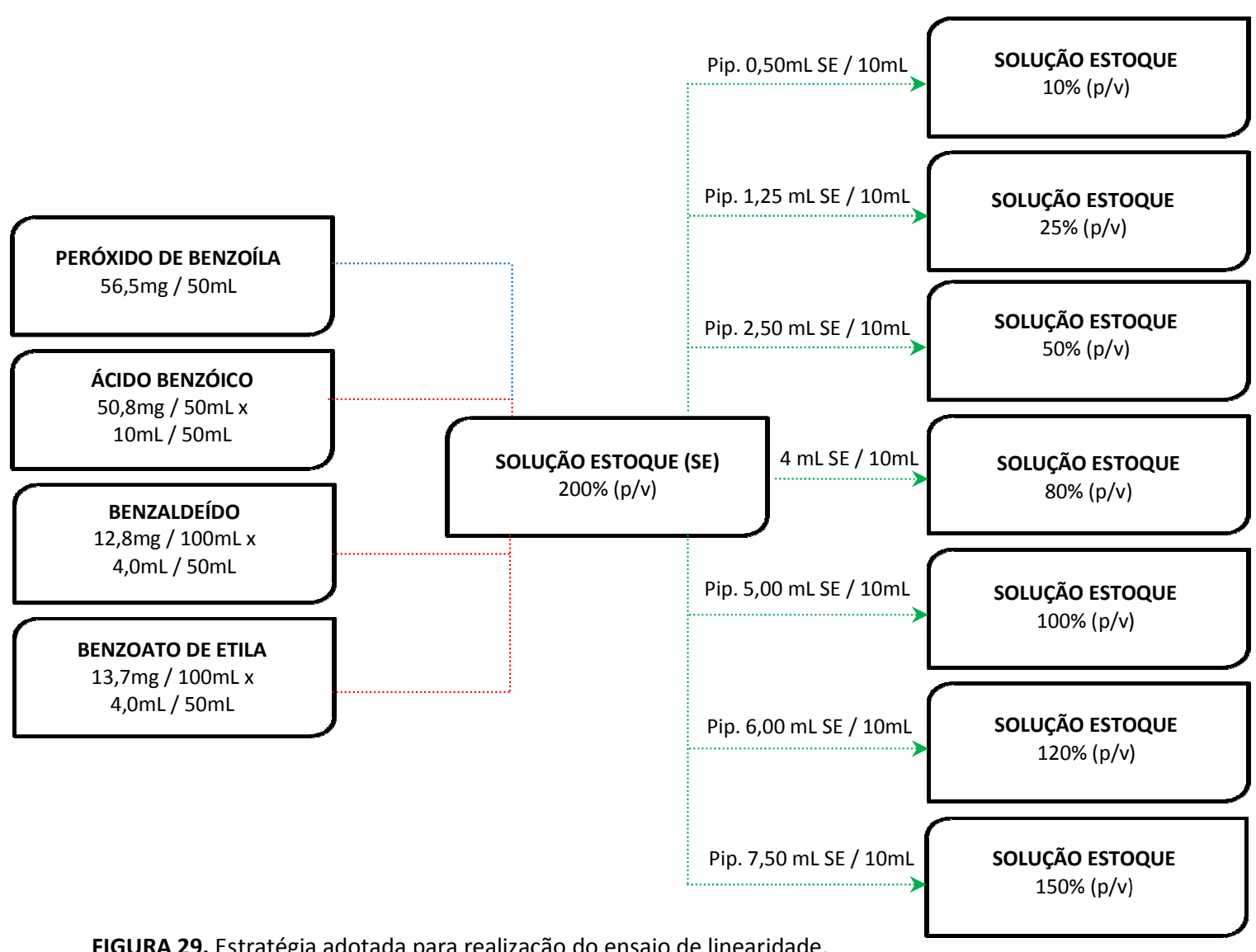




\subsubsection{CRITÉRIOS DE ACEITAÇÃO}

\begin{tabular}{|c|c|c|}
\hline Tipo de Ensaio & Coeficiente de correlação & Intercepto $Y$ \\
\hline Teor & $R \geq 0,9997$ (ou $R^{2} \geq 0,999$ ) & $\leq 2,0 \%$ relativo $^{*}$ \\
Quantificação de impurezas & $R \geq 0,995$ (ou $R^{2} \geq 0,990$ ) & $\leq 20,0 \%$ relativo $^{*}$ \\
\hline
\end{tabular}

'Relativo à resposta do pico na concentração nominal da metodologia

QUADRO 6. Critérios de aceitação linearidade

\subsubsection{RESULTADOS OBTIDOS NO ENSAIO DE LINEARIDADE}

\subsubsection{1. ÁCIDO BENZÓICO}

a) PREPARO dAS SOLUÇÕES PADRÕES

\begin{tabular}{ccc}
\hline Concentração & Preparação / Diluição & Concentração Teórica $(\mu \mathrm{g} / \mathrm{mL})$ \\
\hline $25 \%(\mathrm{p} / \mathrm{v})$ & Pipetar 1,25mL da Sol. Estoque / 10mL & 0,025 \\
$50 \%(\mathrm{p} / \mathrm{v})$ & Pipetar 2,5mL da Sol. Estoque / 10mL & 0,050 \\
$80 \%(\mathrm{p} / \mathrm{v})$ & Pipetar 4,0 $\mathrm{mL}$ da Sol. Estoque / 10mL & 0,081 \\
$100 \%(\mathrm{p} / \mathrm{v})$ & Pipetar 5,0mL da Sol. Estoque / 10mL & 0,101 \\
$120 \%(\mathrm{p} / \mathrm{v})$ & Pipetar 6,0mL da Sol. Estoque / 10mL & 0,121 \\
$150 \%(\mathrm{p} / \mathrm{v})$ & Pipetar 7,5mL da Sol. Estoque / 10mL & 0,152 \\
Solução Estoque - 200\%(p/v) & $50,8 \mathrm{mg} / 50 \mathrm{~mL} \times 10 \mathrm{~mL} / 50 \mathrm{~mL}$ & 0,203 \\
\hline
\end{tabular}

TABELA 3. Ácido Benzóico: Preparo das soluções padrões - Linearidade

b) VALORES DE ÁREA OBTIDOS PARA ÁCIDO BENZÓICO

\begin{tabular}{|c|c|c|c|c|c|}
\hline Concentração & $\begin{array}{c}\text { Área } \\
\text { 1a Injeção } \\
\text { (mAU) }\end{array}$ & $\begin{array}{c}\text { Área } \\
\text { 2a Injeção } \\
\text { (mAU) }\end{array}$ & $\begin{array}{c}\text { Área } \\
\text { 3a Injeção } \\
\text { (mAU) }\end{array}$ & $\begin{array}{l}\text { Área Média } \\
\text { (mAU) }\end{array}$ & DPR (\%) \\
\hline $25 \%(p / v)$ & 1124,35 & 1125,99 & 1121,24 & 1123,86 & 0,21 \\
\hline $50 \%(p / v)$ & 2305,81 & 2256,41 & 2267,23 & 2276,49 & 1,14 \\
\hline $80 \%(p / v)$ & 3458,66 & 3637,25 & 3630,78 & 3575,56 & 2,83 \\
\hline $100 \%(p / v)$ & 4526,34 & 4554,21 & 4530,76 & 4537,10 & 0,33 \\
\hline $120 \%(p / v)$ & 5438,18 & 5415,17 & 5464,85 & 5439,40 & 0,46 \\
\hline $150 \%(p / v)$ & 6829,46 & 6794,58 & 6836,49 & 6820,18 & 0,27 \\
\hline $200 \%(p / v)$ & 8883,04 & 9002,44 & 9098,55 & 8994,68 & 1,20 \\
\hline
\end{tabular}

TABELA 4. Ácido Benzóico: Valores de área obtidos - Linearidade 


\section{c) CURVA DE CALIBRAÇÃO ÁCIDO BENZÓICO}

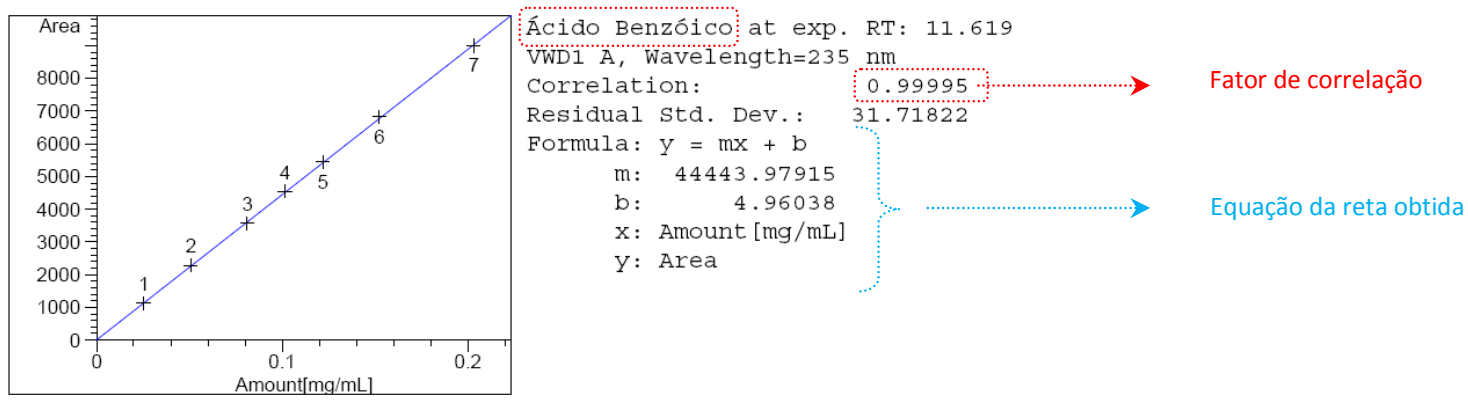

FIGURA 30. Ácido benzóico - Curva de calibração

\subsubsection{BENZALDEÍDO}

a) PREPARO DAS SOLUÇÕES PADRÕES

\begin{tabular}{|c|c|c|}
\hline Concentração & Preparação / Diluições & Concentração Teórica $(\mu \mathrm{g} / \mathrm{mL})$ \\
\hline $25 \%(p / v)$ & Pipetar $1,25 \mathrm{~mL}$ da Sol. Estoque / 10mL & 0,001 \\
\hline $50 \%(p / v)$ & Pipetar 5,0mL da Sol. $100 \%(p / v) / 10 m L$ & 0,002 \\
\hline $75 \%(p / v)$ & Pipetar 5,0mL da Sol. $150 \%(\mathrm{p} / \mathrm{v}) / 10 \mathrm{~mL}$ & 0,003 \\
\hline $80 \%(p / v)$ & Pipetar 4,0mL da Sol. Estoque / 10mL & 0,004 \\
\hline $100 \%(p / v)$ & Pipetar 5,0mL da Sol. Estoque / $10 \mathrm{~mL}$ & 0,005 \\
\hline $120 \%(p / v)$ & Pipetar $6,0 \mathrm{~mL}$ da Sol. Estoque / $10 \mathrm{~mL}$ & 0,006 \\
\hline $150 \%(p / v)$ & Pipetar 7,5mL da Sol. Estoque / $10 \mathrm{~mL}$ & 0,007 \\
\hline Solução Estoque - 200\% (p/v) & $12,8 \mathrm{mg} / 100 \mathrm{~mL} \times 4,0 \mathrm{~mL} / 50 \mathrm{~mL}$ & 0,010 \\
\hline
\end{tabular}

TABELA 5. Benzaldeído: Preparo das soluções padrões - Linearidade

b) VALORES DE ÁREA OBTIDOS PARA O BENZALDEÍDO

\begin{tabular}{|c|c|c|c|c|c|}
\hline Concentração & $\begin{array}{c}\text { Área } \\
\text { 1a Injeção } \\
\text { (mAU) }\end{array}$ & $\begin{array}{c}\text { Área } \\
\text { 2a Injeção } \\
\text { (mAU) }\end{array}$ & $\begin{array}{c}\text { Área } \\
\text { 3a Injeção } \\
\text { (mAU) }\end{array}$ & $\begin{array}{c}\text { Área Média } \\
\text { (mAU) }\end{array}$ & DPR (\%) \\
\hline $25 \%(p / v)$ & 56,56 & 44,83 & 51,70 & 51,03 & 11,55 \\
\hline $50 \%(p / v)$ & 109,95 & 107,43 & 112,39 & 109,92 & 2,25 \\
\hline $75 \%(p / v)$ & 165,20 & 159,56 & 162,46 & 162,40 & 1,74 \\
\hline $80 \%(p / v)$ & 173,84 & 171,59 & 168,75 & 171,39 & 1,49 \\
\hline $100 \%(p / v)$ & 214,11 & 216,92 & 216,18 & 215,73 & 0,68 \\
\hline $120 \%(p / v)$ & 252,49 & 254,60 & 250,45 & 252,51 & 0,82 \\
\hline $150 \%(p / v)$ & 318,51 & 332,09 & 322,75 & 324,45 & 2,14 \\
\hline $200 \%(p / v)$ & 428,86 & 411,72 & 414,86 & 418,48 & 2,18 \\
\hline
\end{tabular}

TABELA 6. Benzaldeído: Valores de área obtidos - Linearidade 


\section{c) CURVA DE CALIBRAÇÃO BENZALDEÍDO}

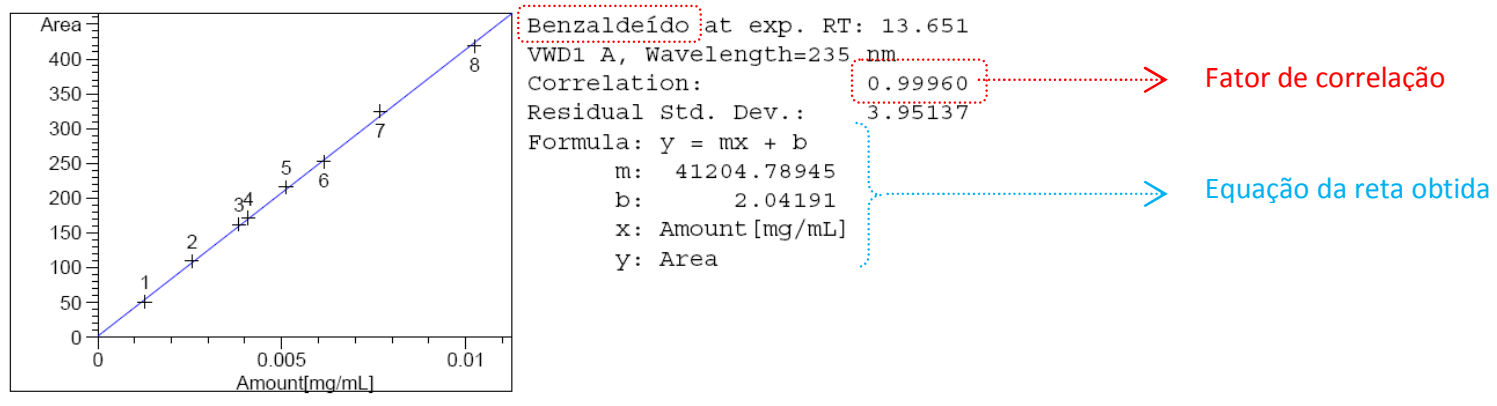

FIGURA 31. Benzaldeído - Curva de calibração

\subsubsection{BENZOATO DE ETILA}

a) PREPARO DAS SOLUÇÕES PADRÕES

\begin{tabular}{ccc}
\hline Concentração & Preparação / Diluições & Concentração teórica $(\mu \mathrm{g} / \mathrm{mL})$ \\
\hline $25 \%(p / v)$ & Pipetar 1,25mL da Sol. Estoque / 10mL & 0,001 \\
$50 \%(p / v)$ & Pipetar 5,0mL da Sol. 100\%(p/v) / 10mL & 0,002 \\
$75 \%(p / v)$ & Pipetar 5,0mL da Sol. $150 \%(p / v) / 10 \mathrm{~mL}$ & 0,004 \\
$80 \%(p / v)$ & Pipetar 4,0mL da Sol. Estoque / 10mL & 0,004 \\
$100 \%(p / v)$ & Pipetar 5,0mL da Sol. Estoque / 10mL & 0,005 \\
$120 \%(p / v)$ & Pipetar 6,0mL da Sol. Estoque / 10mL & 0,006 \\
$150 \%(p / v)$ & Pipetar 7,5mL da Sol. Estoque / 10mL & 0,008 \\
Solução Estoque - 200\% $(p / v)$ & $13,7 m g / 100 \mathrm{~mL} \times 4,0 \mathrm{~mL} / 50 \mathrm{~mL}$ & 0,010 \\
\hline
\end{tabular}

TABELA 7. Benzoato de Etila: Preparo das soluções padrões - Linearidade

b) VALORES DE ÁREA OBTIDOS PARA BENZOATO DE ETILA

\begin{tabular}{|c|c|c|c|c|c|}
\hline Concentração & $\begin{array}{c}\text { Área } \\
\text { 1a Injeção } \\
\text { (mAU) }\end{array}$ & $\begin{array}{c}\text { Área } \\
\text { 2a Injeção } \\
\text { (mAU) }\end{array}$ & $\begin{array}{c}\text { Área } \\
\text { 3a Injeção } \\
\text { (mAU) }\end{array}$ & $\begin{array}{l}\text { Área Média } \\
\text { (mAU) }\end{array}$ & DPR (\%) \\
\hline $25 \%(p / v)$ & 55,72 & 51,56 & 53,95 & 53,75 & 3,88 \\
\hline $50 \%(p / v)$ & 110,30 & 110,40 & 108,16 & 109,62 & 1,16 \\
\hline $75 \%(p / v)$ & 161,52 & 162,32 & 164,89 & 162,91 & 1,08 \\
\hline $80 \%(p / v)$ & 172,47 & 176,28 & 175,80 & 174,85 & 1,19 \\
\hline $100 \%(p / v)$ & 220,35 & 214,81 & 214,15 & 216,44 & 1,57 \\
\hline $120 \%(p / v)$ & 254,75 & 260,21 & 257,45 & 257,47 & 1,06 \\
\hline $150 \%(p / v)$ & 323,69 & 323,99 & 325,16 & 324,28 & 0,24 \\
\hline $200 \%(p / v)$ & 425,98 & 430,58 & 436,57 & 431,04 & 1,23 \\
\hline
\end{tabular}

TABELA 8. Benzoato de etila: Valores de área obtidos - Linearidade 


\section{c) CURVA DE CALIBRAÇÃO BENZOATO DE ETILA}

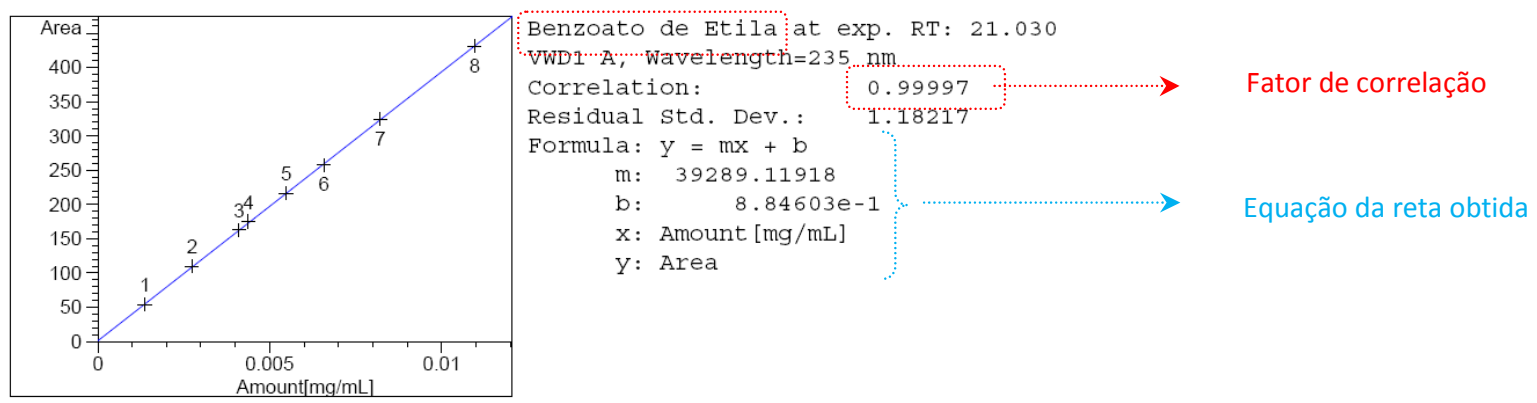

FIGURA 32. Benzoato de etila - Curva de calibração

\subsubsection{PERÓXIDO DE BENZOÍLA}

a) PREPARO DAS SOLUÇÕES PADRÕES

\begin{tabular}{ccc}
\hline Concentração & Preparação / Diluições & Concentração teórica $(\mu \mathrm{g} / \mathrm{mL})$ \\
\hline $10 \%(p / v)$ & Pipetar 0,5mL da Sol. Estoque / 10mL & 0,042 \\
$25 \%(p / v)$ & Pipetar 1,25mL da Sol. Estoque / 10mL & 0,105 \\
$50 \%(p / v)$ & Pipetar 2,5mL da Sol. Estoque / 10mL & 0,211 \\
$75 \%(p / v)$ & Pipetar 3,75mL da Sol. Estoque / 10mL & 0,317 \\
$100 \%(p / v)$ & Pipetar 5mL da Sol. Estoque / 10mL & 0,423 \\
$125 \%(p / v)$ & Pipetar 6,25mL da Sol. Estoque / 10mL & 0,529 \\
$150 \%(p / v)$ & Pipetar 7,5mL da Sol. Estoque / 10mL & 0,635 \\
Solução Estoque - 200\% (p/v) & $56,5 \mathrm{mg} / 50 \mathrm{~mL}$ & 0,847 \\
\hline
\end{tabular}

TABELA 9. Peróxido de Benzoíla: Preparo das soluções padrões - Linearidade

b) VALORES DE ÁREA OBTIDOS PARA PERÓXIDO DE BENZOÍLA

\begin{tabular}{|c|c|c|c|c|c|}
\hline Concentração & $\begin{array}{c}\text { Área } \\
\text { 1a Injeção } \\
\text { (mAU) }\end{array}$ & $\begin{array}{c}\text { Área } \\
\text { 2a Injeção } \\
\text { (mAU) }\end{array}$ & $\begin{array}{c}\text { Área } \\
\text { 3å Injeção } \\
\text { (mAU) }\end{array}$ & $\begin{array}{c}\text { Área Média } \\
\text { (mAU) }\end{array}$ & DPR (\%) \\
\hline $10 \%(p / v)$ & 2942,89 & 2991,68 & 2966,17 & 2966,17 & 0,82 \\
\hline $25 \%(p / v)$ & 7476,34 & 7534,37 & 7492,05 & 7500,92 & 0,40 \\
\hline $50 \%(p / v)$ & 15089,40 & 15170,20 & 15108,10 & 15122,57 & 0,28 \\
\hline $75 \%(p / v)$ & 22328,00 & 22688,20 & 22741,70 & 22585,97 & 1,00 \\
\hline $100 \%(p / v)$ & 30138,50 & 30299,20 & 30658,30 & 30365,33 & 0,88 \\
\hline $125 \%(p / v)$ & 37194,40 & 37749,80 & 37549,60 & 37497,93 & 0,75 \\
\hline $150 \%(p / v)$ & 43539,60 & 43674,70 & 43659,50 & 43624,60 & 0,17 \\
\hline $200 \%(p / v)$ & 53186,90 & 53566,40 & 53609,40 & 53454,23 & 0,43 \\
\hline
\end{tabular}

TABELA 10. Peróxido de benzoíla: Valores de área obtidos - Linearidade 


\section{c) CURVA DE CALIBRAÇÃO PERÓXIDO DE BENZOÍLA}

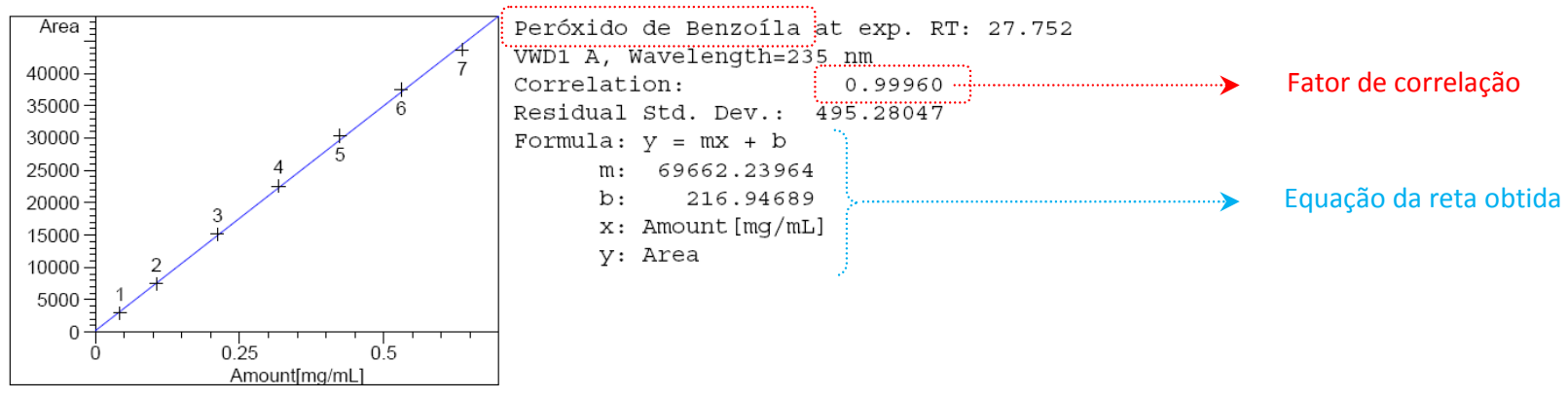

FIGURA 33. Peróxido de benzoíla - Curva de calibração 


\subsection{PRECISÃO}

A repetibilidade do método é avaliada por, no mínimo 9 determinações, contemplando seu intervalo linear, ou seja, 3 concentrações baixa, média e alta, com 3 replicatas ou no mínimo 6 determinações a 100\% da concentração do ensaio (BRASIL, 2003).

O ensaio de repetibilidade foi realizado a partir de 6 determinações das soluções amostra de Peróxido de Benzoíla Gel 40 e $80 \mathrm{mg} / \mathrm{g}$, preparadas conforme o item "PREPARAÇÃO DAS SOLUÇÕES AMOSTRA".

\subsubsection{ESTRATÉGIA ADOTADA PARA REALIZAÇÃO DO ENSAIO DE PRECISÃO}

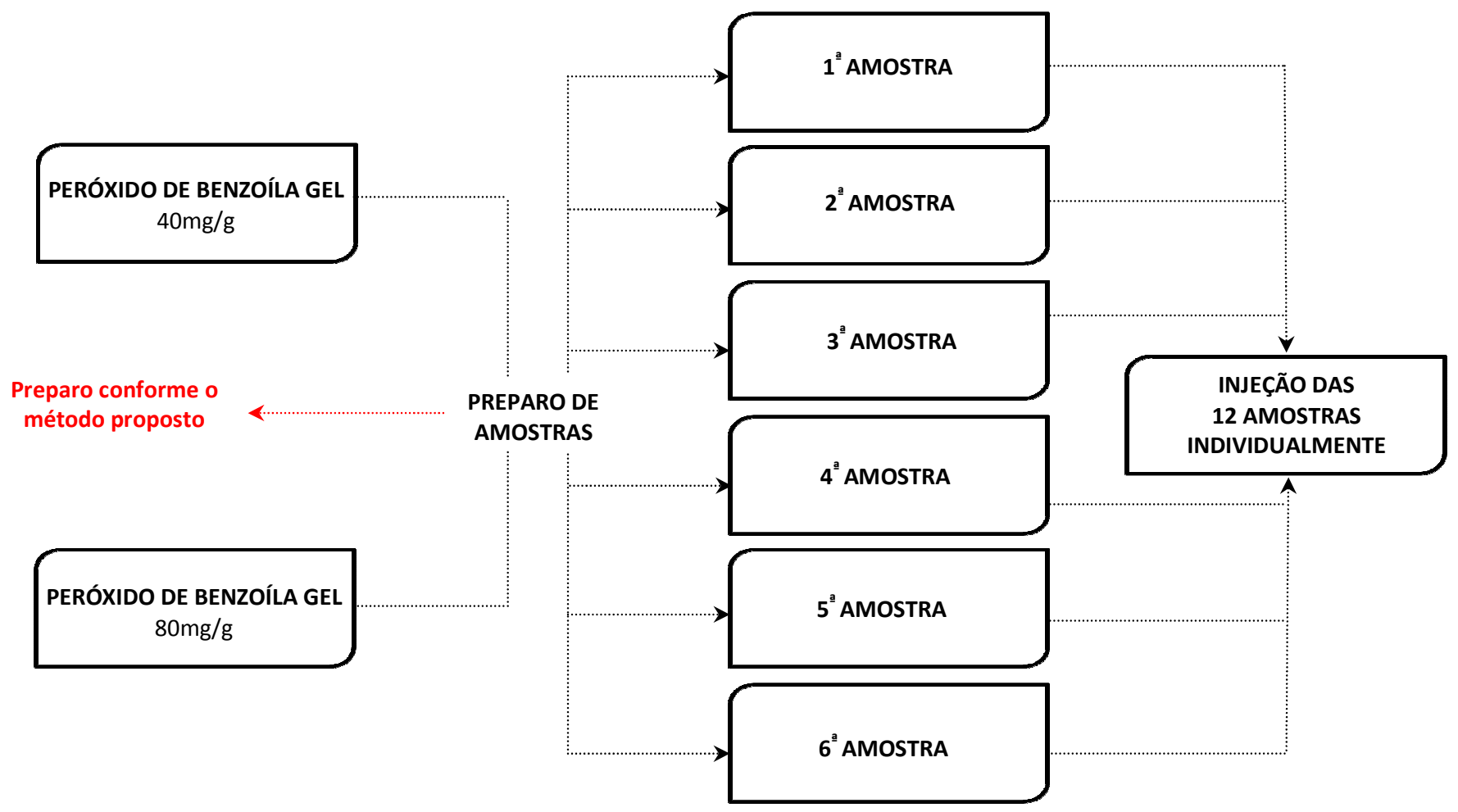

FIGURA 34. Estratégia adotada para realização do ensaio de precisão 


\subsubsection{CRITÉRIOS DE ACEITAÇÃO}

A precisão de um método analítico pode ser expressa como o desvio padrão relativo (coeficiente de variação) de uma série de medidas (BRASIL 2003).

A precisão expressa como desvio padrão relativo ou coeficiente de variação, é determinado segundo a fórmula a seguir:

$$
\frac{D P}{C M D} \times 100=D P R
$$

Onde:

DP - Desvio padrão (\%);

CMD - Concentração média do analito determinado (\%);

DPR - Desvio padrão relativo (\%);

O valor máximo aceitável deve ser definido de acordo com a metodologia empregada, a concentração do analito na amostra, o tipo de matriz e a finalidade do método, não sendo admitido valores superiores a 5\% (BRASIL, 2003).

O desvio padrão relativo (DPR) entre as 6 determinações para peróxido de benzoíla deve ser $\leq 2,0 \%$. Já o desvio padrão relativo entre as 6 determinações para as impurezas conhecidas deve ser $\leq 20,0 \%$. 


\subsubsection{RESULTADOS OBTIDOS NO ENSAIO DE PRECISÃO}

\section{A) PERÓXIDO DE BENZOÍLA GEL 40mg/g}

\begin{tabular}{|c|c|}
\hline \multicolumn{2}{|c|}{ ÁCIDO BENZÓICO } \\
\hline Amostra & $\%(p / p)$ \\
\hline 1 & 0,11801 \\
\hline 2 & 0,109919 \\
\hline 3 & 0,112284 \\
\hline 4 & 0,113027 \\
\hline 5 & 0,111603 \\
\hline 6 & 0,112645 \\
\hline Média [\% (p/p)] & 0,113 \\
\hline Desv. Pad(\%) & 0,00 \\
\hline DPR (\%) & 2,41 \\
\hline
\end{tabular}

\begin{tabular}{|c|c|}
\hline \multicolumn{2}{|c|}{ BENZALDEÍDO } \\
\hline Amostra & $\%(p / p)$ \\
\hline 1. & ND \\
\hline 2 & ND \\
\hline 3 & ND \\
\hline 4 & ND \\
\hline 5 & ND \\
\hline 6 & ND \\
\hline Média [\%(p/p)] & NA \\
\hline Desv. Pad (\%) & NA \\
\hline DPR (\%) & NA \\
\hline
\end{tabular}

\section{BENZOATO DE ETILA}

\begin{tabular}{|c|c|}
\hline Amostra & $\%(p / p)$ \\
\hline 1 & ND \\
\hline 2 & ND \\
\hline 3 & ND \\
\hline 4 & ND \\
\hline 5 & ND \\
\hline 6 & ND \\
\hline Média [\% (p/p)] & NA \\
\hline Desv. Pad (\%) & NA \\
\hline DPR (\%) & NA \\
\hline
\end{tabular}

PERÓXIDO DE BENZOÍLA

\begin{tabular}{cc}
\hline Amostra & $\%(p / p)$ \\
\hline 1 & 4,204419 \\
\hline 2 & 4,174606 \\
\hline 3 & 4,181350 \\
\hline 4 & 4,188159 \\
\hline 6 & 4,232470 \\
\hline Média [\% (p/p)] & 4,300602 \\
\hline Desv. Pad (\%) & 4,213 \\
\hline DPR (\%) & 0,05 \\
\hline
\end{tabular}

Legenda: DPR - Desvio padrão relativo

ND - Não detectado

NA - Não se aplica

\section{B) PERÓXIDO DE BENZOÍLA GEL 80mg/g}

\section{ÁCIDO BENZÓıCO}

\begin{tabular}{cc}
\hline Amostra & $\%$ (p/p) \\
\hline 1 & 0,344592 \\
2 & 0,351401 \\
3 & 0,352056 \\
4 & 0,356248 \\
5 & 0,356632 \\
6 & 0,350359 \\
\hline Média [\% (p/p)] & 0,352 \\
\hline Desv. Pad (\%) & 0,00 \\
\hline DPR (\%) & 1,27 \\
\hline
\end{tabular}

BENZALDEÍDO

\begin{tabular}{cc}
\hline Amostra & $\%(p / p)$ \\
\hline 1 & ND \\
\hline 2 & ND \\
\hline 3 & $N D$ \\
\hline Média [\% (p/p)] & ND \\
\hline Desv. Pad (\%) & NA \\
\hline DPR (\%) & NA \\
\hline
\end{tabular}




\begin{tabular}{cc}
\multicolumn{2}{c}{ BENZOATO DE ETILA } \\
\hline Amostra & \% (p/p) \\
\hline 1 & ND \\
\hline 2 & $N D$ \\
\hline 4 & $N D$ \\
\hline 5 & $N D$ \\
\hline Média [\% (p/p)] & ND \\
\hline Desv. Pad(\%) & NA \\
\hline DPR (\%) & NA \\
\hline
\end{tabular}

TABELA 11. Peróxido de benzoíla gel 40mg/g e $80 \mathrm{mg} / \mathrm{g}$ - Precisão

\begin{tabular}{cc}
\multicolumn{2}{c}{ PERÓXIDO DE BENZOÍLA } \\
\hline Amostra & $\%$ (p/p) \\
\hline 1 & 7,874090 \\
\hline 3 & 7,831262 \\
\hline 4 & 7,815658 \\
\hline 5 & 7,823937 \\
\hline Média [\% (p/p)] & 7,889459 \\
\hline Desv. Pad(\%) & 7,854248 \\
\hline DPR (\%) & 7,848 \\
\hline
\end{tabular}

Legenda: DPR - Desvio padrão relativo ND - Não detectado NA - Não se aplica 


\subsection{EXATIDÃO}

Foram avaliados placebos contaminados nas concentrações $50 \%$, $100 \%$ e $\mathbf{1 5 0} \%$ em relação à concentração proposta na metodologia para a substância ativa peróxido de benzoíla e seus produtos de degradação ácido benzóico, benzoato de etila e benzaldeído.

\subsubsection{ESTRATÉGIA ADOTADA PARA REALIZAÇÃO DO ENSAIO DE EXATIDÃO}

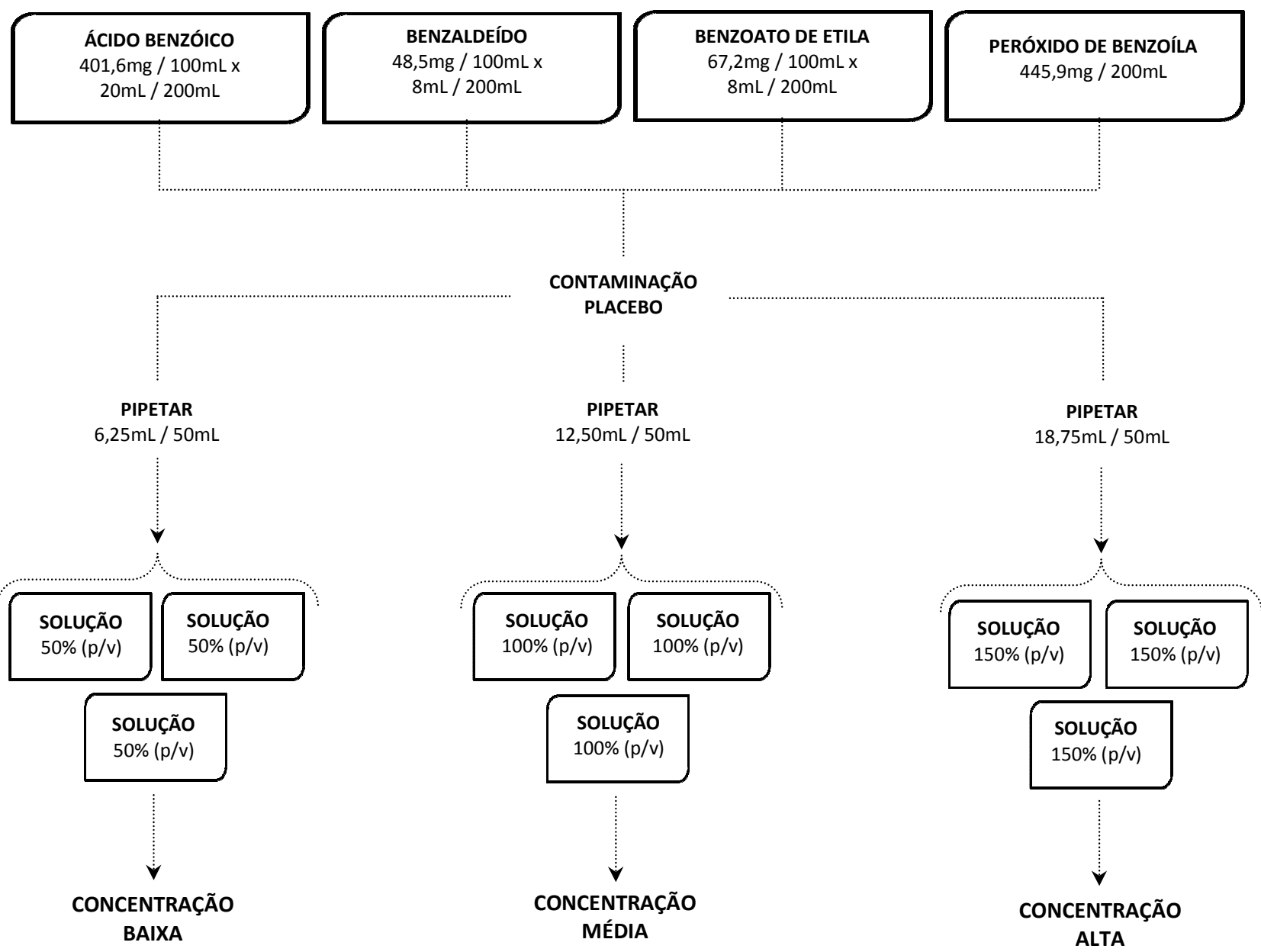

FIGURA 35. Estratégia adotada para realização do ensaio de exatidão 


\subsubsection{CRITÉRIOS DE ACEITAÇÃO}

A exatidão é calculada como a porcentagem de recuperação da quantidade conhecida do analito adicionada ao placebo (BRASIL, 2003).

\begin{tabular}{|c|c|}
\hline Analito & Faixa de Recuperação \\
\hline Substância Ativa & $98,00-102,00 \%$ \\
\hline Produtos de Degradação & $90,00-110,00 \%$ \\
\hline
\end{tabular}

QUADRO 7. Critérios de aceitação para o ensaio de exatidão (BRASIL, 2003)

\subsubsection{RESULTADOS OBTIDOS NO ENSAIO DE EXATIDÃO}

\subsubsection{1. ÁCIDO BENZÓICO}

a) PREPARO DAS SOLUÇÕES AMOSTRAS

\begin{tabular}{|c|c|c|}
\hline Concentração & Preparação / Diluições & Concentração teórica $(\mathrm{mg} / \mathrm{mL})$ \\
\hline Solução Estoque - Sol. $400 \%(p / v)$ & $401,6 \mathrm{mg} / 100 \mathrm{~mL} \times 20 \mathrm{~mL} / 200 \mathrm{~mL}$ & 0,401 \\
\hline Solução $50 \%(p / v)$ & $6,25 \mathrm{~mL}$ Sol. Estoque / $50 \mathrm{~mL}$ & 0,050 \\
\hline Solução $100 \%$ (p/v) & $12,50 \mathrm{~mL}$ Sol. Estoque / $50 \mathrm{~mL}$ & 0,100 \\
\hline Solução $150 \%$ (p/v) & $18,75 \mathrm{~mL}$ Sol. Estoque $/ 50 \mathrm{~mL}$ & 0,150 \\
\hline
\end{tabular}

TABELA 12. Ácido benzóico: Preparo das soluções amostras - Exatidão

b) VALORES DE RECUPERAÇÃO OBTIDOS

\begin{tabular}{cccccc}
\hline Concentração & $\begin{array}{c}\text { Recuperação (\%) } \\
\text { 1a Injeção }\end{array}$ & $\begin{array}{c}\text { Recuperação (\%) } \\
\text { 2a Injeção }\end{array}$ & $\begin{array}{c}\text { Recuperação (\%) } \\
\text { 3a Injeção }\end{array}$ & $\begin{array}{c}\text { Recuperação (\%) } \\
\text { Média }\end{array}$ & DPR (\%) \\
\hline Solução $\mathbf{5 0 \% ~ ( p / v ) ~}$ & 108,46 & 109,62 & 109,54 & $\mathbf{1 0 9 , 2 1}$ & 0,592 \\
Solução $\mathbf{1 0 0 \% ~ ( p / v ) ~}$ & 107,42 & 107,34 & 109,56 & $\mathbf{1 0 8 , 1 1}$ & 1,167 \\
Solução 150\% (p/v) & 108,27 & 108,74 & 109,037 & $\mathbf{1 0 8 , 6 8}$ & 0,353 \\
\hline
\end{tabular}

TABELA 13. Ácido benzóico: Valores de recuperação obtidos - Exatidão 


\subsubsection{BENZOATO DE ETILA}

a) PREPARO DAS SOLUÇÕES DAS AMOSTRAS

\begin{tabular}{|c|c|c|}
\hline Concentração & Preparação / Diluições & Concentração teórica $(\mathrm{mg} / \mathrm{mL})$ \\
\hline Solução Estoque - Sol. $400 \%$ (p/v) & $67,2 \mathrm{mg} / 100 \mathrm{~mL} \times 8 \mathrm{~mL} / 200 \mathrm{~mL}$ & 0,02688 \\
\hline Solução 50\% (p/v) & $6,25 \mathrm{~mL}$ Sol. Estoque / 50mL & 0,00336 \\
\hline Solução $100 \%(p / v)$ & $12,50 \mathrm{~mL}$ Sol. Estoque / $50 \mathrm{~mL}$ & 0,00672 \\
\hline Solução 150\% (p/v) & $18,75 \mathrm{~mL}$ Sol. Estoque / $50 \mathrm{~mL}$ & 0,01008 \\
\hline
\end{tabular}

TABELA 14. Benzoato de etila: Preparo das soluções amostras - Exatidão

b) VALORES DE RECUPERAÇÃO OBTIDOS

\begin{tabular}{cccccc}
\hline Concentração & $\begin{array}{c}\text { Recuperação (\%) } \\
\text { 1a Injeção }\end{array}$ & $\begin{array}{c}\text { Recuperação (\%) } \\
\text { 2a Injeção }\end{array}$ & $\begin{array}{c}\text { Recuperação (\%) } \\
\text { 3a Injeção }\end{array}$ & $\begin{array}{c}\text { Recuperação (\%) } \\
\text { Média }\end{array}$ & DPR (\%) \\
\hline Solução $\mathbf{5 0 \% ~ ( p / v ) ~}$ & 105,32 & 108,33 & 107,69 & $\mathbf{1 0 7 , 1 1}$ & 1,481 \\
Solução $\mathbf{1 0 0 \% ~ ( p / v ) ~}$ & 105,80 & 105,88 & 108,06 & $\mathbf{1 0 6 , 5 8}$ & 1,202 \\
Solução $\mathbf{1 5 0 \%}(\mathbf{p} / \mathrm{v})$ & 106,26 & 106,12 & 106,56 & $\mathbf{1 0 6 , 3 2}$ & 0,209 \\
\hline
\end{tabular}

DPR - Desvio padrão relativo

TABELA 15. Benzoato de etila: Valores de recuperação obtidos - Exatidão

\subsubsection{BENZALDEÍDO}

a) PREPARO DE SOLUÇÕES DAS AMOSTRAS

\begin{tabular}{ccc}
\hline Concentração & Preparações / Diluições & Concentração teórica (mg/mL) \\
\hline Sol. Estoque - Sol. $\mathbf{4 0 0 \%}(\mathrm{p} / \mathrm{v})$ & $48,5 \mathrm{mg} / \mathrm{mL} \times \mathbf{8 m L} / 200 \mathrm{~mL}$ & $\mathbf{0 , 0 1 9}$ \\
Solução $\mathbf{5 0 \%}(\mathrm{p} / \mathrm{v})$ & $6,25 \mathrm{~mL}$ Sol. Estoque / $50 \mathrm{~mL}$ & $\mathbf{0 , 0 0 2}$ \\
Solução $\mathbf{1 0 0 \%}(\mathrm{p} / \mathrm{v})$ & $12,50 \mathrm{~mL}$ Sol. Estoque / $50 \mathrm{~mL}$ & $\mathbf{0 , 0 0 4}$ \\
Solução $\mathbf{1 5 0 \%}(\mathrm{p} / \mathrm{v})$ & $18,75 \mathrm{~mL}$ Sol. Estoque / $50 \mathrm{~mL}$ & $\mathbf{0 , 0 0 7}$ \\
\hline
\end{tabular}

TABELA 16. Benzaldeído: Preparo de soluções amostras - Exatidão 


\section{b) VALORES DE RECUPERAÇÃO PARA OBTIDOS}

\begin{tabular}{cccccc}
\hline Concentração & $\begin{array}{c}\text { Recuperação (\%) } \\
\text { 1a Injeção }\end{array}$ & $\begin{array}{c}\text { Recuperação (\%) } \\
\text { 2a Injeção }\end{array}$ & $\begin{array}{c}\text { Recuperação (\%) } \\
\text { 3a Injeção }\end{array}$ & $\begin{array}{c}\text { Recuperação (\%) } \\
\text { Média }\end{array}$ & DRP (\%) \\
\hline Solução $\mathbf{5 0 \% ~ ( p / v ) ~}$ & 102,34 & 99,95 & 102,82 & $\mathbf{1 0 1 , 7 0}$ & 1,511 \\
Solução $\mathbf{1 0 0 \% ~ ( p / v ) ~}$ & 100,65 & 101,98 & 101,63 & $\mathbf{1 0 1 , 4 2}$ & 0,682 \\
Solução $\mathbf{1 5 0 \%}(\mathbf{p} / \mathbf{v})$ & 99,98 & 97,91 & 100,30 & $\mathbf{9 9 , 4 0}$ & 1,305 \\
\hline
\end{tabular}

TABELA 17. Benzaldeído: Valores de recuperação obtidos - Exatidão

\subsubsection{PERÓXIDO DE BENZOÍLA}

a) PREPARO DE SOLUÇÕES DAS AMOSTRAS

\begin{tabular}{ccc}
\hline Concentração & Preparações/ Diluições & Concentração teórica (mg/mL) \\
\hline Sol. Estoque - Sol. $\mathbf{4 0 0 \%}(\mathbf{p} / \mathbf{v})$ & $445,9 \mathrm{mg} / 200 \mathrm{~mL}$ & $\mathbf{1 , 6 0}$ \\
Solução $\mathbf{5 0 \%}(\mathbf{p} / \mathrm{v})$ & $6,25 \mathrm{~mL}$ Sol. Estoque / $50 \mathrm{~mL}$ & $\mathbf{0 , 2 0 0}$ \\
Solução $\mathbf{1 0 0 \%}(\mathbf{p} / \mathrm{v})$ & $12,50 \mathrm{~mL}$ Sol. Estoque / $50 \mathrm{~mL}$ & $\mathbf{0 , 4 0 0 7}$ \\
Solução $\mathbf{1 5 0 \%}(\mathbf{p} / \mathbf{v})$ & $18,75 \mathrm{~mL}$ Sol. Estoque / 50mL & $\mathbf{0 , 6 0 1}$ \\
\hline
\end{tabular}

TABELA 18.Peróxido de benzoíla: Preparo das soluções amostras - Exatidão

\section{b) VALORES DE RECUPERAÇÃO OBTIDOS}

\begin{tabular}{cccccc}
\hline Concentração & $\begin{array}{c}\text { Recuperação (\%) } \\
\text { 1a Injeção }\end{array}$ & $\begin{array}{c}\text { Recuperação (\%) } \\
\text { 2a Injeção }\end{array}$ & $\begin{array}{c}\text { Recuperação (\%) } \\
\text { 3a Injeção }\end{array}$ & $\begin{array}{c}\text { Recuperação (\%) } \\
\text { Média }\end{array}$ & DRP (\%) \\
\hline Solução $\mathbf{5 0 \% ~ ( p / v ) ~}$ & 98,25 & 100,86 & 100,31 & $\mathbf{9 9 , 8 1}$ & $\mathbf{1 , 3 7 8}$ \\
Solução 100\% (p/v) & 100,14 & 99,88 & 101,19 & $\mathbf{1 0 0 , 4 0}$ & 0,214 \\
\hline
\end{tabular}

DPR - Desvio padrão relativo

TABELA 19. Peróxido de benzoíla: Valores de recuperação obtidos - Exatidão 


\subsection{ROBUSTEZ}

Durante a realização do ensaio de robustez, foram avaliados fatores relacionados à técnica CLAE como variação do comprimento de onda de detecção e variação do volume de injeção, além de fatores relacionados ao preparo de amostras como estabilidade do fármaco peróxido de benzoíla em solução.

\subsubsection{ESTRATÉGIA ADOTADA PARA REALIZAÇÃO DO ENSAIO DE ROBUSTEZ}

\section{(a) Fatores relacionados à técnica CLAE}

Variação do comprimento de onda de detecção

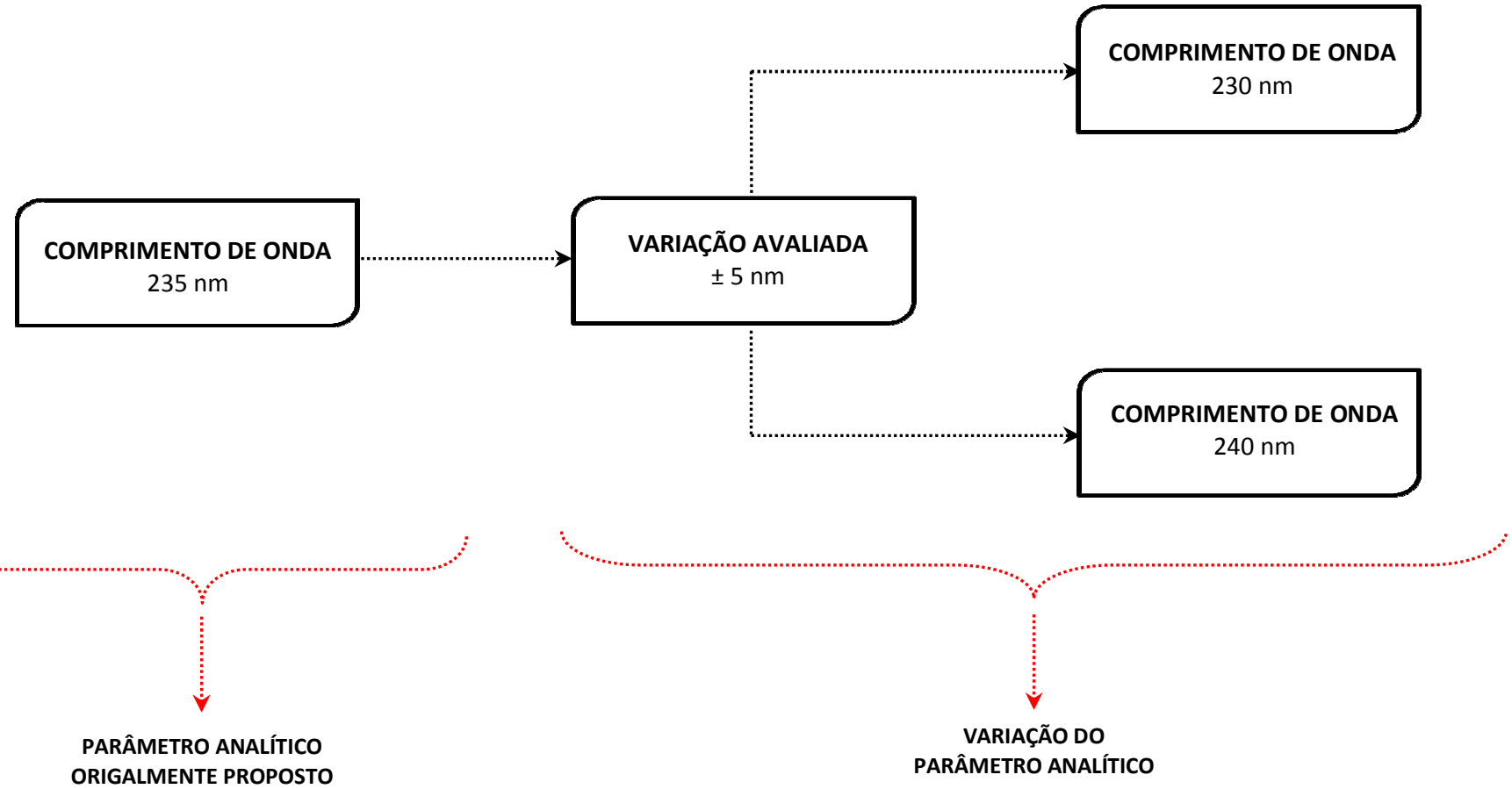

FIGURA 36. Estratégia adotada para realização do ensaio de robustez: (a) Fatores relacionados à técnica CLAE 
(b) Fatores relacionados à técnica CLAE

Variação no volume de injeção

VOLUME DE INJEÇÃO $15 \mu \mathrm{L}$
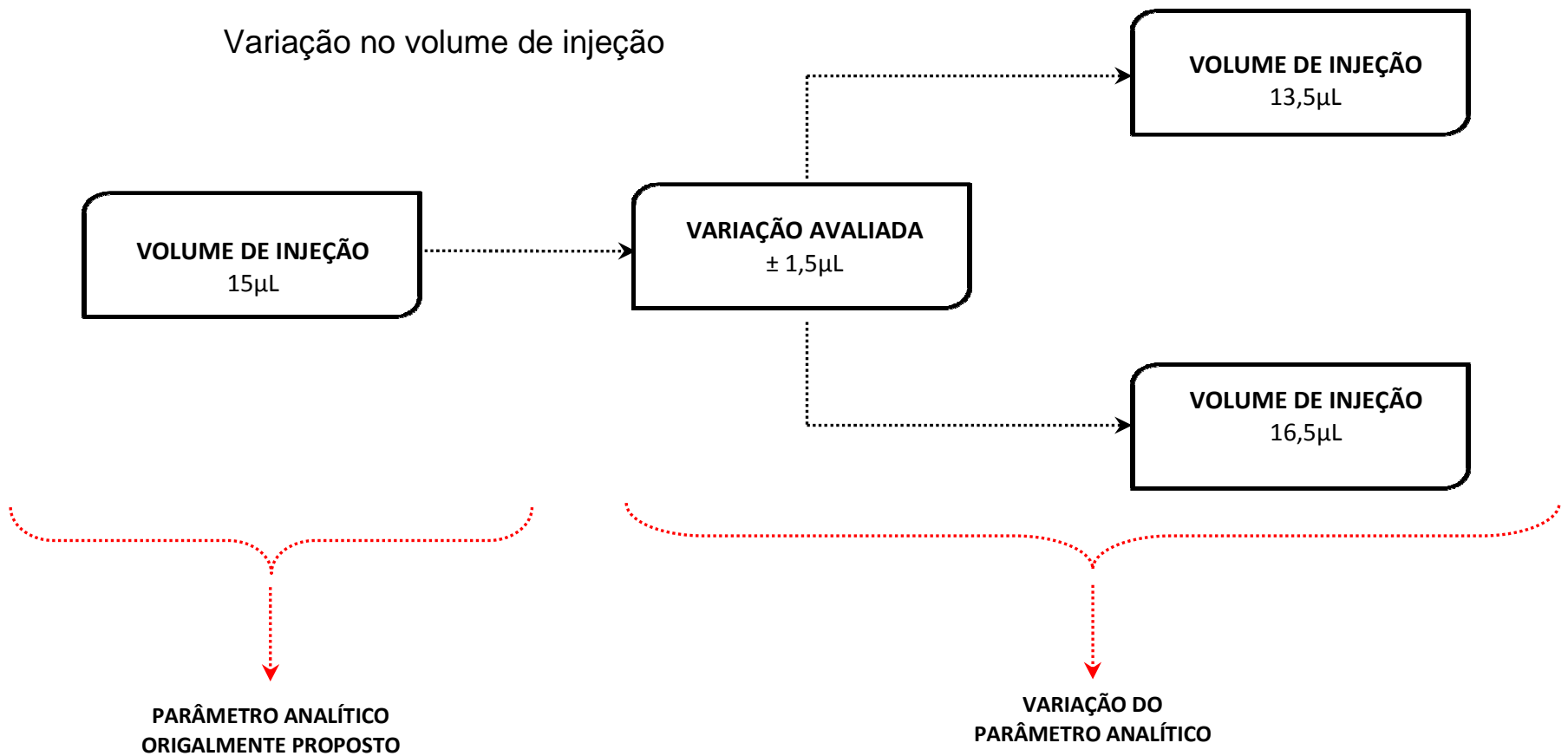

FIGURA 37. Estratégia adotada para realização do ensaio de robustez: (b) Fatores relacionados à técnica CLAE e (c) Fatores relacionados ao preparo de amostra

(c) Fatores relacionados ao preparo de amostra

Estabilidade do fármaco peróxido de benzoíla em solução

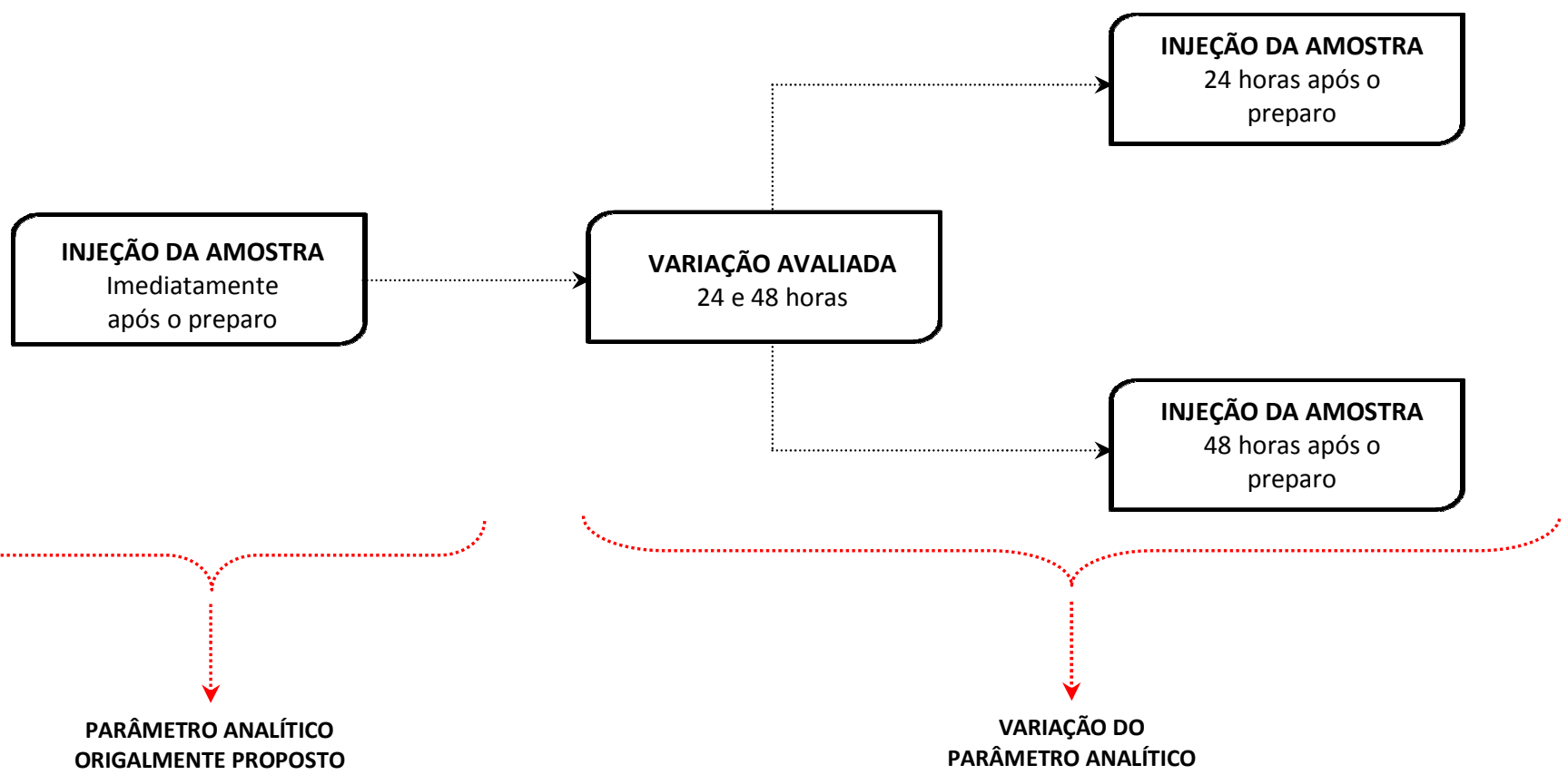




\subsubsection{RESULTADOS OBTIDOS NO ENSAIO DE ROBUSTEZ}

\section{(a) AVALIAÇÃO DA VARIAÇÃO DO COMPRIMENTO DE ONDA}

\section{Peróxido de benzoíla gel $40 \mathrm{mg} / \mathrm{g}$}

\begin{tabular}{|c|c|c|}
\hline Condição & Ácido benzóico & Peróxido de benzoíla \\
\hline Área obtida em 235 nm - Referência & $649,62280 \mathrm{mAU}$ & $3,62670 \times 10^{4} \mathrm{mAU}$ \\
\hline Área obtida em 230 nm - Alteração & 1041,37903 mAU & $3,17307 \times 10^{4} \mathrm{mAU}$ \\
\hline Variação da área (\%) & $160,31 \%$ & $87,49 \%$ \\
\hline Variação da área (\%) & $96,55 \%$ & $92,73 \%$ \\
\hline
\end{tabular}

TABELA 20. Peróxido de benzoíla gel 40mg/g: Avaliação da variação do comprimento de onda - Robustez

Peróxido de benzoíla gel $80 \mathrm{mg} / \mathrm{g}$

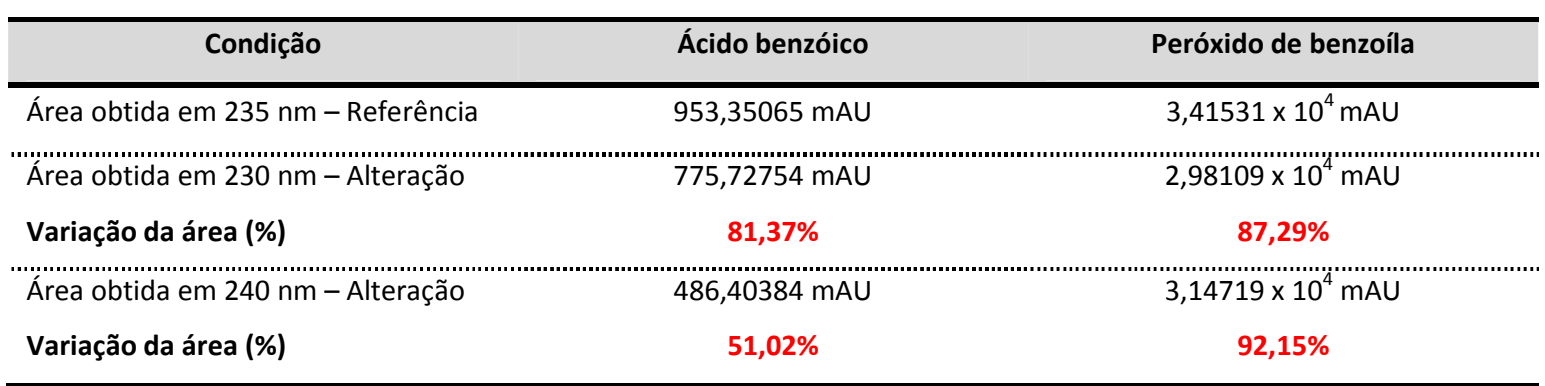

TABELA 21. Peróxido de benzoíla gel $80 \mathrm{mg} / \mathrm{g}$ : Avaliação da variação do comprimento de onda - Robustez

(b) AVALIAÇÃO DA VARIAÇÃO DO VOLUME DE INJEÇÃO

\section{Peróxido de benzoíla gel $40 \mathrm{mg} / \mathrm{g}$}

\begin{tabular}{|c|c|c|}
\hline Condição & Ácido benzóico & Peróxido de benzoíla \\
\hline Área obtida em $15 \mu \mathrm{L}$ - Referência & $649,62280 \mathrm{mAU}$ & $3,62670 \times 10^{4} \mathrm{mAU}$ \\
\hline Ârea obtida em 13,5 $\mu \mathrm{L}$ - Alteração & $884,41852 \mathrm{mAU}$ & $3,25626 \times 10^{4} \mathrm{mAU}$ \\
\hline Variação da área (\%) & $136,14 \%$ & $89,79 \%$ \\
\hline Área obtida em $16,5 \mu \mathrm{L}$ - Alteração & $1138,95068 \mathrm{mAU}$ & $3,97346 \times 10^{4} \mathrm{mAU}$ \\
\hline Variação da área (\%) & $175,32 \%$ & $109,56 \%$ \\
\hline
\end{tabular}

TABELA 22. Peróxido de benzoíla gel 40mg/g: Avaliação da variação do volume de injeção - Robustez 


\section{Peróxido de benzoíla gel $80 \mathrm{mg} / \mathrm{g}$}

\begin{tabular}{|c|c|c|}
\hline Condição & Ácido benzóico & Peróxido de benzoíla \\
\hline Área obtida em $15 \mu \mathrm{L}$ - Referência & $953,35065 \mathrm{mAU}$ & $3,41531 \times 10^{4} \mathrm{mAU}$ \\
\hline Área obtida em 13,5 $\mathrm{LL}$ - Alteração & 674,08118 mAU & $3,06907 \times 10^{4} \mathrm{mAU}$ \\
\hline Variação da área (\%) & $70,71 \%$ & $89,86 \%$ \\
\hline Área obtida em 16,5 LL - Alteração & 845,67053 mAU & $3,72863 \times 10^{4} \mathrm{mAU}$ \\
\hline Variação da área (\%) & $88,71 \%$ & $109,17 \%$ \\
\hline
\end{tabular}

TABELA 23. Peróxido de benzoíla gel $80 \mathrm{mg} / \mathrm{g}$ : Avaliação da variação do volume de injeção - Robustez 


\subsection{LIMITE DE DETECÇÃO}

O limite de deteç̧ão é estabelecido por meio por meio da análise de soluções de concentrações conhecidas e decrescentes do analito, até o menor nível detectado (BRASIL, 2003).

\subsubsection{ESTRATÉGIA ADOTADA PARA REALIZAÇÃO DO ENSAIO DE LIMITE DE DETECÇÃO}

Para avaliação limite de detecção da metodologia proposta, foram preparadas amostras em diferentes níveis de concentração, em função dos analitos avaliados.

As soluções finais apresentaram as seguintes concentrações em relação a sua respectiva concentração de trabalho, proposta na metodologia:
○ Ácido Benzóico: 1\% (p/v);
- Benzoato de Etila: $15 \%(p / v)$;
- Benzaldeído: $25 \%(\mathrm{p} / \mathrm{v})$;
- Peróxido de Benzoíla: 0,05\%(p/v);

\subsubsection{CRITÉRIOS DE ACEITAÇÃO}

No caso de métodos instrumentais tais como CLAE, CG e absorção atômica, a estimativa do limite de detecção pode ser feita com base na relação de 3 vezes o ruído da linha de base. Pode ser determinado pela equação: 


$$
\frac{D P a \times 3}{I C}=L D
$$

Onde:

$D P a$ - Desvio padrão do intercepto com o eixo $Y$ de, no mínimo, 3 curvas de calibração construídas contendo concentrações do fármaco próximas ao suposto limite de quantificação.

$$
\begin{aligned}
& \text { IC - Inclinação da curva de calibração; } \\
& \text { LD - Limite de detecção; }
\end{aligned}
$$

\subsubsection{RESULTADOS OBTIDOS NO ENSAIO DE LIMITE DE DETECÇÃO}

\subsubsection{1. ÁCIDO BENZÓICO}

a) PREPARO DA SOLUÇÃO ÁCIDO BENZÓICO 1\% (p/v)

\begin{tabular}{ccc}
\hline Concentração & Preparação / Diluição & Concentração Teórica (mg/mL) \\
\hline Solução Estoque $-200 \%(\mathrm{p} / \mathrm{v})$ & $50,8 \mathrm{mg} / 50 \mathrm{~mL} \times 10 \mathrm{~mL} / 50 \mathrm{~mL}$ & 0,203139040 \\
Solução $10 \%(\mathrm{p} / \mathrm{v})$ & $0,5 \mathrm{~mL}$ Sol. Estoque / 10mL & 0,010156952 \\
Solução $1 \%(\mathrm{p} / \mathrm{v})$ & $1 \mathrm{~mL}$ Sol.10\%(p/v) / 10mL & 0,001015695 \\
\hline
\end{tabular}

TABELA 24. Ácido benzóico: Preparo da solução 1\% (p/v) - Limite de detecção

b) VALORES DE ÁREA OBTIDOS PARA ÁCIDO BENZÓICO 1\% (p/v)

\begin{tabular}{c|c}
\hline Injeções & Valores de Área obtidos (mAU) \\
\hline 1 & 41,48990 \\
2 & 42,44486 \\
3 & 47,57531 \\
\hline Média (mAU) & $\mathbf{4 3 , 8 3 6 6 9}$ \\
\hline Desvio Padrão (\%) & $\mathbf{3 , 2 7 3}$ \\
\hline Desvio Padrão Relativo (\%) & $\mathbf{7 , 4 6 6}$ \\
\hline
\end{tabular}

TABELA 25. Ácido Benzóico: Valores de área obtidos - Limite de detecção 


\section{c) CROMATOGRAMA CARACTERÍSTICO OBTIDO}

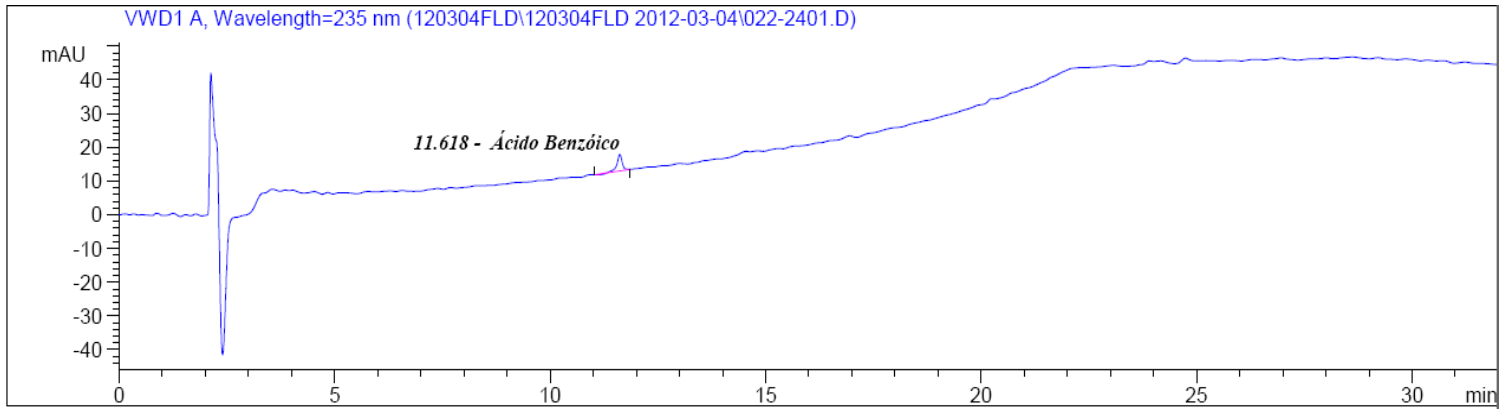

FIGURA 38. Cromatograma da solução de ácido benzóico $0,001015695 \mathrm{mg} \cdot \mathrm{mL}^{-1}$; Condições: coluna Luna C18 $100 \AA ̊$ ( $5 \mu \mathrm{m}$, 250 x 4,6mm), vazão: 1,5mL.min-1, fase móvel: ACN:HÁc (1000:1) e Água:HÁc (1000:1) - gradiente; deteç̧ão: 235nm.

\subsubsection{BENZOATO DE ETILA}

a) PREPARODA SOLUÇÃO BENZOATO DE ETILA 15\%(p/v)

\begin{tabular}{|c|c|c|}
\hline Concentração & Preparação / Diluição & Concentração Teórica $(\mathrm{mg} / \mathrm{mL})$ \\
\hline Solução Estoque - 200\% (p/v) & $13,7 \mathrm{mg} / 100 \mathrm{~mL} \times 4,0 \mathrm{~mL} / 50 \mathrm{~mL}$ & 0,010960 \\
\hline Solução 150\% (p/v) & 7,5mL Sol. Estoque / 10mL & 0,008220 \\
\hline Solução 15\% (p/v) & 1mL Sol. $150 \%(p / v) / 10 m L$ & 0,000822 \\
\hline
\end{tabular}

TABELA 26. Benzoato de etila: Preparo da solução 15\% (p/v) - Limite de detecção

b) VALORES OBTIDOS PARA BENZOATO DE ETILA

\begin{tabular}{c|c}
\hline Injeções & Valores de Área obtidos (mAU) \\
\hline 1 & 29,24351 \\
2 & 26,61389 \\
3 & 35,10937 \\
\hline Média (mAU) & $\mathbf{3 0 , 3 2 2 2 5 6 6 7}$ \\
\hline Desvio Padrão (\%) & $\mathbf{4 , 3 4 9}$ \\
\hline Desvio Padrão Relativo (\%) & $\mathbf{1 4 , 3 4 3}$ \\
\hline
\end{tabular}

TABELA 27. Benzoato de etila: Valores de área obtidos - Limite de detecção 


\section{c) CROMATOGRAMA CARACTERÍSTICO OBTIDO}

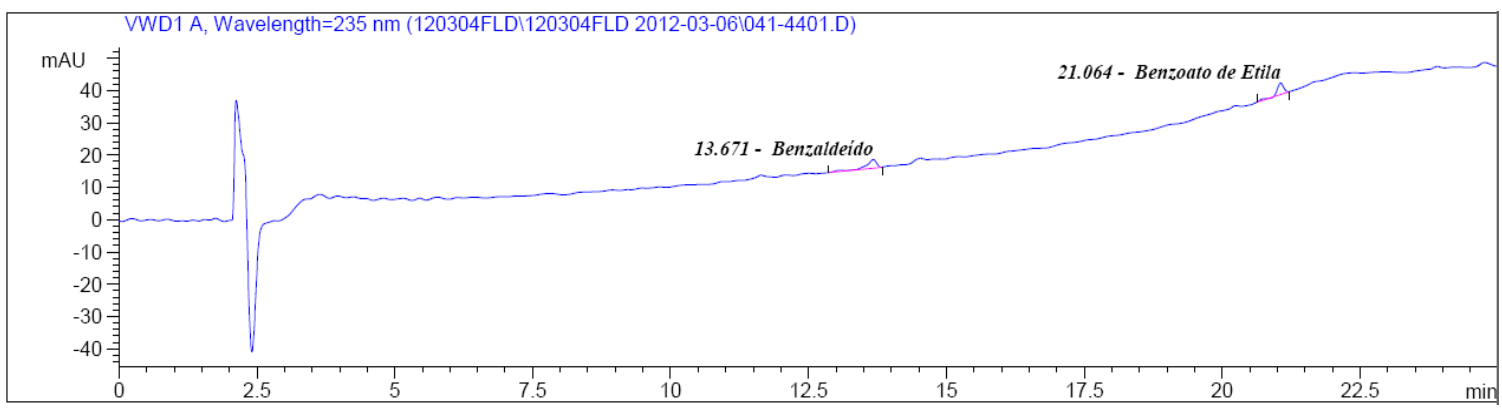

FIGURA 39. Cromatograma da solução de Benzoato de Etila 0,000822 mg.mL ${ }^{-1}$; Condições: coluna Luna C18 $100 \AA ̊$ ( $5 \mu \mathrm{m}$, 250 x 4,6mm), vazão: 1,5mL.min-1, fase móvel: ACN:HÁc (1000:1) e Água:HÁc (1000:1) - gradiente; detecção: 235nm.

\subsubsection{BENZALDEÍDO}

\section{a) PREPARO DA SOLUÇÃO DE BENZALDEÍDO 25\% (p/v)}

\begin{tabular}{ccc}
\hline Concentração & Preparação / Diluição & Concentração Teórica (mg/mL) \\
\hline Solução Estoque - $200 \%(\mathrm{p} / \mathrm{v})$ & $12,8 \mathrm{mg} / 100 \mathrm{~mL} \times 4,0 \mathrm{~mL} / 50 \mathrm{~mL}$ & 0,010238976 \\
Solução $25 \%(\mathrm{p} / \mathrm{v})$ & $1,25 \mathrm{~mL}$ Sol. Estoque / $10 \mathrm{~mL}$ & 0,001279872 \\
\hline
\end{tabular}

TABELA 28. Benzaldeído: Preparo da solução $25 \%(p / v)$ - Limite de detecção

b) VALORES DE ÁREA OBTIDOS PARA SOLUÇÃO DE BENZALDEÍDO 25\% (p/v)

\begin{tabular}{c|c}
\hline Injeções & Valores de Área obtidos (mAU) \\
\hline 1 & 56,56079 \\
2 & 44,83412 \\
3 & 51,70044 \\
\hline Média (mAU) & $\mathbf{5 1 , 0 3 1 7 8}$ \\
\hline Desvio Padrão (\%) & $\mathbf{5 , 8 9 2}$ \\
\hline Desvio Padrão Relativo (\%) & $\mathbf{1 1 , 5 4 5}$ \\
\hline
\end{tabular}

TABELA 29. Benzaldeído: Valores de área obtidos - Limite de detecção 


\section{c) CROMATOGRAMA CARACTERÍSTICO OBTIDO}

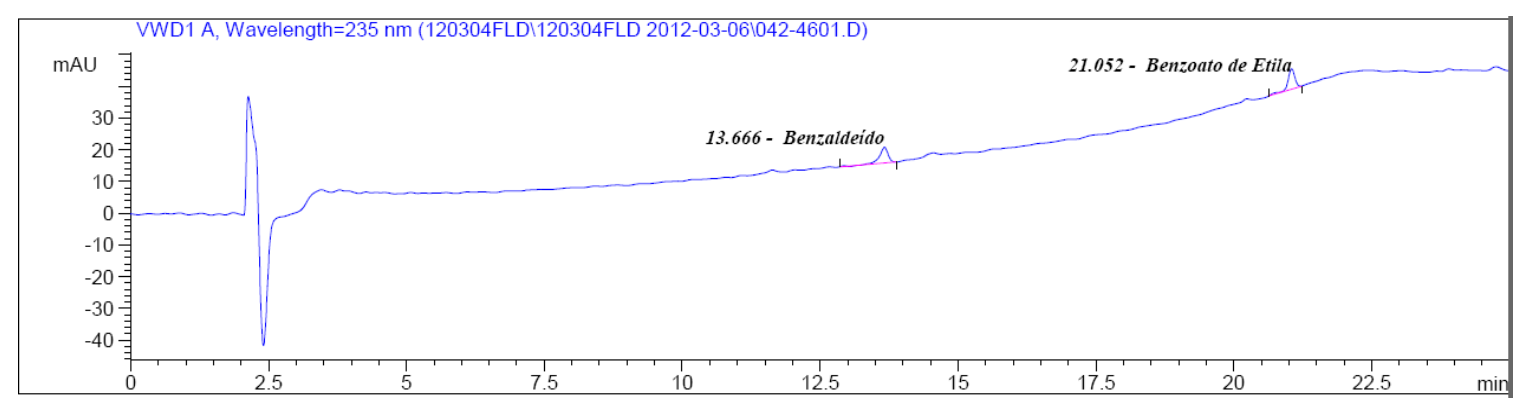

FIGURA 40. Cromatograma da solução de Benzaldeído 0,001279872 mg.mL ${ }^{-1}$; Condições: coluna Luna C18 $100 \AA$ ( $5 \mu \mathrm{m}$, 250 x 4,6mm), vazão: 1,5mL.min-1, fase móvel: ACN:HÁc (1000:1) e Água:HÁc (1000:1) - gradiente; detecção: 235nm.

\subsubsection{PERÓXIDO DE BENZOÍLA}

a) PREPARO DA SOLUÇÃO DE PERÓXIDO DE BENZOÍLA 0,05\% (p/v)

\begin{tabular}{ccc}
\hline Concentração & Preparação / Diluição & Concentração Teórica (mg/mL) \\
\hline Solução Estoque - $200 \%(\mathrm{p} / \mathrm{v})$ & $12,8 \mathrm{mg} / 100 \mathrm{~mL} \times 4,0 \mathrm{~mL} / 50 \mathrm{~mL}$ & 0,010238976 \\
Solução $10 \%(\mathrm{p} / \mathrm{v})$ & $0,5 \mathrm{~mL}$ Sol. Estoque / 10mL & 0,000511938 \\
Solução $0,05 \%(\mathrm{p} / \mathrm{v})$ & $0,5 \mathrm{~mL}$ Sol. $10 \%(\mathrm{p} / \mathrm{v}) / 100 \mathrm{~mL}$ & 0,000002559 \\
\hline
\end{tabular}

TABELA 30. Peróxido de benzoíla: Preparo da solução 0,05\% (p/v) - Limite de detecção

b) VALORES DE ÁREA PARA SOLUÇÃO DE PERÓXIDO DE BENZOÍLA 0,05\% (p/v)

\begin{tabular}{c|c|c}
\hline Injeções & Valores de Área obtidos (mAU) & Relação Sinal : Ruído \\
\hline 1 & 149,69930 \\
2 & 153,99701 \\
3 & 150,80803 \\
\hline Média (mAU) & $\mathbf{1 5 1 , 5 0 1 4 5}$ \\
\hline Desvio Padrão (\%) & $\mathbf{2 , 2 3 1}$ \\
\hline Desvio Padrão Relativo (\%) & $\mathbf{1 , 4 7 3}$ \\
\hline
\end{tabular}

TABELA 31. Peróxido de benzoíla: Valores de área obtidos - Limite de detecção 


\section{c) CROMATOGRAMA CARACTERÍSTICO OBTIDO}

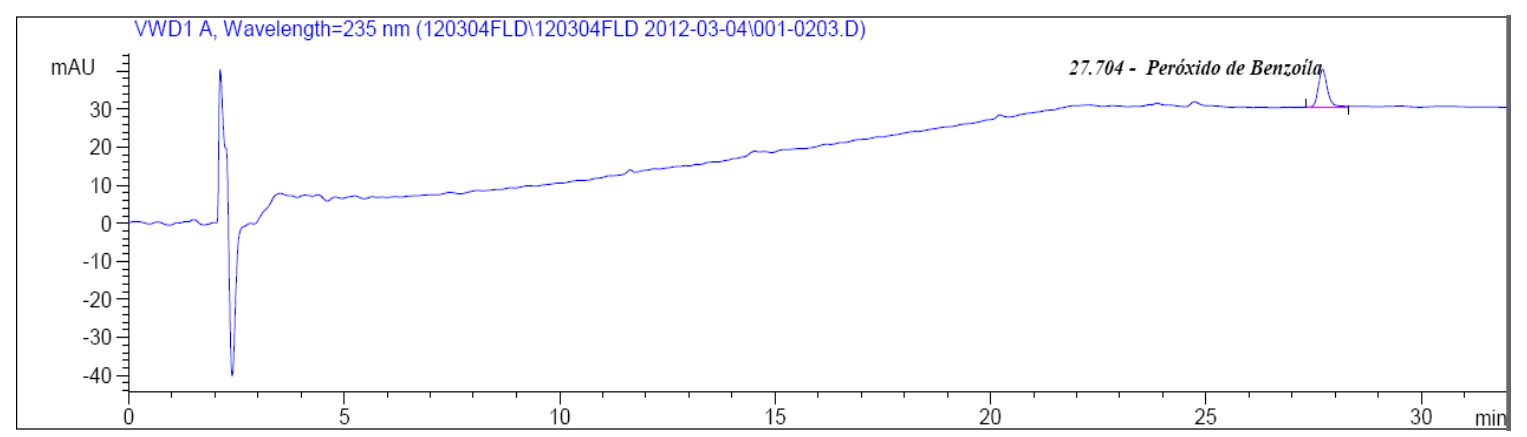

FIGURA 41. Cromatograma da solução de Peróxido de Benzoíla 0,000002559mg.mL ${ }^{-1}$; Condições: coluna Luna C18 $100 \AA$ $(5 \mu \mathrm{m}, 250$ x 4,6mm), vazão: 1,5mL.min-1, fase móvel: ACN:HÁc (1000:1) e Água:HÁc (1000:1) - gradiente; detecção: $235 \mathrm{~nm}$. 


\subsection{LIMITE DE QUANTIFICAÇÃO}

O limite de quantificação é um parâmetro determinado, principalmente, para ensaios quantitativos de impurezas, produtos de degradação em fármacos e produtos de degradação em formas farmacêuticas e é expresso como concentração do analito na amostra (BRASIL, 2003).

\subsubsection{ESTRATÉGIA ADOTADA PARA REALIZAÇÃO DO ENSAIO DE LIMITE DE QUANTIFICAÇÃO}

Para avaliação limite de detecção da metodologia proposta, foram preparadas amostras em diferentes níveis de concentração, em função dos analitos avaliados.

As soluções finais apresentaram as seguintes concentrações em relação a sua respectiva concentração de trabalho, proposta na metodologia:

○ Ácido Benzóico: 2,5\% (p/v);

○ Benzoato de Etila: $50 \%(\mathrm{p} / \mathrm{v})$;

- Benzaldeído: $75 \%(\mathrm{p} / \mathrm{v})$;

- Peróxido de Benzoíla: 0,1\%(p/v);

\subsubsection{CRITÉRIOS DE ACEITAÇÃO}

O limite de quantificação é estabelecido por meio da análise de soluções contendo concentrações decrescentes do fármaco até o menor nível determinado com precisão e exatidão aceitáveis. O limite de quantificação é expresso pela equação: 


$$
\frac{D P a \times 10}{I C}=L Q
$$

Onde:

DPa - Desvio padrão do intercepto com o eixo $Y$ de, no mínimo, 3 curvas de calibração construídas contendo concentrações do fármaco próximas ao suposto limite de quantificação.

IC - Inclinação da curva de calibração;

LQ - Limite de quantificação;

\subsubsection{RESULTADOS OBTIDOS NO ENSAIO DE LIMITE DE QUANTIFICAÇÃO}

\subsubsection{1. ÁCIDO BENZÓICO}

a) PREPARAÇÃO DA SOLUÇÃO ÁCIDO BENZÓICO 2,5\% (p/v)

\begin{tabular}{ccc}
\hline Concentração & Preparação / Diluição & Concentração Teórica (mg/mL) \\
\hline Solução Estoque $-200 \%(\mathrm{p} / \mathrm{v})$ & $50,8 \mathrm{mg} / 50 \mathrm{~mL} \times 10 \mathrm{~mL} / 50 \mathrm{~mL}$ & 0,203139040 \\
Solução $10 \%(\mathrm{p} / \mathrm{v})$ & $0,5 \mathrm{~mL}$ Sol. Estoque / 10mL & 0,010156952 \\
Solução 2,5\% (p/v) & $2,5 \mathrm{~mL}$ Sol.10\%(p/v)/10mL & 0,002539238 \\
\hline
\end{tabular}

TABELA 32. Ácido benzóico: Preparação da solução 2,5\% (p/v) - Limite de quantificação

b) VALORES DE ÁREA OBTIDOS PARA SOLUÇÃO ÁCIDO BENZÓICO 2,5\% (p/v)

\begin{tabular}{c|c|c}
\hline Injeções & Valores de Área obtidos (mAU) \\
\hline 1 & 107,74989 \\
2 & 109,71395 \\
3 & 118,04284 \\
\hline Média (mAU) & $\mathbf{1 1 0 , 0 5 6 7 2}$ \\
\hline Desvio Padrão (\%) & $\mathbf{2 , 4 9 6}$ \\
\hline Desvio Padrão Relativo (\%) & $\mathbf{2 , 2 6 8}$ \\
\hline
\end{tabular}

TABELA 33. Ácido benzóico: Valores de área obtidos - Limite de quantificação 


\section{c) CROMATOGRAMA CARACTERÍSTICO OBTIDO}

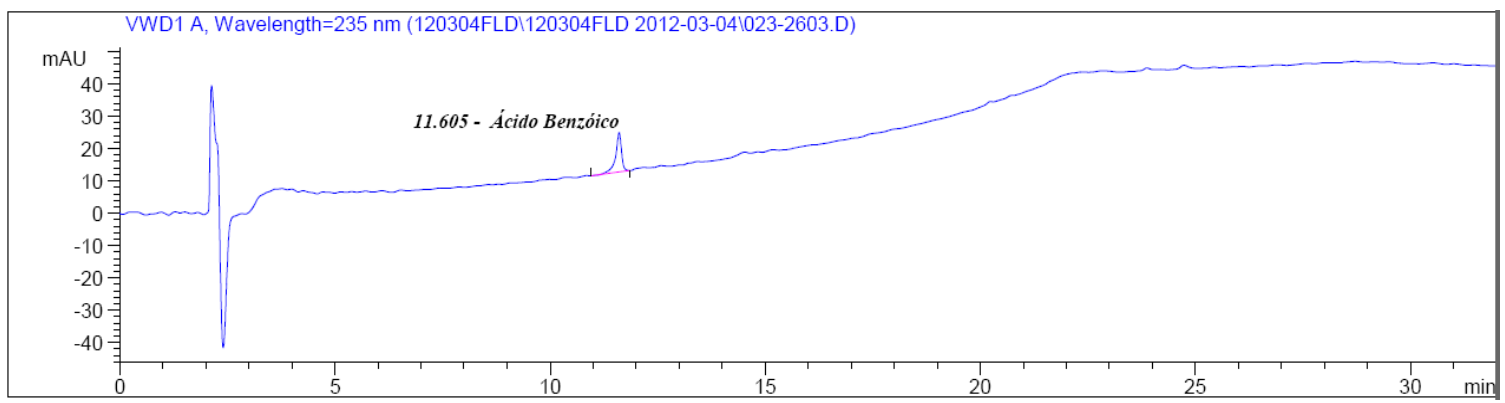

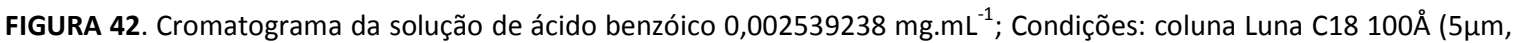
250 x 4,6mm), vazão: 1,5mL.min-1, fase móvel: ACN:HÁc (1000:1) e Água:HÁc (1000:1) - gradiente; detecção: 235nm.

\subsubsection{BENZOATO DE ETILA}

\section{a) PREPARAÇÃO DA SOLUÇÃO BENZOATO DE ETILA 50\%(p/v)}

\begin{tabular}{ccc}
\hline Concentração & Preparação / Diluição & Concentração Teórica (mg/mL) \\
\hline Solução Estoque - $200 \%(\mathrm{p} / \mathrm{v})$ & $13,7 \mathrm{mg} / 100 \mathrm{~mL} \times 4,0 \mathrm{~mL} / 50 \mathrm{~mL}$ & 0,010960 \\
Solução $100 \%(\mathrm{p} / \mathrm{v})$ & $5 \mathrm{~mL}$ Sol. Estoque / 10mL & 0,00548 \\
Solução $50 \%(\mathrm{p} / \mathrm{v})$ & $5 \mathrm{~mL}$ Sol. $100 \%(\mathrm{p} / \mathrm{v}) / 10 \mathrm{~mL}$ & 0,00274 \\
\hline
\end{tabular}

TABELA 34. Benzoato de etila: Preparação da solução 50\% (p/v) - Limite de quantificação

b) VALORES DE ÁREA OBTIDOS PARA BENZOATO DE ETILA $50 \%(\mathrm{p} / \mathrm{v})$

\begin{tabular}{c|c|c}
\hline Injeções & Valores de Área obtidos & Relação Sinal : Ruído \\
\hline 1 & 110,30550 \\
\hline 2 & 110,40508 \\
\hline Média (mAU) & 108,16140 \\
\hline Desvio Padrão (\%) & $\mathbf{1 0 9 , 6 2 3 9 9}$ \\
\hline Desvio Padrão Relativo (\%) & $\mathbf{1 , 2 6 8}$ \\
\hline
\end{tabular}

TABELA 35. Benzoato de etila: Valores de área obtidos - Limite de quantificação 


\section{c) CROMATOGRAMA CARACTERÍSTICO OBTIDO}

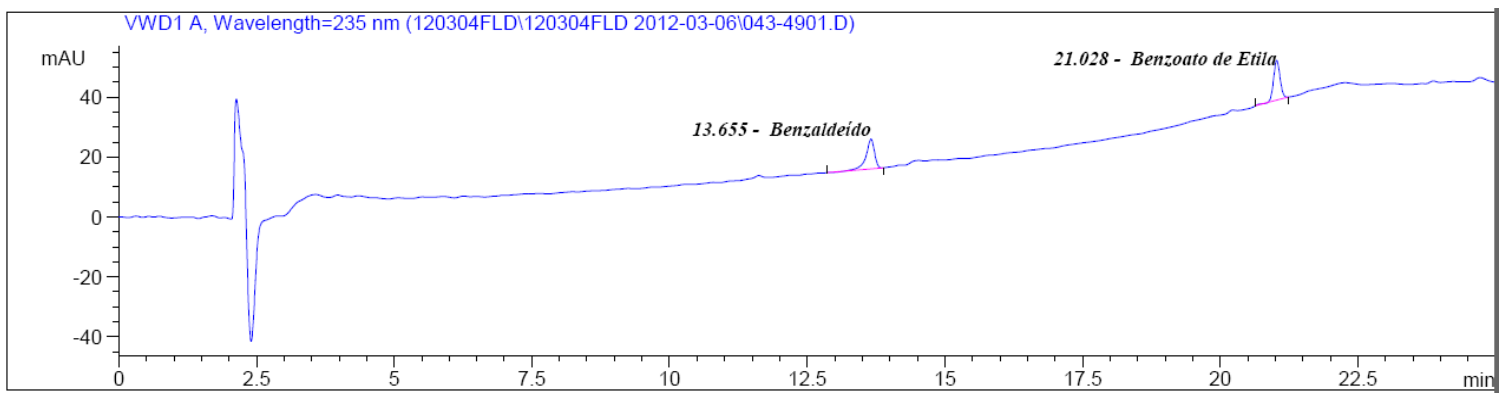

FIGURA 43. Cromatograma da solução de Benzoato de Etila $0,00274 \mathrm{mg} \cdot \mathrm{mL}^{-1}$; Condições: coluna Luna C18 $100 \AA$ ( $5 \mu \mathrm{m}, 250$ x 4,6mm), vazão: 1,5mL.min-1, fase móvel: ACN:HÁc (1000:1) e Água:HÁc (1000:1) - gradiente; detecção: 235nm.

\subsubsection{BENZALDEÍDO}

a) PREPARAÇÃO DA SOLUÇÃO DE BENZALDEÍDO 75\% (p/v)

\begin{tabular}{ccc}
\hline Concentração & Preparação / Diluição & Concentração Teórica (mg/mL) \\
\hline Solução Estoque - 200\% (p/v) & $12,8 \mathrm{mg} / 100 \mathrm{~mL} \times$ 4,0mL / 50mL & 0,010238976 \\
Solução $150 \%(\mathrm{p} / \mathrm{v})$ & Pipetar 7,5mL Sol. Estoque / 10mL & 0,007679232 \\
Solução 75\% $(\mathrm{p} / \mathrm{v})$ & Pipetar $5 \mathrm{~mL}$ Sol. 150\%(p/v) / 10mL & 0,003839616 \\
\hline
\end{tabular}

TABELA 36. Benzaldeído: Preparação da solução 75\% (p/v) - Limite de quantificação

\section{b) VALORES DE ÁREA OBTIDOS PARA SOLUÇÃO DE BENZALDEÍDO 75\% (p/v)}

\begin{tabular}{c|c|c}
\hline Injeções & Valores de Área obtidos & Relação Sinal : Ruído \\
\hline 1 & 165,20164 \\
2 & 159,56137 \\
\hline Média (mAU) & 162,46321 & $12,7: 1$ \\
\hline Desvio Padrão (\%) & $\mathbf{1 6 2 , 4 0 8 7 4}$ \\
\hline Desvio Padrão Relativo (\%) & $\mathbf{2 , 8 2 1}$ \\
\hline
\end{tabular}

TABELA 37. Benzaldeído: Valores de área obtidos - Limite de quantificação 


\section{c) CROMATOGRAMA CARACTERÍSTICO OBTIDO}

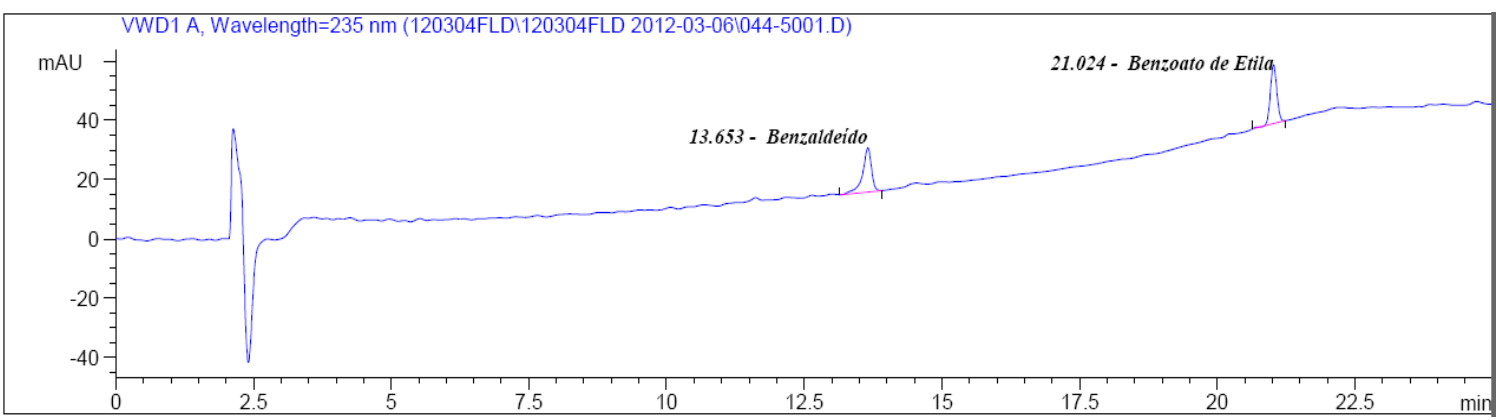

FIGURA 44. Cromatograma da solução de Benzaldeído $0,003839616 \mathrm{mg}^{-\mathrm{mL}^{-1}}$; Condições: coluna Luna C18 $100 \AA ̊$ ( $5 \mu \mathrm{m}$, 250 x 4,6mm), vazão: 1,5mL.min-1, fase móvel: ACN:HÁc (1000:1) e Água:HÁc (1000:1) - gradiente; detecção: 235nm.

\subsubsection{PERÓXIDO DE BENZOÍLA}

\section{a) PREPARO DA SOLUÇÃO DE PERÓXIDO DE BENZOÍLA 0,1\% (p/v)}

\begin{tabular}{ccc}
\hline Concentração & Preparação / Diluição & Concentração Teórica (mg/mL) \\
\hline Solução Estoque - $200 \%(\mathrm{p} / \mathrm{v})$ & $12,8 \mathrm{mg} / 100 \mathrm{~mL} \times 4,0 \mathrm{~mL} / 50 \mathrm{~mL}$ & 0,010238976 \\
Solução $10 \%(\mathrm{p} / \mathrm{v})$ & $0,5 \mathrm{~mL}$ Sol. Estoque / 10mL & 0,000511948 \\
Solução 0,05\% $(\mathrm{p} / \mathrm{v})$ & $0,5 \mathrm{~mL}$ Sol. $10 \%(\mathrm{p} / \mathrm{v}) / 100 \mathrm{~mL}$ & 0,000002559 \\
\hline
\end{tabular}

TABELA 38. Peróxido de benzoíla: Preparação da solução $0,1 \%(p / v)$ - Limite de quantificação

b) VALORES DE ÁREA PARA PERÓXIDO DE BENZOLÍLA $0,1 \%$ (p/v)

\begin{tabular}{c|c|c}
\hline Injeções & Valores de Área obtidos & Relação Sinal : Ruído \\
\hline 1 & 288,78467 \\
2 & 291,73343 \\
3 & 285,30014 \\
\hline Média (mAU) & $\mathbf{2 8 8 , 6 0 6 0 8}$ \\
\hline Desvio Padrão (\%) & $\mathbf{3 , 2 2 0}$ & $11,4: 1$ \\
\hline Desvio Padrão Relativo (\%) & $\mathbf{1 , 1 1 6}$ & \\
\hline
\end{tabular}

TABELA 39. Peróxido de benzoíla: Valores de área obtidos - Limite de quantificação 


\section{c) CROMATOGRAMA CARACTERÍSTICO OBTIDO}

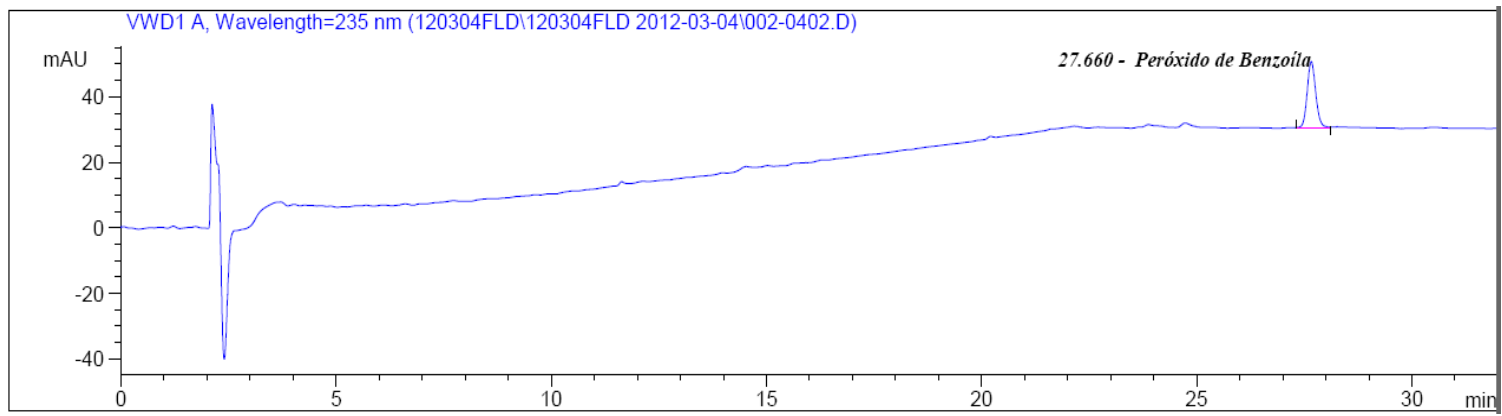

FIGURA 45. Cromatograma da solução de Peróxido de Benzoíla 0,000002559 mg.mL ${ }^{-1}$; Condições: coluna Luna C18 $100 \AA$

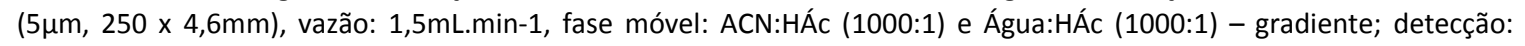
$235 \mathrm{~nm}$. 


\subsection{ESPECIFICIDADE E SELETIVIDADE}

De acordo com o guia de validação do ICH (2008), seletividade é o teste realizado com o placebo para a avaliação da presença do analito, impurezas, produtos de degradação, etc. presentes na matriz da amostra, que possam interferir no resultado final do analito em questão, garantindo que a resposta seja, exclusivamente, a do composto de interesse.

Há diversos procedimentos para a determinação da seletividade. Uma das formas é comparando-se a matriz isenta de substâncias de interesse (placebo), com a matriz adicionada de padrão de interesse, sendo neste caso não deve apresentar interferentes eluindo no mesmo tempo de retenção que o analito, bem como se deve apresentar separada dos demais compostos presentes na amostra. Outra maneira de identificar e determinar os compostos é submeter à amostra a condições de estresse utilizando variação de temperatura e meios ácidos e alcalino, avaliando-se os produtos de degradação que possam interferir no resultado final (RIBANI et al., 2004).

Para análise quantitativa (teor) e análise de impurezas, a especificidade pode ser determinada pela comparação dos resultados obtidos de amostra (fármaco ou medicamento) contaminadas com quantidades apropriadas de impurezas ou excipientes e amostras não contaminadas, para demonstrar que o resultado do teste não é afetado por esses materiais. Quando a impureza ou o padrão do produto de degradação não estiverem disponíveis, pode-se comparar os resultados do teste das amostras contendo impurezas ou produtos de degradação com os resultados de um segundo procedimento bem caracterizado (por exemplo metodologia farmacopêica ou outro procedimento validado). Estas comparações devem incluir amostras armazenadas sob condições de 
estresse tais como: luz, calor, umidade, hidrólise ácida, hidrólise básica, e oxidação (BRASIL, 2003).

\subsubsection{CRITÉRIOS DE ACEITAÇÃO}

Em métodos cromatográficos, deve-se tomar as precauções necessárias para garantir a pureza dos picos cromatográficos. A utilização de testes de pureza de pico (por exemplo, com o auxílio de detector de arranjo de fotodiodos ou espectrometria de massas) são interessantes para demonstrar que o pico cromatográfico é atribuído a somente um componente (BRASIL, 2003).

\subsubsection{ESTRATÉGIA ADOTADA PARA REALIZAÇÃO DO ENSAIO DE DEGRADAÇÃO FORÇADA}

(a)

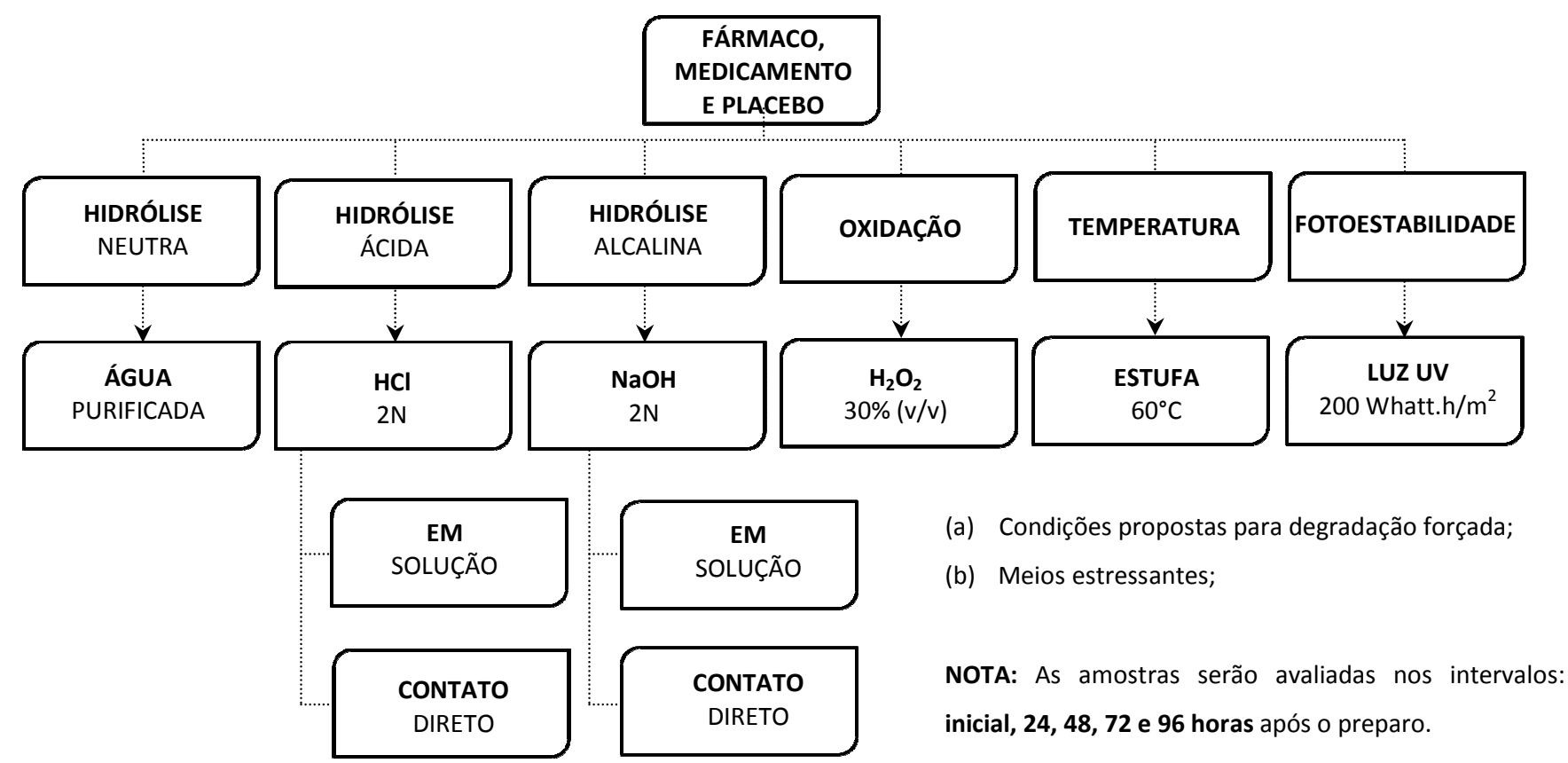

FIGURA 46. Descrição das condições de degradação forçada avaliadas 


\subsubsection{PREPARO DAS AMOSTRAS}

Para realização dos experimentos foram pesadas as seguinte tomadas de ensaio, para balões volumétricos âmbar de $50 \mathrm{~mL}$ :

\begin{tabular}{|c|c|c|c|}
\hline Condição de estresse & $\begin{array}{l}\text { Peróxido de Benzoíla gel } \\
\qquad 40 \mathrm{mg} / \mathrm{g}\end{array}$ & Placebo & Fármaco Isolado \\
\hline Hidrólise neutra & $543,2 \mathrm{mg}$ & $598,2 \mathrm{mg}$ & $30,0 \mathrm{mg}$ \\
\hline Hidrólise Alcalina & $537,7 \mathrm{mg}$ & $516,3 \mathrm{mg}$ & $27,2 \mathrm{mg}$ \\
\hline Oxidação & $525,0 \mathrm{mg}$ & $507,9 \mathrm{mg}$ & $28,8 \mathrm{mg}$ \\
\hline Fotólise & $539,6 \mathrm{mg}$ & $640,6 \mathrm{mg}$ & $28,4 \mathrm{mg}$ \\
\hline
\end{tabular}

TABELA 40. Tomadas de ensaio: Peróxido de benzoíla gel $40 \mathrm{mg} / \mathrm{g}$, placebo e fármaco isolado - Degradação forçada

\section{A) HIDRÓLISE NEUTRA}

Imediatamente adicionar $10 \mathrm{~mL}$ de água purificada e agitar em vortéx ${ }^{\circledR}$ durante 30 segundos. Logo após completar o volume com água purificada e homogeneizar. Filtrar em membrana filtrante de $0,45 \mu \mathrm{m}$ de diâmetro de poro.

\section{B) HIDRÓLISE ÁCIDA}

Imediatamente adicionar $10 \mathrm{~mL}$ de água purificada e agitar em vorté ${ }^{\circledR}$ durante 30 segundos. Em seguida adicionar $5 \mathrm{~mL}$ de $\mathrm{HCl} 2 \mathrm{~N}$, e cerca de $30 \mathrm{~mL}$ de acetonitrila grau HPLC e manter a solução amostra em repouso durante 20 minutos e/ou até que re- 
estabeleça a temperatura ambiente. Logo após completar o volume com acetonitrila grau HPLC e homogeneizar. Filtrar em membrana filtrante de $0,45 \mu \mathrm{m}$ de diâmetro de poro.

\section{C) HIDRÓLISE ALCALINA}

Imediatamente adicionar $10 \mathrm{~mL}$ de água purificada e agitar em vortéx ${ }^{\circledR}$ durante 30 segundos. Em seguida adicionar $0,5 \mu \mathrm{L}$ de $\mathrm{NaOH} 2 \mathrm{~N}$, e cerca de $30 \mathrm{~mL}$ de acetonitrila grau HPLC e manter a solução amostra em repouso durante 20 minutos e/ou até que reestabeleça a temperatura ambiente. Logo após completar o volume com acetonitrila grau HPLC e homogeneizar. Filtrar em membrana filtrante de $0,45 \mu \mathrm{m}$ de diâmetro de poro.

\section{D) OXIDAÇÃO}

Imediatamente adicionar $10 \mathrm{~mL}$ de água purificada e agitar em vortéx ${ }^{\circledR}$ durante 30 segundos. Em seguida adicionar $5 \mathrm{~mL}$ de $\mathrm{H}_{2} \mathrm{O}_{2} 30 \%(\mathrm{v} / \mathrm{v})$, e cerca de $30 \mathrm{~mL}$ de acetonitrila grau HPLC e manter a solução amostra em repouso durante 20 minutos e/ou até que reestabeleça a temperatura ambiente. Logo após completar o volume com acetonitrila grau HPLC e homogeneizar. Filtrar em membrana filtrante de $0,45 \mu \mathrm{m}$ de diâmetro de poro.

\section{E) CALOR}

Imediatamente adicionar $10 \mathrm{~mL}$ de água purificada e agitar em vortéx ${ }^{\circledR}$ durante 30 segundos. Em cerca de $30 \mathrm{~mL}$ de acetonitrila grau HPLC e manter a solução amostra em repouso durante 20 minutos e/ou até que re-estabeleça a temperatura ambiente. Logo após completar o volume com acetonitrila grau HPLC e homogeneizar. Manter a solução amostra em estufa a $60^{\circ} \mathrm{C}$, e nos intervalos de avaliação pré-estabelecidos, filtrar em membrana filtrante de $0,45 \mu \mathrm{m}$ de diâmetro de poro. 


\section{F) FOTÓLISE}

Imediatamente adicionar $10 \mathrm{~mL}$ de água purificada e agitar em vortéx ${ }^{\circledR}$ durante 30 segundos. Em cerca de $30 \mathrm{~mL}$ de acetonitrila grau HPLC e manter a solução amostra em repouso durante 20 minutos e/ou até que re-estabeleça a temperatura ambiente. Logo após completar o volume com acetonitrila grau HPLC e homogeneizar. Estressar as soluções em luz UV 200 Watt.h/m², e por fim filtrar em membrana filtrante de $0,45 \mu \mathrm{m}$ de diâmetro de poro. 


\subsubsection{RESULTADOS OBTIDOS NO ENSAIO DE DEGRADAÇÃO FORÇADA}

\subsubsection{HIDRÓLISE NEUTRA}

a) Sobreposição dos cromatogramas da solução placebo - Hidrólise neutra, nos intervalos: avaliação inicial e 96 horas

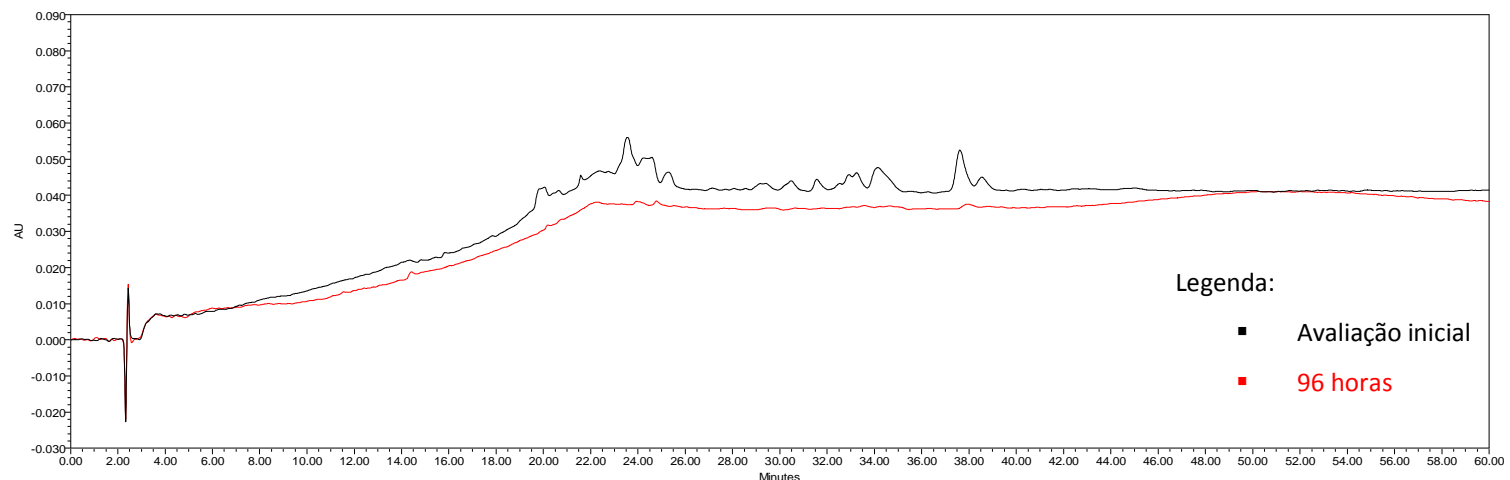

FIGURA 47. Cromatograma da solução placebo: $11,964 \mathrm{mg} \cdot \mathrm{mL}^{-1}$ - Hidrólise neutra; Condições: coluna Luna C18 $100 \AA$ $\left(5 \mu \mathrm{m}, 250 \times\right.$ 4,6mm), vazão: 1,5mL.min ${ }^{-1}$, fase móvel: ACN:HÁc (1000:1) e Água:HÁc (1000:1) - gradiente; deteç̧ão: $235 \mathrm{~nm}$

b) Sobreposição dos cromatogramas da solução peróxido de benzoíla gel $40 \mathrm{mg} / \mathrm{g}$

- Hidrólise neutra, nos intervalos: avaliação inicial, 24, 48, 72 e 96 horas

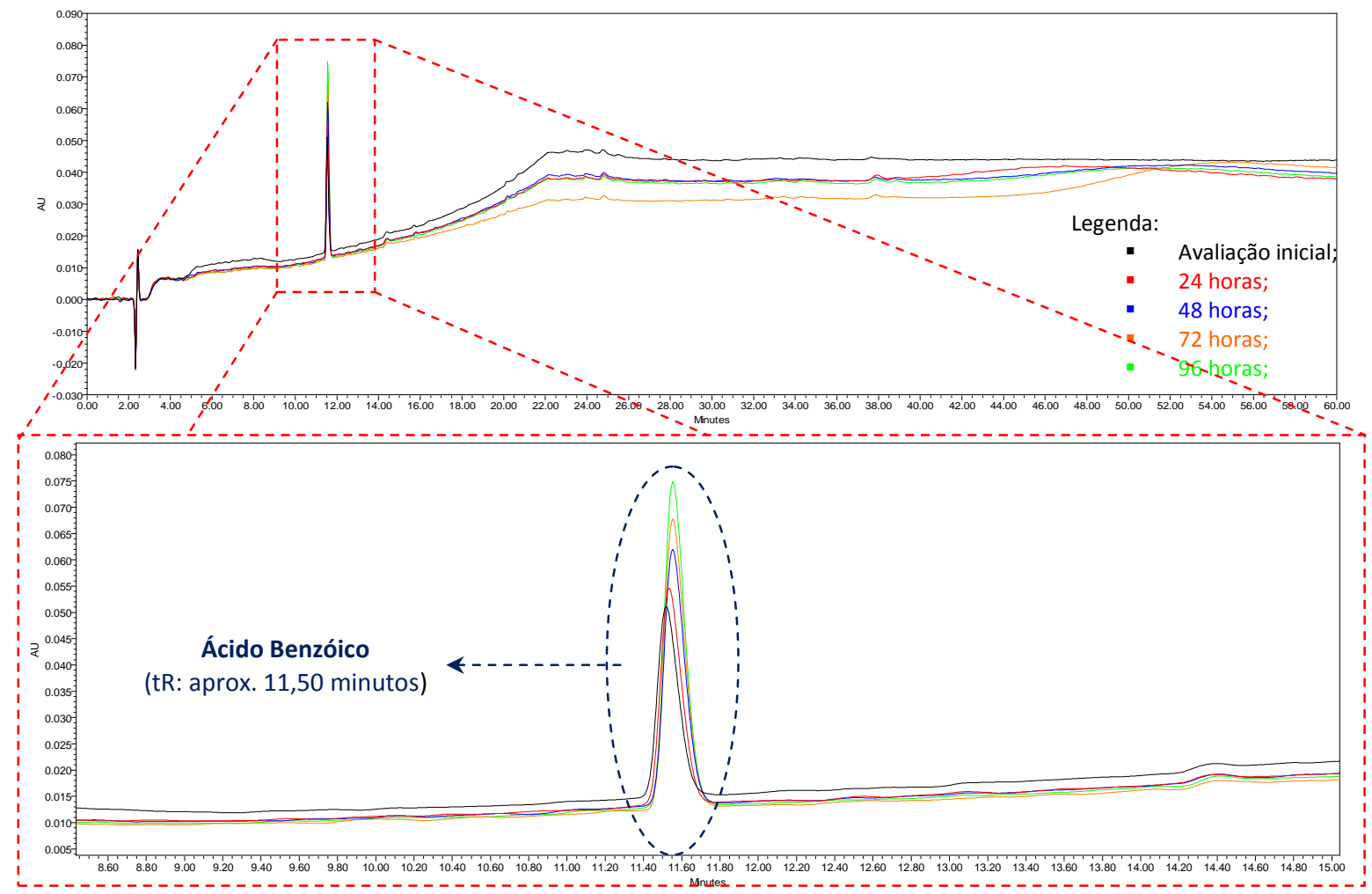

FIGURA 48. Cromatograma da solução peróxido de benzoíla gel 40mg/g: 10,864 mg.mL ${ }^{-1}$ - Hidrólise neutra; Condições: coluna Luna C18 $100 \AA ̊$ ( $5 \mu \mathrm{m}, 250$ x 4,6mm), vazão: 1,5mL. $\mathrm{min}^{-1}$, fase móvel: ACN:HÁc (1000:1) e Água:HÁc (1000:1) - gradiente; detecção: 235nm 
c) Sobreposição dos cromatogramas da solução fármaco peróxido de benzoíla isolado - Hidrólise neutra, nos intervalos: avaliação inicial e 96 horas

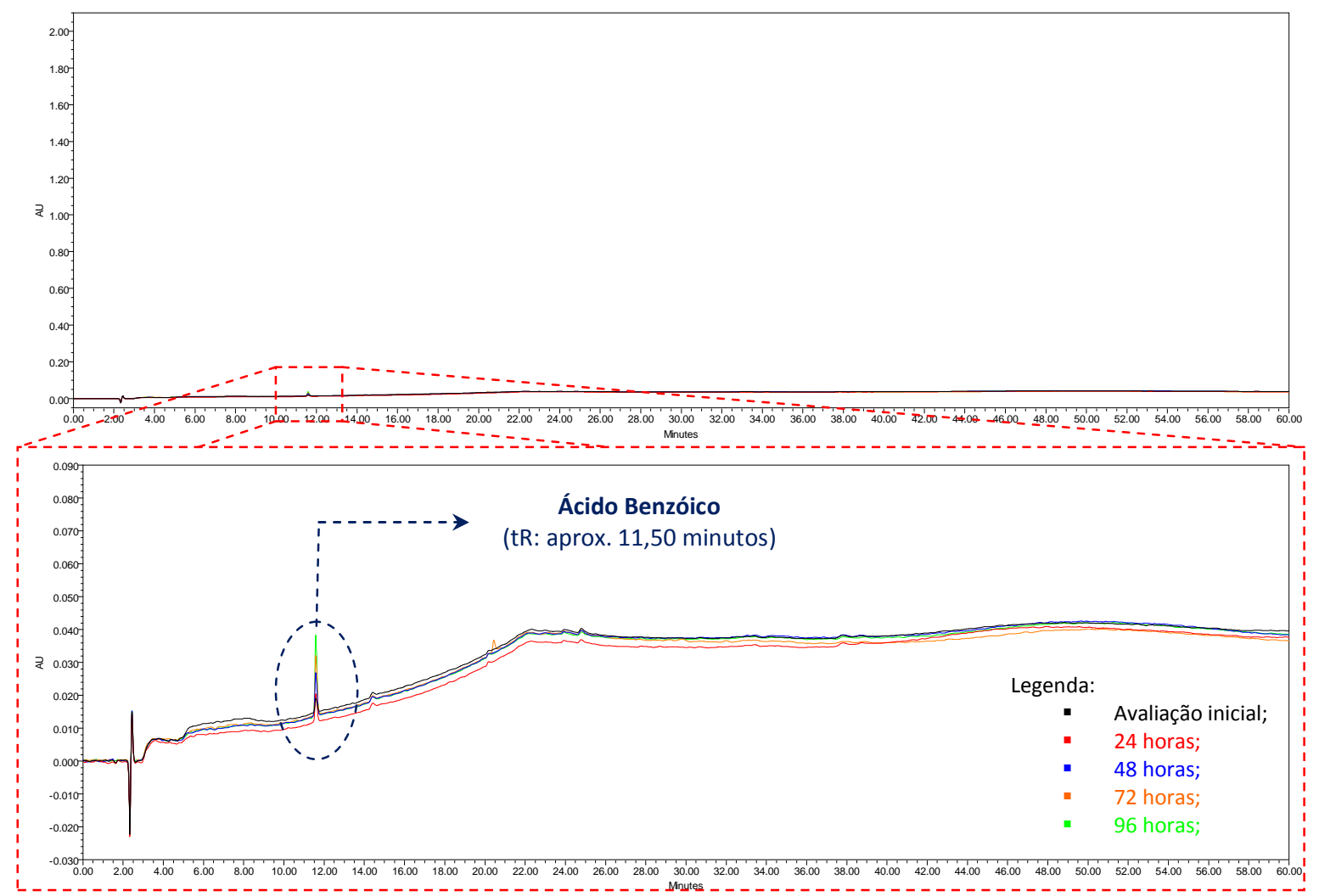

FIGURA 49. Cromatograma da solução do fármaco peróxido de benzoíla isolado: $0,6 \mathrm{mg} \cdot \mathrm{mL}^{-1}$ - Hidrólise neutra; Condições: coluna Luna C18 100Å ( $5 \mu \mathrm{m}, 250$ x 4,6mm), vazão: 1,5mL.min ${ }^{-1}$, fase móvel: ACN:HÁc (1000:1) e Água:HÁc (1000:1) - gradiente; detecção: $235 \mathrm{~nm}$

\subsubsection{TEMPERATURA}

d) Sobreposição dos cromatogramas da solução placebo - Calor, nos intervalos: avaliação inicial e 96 horas

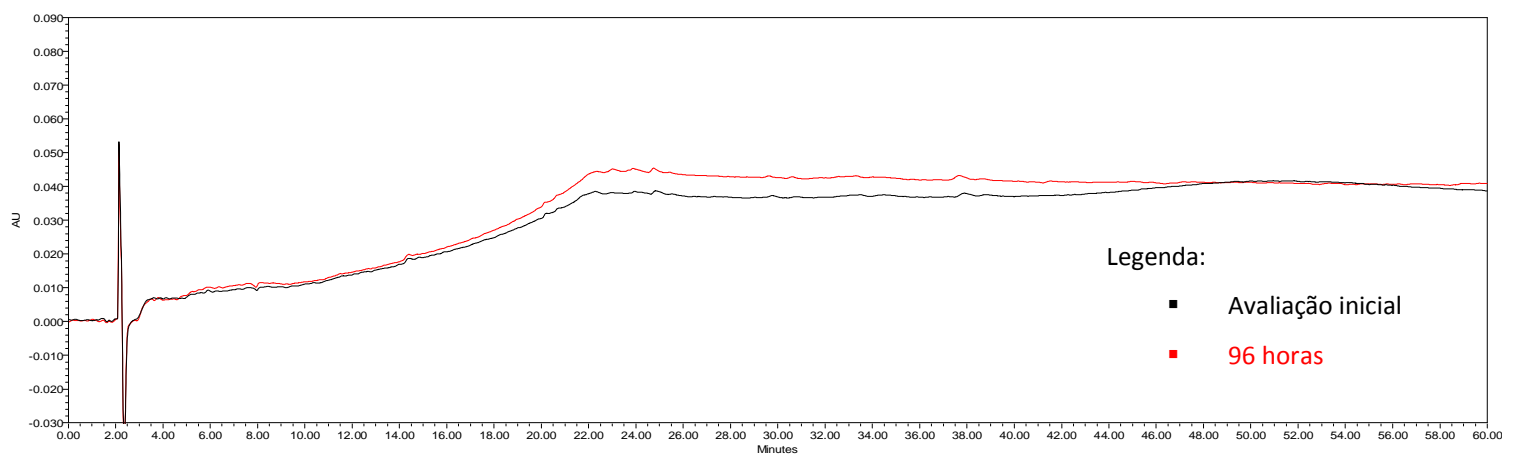

FIGURA 50. Cromatograma da solução placebo: $11,328 \mathrm{mg} \cdot \mathrm{mL}^{-1}$ - Calor; Condições: coluna Luna C18 $100 \AA \AA$ (5 $4 \mathrm{~m}, 250 \mathrm{x}$ 4,6mm), vazão: 1,5mL.min ${ }^{-1}$, fase móvel: ACN:HÁc (1000:1) e Água:HÁc (1000:1) - gradiente; detecção: 235nm 
e) Sobreposição dos cromatogramas da solução peróxido de benzoíla gel $40 \mathbf{m g} / \mathbf{g}$

- Calor, nos intervalos: avaliação inicial, 24, 48, 72 e 96 horas

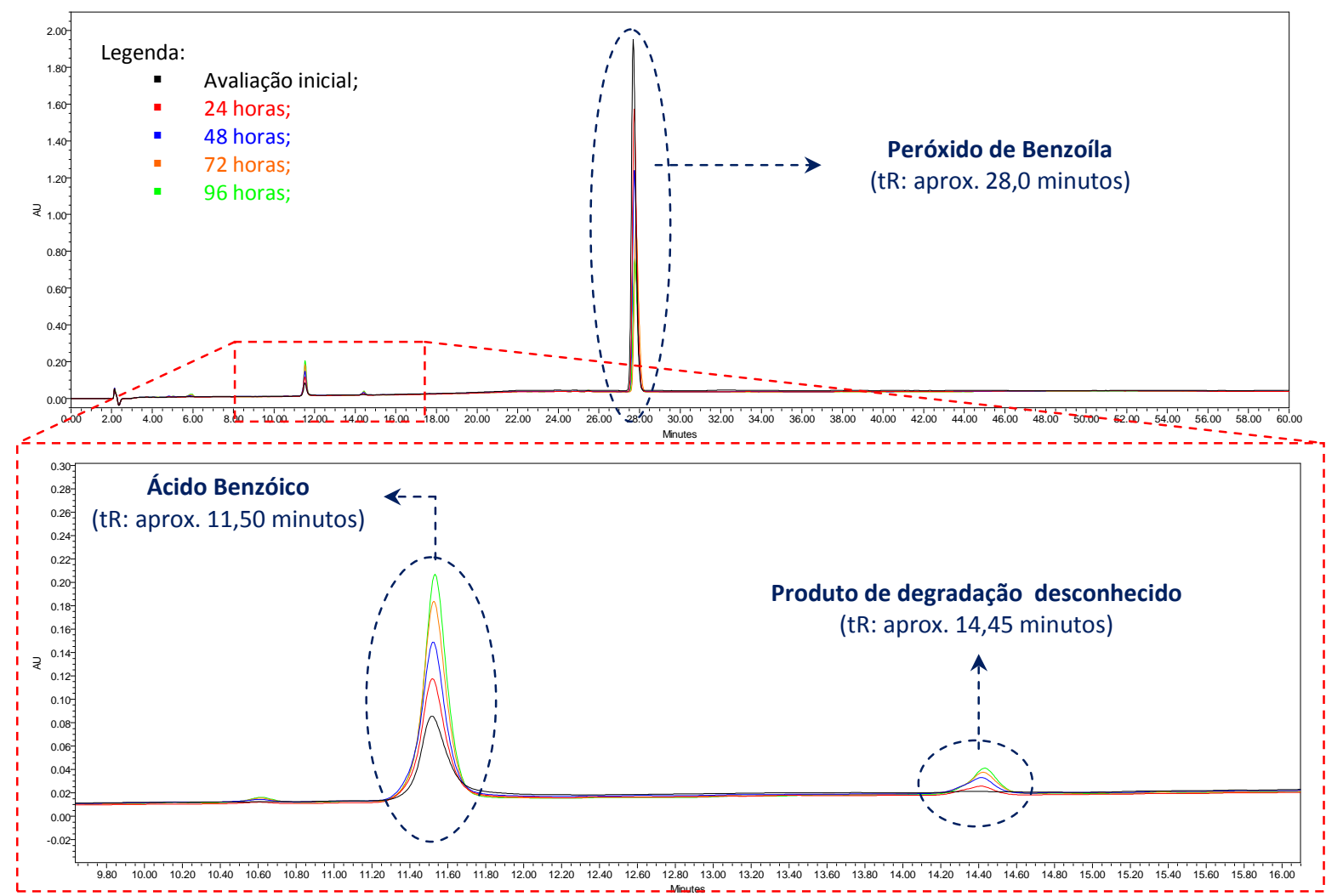

FIGURA 51. Cromatograma da solução do peróxido de benzoíla gel $40 \mathrm{mg} / \mathrm{g}: 10,416 \mathrm{mg} \cdot \mathrm{mL}^{-1}-$ Calor; Condições: coluna

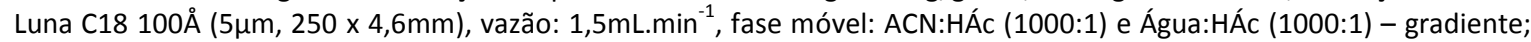
detecção: $235 \mathrm{~nm}$

f) Sobreposição dos cromatogramas da solução do fármaco peróxido de benzoíla

isolado - Calor, nos intervalos: avaliação inicial, 24, 48, 72 e 96 horas

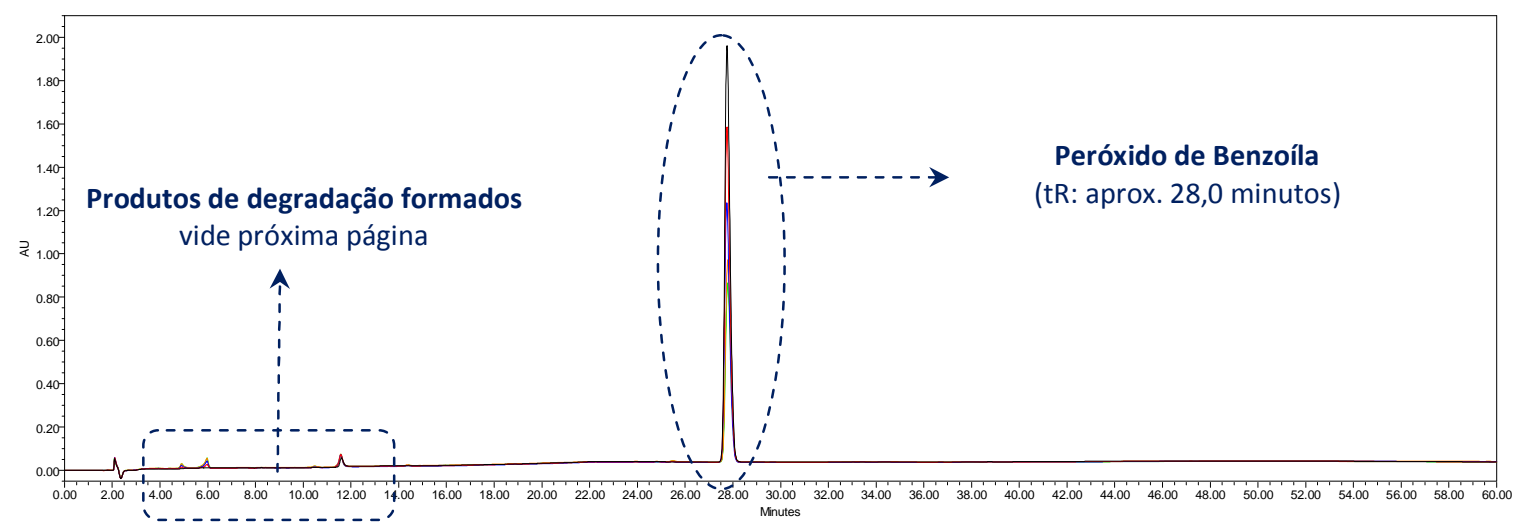

FIGURA 52. Cromatograma da solução do fármaco peróxido de benzoíla isolado: $0,628 \mathrm{mg} \cdot \mathrm{mL}^{-1}-$ Calor; Condições: coluna

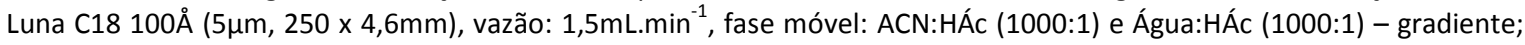
deteç̧ão: $235 \mathrm{~nm}$ 


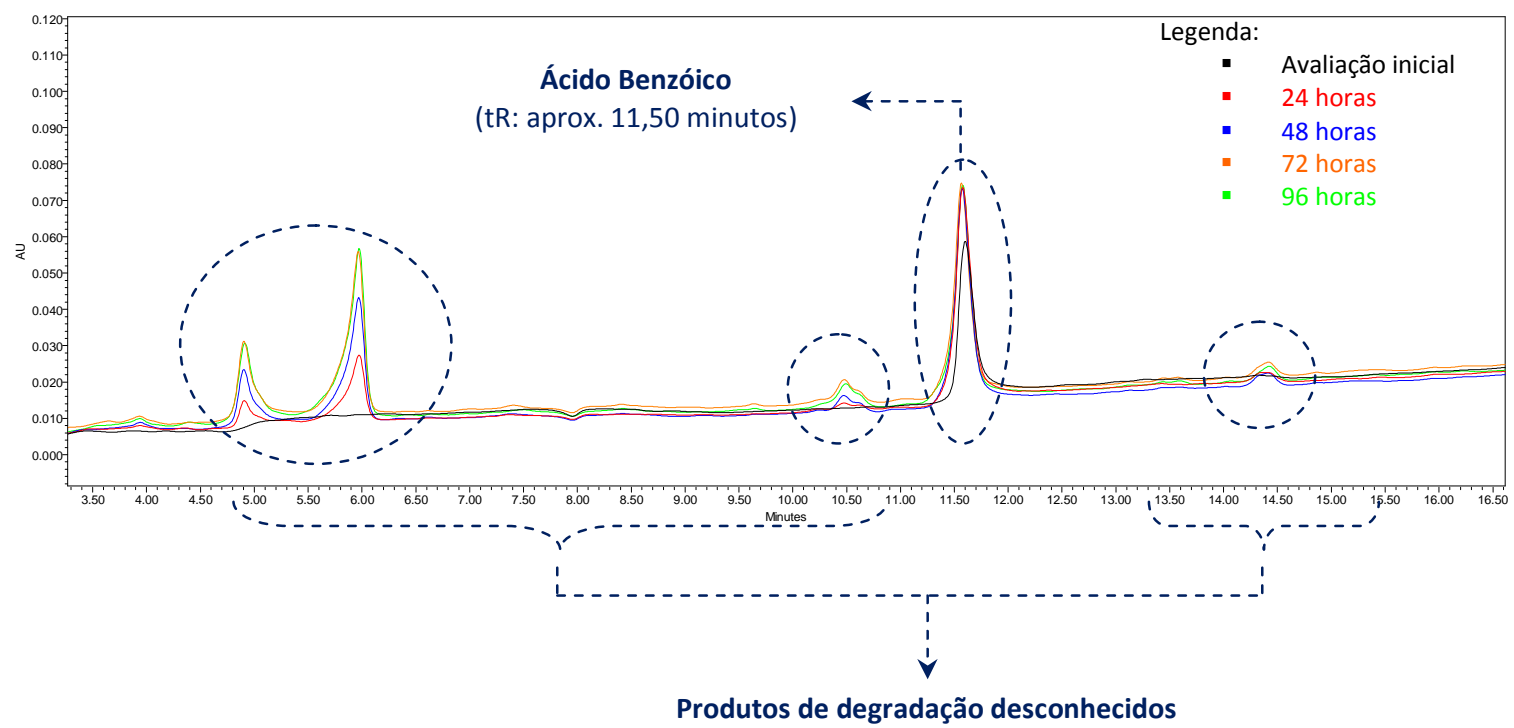

(tRs: aprox. 4,90; 5,90; 10,50 e 14,40 minutos)

FIGURA 52. Cromatograma da solução do fármaco peróxido de benzoíla isolado: $0,628 \mathrm{mg} \cdot \mathrm{mL}^{-1}-$ Calor; Condições: coluna

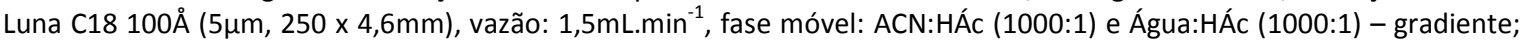
detecção: $235 \mathrm{~nm}$

\subsubsection{HIDRÓLISE ÁCIDA}

g) Sobreposição dos cromatogramas da solução placebo - Hidrólise ácida, nos intervalos: avaliação inicial e 96 horas

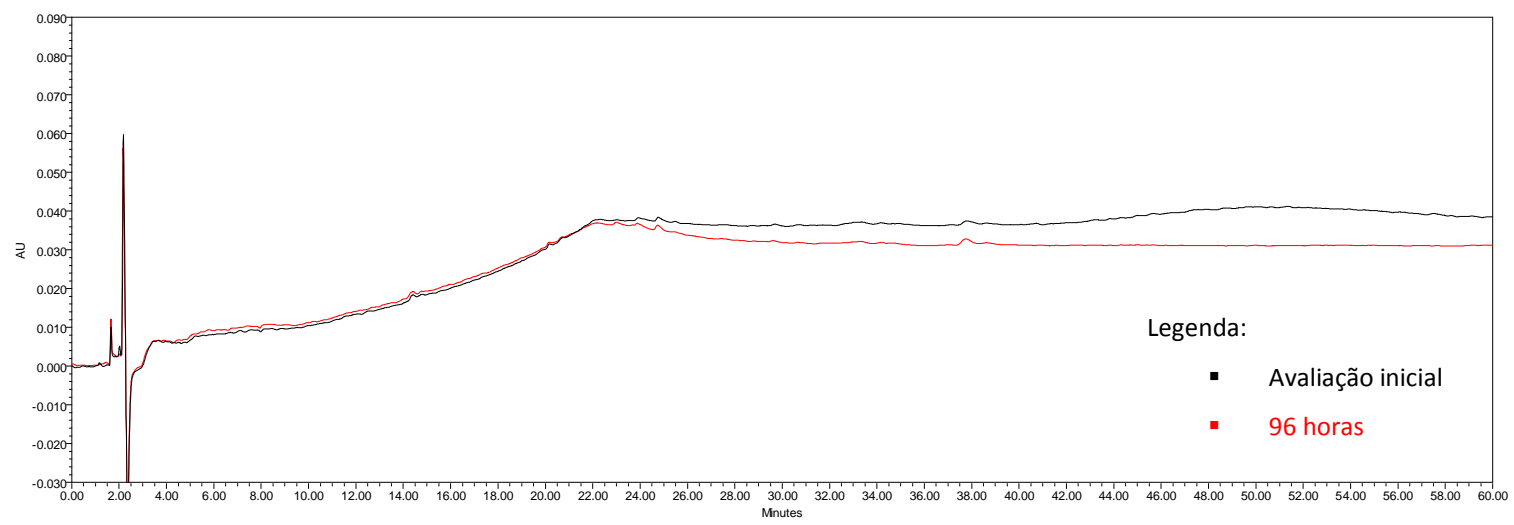

FIGURA 53. Cromatograma da solução placebo: $12,92 \mathrm{mg} \cdot \mathrm{mL}^{-1}$ - Hidrólise ácida; Condições: coluna Luna C18 $100 \AA ̊$ (5 $\mu \mathrm{m}$, 250 x 4,6mm), vazão: 1,5mL.min ${ }^{-1}$, fase móvel: ACN:HÁc (1000:1) e Água:HÁc (1000:1) - gradiente; deteç̧ão: 235nm 
h) Sobreposição dos cromatogramas da solução peróxido de benzoíla gel $\mathbf{4 0} \mathbf{~ m g / g}$

- Hidrólise ácida, nos intervalos: avaliação inicial, 24, 48, 72 e 96 horas

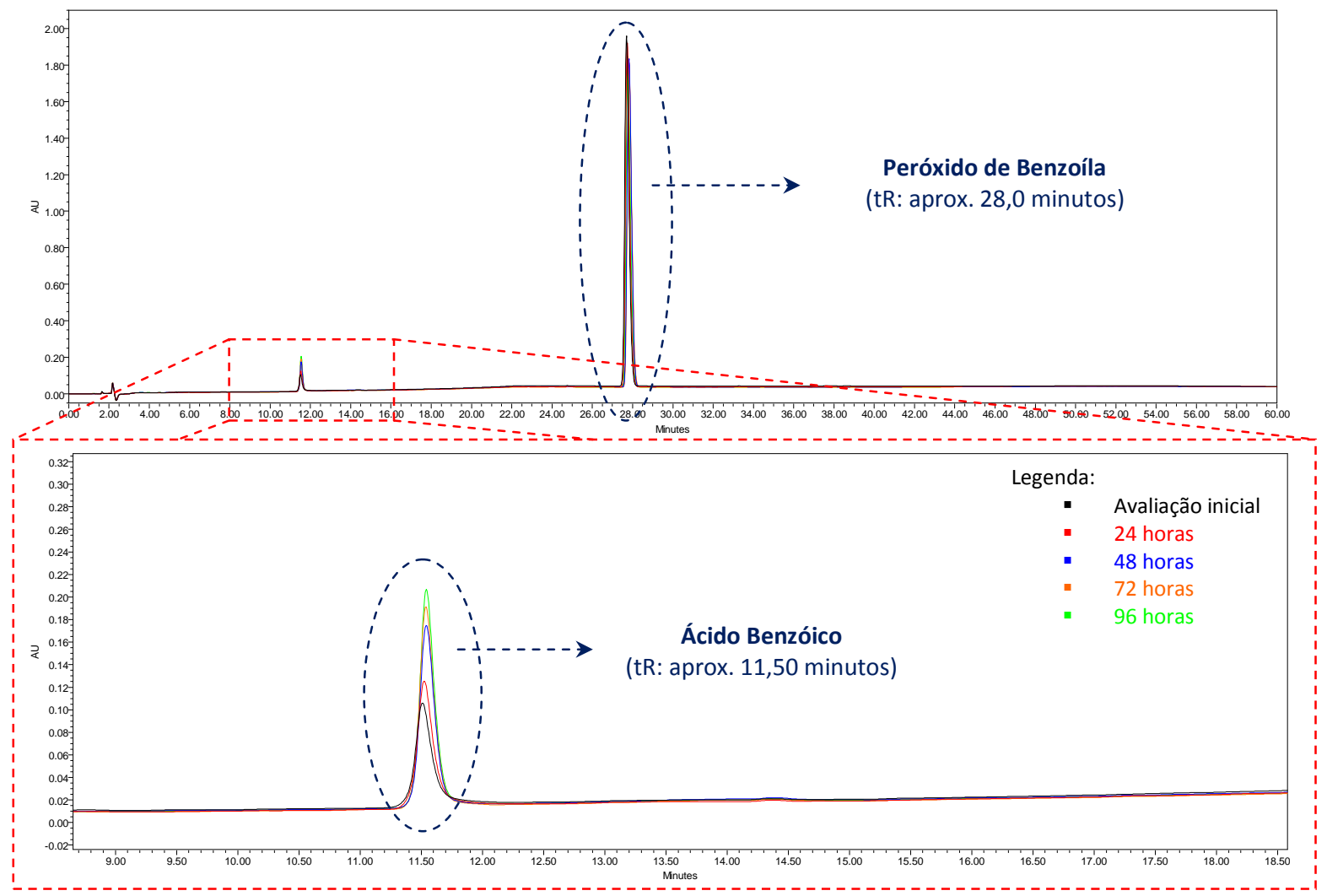

FIGURA 54. Cromatograma da solução do peróxido de benzoíla gel 40mg/g: 10,772 mg.mL ${ }^{-1}$ - Hidrólise ácida; Condições: coluna Luna C18 $100 \AA ̊$ ( $5 \mu \mathrm{m}, 250$ x 4,6mm), vazão: 1,5mL.min ${ }^{-1}$, fase móvel: ACN:HÁc (1000:1) e Água:HÁc (1000:1) - gradiente; deteç̧ão: 235nm

i) Sobreposição dos cromatogramas da solução do fármaco peróxido de benzoíla

isolado - Hidrólise ácida, nos intervalos: avaliação inicial, 24, 48, 72 e 96 horas

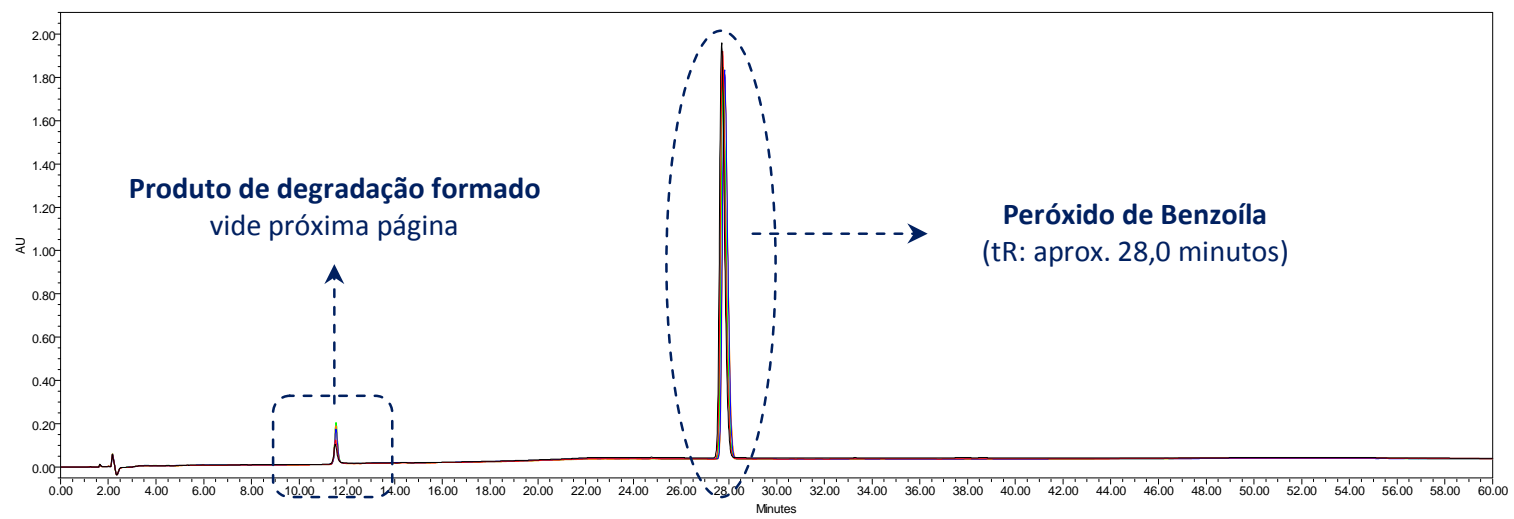

FIGURA 55. Cromatograma da solução do fármaco peróxido de benzoíla isolado: $0,57 \mathrm{mg} \cdot \mathrm{mL}^{-1}$ - Hidrólise ácida; Condições: coluna Luna C18 $100 \AA ̊$ (5 $\mu \mathrm{m}, 250$ x 4,6mm), vazão: 1,5mL.min ${ }^{-1}$, fase móvel: ACN:HÁc (1000:1) e Água:HÁc (1000:1) - gradiente; detecção: 235nm 


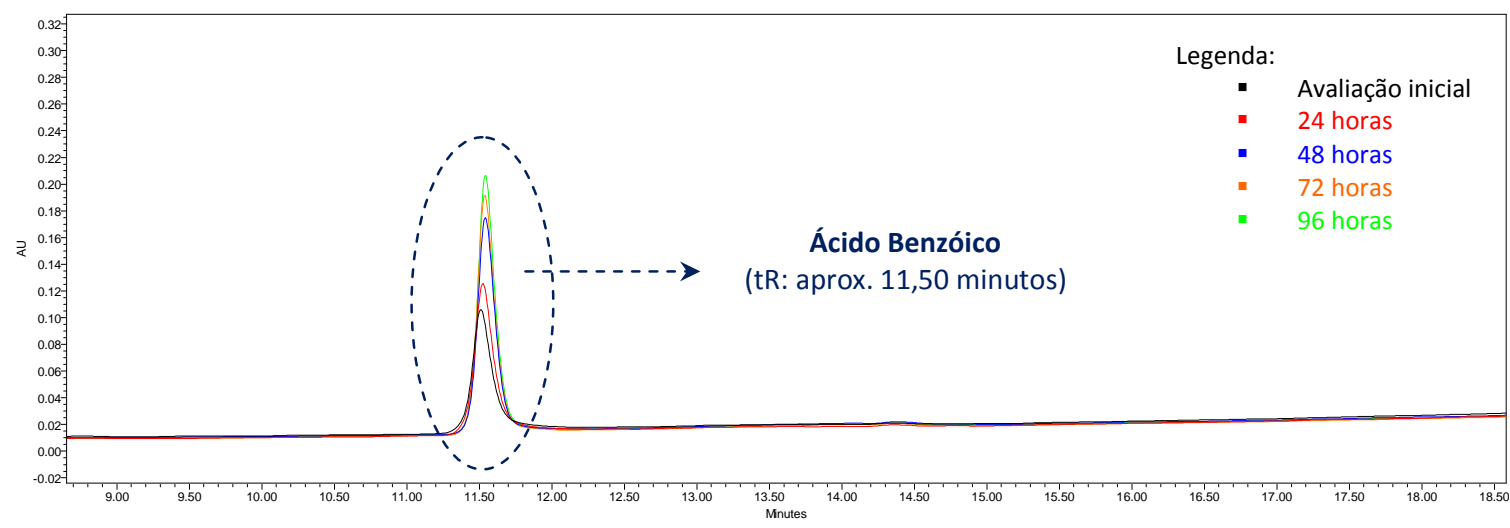

FIGURA 55. Cromatograma da solução do fármaco peróxido de benzoíla isolado: $0,57 \mathrm{mg} \cdot \mathrm{mL}^{-1}$ - Hidrólise ácida; Condições: coluna Luna C18 $100 \AA ̊$ ( $5 \mu \mathrm{m}, 250$ x 4,6mm), vazão: 1,5mL.min ${ }^{-1}$, fase móvel: ACN:HÁc (1000:1) e Água:HÁc (1000:1) - gradiente; deteç̧ão: $235 \mathrm{~nm}$

\subsubsection{HIDRÓLISE ALCALINA}

j) Sobreposição dos cromatogramas da solução placebo - Hidrólise alcalina, nos intervalos: avaliação inicial e 96 horas

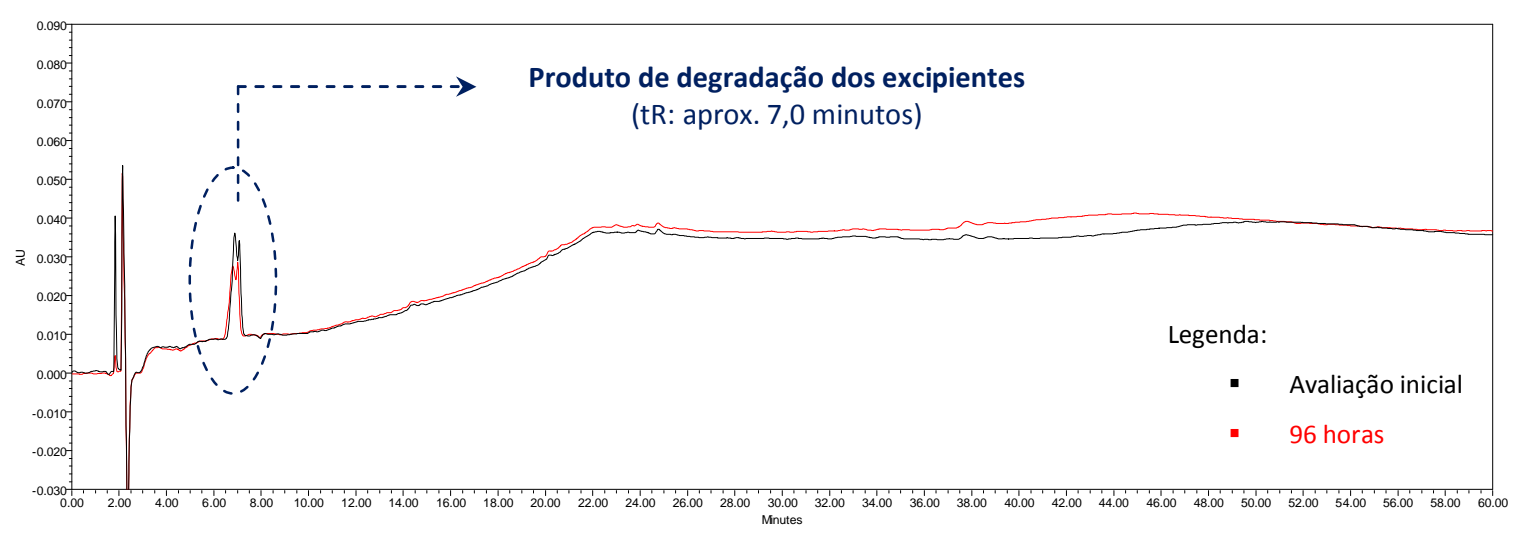

FIGURA 56. Cromatograma da solução placebo: $10,326 \mathrm{mg} \mathrm{mL}^{-1}$ - Hidrólise alcalina; Condições: coluna Luna C18 $100 \AA$ $\left(5 \mu \mathrm{m}, 250\right.$ x 4,6mm), vazão: 1,5mL.min ${ }^{-1}$, fase móvel: ACN:HÁc (1000:1) e Água:HÁc (1000:1) - gradiente; detecção: $235 \mathrm{~nm}$ 
k) Sobreposição dos cromatogramas da solução peróxido de benzoíla gel $40 \mathrm{mg} / \mathrm{g}$

- Hidrólise alcalina, nos intervalos: avaliação inicial, 24, 48, 72 e 96 horas

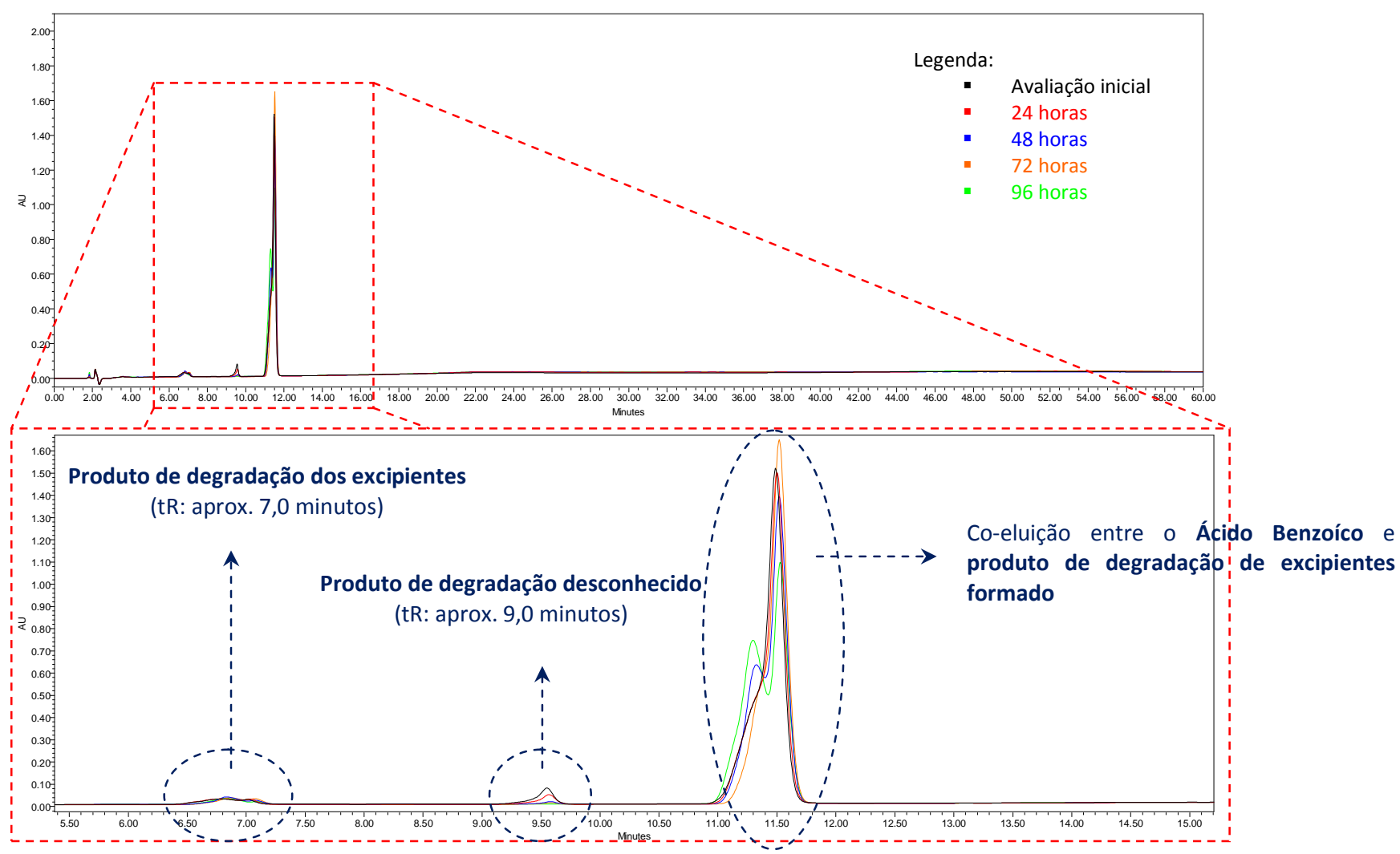

FIGURA 57. Cromatograma da solução do peróxido de benzoíla gel 40mg/g: 10,754 mg.mL ${ }^{-1}$ - Hidrólise alcalina; Condições: coluna Luna

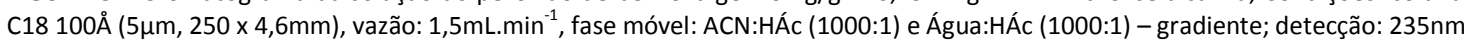

\section{I) Sobreposição dos cromatogramas da solução fármaco peróxido de benzoíla}

isolado-Hidrólise alcalina, nos intervalos: avaliação inicial, 24, 48, 72 e 96 horas

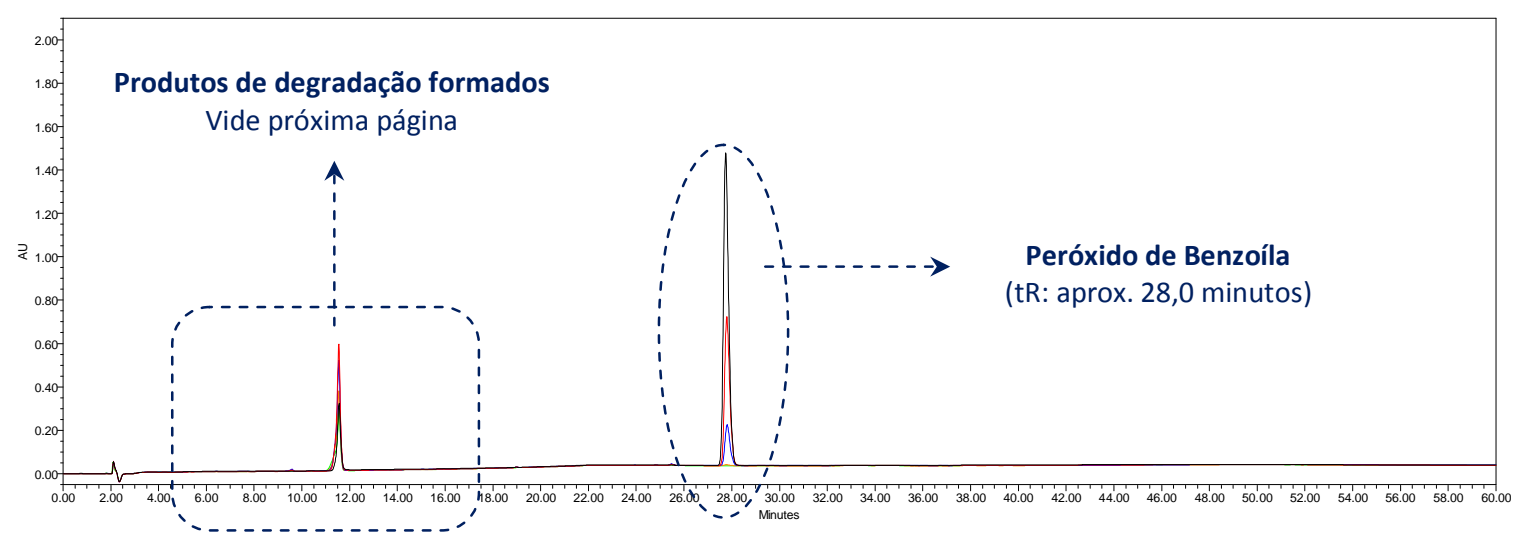

FIGURA 58. Cromatograma da solução do fármaco peróxido de benzoíla isolado: $0,544 \mathrm{mg} \cdot \mathrm{mL}^{-1}$ - Hidrólise alcalina; Condições: coluna

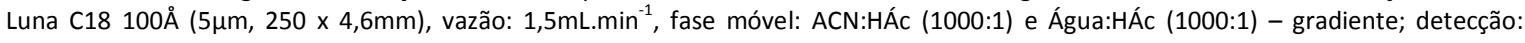
$235 \mathrm{~nm}$ 


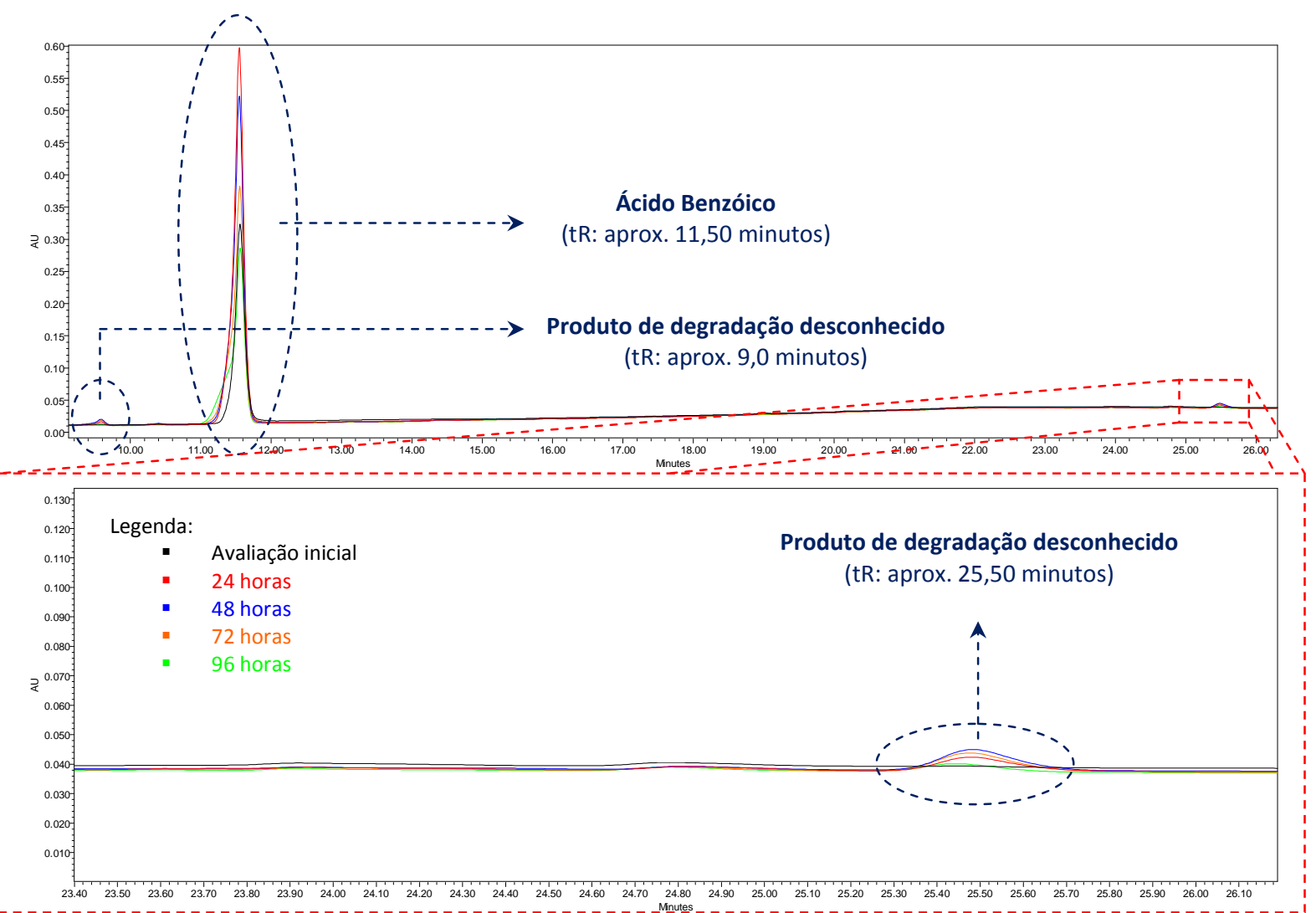

FIGURA 58. Cromatograma da solução do fármaco peróxido de benzoíla isolado: $0,544 \mathrm{mg} \cdot \mathrm{mL}^{-1}$ - Hidrólise alcalina;

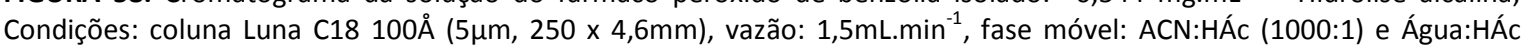
(1000:1) - gradiente; detecção: $235 \mathrm{~nm}$

\subsubsection{OXIDACC̃̃O}

m) Sobreposição dos cromatogramas da solução placebo - oxidação, nos

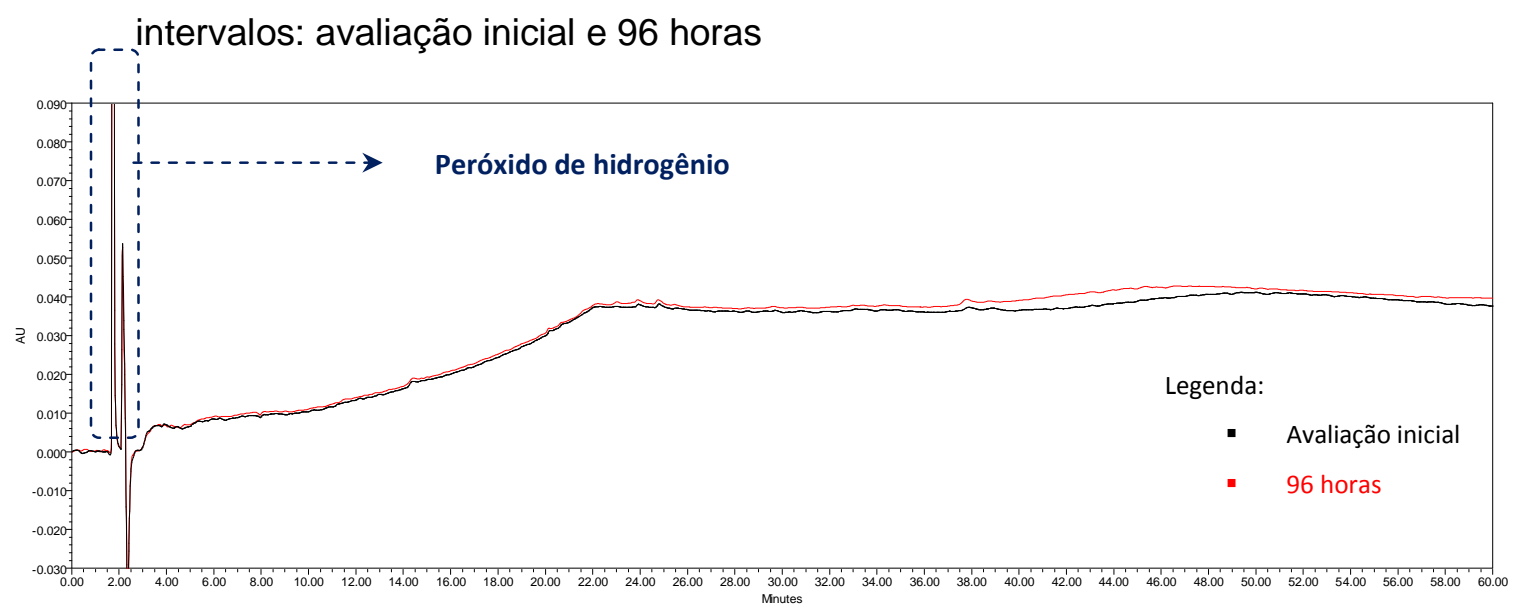

FIGURA 59. Cromatograma da solução placebo: $10,158 \mathrm{mg} \cdot \mathrm{mL}^{-1}$ - Oxidação; Condições: coluna Luna C18 $100 \AA ̊$ (5 $\mu \mathrm{m}, 250$ x 4,6mm), vazão: 1,5mL.min ${ }^{-1}$, fase móvel: ACN:HÁc (1000:1) e Água:HÁc (1000:1) - gradiente; detecção: 235nm 
n) Sobreposição dos cromatogramas da solução peróxido de benzoíla gel $40 \mathrm{mg} / \mathbf{g}$

- Oxidação, nos intervalos: avaliação inicial, 24, 48, 72 e 96 horas

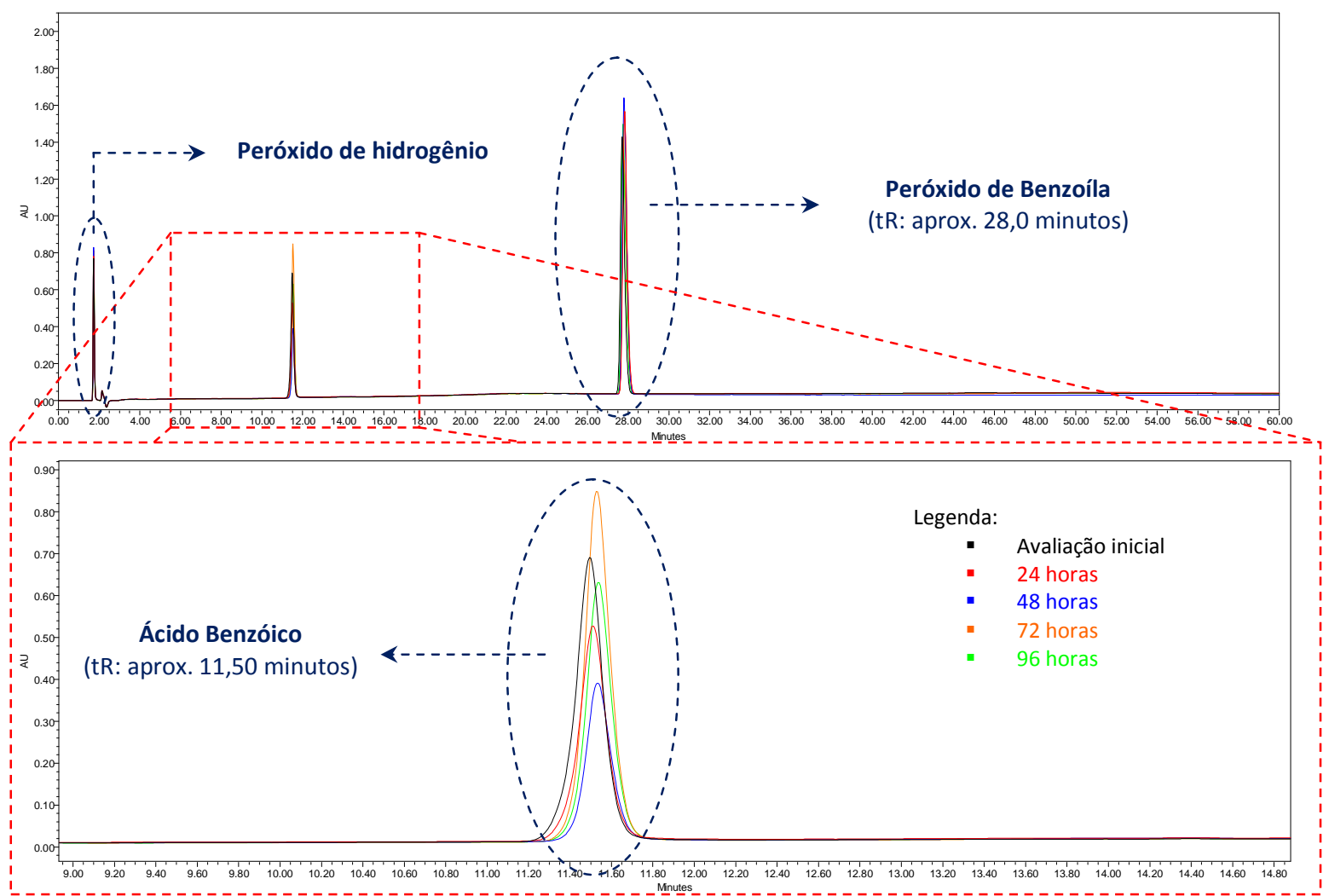

FIGURA 60. Cromatograma da solução do peróxido de benzoíla gel 40mg/g: 10,50 mg.mL ${ }^{-1}$ - Oxidação; Condições: coluna Luna C18 $100 \AA$ $\left(5 \mu \mathrm{m}, 250\right.$ x 4,6mm), vazão: 1,5mL.min ${ }^{-1}$, fase móvel: ACN:HÁc (1000:1) e Água:HÁc (1000:1) - gradiente; detecção: 235nm

o) Sobreposição dos cromatogramas da solução fármaco peróxido de benzoíla isolado-Oxidação, nos intervalos de avaliação: avaliação inicial, 24, 48, 72 e 96 horas

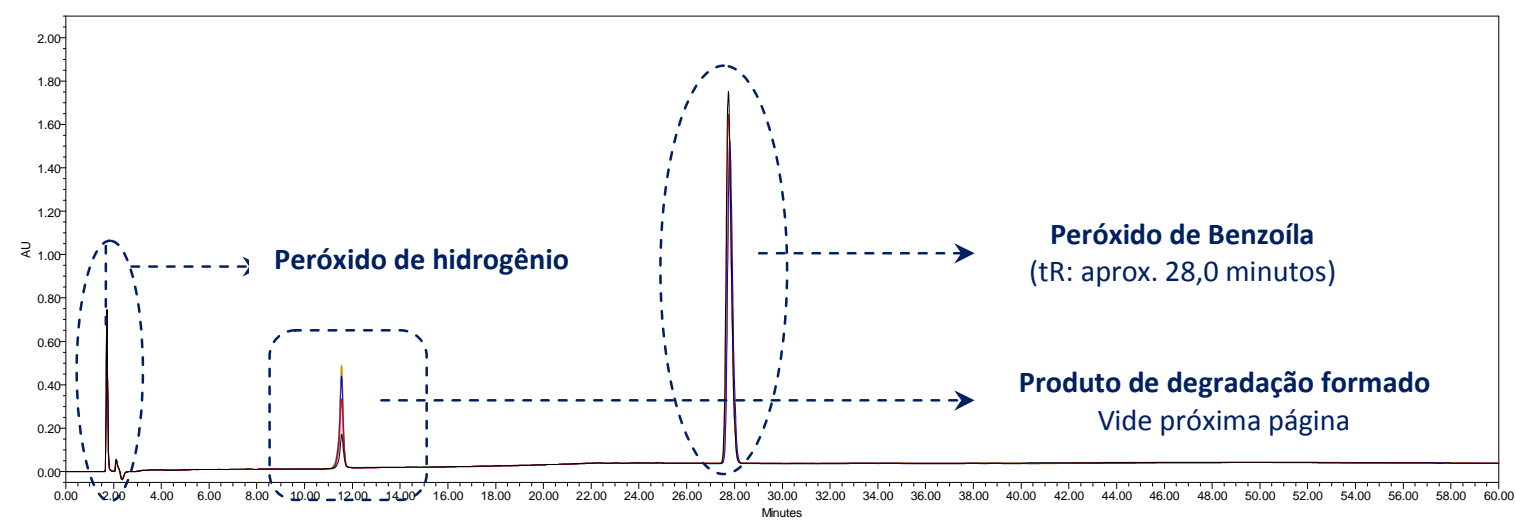

FIGURA 61. Cromatograma da solução do fármaco peróxido de benzoíla isolado: $0,576 \mathrm{mg}^{-\mathrm{mL}^{-1}}$ - Oxidação; Condições: coluna Luna C18 $100 \AA ̊$ ( $5 \mu \mathrm{m}, 250$ x 4,6mm), vazão: 1,5 mL.min ${ }^{-1}$, fase móvel: ACN:HÁc (1000:1) e Água:HÁc (1000:1) - gradiente; deteç̧ão: 235nm 


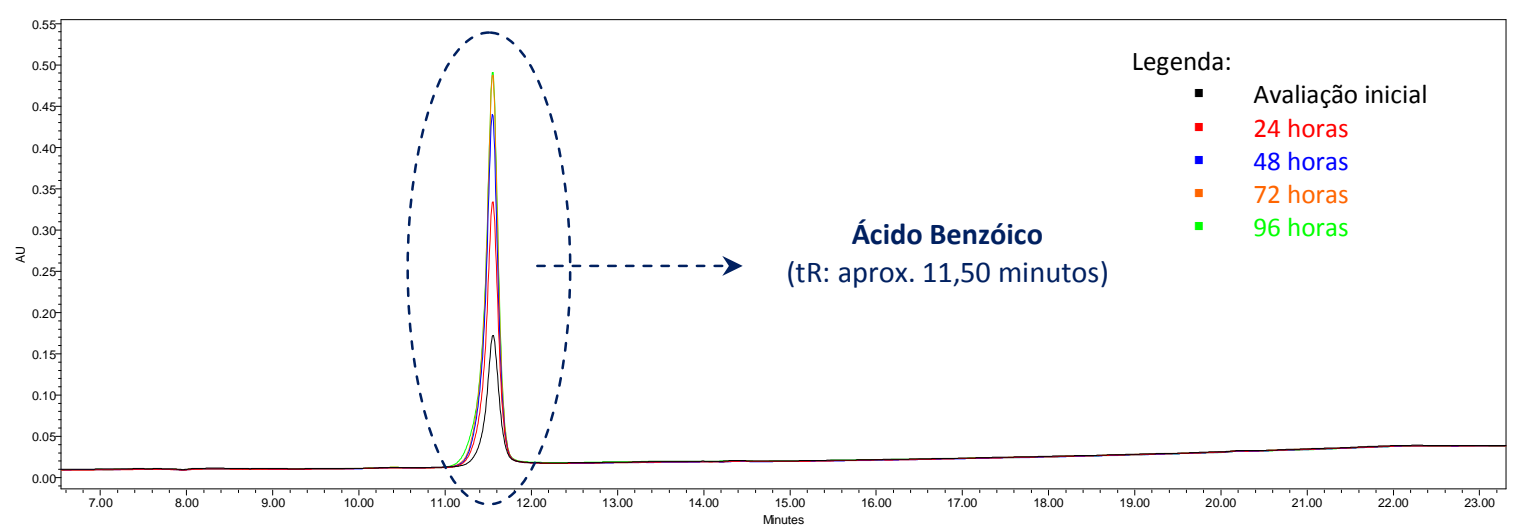

FIGURA 61. Cromatograma da solução do fármaco peróxido de benzoíla isolado: $0,576 \mathrm{mg}^{\mathrm{mL}} \mathrm{L}^{-1}$ - Oxidação; Condições: coluna Luna C18 $100 \AA$ ( $5 \mu \mathrm{m}, 250$ x 4,6mm), vazão: 1,5mL.min ${ }^{-1}$, fase móvel: ACN:HÁc (1000:1) e Água:HÁc (1000:1) gradiente; detecção: $235 \mathrm{~nm}$

\subsubsection{FOTÓLISE}

p) Sobreposição dos cromatogramas da solução placebo - Fotólise, nos intervalos: avaliação inicial versus amostra estressada a 200 Whatt.h/m²

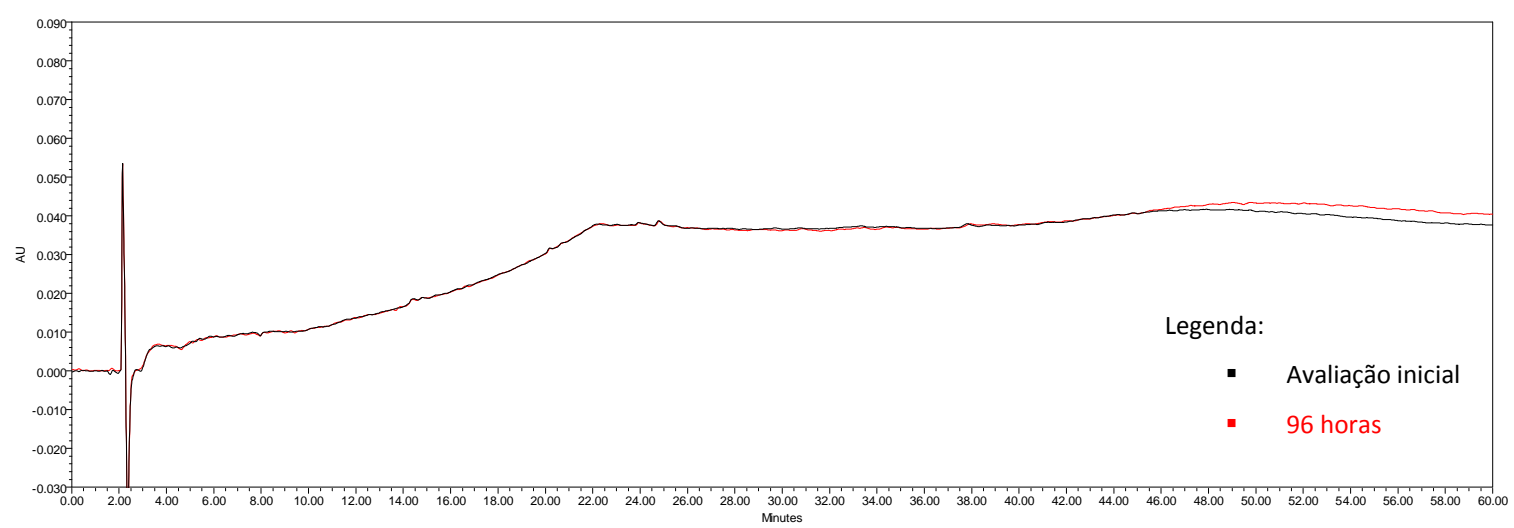

FIGURA 62. Cromatograma da solução placebo: $12,812 \mathrm{mg} \cdot \mathrm{mL}^{-1}$ - Fotólise; Condições: coluna Luna C18 $100 \AA ̊$ (5 $\mu \mathrm{m}, 250 \mathrm{x}$ 4,6mm), vazão: 1,5mL.min ${ }^{-1}$, fase móvel: ACN:HÁc (1000:1) e Água:HÁc (1000:1) - gradiente; detecção: 235nm 
q) Sobreposição dos cromatogramas da solução peróxido de benzoíla gel $40 \mathrm{mg} / \mathbf{g}$

- Fotólise, nos intervalos: avaliação inicial versus amostra estressada à 200Whatt.h $/ \mathrm{m}^{2}$

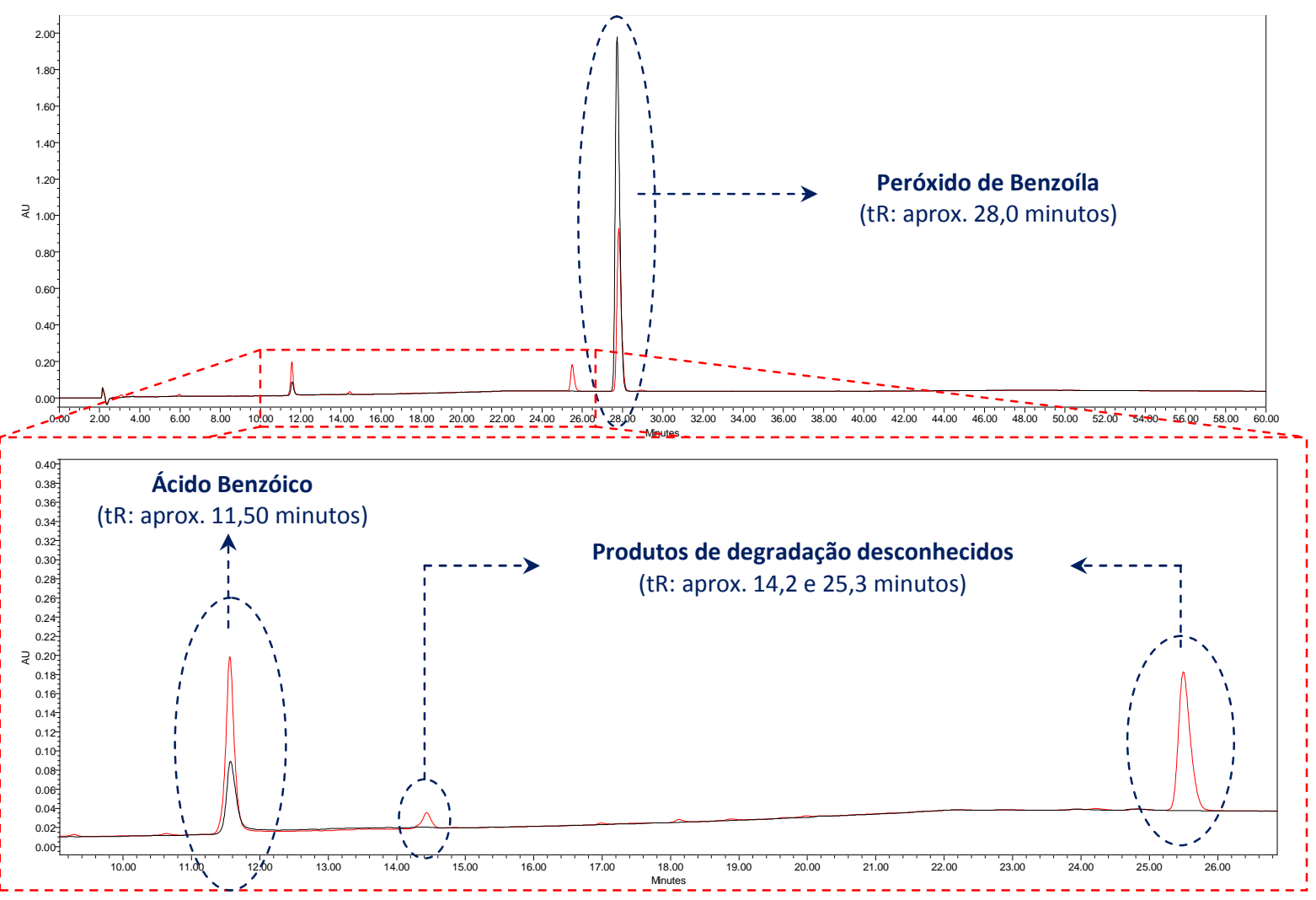

FIGURA 63. Cromatograma da solução do peróxido de benzoíla gel 40mg/g: 10,792 mg.mL ${ }^{-1}$ - Fotólise; Condições: coluna

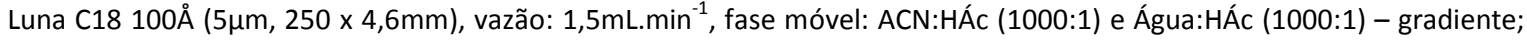
deteç̧ão: $235 \mathrm{~nm}$ 
r) Sobreposição dos cromatogramas da solução do fármaco peróxido de benzoíla isolado - Fotólise, nos intervalos de avaliação: análise inicial versus amostra estressada a 200 Whatt.h/m²

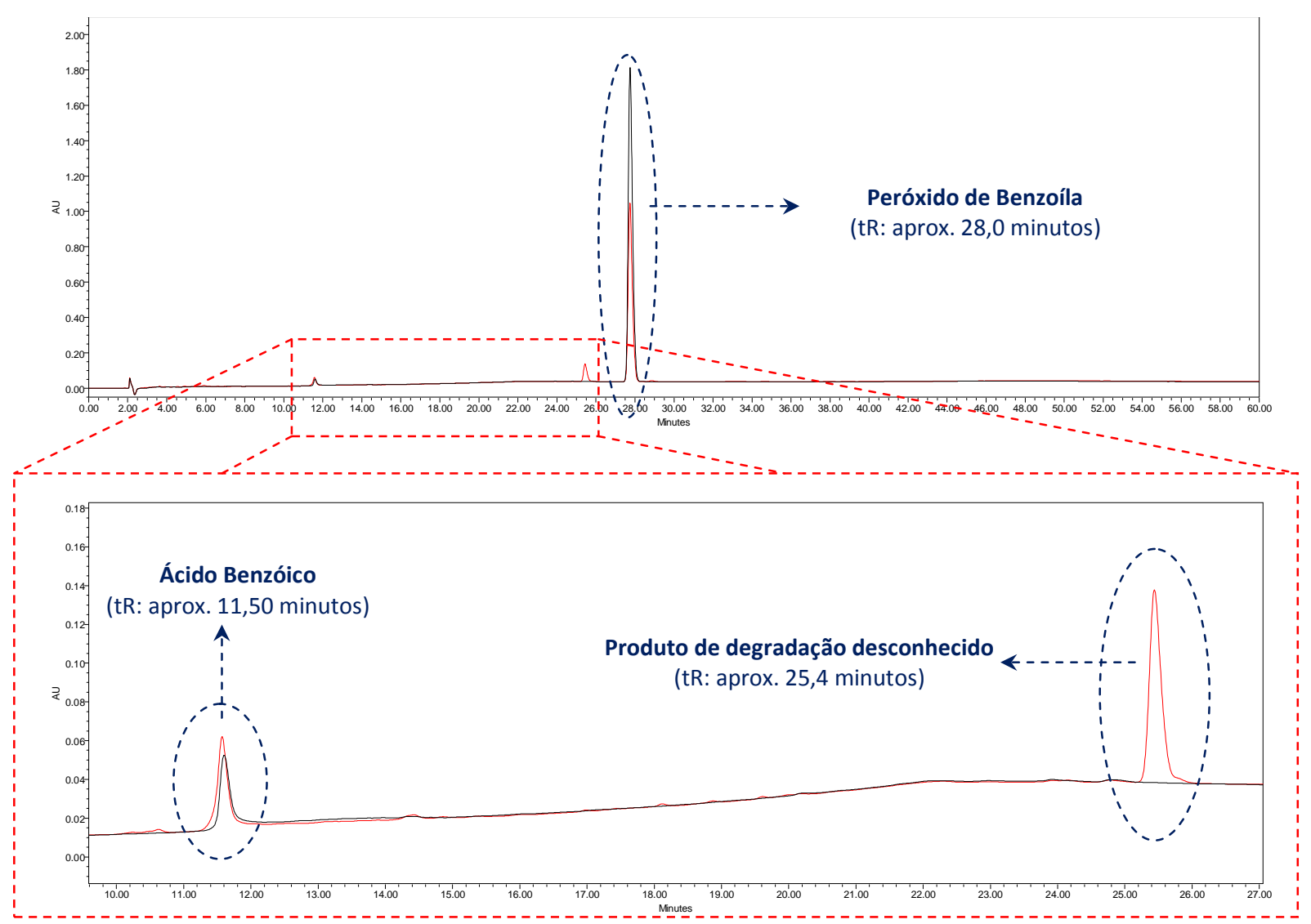

FIGURA 64. Cromatograma da solução do fármaco peróxido de benzoíla isolado: $0,568 \mathrm{mg} \cdot \mathrm{mL}^{-1}$ - Fotólise; Condições:

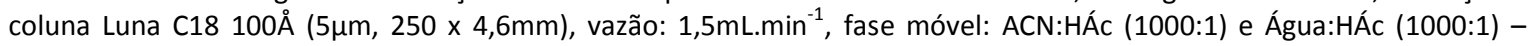
gradiente; detecção: $235 \mathrm{~nm}$

\section{s) Cromatograma da solução branco - Acetronitrila grau HPLC}

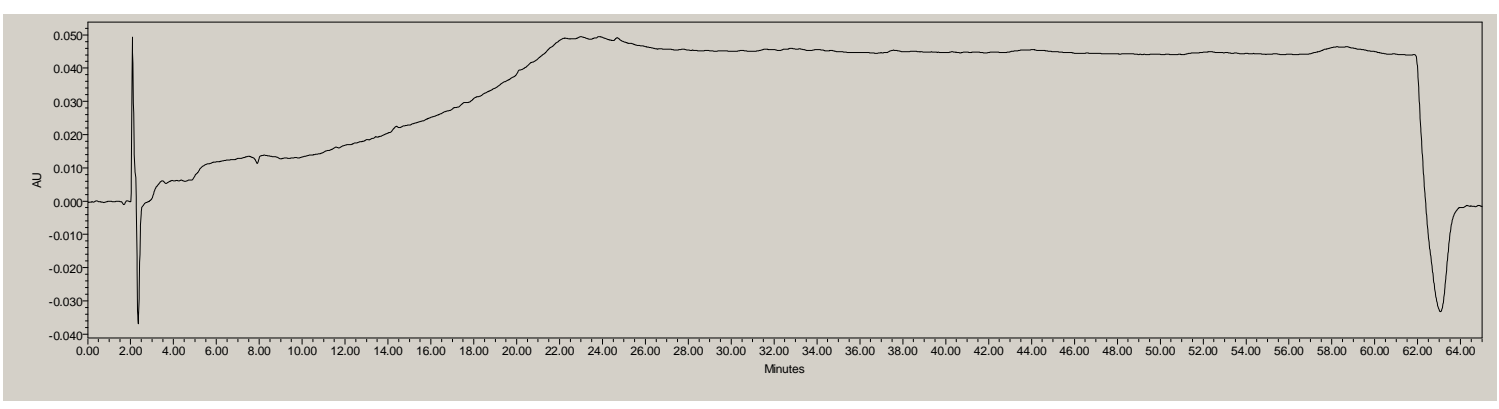

FIGURA 65. Cromatograma da solução branco - Acetonitrila grau HPLC; Condições: coluna Luna C18 $100 \AA$ ( $5 \mu \mathrm{m}, 250 \mathrm{x}$ 4,6mm), vazão: 1,5mL. $\mathrm{min}^{-1}$, fase móvel: ACN:HÁc (1000:1) e Água:HÁc (1000:1) - gradiente; detecção: 235nm 
t) Sobreposição dos cromatograma da solução de peróxido de benzoíla gel 40mg/g - referência, nos intervalos: avaliação inicial, 24, 48, 72 e 96 horas

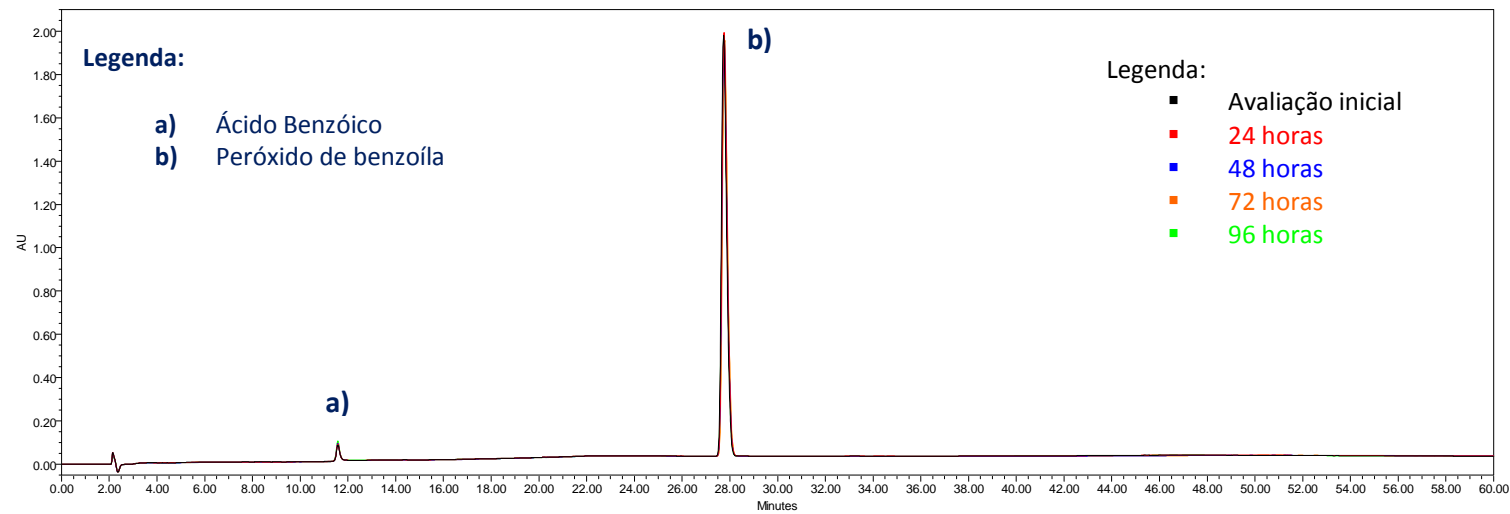

FIGURA 66. Cromatograma da solução do peróxido de benzoíla gel 40mg/g: 10,50 mg.mL $\mathrm{m}^{-1}$ - Oxidação; Condições: coluna Luna C18 $100 \AA ̊$ ( $5 \mu \mathrm{m}, 250$ x 4,6mm), vazão: 1,5 $\mathrm{mL} \mathrm{min}^{-1}$, fase móvel: ACN:HÁc (1000:1) e Água:HÁc (1000:1) - gradiente; detecção: $235 \mathrm{~nm}$

u) Sobreposição dos cromatograma da solução de peróxido de benzoíla gel 40mg/g - referência, com zoom no comportamento do peróxido de benzoíla, nos intervalos: avaliação inicial, 24, 48, 72 e 96 horas

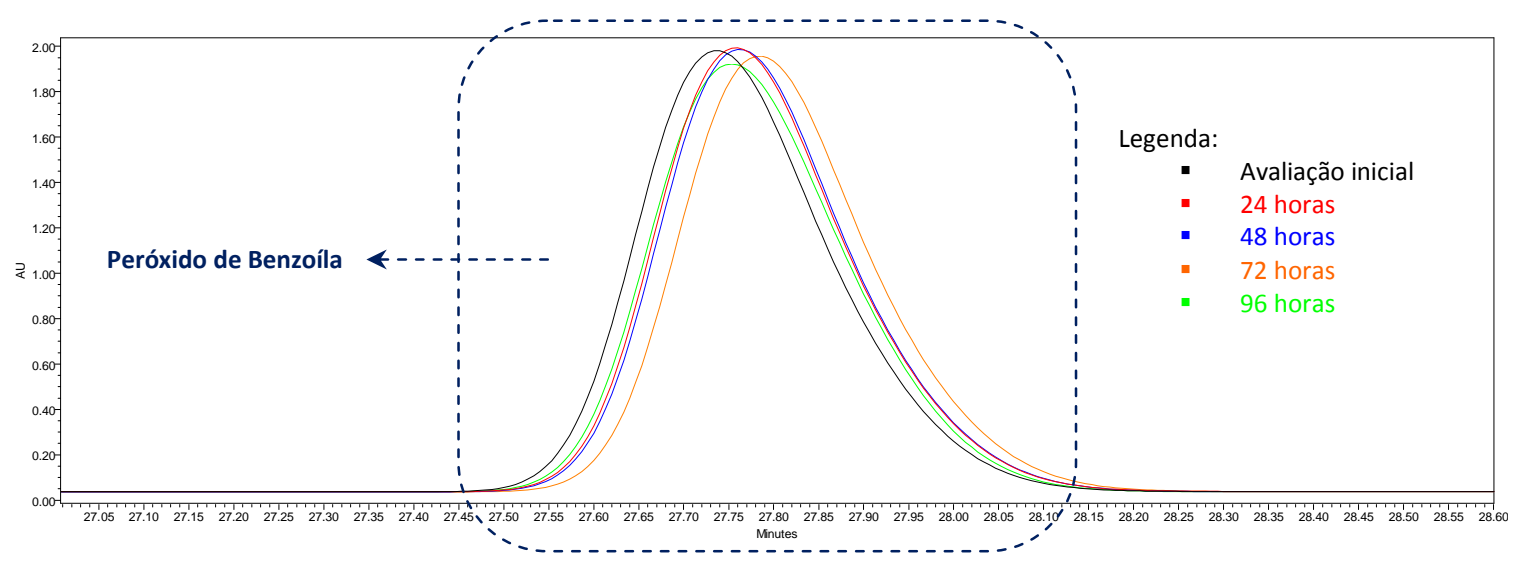

FIGURA 67. Cromatograma da solução do peróxido de benzoíla gel 40mg/g: 10,50 mg.mL ${ }^{-1}$ - Oxidação; Condições: coluna Luna C18 $100 \AA ̊$ (5 $\mu \mathrm{m}, 250$ x 4,6mm), vazão: 1,5mL.min ${ }^{-1}$, fase móvel: ACN:HÁc (1000:1) e Água:HÁc (1000:1) - gradiente; detecção: 235nm 
v) Sobreposição dos cromatogramas da solução de peróxido de benzoíla gel 40mg/g - referência, com zoom no comportamento do ácido benzóico, nos intervalos: avaliação inicial, 24, 48, 72 e 96 horas

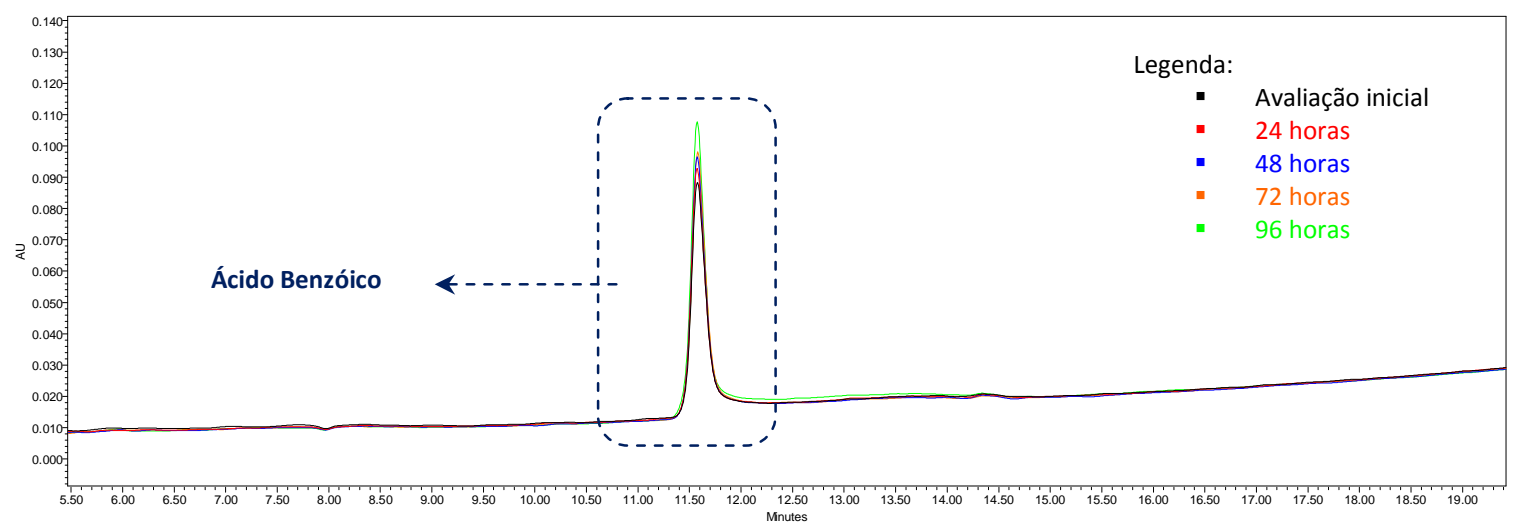

FIGURA 68. Cromatograma da solução do peróxido de benzoíla gel $40 \mathrm{mg} / \mathrm{g}: 10,50 \mathrm{mg} \cdot \mathrm{mL}^{-1}$ - Oxidação; Condições: coluna

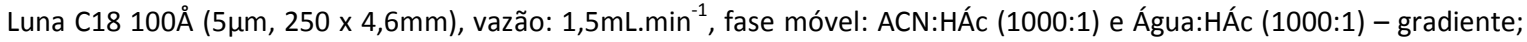
detecção: $235 \mathrm{~nm}$

w) Sobreposição dos cromatogramas da solução padrão de trabalho - referência, nos intervalos: avaliação inicial, 24, 48, 72 e 96 horas

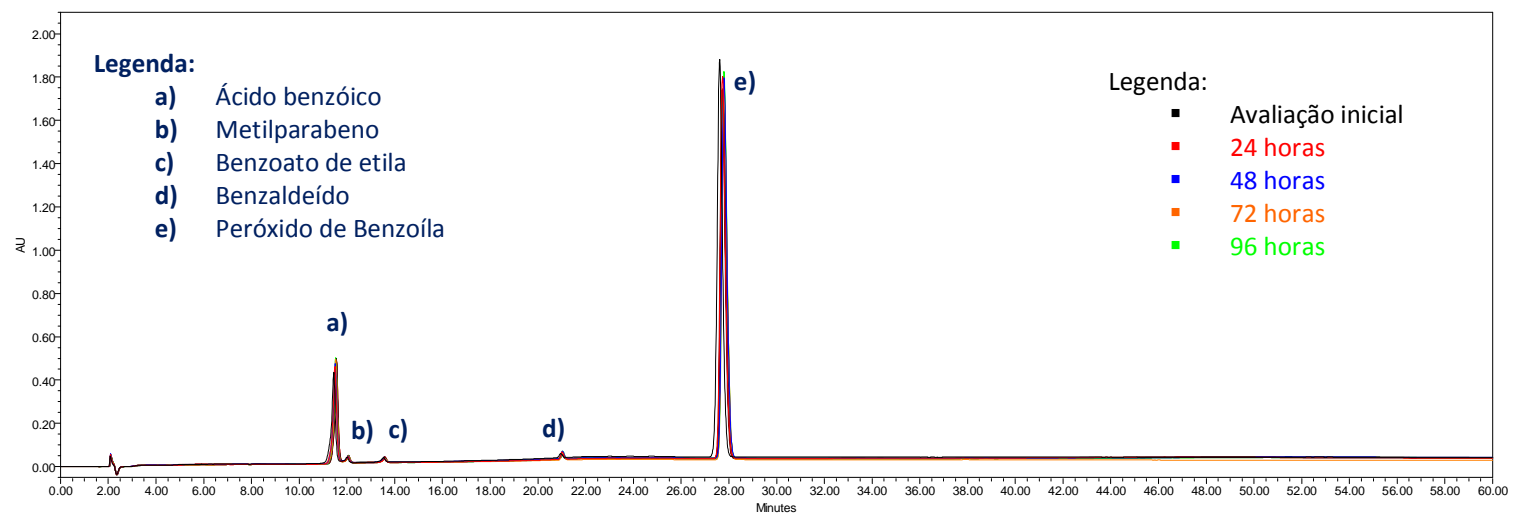

FIGURA 69. Cromatograma da solução de peróxido de benzoíla (referência) 0,42375 mg.mL $\mathrm{mL}^{-1}$, ácido benzóico 0,10157 mg.mL $\mathrm{mL}^{-1}$, benzaldeído $0,0051 \mathrm{mg} \cdot \mathrm{mL}^{-1}$, benzoato de etila $0,00548 \mathrm{mg} \mathrm{mL}^{-1}$ e metilparabeno $0,016 \mathrm{mg} \cdot \mathrm{mL}^{-1}$; Condições: coluna Luna C18 $100 \AA ̊(5 \mu \mathrm{m}, 250$ x 4,6mm), vazão: 1,5mL.min-1, fase móvel: ACN:HÁc (1000:1) e Água:HÁc (1000:1) - gradiente; detecção: $235 \mathrm{~nm}$. 


\section{RESULTADOS DE LC-MS/MS OBTIDOS DURANTE A IDENTIFICAÇÃO DO PRODUTOS DE DEGRADAÇÃO FORMADO NA FOTÓLISE}

\subsection{FÁRMACO ISOLADO}

a) Espectro de massas do Peróxido de Benzoíla isolado estressado a 200 Whatt.h/m² - Modo TIC

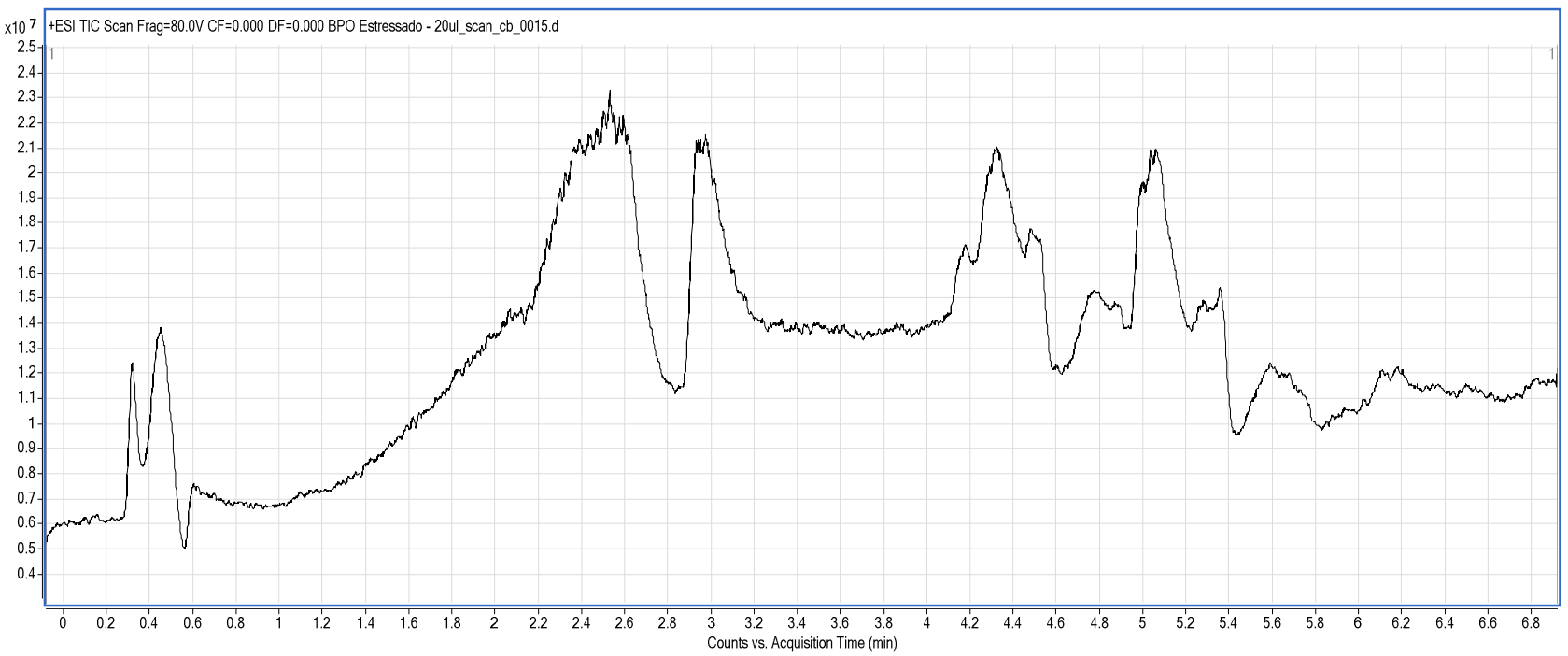

FIGURA 70. Cromatograma exploratório no modo TIC do Peróxido de Benzoíla estressado por fotólise - volume de injeção $20 \mu \mathrm{L}$.

b) Cromatograma do peróxido de benzoíla estressado a 200 Whatt.h $/ \mathrm{m}^{2}$

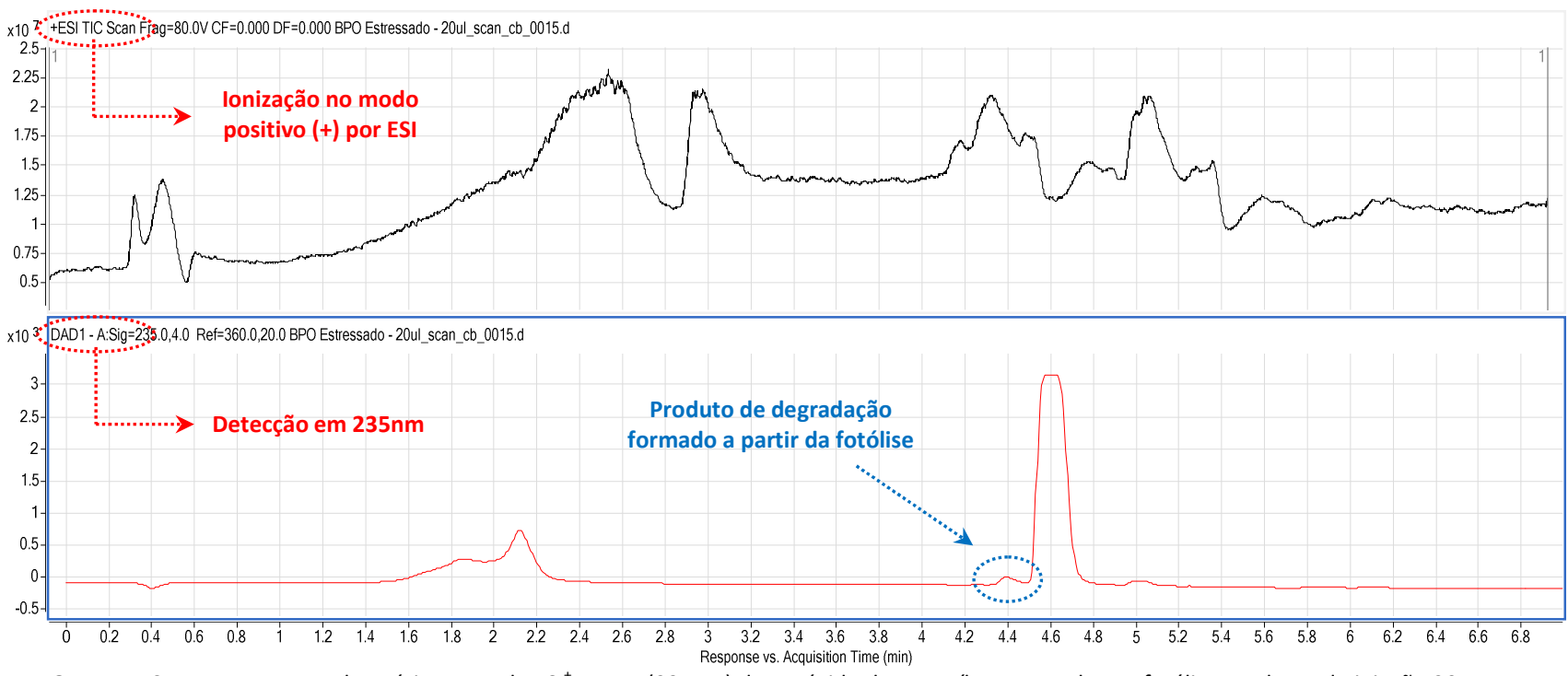

FIGURA 71.Cromatograma exploratório no modo ESI ${ }^{+}$e DAD $(235 \mathrm{~nm})$ do Peróxido de Benzoíla estressado por fotólise - volume de injeção $20 \mu \mathrm{L}$. 
c) Espectro de massas do produto de degradação formado após degradação do peróxido de benzoíla a 200 Whatt.h/m²

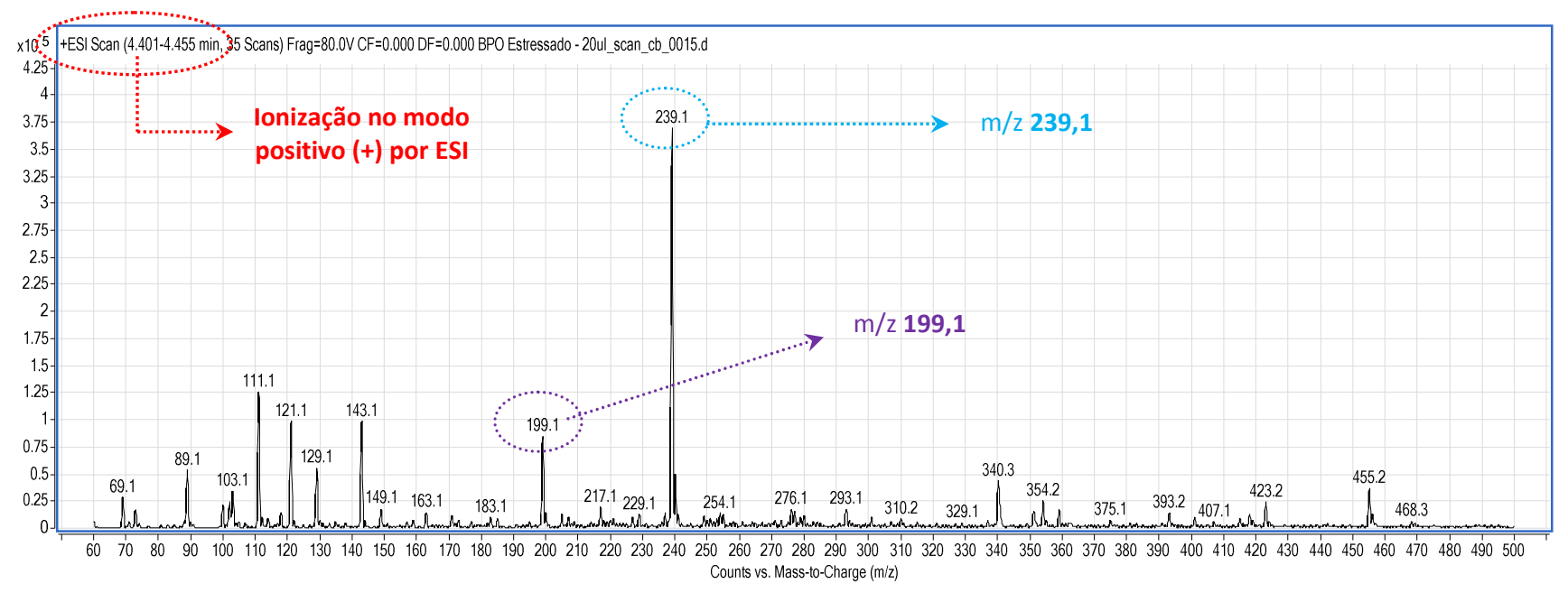

FIGURA 72. Espectro de massas do produto de degradação formado durante a fotólise.

d) Espectro de massas da região sem a presença de grupos cromóforos (Fase Móvel)

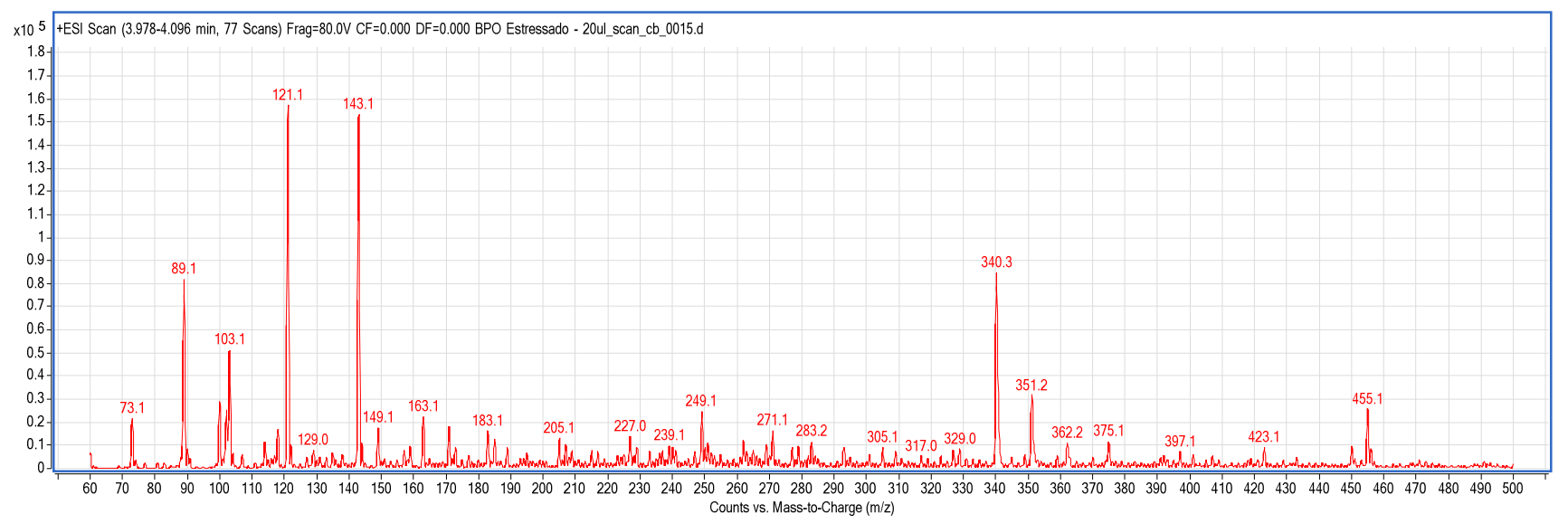

FIGURA 73. Espectro de massas da região sem a presença de grupos cromóforos. 
e) Sobreposição dos espectros de massa do produto de degradação formado e a região sem a presença de grupos cromóforos (Fase Móvel)

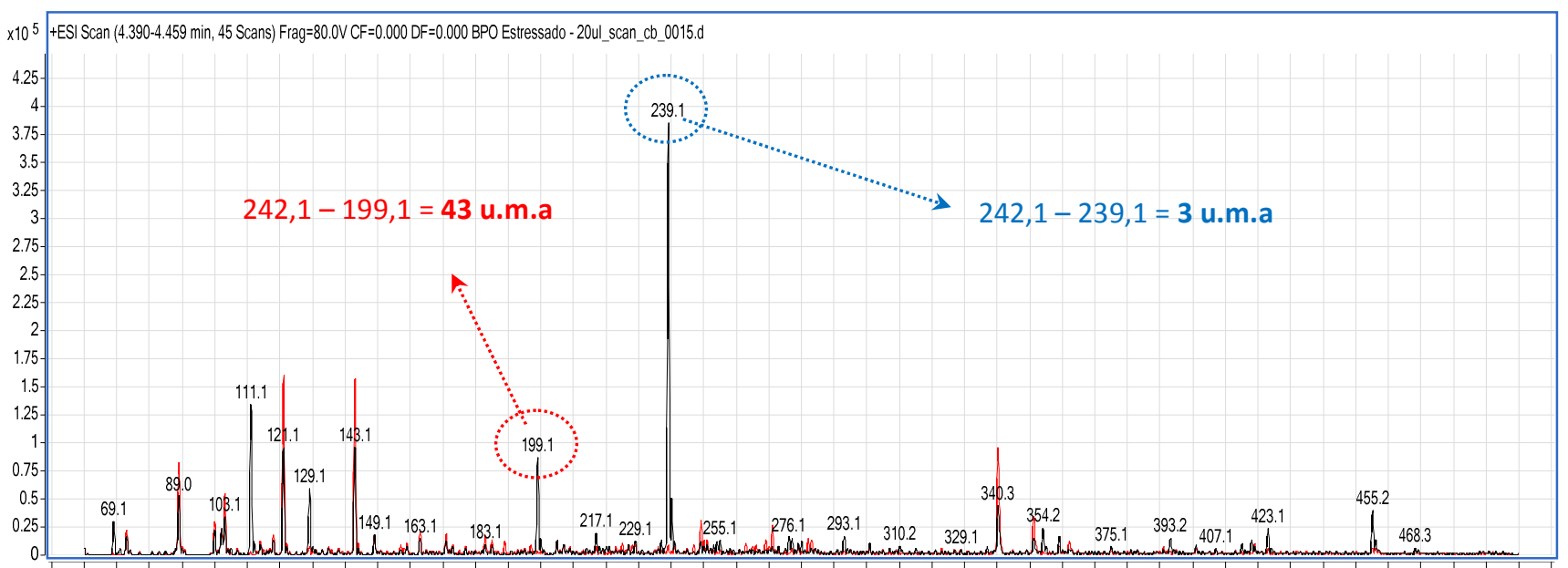

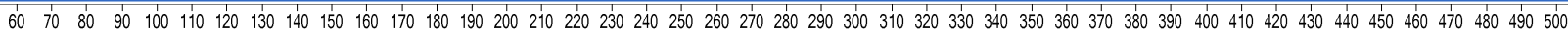
Counts vs. Mass-to-Charge $(\mathrm{m} / \mathrm{z})$

FIGURA 74. Sobreposição dos Espectros de massas do produto de degradação formado durante a fotólise e da região sem a formação de cromóforos.

f) Vista no detalhe do espectro de massas do íon de $\mathbf{m} / \mathbf{z} 199,1$

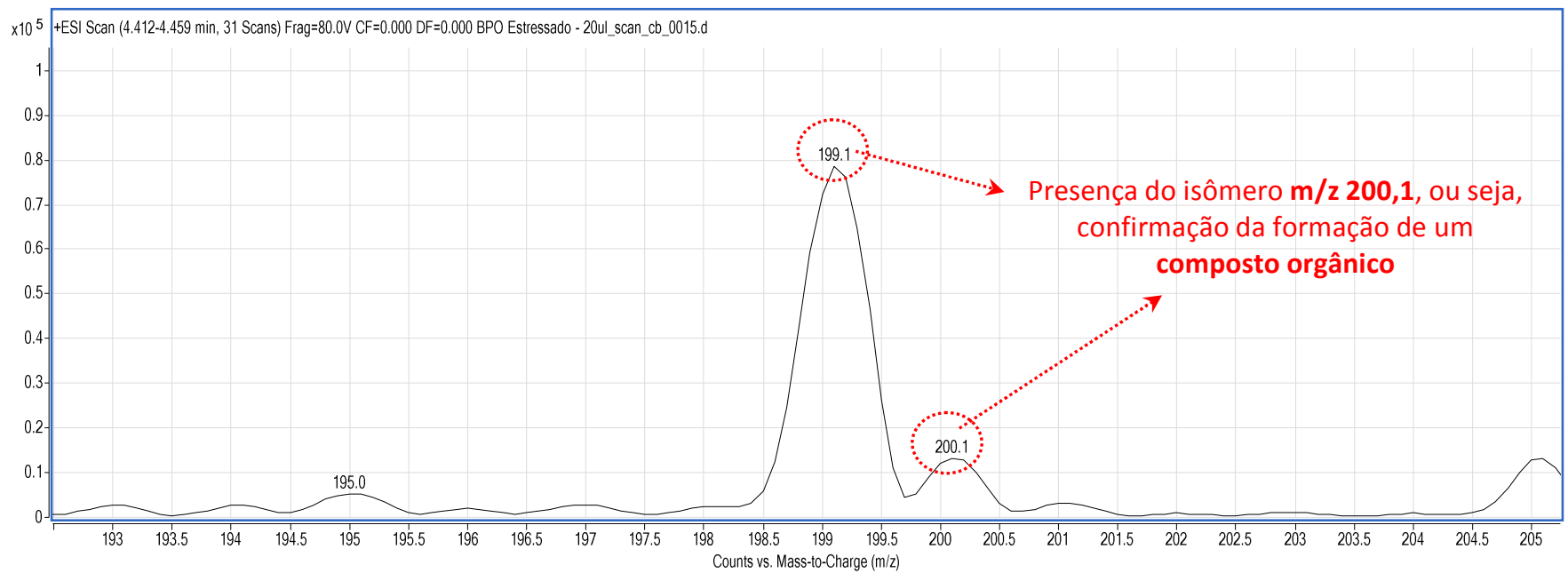

FIGURA 75. Espectro de massas do produto de degradação formado durante a fotólise, com detalhe no íon de m/z 199,1. 
g) Vista no detalhe do espectro de massas íon de $\mathbf{m} / \mathbf{z} \mathbf{2 3 9 , 1}$

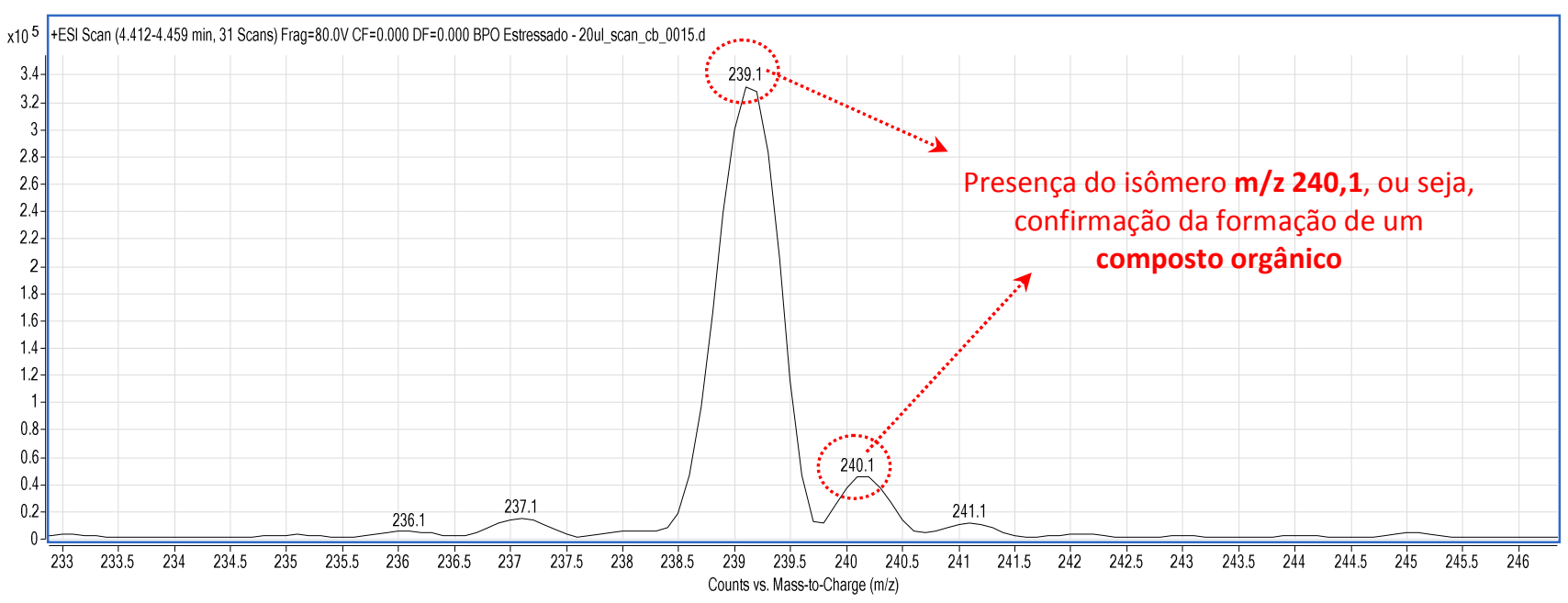

FIGURA 76. Espectro de massas do produto de degradação formado durante a fotólise, com detalhe no íon de m/z 239,1.

\section{h) Confirmação da pureza do pico do produto de degradação formado na degradação do peróxido de benzoíla a 200 Whatt.h/m²}

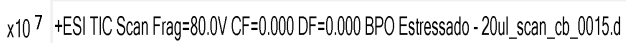

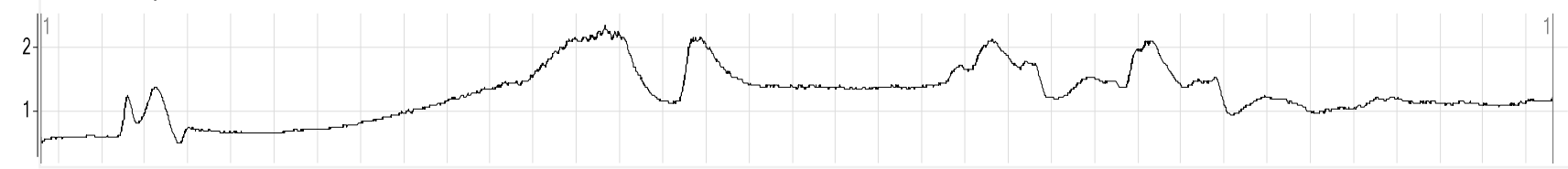

x10 3 DAD1-A.Sig=235.0,4.0 Ref=360.0,20.0BPOEEstressado-20ul_scan_cb_0015.d

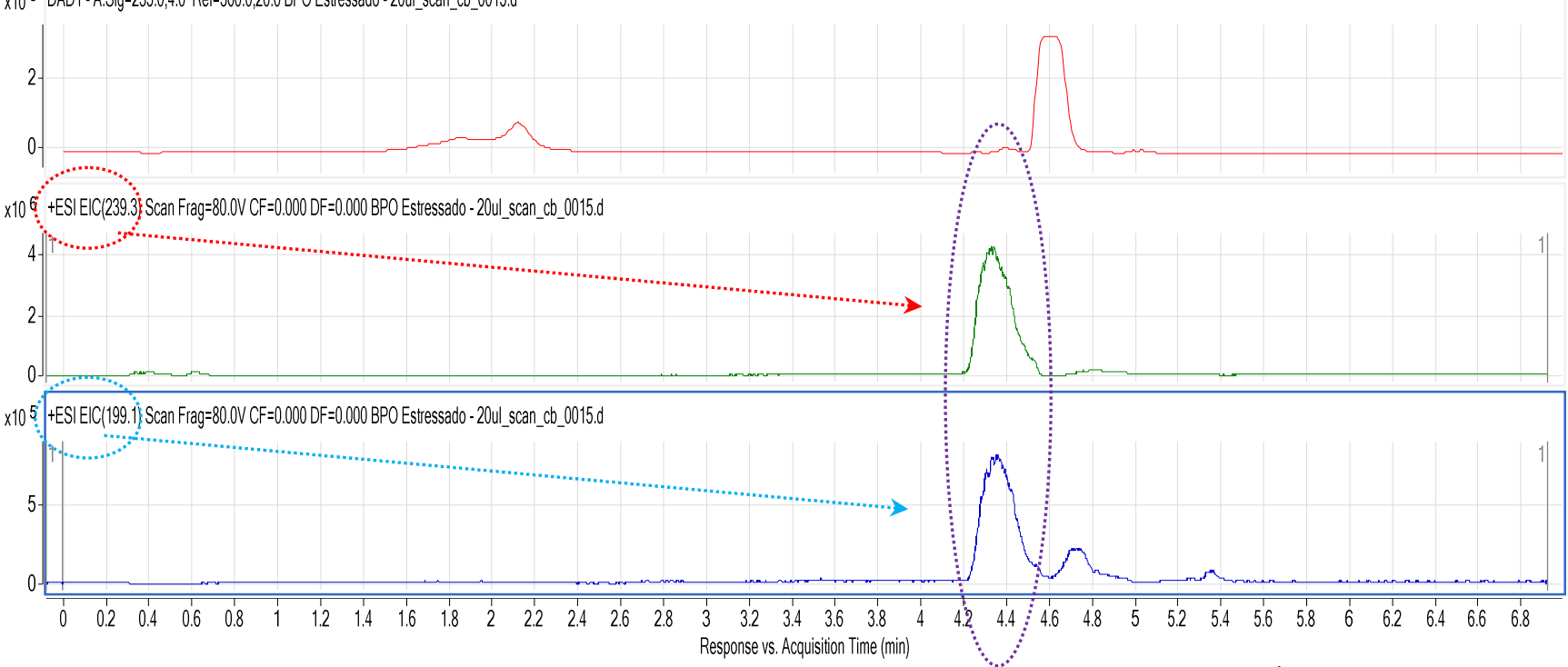

FIGURA 77. Espectro de massas do produto de degradação formado durante a fotólise, com detalhe no íon de m/z 199,0 e239,1. 


\subsection{FÁRMACO INSERIDO NA PREPARAÇÃO MEDICAMENTOSA}

a) Espectro de Massas do peróxido de benzoíla estressado a 200 Whatt.h/m $\mathbf{m}^{2}$ Modo TIC

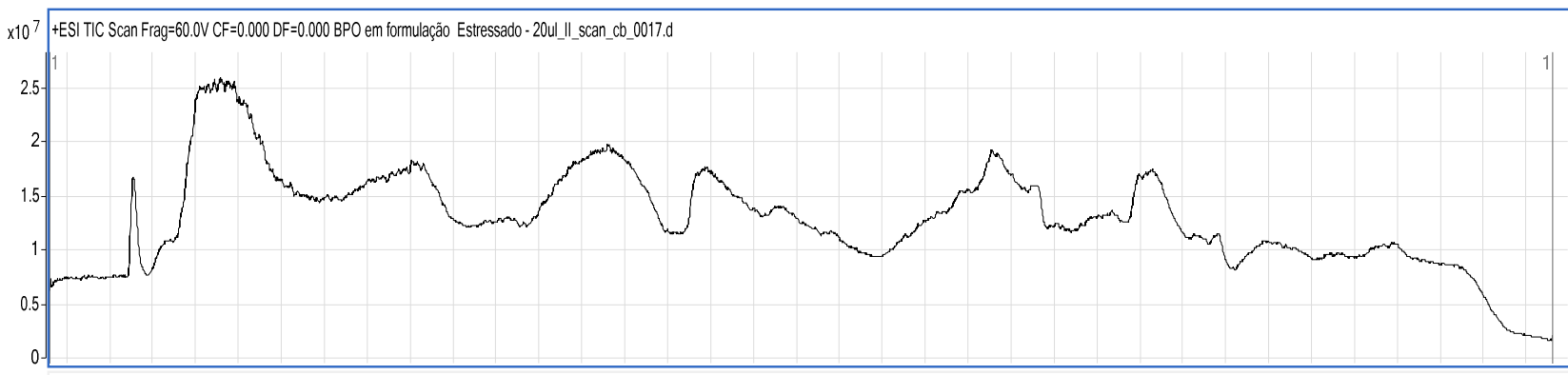

x10 3 DAD1 - A:Sig=235.0,4.0 Ref=360.0,20.0 BP0 em formulaçăo Estressado - 20ul_l__scan_cb_0017.d

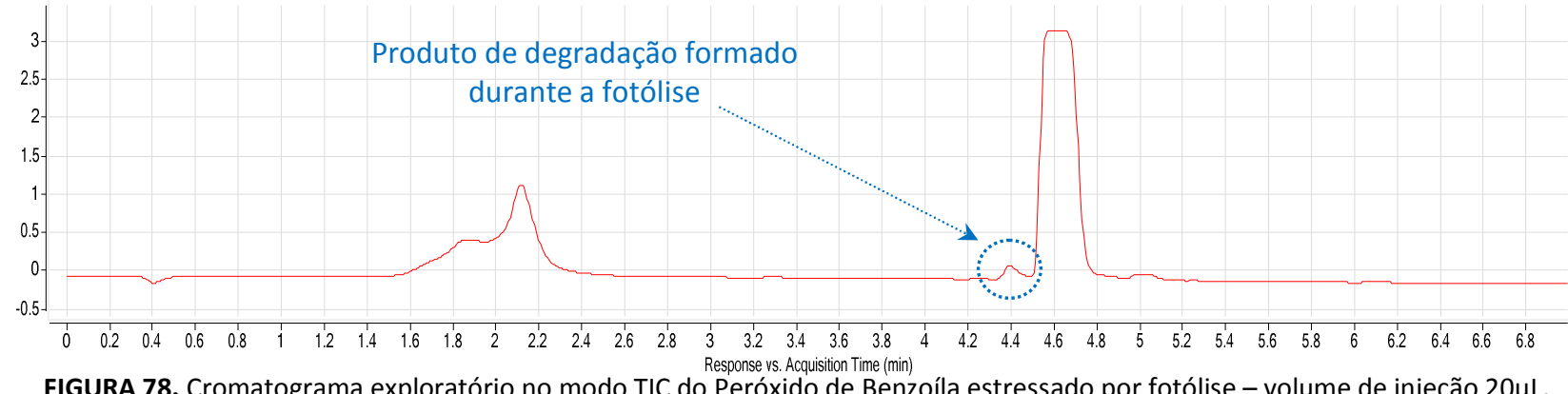

FIGURA 78. Cromatograma exploratório no modo TIC do Peróxido de Benzoíla estressado por fotólise - volume de injeção $20 \mu \mathrm{L}$.

b) Cromatograma do espectro de massas do peróxido de benzoíla estressado a 200 Whatt.h/m $\mathbf{m}^{2}$ - Modo TIC
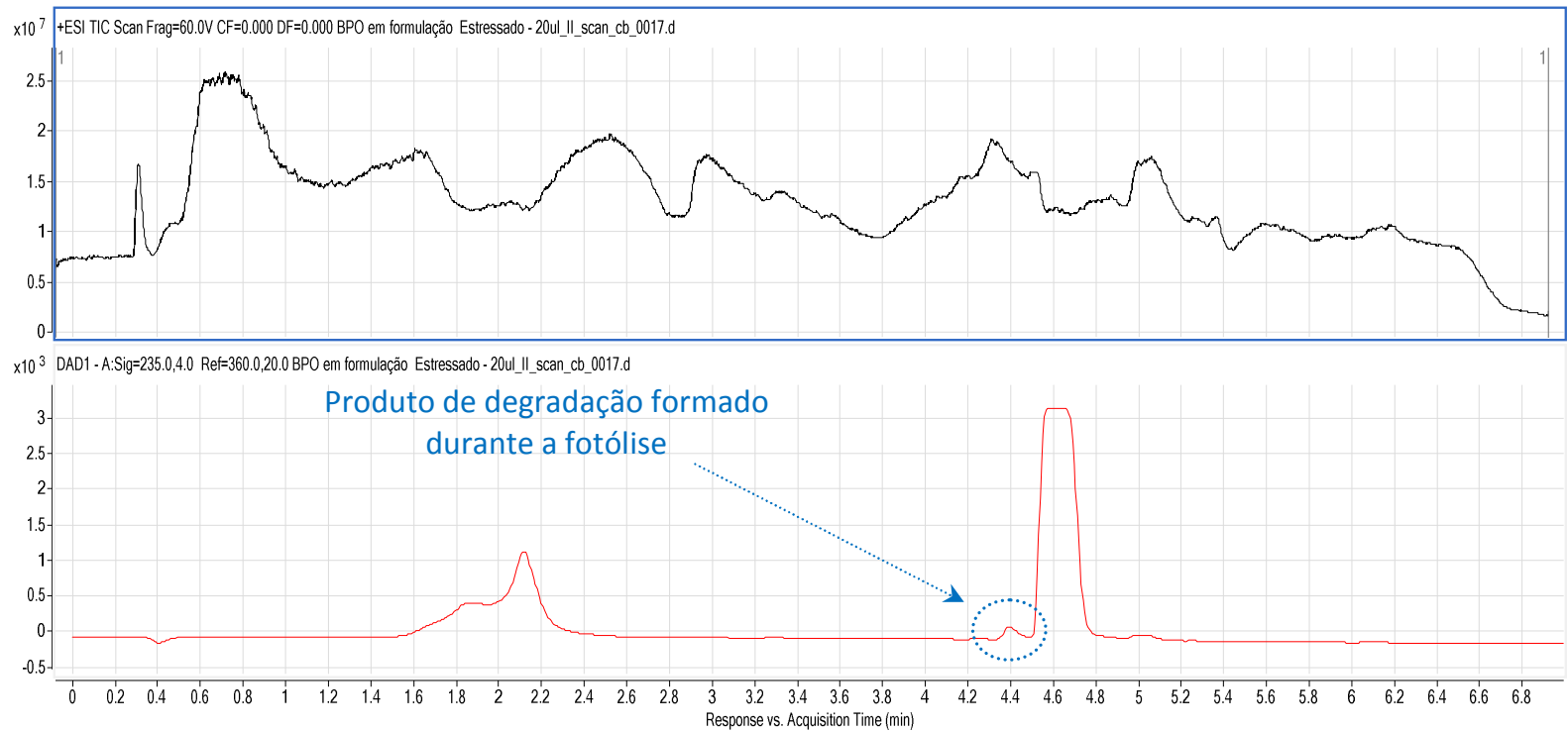

FIGURA 79. Cromatograma exploratório no modo TIC do Peróxido de Benzoíla estressado por fotólise - volume de injeção $20 \mu \mathrm{L}$.

\footnotetext{
Universidade de São Paulo - Faculdade de Ciências Farmacêuticas - FCF/USP
} 
c) Espectro de massas do peróxido de benzoíla, incorporado ao medicamento, estressado a 200 Whatt.h $/ \mathrm{m}^{2}$

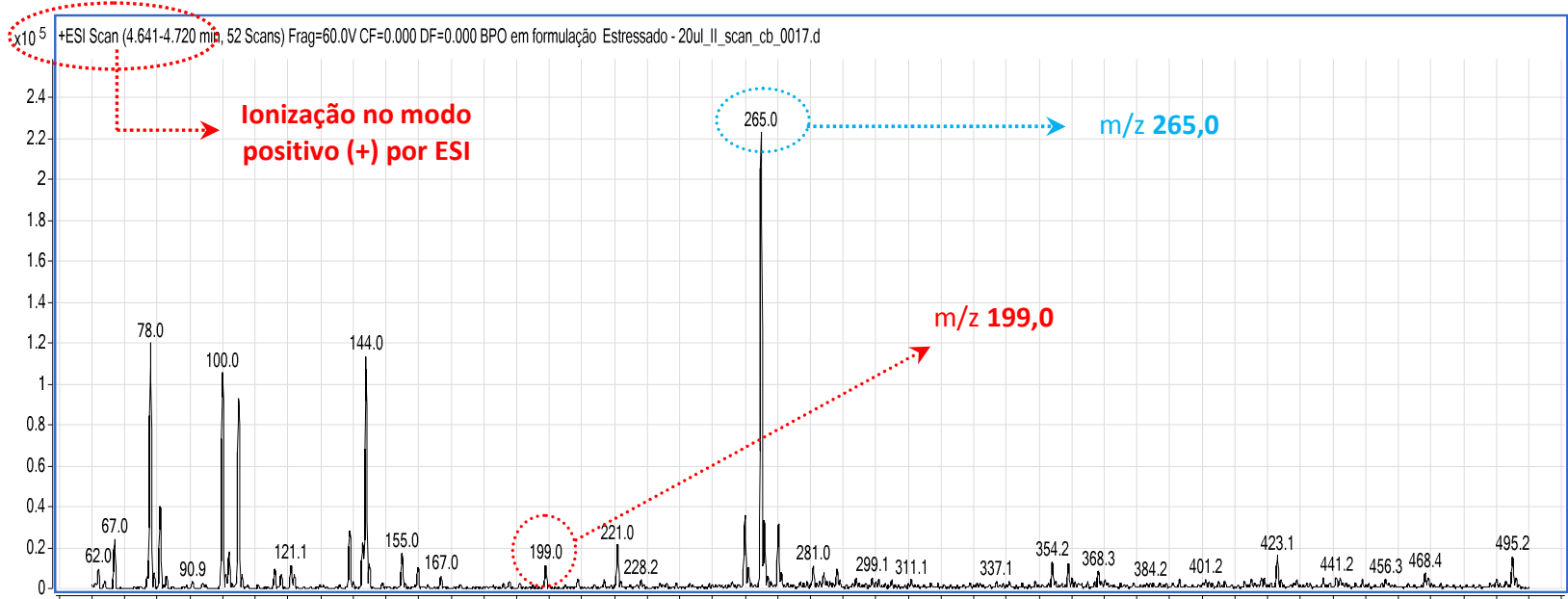

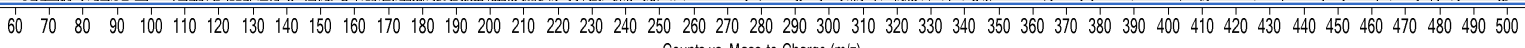
Counts vs. Mass-to-Charge $(\mathrm{m} / \mathrm{z})$

FIGURA 80. Espectro de massas do peróxido de benzoíla estressado e incorporado ao medicamento.

i) Sobreposição dos espectros de massa do produto de degradação formado e a região sem a presença de grupos cromóforos (Fase Móvel)

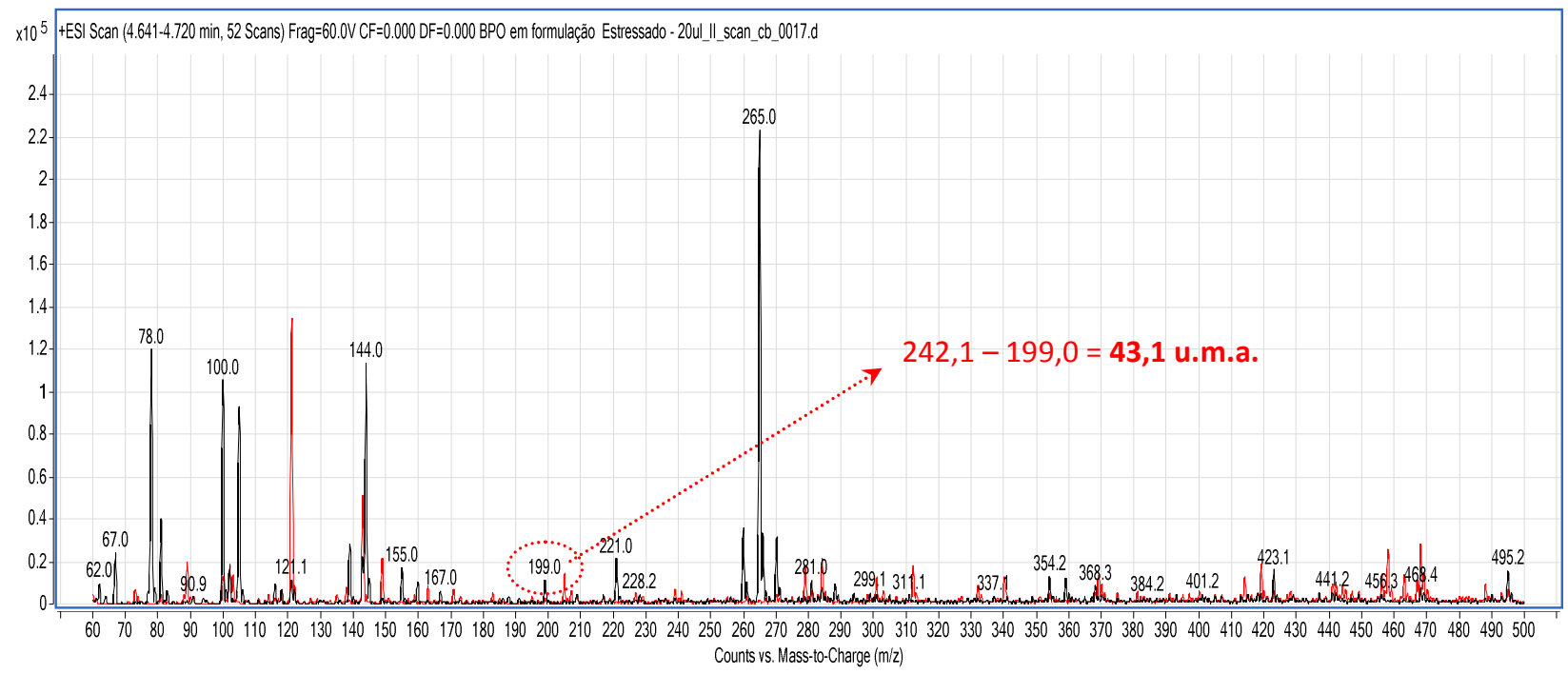

FIGURA 81. Sobreposição de espectros de massas do produto de degradação formado e a região sem a presença de cromóforos. 


\section{CAPÍTULO IX - DISCUSSÃO}

Neste capítulo são discutidos os resultados analíticos obtidos durante a validação do método indicativo de estabilidade, método de doseamento de peróxido de benzoíla por LC-MS/MS e identificação do produto de degradação produzido durante a fotólise. 


\section{DISCUSSÃO}

\subsection{DESENVOLVIMENTO DO MÉTODO INDICATIVO DE ESTABILIDADE}

A utilização do método farmacopêico, originalmente proposto somente para o doseamento do peróxido de benzoíla, conforme demonstrado anteriormente no “CAPÍTULO VIII - RESULTADOS”, para a quantificação simultânea do fármaco e seus produtos de degradação ácido benzóico, benzoato de etila e benzaldeído, se mostrou adequado, pois através dos ensaios de validação (linearidade, exatidão, precisão, limite de detecção, limite de quantificação, robustez e especificidade/seletividade), o método provou-se capaz de quantificar, de maneira precisa e exata, cada uma das substâncias avaliadas, através da sua respectiva curva de calibração, aumentando assim a precisão dos resultados obtidos, devido à "incerteza" existente no método farmacopêico atualmente preconizado pela USP, em que a quantificação dos produtos de degradação é feita através da relação do valor de área dos mesmos versus o valor de área do peróxido de benzoíla.

Outra característica que nos permite recomendar o método proposto como um indicador de estabilidade, são os seus limites de detecção e quantificação, de 0,05\% e $0,1 \%$, respectivamente, em relação à concentração nominal do peróxido de benzoíla. Conforme recomendação do $\mathrm{ICH}$ esses baixos valores demonstram que o método tem a sensibilidade de detectar pequenas concentrações das substâncias avaliadas, ponto extremamente importante durante a realização do estudo de estabilidade que visa simular a vida de prateleira do medicamento já comercializado. 


\subsection{DESENVOLVIMENTO DO MÉTODO QUANTITATIVO DE PERÓXIDO DE BENZOÍLA POR ESPECTROMETRIA DE MASSAS}

A necessidade do desenvolvimento de um novo método quantitativo para o princípio ativo peróxido de benzoíla, surgiu de uma oportunidade observada na fragilidade de doseamento preciso e exato observada no método atualmente proposto pela USP, onde o mesmo é doseado através de um ensaio titulométrico com tiossulfato $0,1 \mathrm{~N}$ como titulante; O analito é dissolvido em meio ácido (ácido acético glacial) e a solução de iodeto de potássio age como indicador.

O método neste trabalho proposto sugere o doseamento do princípio ativo através da cromatografia líquida de alta eficiência acoplada a detecção por espectrometria de massas, a partir das transições 260,1>105 e/ou 260,1>78,1. Entretanto, embora ainda não haja registros, até o presente momento, na literatura de métodos quantitativos do peróxido de benzoíla por esta técnica analítica, o método proposto ainda requer validação, afim de confirmar sua adequada performance como ensaio quantitativo, principalmente quando o objetivo seja avaliá-lo já presente em uma formulação farmacêutica, onde o efeito de matriz se torna um item extremamente crítico a ser considerado. 


\subsection{IDENTIFICAÇÃO DO PRODUTO DE DEGRADAÇÃO GERADO NA FOTÓLISE}

A investigação dos produtos de degradação originou a partir do surgimento de substâncias, até então desconhecidas, durante o estudo de degradação forçada realizada para execução do ensaio do especificidade/seletividade do item "11.1. DESENVOLVIMENTO DO MÉTODO INDICATIVO DE ESTABILIDADE”.

Entretanto, durante a realização deste projeto priorizamos a aquele gerado durante a fotólise, isso porque o medicamento estudado além de ser comercializado na zona climática (quente e úmida) IV, tem a via tópica como de administração, logo, esta seria a condição mais favorável ao surgimento deste produto de degradação, até o presente momento não descrito na monografia USP do material.

Para realização do estudo foi feita a avaliação do espectro de massas do pico observado na região do visível inerente ao produto de degradação desconhecido, e isso nos permitiu constatar que o produto de degradação possui $\mathrm{m} / \mathrm{z}$ de 199,0, que por sua vez nos permite pressupor que o mecanismo mais provável que tinha ocorrido com o material tenha sido sua descarboxilação do material (44 u.m.a), entretanto, para inferir esta informação de maneira mais criteriosa há a necessidade da realização de ensaios adicionais, que serão tratados durante o doutorado. 


\section{CAPÍTULO X - CONCLUSÕES}

Neste capítulo são apresentadas as conclusões e oportunidades de melhorias levantadas durante a execução deste trabalho. 


\section{CONCLUSÕES}

Foi concluído que o método compendial (USP36 - NF31) destinado ao doseamento dos produtos de degradação ácido benzóico, benzoato de etila e benzaldeído, pela técnica de cromatografia líquida de alta eficiência (CLAE), também pode ser utilizado para o doseamento de maneira precisa e exata do princípio ativo peróxido de benzoíla, a partir dos resultados satisfatórios, obtidos durante ensaios de validação de metodologia analítica realizados.

A partir das variadas condições de estresse às quais o fármaco peróxido de benzoíla isolado, peróxido de benzoíla gel $40 \mathrm{mg} / \mathrm{g}$ e o placebo, foram submetidos durante a degradação forçada (etapa do ensaio de seletividade e especificidade), foi verificado a formação de produtos de degradação diferentes dos já encontrados nas literaturas científicas do material, em especial quando amostras do material foram submetidas às condições de hidrólise alcalina e fotólise.

Foi desenvolvido um novo método analítico para o doseamento do peróxido de benzoíla pela técnica de cromatografia líquida de alta eficiência com detecção por espectrometria de massas.

Uma oportunidade futura complementar a este trabalho, será a necessidade de caracterização estrutural do produto de degradação gerado durante a fotólise, empregando técnicas analíticas tais como ressonância magnética nuclear (RMN), a fim de determinar corretamente sua estrutura, permitindo sua síntese e determinação de atividade terapêutica. 


\section{CAPÍTULO XII - ANEXOS}

Neste capítulo estão listados os documentos primários citados ao longo dessa dissertação, além dos documentos obrigatórios exigidos pela pós-graduação. 


\section{CAPITULO XIII - REFERÊNCIAS}

Neste capítulo estão listadas as referências utilizadas para a confecção dessa dissertação de mestrado. 


\section{REFERÊNCIAS}

ALENCAR, J.R.B; BEDOR, D.C.G.; MEDEIROS, F.P.M; LEITE, A.C.L.; BRONDANI, D.J.; GALENBECK, A.; MACÊDO, R.; ALBURQUERQUE, M.M., ROLIM NETO, P.J. Caracterização e propriedades térmicas do ritonavir para qualidade de fornecedores. Acta Farm Bonaer. 2006; 25(2):170-6.

ALVES, G.M.C; ROLIM, L.A.; ROLIM NETO, P.J.; LEITE, A.C.; BRONDANI, D.J.; MEDEIROS, F.P.M.; BIEBER, L.W.; MENDONÇA Jr, F.J.B.; Purificação e caractetização da $\beta$-Lapachona e estudo de estabilidade dos cristais em diferentes condições de armazenamento. Quim Nova 2008; 31(2):413-16.

ALSANTE, K.; MARTIN, L.; BAETSCHI, S.W.; A stress testing benchmarking study. Pharm Technol. 2003; 27(2):60-72.

ANSEL, H.C.; POPOVICH, N.G.; ALLEN-Jr, L.V.; Farmacotécnica: formas farmacêuticas \& sistemas de liberação de fármacos. 8a ed. Porto Alegre: Artemed; 2007. p.775.

ARAUJO, P. Key aspects of analytical method validation and linearity evaluation. Journal of chromatography B, 2009; v. 877, p.2224-34.

AULTON, M.E. Pré-formulação farmacêutica: delineamento de formas farmacêuticas. 2a ed. Porto Alegre: Artemed; 2005. p.677. 
BAKSHI, M.; SINGH, S. Development of validated stability indicating assay methods: critical review. J Pharm Biomed Anal. 2002; 28:1011-40.

BAZZO, G.C.; SILVA, M.A.S. Estudo termoanalítico de comprimidos revestidos contendo Captopril através de termogravimetria (TG) e calorimetria exploratória diferencial (DSC). Rev Bras Cienc Farm. 2005; 41(3):315-22.

BERGFELD, W.F. The evolving role of retinoids in the management of cutaneous conditions. Clinician. 1998; 16:1-32.

BERSON, D.S.; SHALITA, A.R. The treatment of acne: the role of combination therapies. J Am Acad Dermatol. 1995; 32(5 Pt 3): 531-41.

BESDE, G.; KUMAR, V.; SINGH, S. Study of forced decomposition behavior of lamivudine using LC, LC-MS/TOF and MS. J Pharm Biomed Anal. 2009; 49:55-63.

BOTT, R.F.; OLIVEIRA, W.P. Storage conditions for stability testing of pharmaceuticals in hot and humid regions. Drug Dev Ind Pharm. 2007; 33(4):393-401.

BORDREAU, S.P.; McELVAIN, J.S.; MARTIN, L.D.; DOWLING, T.; FIELDS, S.M. Method validation by phase of development an acceptable analytical practice. Pharm Technol. 2004; 28(11):54-66;

BRASIL. Resolução ${ }^{\circ} 899$, de 29 de maio de 2003. Guia para validação de métodos analíticos e bioanalíticos. [Internet]. Agência Nacional de Vigilância Sanitária. Poder 
Executivo, Brasília, DF, Diário Oficial da União, 02 jun 2003. [citado jun 2012]. Disponível em: http://www.anvisa.gov.br/legis/resol/2003/re/899_03re.htm.

BRASIL. Resolução n¹, de 29 de julho de 2005. Guia para a realização de estudos de estabilidade. [Internet]. Agência Nacional de Vigilância Sanitária. Poder Executivo, Brasília, DF, Diário Oficial da União, 01 ago 2005 [citado jun 2012] Disponível em: http://www.anvisa.gov.br/medicamentos/legis/01_05_re_comentada.pdf.

BRASIL. Informe Técnico $n^{\circ} 1$, de 15 de julho de 2008 - Esclarecimento sobre item 2.9 do anexo da Resolução RE ${ }^{\circ} 1$ de 29/07/2005, que trata do Guia para realização dos estudos de estabilidade [Internet]. Agência Nacional de Vigilância Sanitária. Poder executivo, Brasília, DF, Diário Oficial da União, 15 jul 2008. [citado jun 2012] Disponível em: http://www.anvisa.gov.br/medicamentos/informes/2008/01_160708.htm.

CARVALHO, J.P.; SANTOS, A.S.; SÁ, A.S.; TEIXEIRA, C.S.; NOGUEIRA, M.S. Estabilidade de medicamentos no âmbito farmacológico. Rev Farm Med. 2005; $34(6): 22-7$

CHALKER, D.K.; SHALITA, A.; SMITH, J.G.; SWANN, R.W. A double-blind study of effectiveness of a $3 \%$ erythromycin and $5 \%$ benzoyl peroxide combination on the treatment of acne vulgaris. J Am Acad Dermatol. 1983; 9(6): 933-6.

COLLINS, C.H.; BRAGA, G.L.; BONATO, P.S. Fundamentos de cromatografia. 2006; 1ed. Campinas: Editora da UNICAMP. 
CUNLIFFE, W.F.; PONCET, M.; LOESCHE, C.; VERSCHOORE, M. A comparison of the efficacy and tolerability of adapaleno $0,1 \%$ gel versus tretinoin $0,025 \%$ gel in pacients with acne vulgaris: a meta-analysis of five randomized trials. $\mathrm{Br} \mathrm{J}$ Dermatol. 1998; 139(Suppl 52):48-56.

EADY, E.A.; BOJAR. R.A.; JONES, C.E.; COVE, J.H.; HOLLAND, K.T.; CUNLIFFE, W.J. The effects of acne treatment with combination of benzoyl peroxide and erythromycin on skin carriage of erythromycin-resistant propionibacteria. $\mathrm{Br} \mathrm{J}$ Dermatol. 1996; 134(1); 107-13.

FARIA, E.A.; LELES, M.I.G.; IONASHIRO, M.; ZUPPA, T.O. Estudo da estabilidade térmica de óleos e gorduras vegetais. Eclet Quim. 2002; 27:111-9.

FREEDBERG, I.M.; EISEN, A.Z.; WOLF, K.; AUSTEIN, K.F.; GOLDSMITH, L.A.; KATZ, S.L.; Fitzpatrick's dematology in general medicine. 5th ed. New York: McGraw-Hill, 1999.

FLORENCE, A.T.; ATTWOOD, D. Princípios físico-químicos em farmácia. 3a ed. São Paulo: Edusp; 2003. p. 711.

GIL, E.S. Controle físico-químico de qualidade de medicamentos. 2007; 2ed. São Paulo: Pharmabooks.

GRAGEIRO Jr, S.; STRATTMANN, R.R.; ALBURQUERQUE, M.M.; ARAÚJO, A.A.S.; MATOS, J.R.; ROLIM NETO, P.J. In vitro evaluation of dissolution profiles and 
thermal properties of some commercial formulations of nevirapine tablets. Acta Farm Bonaer. 2006; 25(1): 76-82.

HARRIS, D.C. Análise química quantitativa. 2005; 6ed. Rio de Janeiro: Livros técnicos e cinetíficos.

HERANE, M.I. Actualización terapéutica en acne vulgaris. Dermatol Pediatr Lat. 2005; v.3(1), p.5-19.

International Conference on Harmonization (ICH). Guideline stability testing: photostability testing of new drug substance and products. nov. 1996.

International Conference on Harmonization (ICH). Guidance for industry Q1A(R2) stability testing of new drug substance and products. nov. 2003.

International Conference on Harmonization (ICH). Validation of Analytical Procedures: Text and Methodology, Q2(R1), 2005.

KAPOOR, N.; KHANDAVILI, S.; PANCHAGNULA, R. Simultaneous determination of lamivudine and stavudine in antiretroviral fixed dose combinations by first derivative spectrophotometry and high performance liquid chromatography. $J$ Pharm Biomed Anal. 2006; 41:761-5.

KENNETH, A.A. Manual of dermatologic therapeutic. 5th ed. Boston: Spiral; 1995. p. 9. 
KLICK, S.; MUIJSELAAR, P.G.; WATERVAL, J.; EICHINGER, T.; KORN, C.; GERDING, T.K.; DEBETS, A.J.; DE GRIEND, C.S.; SOMSEN, G.W.; DE JONG, G.J. Towards a generic approach for stressing of drug substance and drug products. Pharm Technol. 2005; 29(2): 48-66.

KLIGMAN, A.M. The growing importance of topical retinoids in clinical dermatology: a retrospective and prospective analysis. J Am Acad Dermatol. 1998; 39(2 Pt 3):S2-7. KUMAR, V.; MALIK, S.; SINGH, S. Polypill for the treatment of cardiovascular Part 2. LC-MS/TOF characterization of interaction/degradation products of atenolol/lisinopril and aspirin, and mechanisms of formation thereof. $J$ Pharm Biomed Anal. 2008; 48: 619-28.

LEYDEN, J.J. A review of the use of combination therapy for the treatment of acne vulgaris. J Am Acad Dematol. 2003; 49:S200-10.

LUCAS, T.I.; BISHARA, R.H.; SEEVERS, R.H. A stability program for the distribution of drug products. Pharm Technol. 2004; 2:68-73;

MATHEWS, B.R. Regulatory aspects of stability testing in Europe. Drug Dev Ind Pharm. 1999; 25(7):831-56.

MAMEDE, L.C.; CAETANO, B.L.; ROCHA, L.A.; FERREIRA, E.M.; CESTARI, A.; KFURI, C.R.; CIUFFI, K.J.; CALEFIS, P.S.; MELLO, C.; CUNHA, W.R.; NASSAR, E.J. Comportamento térmico de alguns fármacos e medicamentos. Rev Cien Farm Básica Apl. 2006; 27(2):151-5. 
MORIWAKI, C.; BRESCANSIN, E.G.; HIOKA, N.; MAIONCHI, F.; MATIOLI, G. Estudo de degradação de fármaco Nabumetona por fotólise direta. Acta Sci. 2001; 23(3): 651-4.

NÓBREGA, I.M.F.; GRANGEIRO Jr, S.; SILVA, R.M.F.; ROLIM NETO, P.J.; ALBURQUERQUE, M.M. Estudo de estabilidade de comprimidos de Captopril 25 mg acondicionados em blister frente a diferentes tipos de filmes moldáveis. Rev Bras Farm. 2006; 87(4):128-31.

NUNES, L.C.C.; SOARES SOBRINHO, J.L.; LIMA, A.A.N.; SILVA, J.L.; ROLIM NETO, P.J. Câmara climática: estudo de caso. Ver Bras Farm. 2007; 88(3):137-40.

PLEWIG, G.; KLIGMAN, A. M. Acne and Rosácea. Berlin: Springer-Verlag; 2000.

RAUSMUSSEN, J.E. Diet and acne. Semin Dematol. 1982; 6:766.

REYNOLDS, D.W.; FACCHINE, K.L.; MULLANEY, F.J.; ALSANTE K.M.; HATAJIK, T.D.; MICHEL, M.G. Available guidance and best practices for conducting forced degradation studies. Pharm Tehcnol. 2002; 26(2): 48-56;

RIBANI, M.; BOTTOLI, C.B.G.; COLLINS, C.H.; JARDIM, I.C.S.F.; MELO, L.F.C Validação em métodos cromatográficos e eletroforéticos. 2004; Química nova, v.27, 771-80. 
RIVITTI, E. A.; SAMPAIO, S. A.P. Dermatologia. 2a. Ed. São Paulo: Artes Médicas, 2000.

RODANTE, F.; VECCHIO, S.; CATALANI, G.; TOMASSETTI, M. Compatibility between active components of a commercial drug. Farmaco 2002; 26(2): 48-56.

SÁ, C.M.D. Acne: tratamento atualizado. São Paulo: EUPB, 2002.

SHABIR, G.A. Validation of high performance liquid chromatography methods for pharmaceutical analysis. Understanding the differences and similarities between validation requirements of the US Food and Drug Administration, the US Pharmacopeia and the International Conference on Harmonization. 2003; Journal of chromatography A, v. 987, p. 57-66.

SILVA, R.M.F.; MEDEIROS, F.P.M.; NASCIMENTO.; TG.; MACEDO, R.O.; ROLIM NETO. PJ. Thermal characterization of indinavir sulfate using TG, DSC and DSCPhotovisual. J Therm Anal Calorim. 2009; 95(3):965-8.

SINGH, S.; BAKSHI, M. Guidance on conduct of stress tests to determine inherent stability of drugs. Pharm Technol. 2000; 24:1-14.

SNYDER, L.R.; KIRKLAND, J.J.; GLACH, J.L.; Practical HPLC method development. 1997; 2ed. USA: Wiley Interscience. 
STRAUSS, J.S. Glândulas sebáceas. In: Fitzpatrick, T.B.; Eisen A.Z.; Wolf K.; etal.

Dermatologia em medicina geral. Buenos Aires: Panamericana; 1997. p. 745-62.

STULZER, H.K.; SILVA. M.A. Estudo de estabilidade de grânulos revestidos e comprimidos contendo Captopril. Acta Farm Boaner. 2006; 25(4):497-504.

SYKES, N.L.; WEBSTER, G.F. Acne. A review of optimum treatment. Drugs. 1994; 48(1): 59-70.

TABORIANSKI, A.M. Validação de métodos para análise e estudos de estabilidade de anti-retrovirais em preparações farmacêuticas [Dissertação] São Paulo: Faculdade de Ciências Farmacêuticas, Universidade de São Paulo; 2003.

TAVENIERS, I.; LOOSE, M.; BOCKSTAELE, E.V. Trends in quality in the analytical laboratory. II. Analytical method validation and quality assurance. 2004; Trends in analytical chemistry, v.23, p.535-51.

THIBOUT, D. Acne. Semin Dermatol. 2002; 47: 109-17.

TOMASSETI, M.; CATALANI, A.; ROSSI, V.; VECCHIO, S. Thermal analysis study of interactions between acetaminophen and excipients in solid dosage forms and in some binary mixtures. J Pharm Biomed Anal. 2005; 37(5):949-55. 
UNITED STATES PHARMACOPEIA. General Chapter <1225>: Validation of compendial procedures. 2010; 33ed. Rockville: United States Pharmacopeial Convention; 33ed.; v.1. p. 773-777.

UNITED STATES PHARMACOPEIA. Hidrous Benzoyl Peroxide. Official Monograph. 2013; 36ed. Rockville: United States Pharmapeial Convetion; 36ed.; National Formulary; 31ed.;

UNITED STATES PHARMACOPEIA. Benzoyl Peroxide gel. Official Monograph. 2013; 36ed. Rockville: United States Pharmapeial Convetion; 36ed.; National Formulary; 31ed.;

VEHABOVIC, M.; HADZOVIC, S.; STAMBOLIC, F.; HADZIC A.; VRANJES, E.; HARACI, E. Stability of ranitidine in injectable solutions. Int J Pharm. 2003; 256:109-15.

VERSCHOORE, M.; PONCET, M.; CZERNIELEWSKI, J.; SORBA, V.; CLUCAS, A. Adapalene $0,1 \%$ gel has low skin-irritation potential. J Am Dermatol. 1997; 36(6 Pt 2):S104-9.

VIANA, O.S.; ARAÚJO, A.A.S.; SIMÕES, R.A.; SOARES, J.L.; MATOS, CRS.; GRANGEIRO Jr, S.; ROLIM NETO, P.J. Kinect analysis of the thermal decomposition of Efavirenz and compatibility studies with selected excipients. Latin Americ J Pharm. $2008 ; 27(2): 211-6$.

WEBSTER, G.F. Topical tretinoin in topical therapy. J Am Acad Dermatol. 1998; 39(2 Pt 3):S38-44. 
WEBSTER, G.F. Acne Vulgaris and Rosacea: Evaluation and Management. Office Dermatology, 2001. v.4, n.1, p. 15-22.

WEISS, J.S. Current options for topical treatment of acne vulgaris. Pediatr Dermatol. $1997 ; 14(6): 480-8$.

WESOLOWSKI, M.; ERECINSKA, J. Thermal analysis in quality assessment of rapeseed oils. Thermochim Acta. 1998; 323:137-43.

WOLF, J.E. Jr; KAPLAN, D.; KRAUS, S.J.; LOVEN, K.H.; RIST, T.; SWINYER, L.J.; et al. Eicacy and tolerability of combined topical treatment of acne vulgaris with adapaleno and clindamycin: a multicenter randomized study, investigator-blinded study. J Am Dermatol. 2003; 49(3 Suppl):S2 11-7.

WESOLOWSKI, M.; ERECINSKA, J. Thermal analysis in quality assessment of rapeseed oils. Thermochim Acta. 1998; 323:137-43. 
DESENVOLVIMENTO E VALIDAÇÃO DE MÉTODO INDICADOR DE ESTABILIDADE DE FORMULAÇÕES FARMACÛTICAS DE USO TÓPICO CONTENDO PERÓXIDO DE BENZOÍLA 